UNIVERSIDADE DE BRASÍLIA

INSTITUTE OF PSYCHOLOGY

GRADUATE PROGRAM IN

SOCIAL, WORK AND ORGANIZATIONAL PSYCHOLOGY

Engaging Politics: Political Participation in Brazil and

Sweden, predicted by Stereotypes about Parliamentarians, Political Education and Behavioral Contagion

\title{
THIAGO LOPES CARNEIRO
}

Brasilia - DF

March 2015 

Engaging Politics: Political Participation in Brazil and Sweden, predicted by Stereotypes about Parliamentarians, Political Education and Behavioral Contagion

\title{
THIAGO LOPES CARNEIRO
}

\begin{abstract}
Doctoral Dissertation presented to the Faculty of the Department of Social and Work Psychology, in partial fulfillment of the requirements for the Degree of Doctor in Social, Work and Organizational Psychology.
\end{abstract}

Brasilia- DF

March 2015 



\section{Universidade de Brasília \\ Institute of Psychology}

Doctorate Dissertation Presented to the Faculty of the Department of Social and Work

Psychology, in partial fulfillment of the requirements for the Degree of Doctor in Social, Work and Organizational Psychology.

Approved by:

$$
\text { Clandio Tanes }
$$

Cláudio Vaz Torres, Ph.D. (President, Main Advisor)

Department of Social, Work and Organizational Psychology

Universidade de Brasília

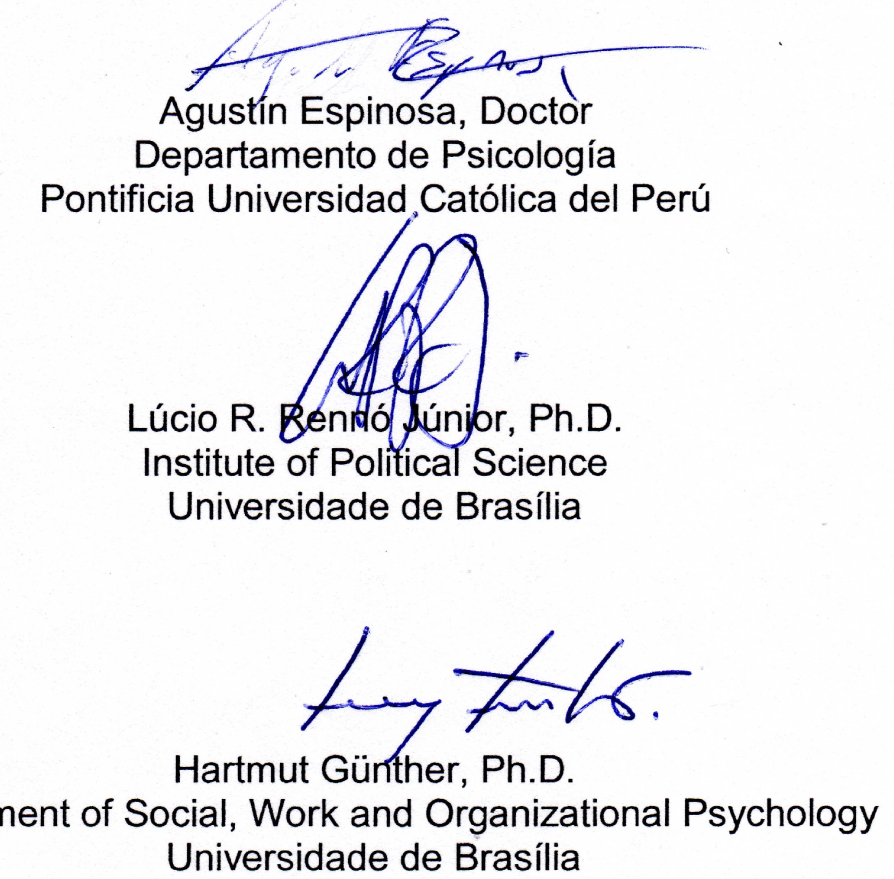

Universidade de Brasília

Department of Social, Work and Organizational Psychology

Universidade de Brasilia

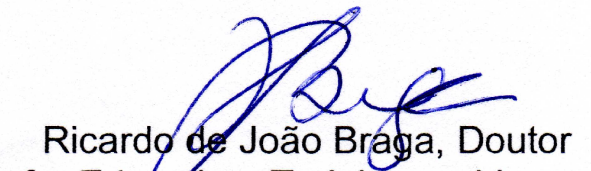

Center for Edukgtion, Training and Improvement

Camara dos Deputados 

With deserved respect,

Professor Joakim Ekman, Filosofie Doktor, from Södertörn University, Sweden, co-advisor of the present work, could not be present to the doctoral defense, for reasons beyond his will.

Thank you, professor, for all support. 

People respond in accordance to how you relate to them. If you approach them on the basis of violence, that's how they'll react. But if you say, 'We want peace, we want stability', we can then do a lot of things that will contribute towards the progress of our society.

Nelson Mandela Interview for The reader's Digest, 2005 

For Renan Monteiro Carneiro,

My son, I am doing what I do the best, study and research, believing in the utopia of leaving you a world better than the one I live in. I would like to ask you, when deciding the paths you will follow, to do what you do the best, believing in the utopia of leaving a better world for your children.

Your loving father, Thiago Lopes Carneiro 



\section{Acknowledgements}

Along these last four years, I have learned a lot more than the next pages allow me to tell. From books and articles I expanded my knowledge. From the people I met, I have earned wisdom. And I have a lot of people to be grateful to.

I thank my family, who steadily endured these four years with me: my wife Fernanda, my son Renan, my father, mother, sister and brother- Paulo, Rita, Thais and Matheus. I love you forever!

Thank you, Professor Claudio Torres, for all the support, wise advices and for the priceless encouragement when things looked like they would go wrong. Learning from you can be so fun! Yes, science can progress on jolly talks! Your open mind carries an impressive amount of knowledge, experiences, wisdom. Either in classroom, congresses, lab, wherever. Our meetings were insightful, with really intense discussions! I learned a lot and I will miss that.

Thank you, Professor Joakim Ekman, for accepting to be my co-advisor and opening the doors to Sweden. I yelled Eureka! when I first read the Political Participation typology you wrote with Professor Erik Amnå, because that was the exactly what I needed to start the investigation. Then you provided me with plenty of access to information and to people in Sweden. It was valuable! I also proffer my gratitude to Erik Amnå and Ali Abdezaldeh, for the insights in our visit to Örebro University.

Thank you, Professors Agustín Espinosa, Lúcio Rennó, Hartmut Günther and Raquel Hoersting, for accepting the invitation to be members of my examination board.

Thank you very much, Delphic Panel experts! I was a total stranger to some of you, and either way you valuably helped me! This actually reinforced my belief that people can be genuinely kind and generous! I would need to write a dissertation-long thank you text to describe how much I appreciated your ideas! I was surrounded by geniuses and I learned a lot from you, Ana Lúcia Henrique, Anders Linnhag, André Sathler, Cristiano Faria, Henric Barkman, Igor Brandão, João Luiz Pereira Marciano, Karin Hansson, Leandro Carneiro, Magnus Boström, Malena Rehbein, Mariana Marques, Michele Micheletti, Nils Gustafsson, Olavo Carneiro, Pedro Palotti, Rayani Mariano, Sofia Palm, Sven Oskarsson, Thiago Moreira da Silva and Viktor Dahl. Tack 
så mycket! Muito obrigado! Those who live far away... I hope we meet in the future. I additionally thank Nils Gustafsson, Sofia Palm, Henric Barkman and Viktor Dahl for the help with the translation to Swedish. To Anders Linnhag, for answering my weird questions about the Riksdag. Thank you, André Sathler, for the encouragement and support.

Thank you, Adalberto Marra, Patrício Marinho and Merlin Tavani, for the help with English grammar and orthography for the questionnaire!

I could not make such complex statistical analyses without the help of Breno Adaid, Thiago Gomes Nascimento and João Luiz Pereira Marciano. You saved me from becoming a statistical wacko! Thank you!

Thank you, Professor Anders Haraldsson! Without you, the Swedish data collection would not happen. Thank you, Hugo Johansson, for the technical support. Finding you two was like a miracle!

Thank you, Izabella Melo, for your engaged disposition on helping me to translate the results to the great public.

I offer special thanks to the hundreds of people who dedicated a few minutes of their day to fulfill the survey questionnaire! Blessed shall be your life!

Thank you, Universidade de Brasília, for the last, unforgettable, seventeen years.

Thank you all, for having entered my life with open arms. You are all part of me, for life.

\section{Thinga Carneira}




\section{Summary}

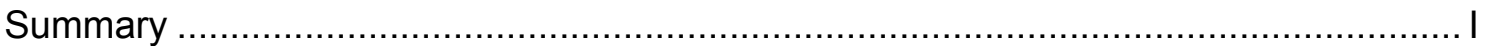

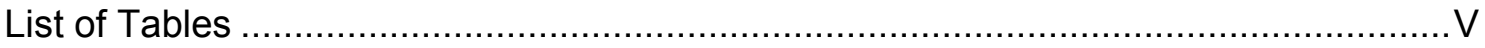

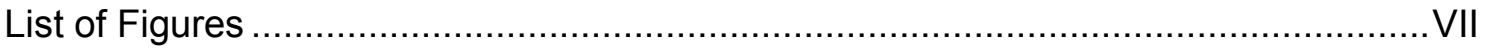

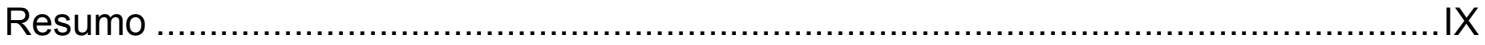

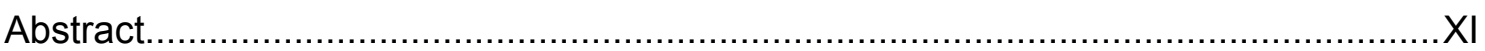

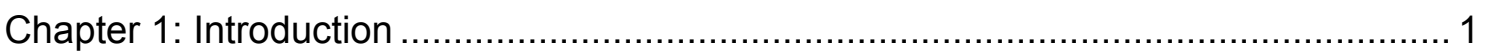

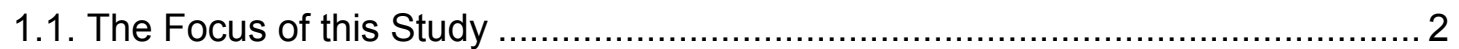

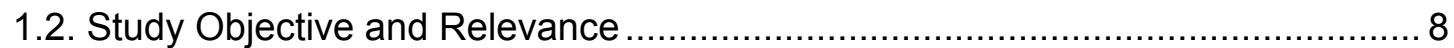

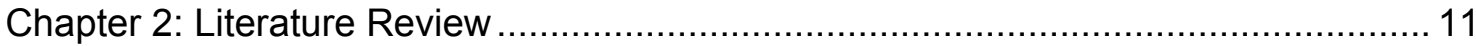

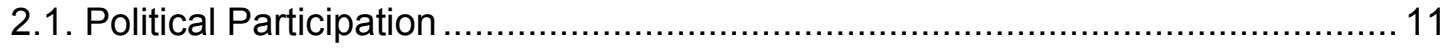

2.1.1. Theoretical Perspectives on Political Participation ................................... 12

2.1.2. Downturn or mutation of Political Participation? ..................................... 14

2.1.3. Concept of Political Participation in this study ........................................ 17

2.1.4. Antecedent Variables of Political Participation ....................................... 25

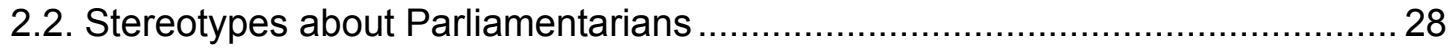

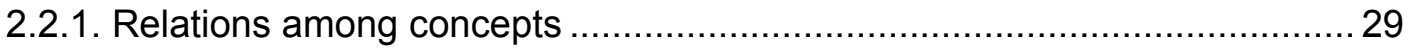

2.2.2. Stereotypes as a system to classify groups ......................................... 30

2.2.3. Stereotypes about Parliamentarians in, Prejudice and Discrimination out.. 34

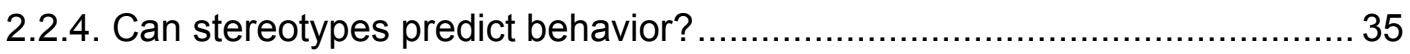

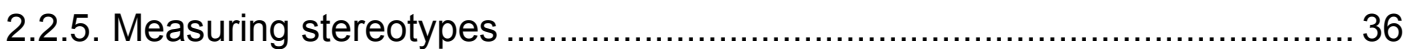

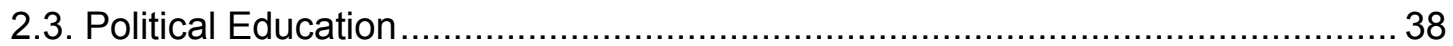

2.3.1. Does Education predict the Political Participation? ................................... 39

2.3.2. Political Education formally included in the School Curriculum .................. 41

2.3.3. Political Education or Political Socialization? ............................................ 44

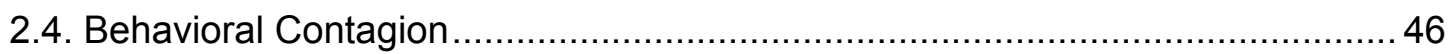




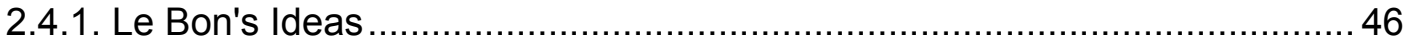

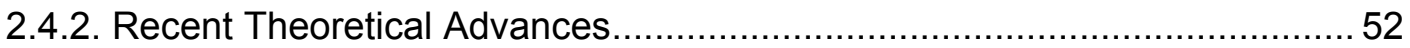

2.4.3. Behavioral Contagion as approached in this study .............................. 57

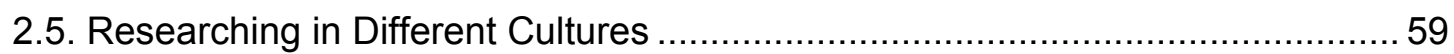

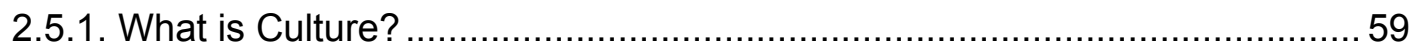

2.5.2. Cross-cultural Studies in Social Psychology .......................................... 61

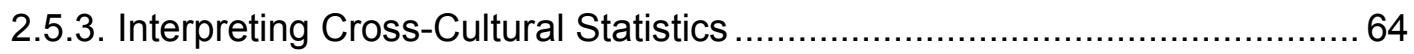

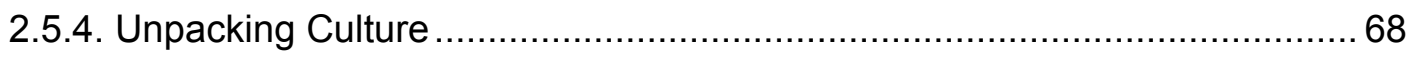

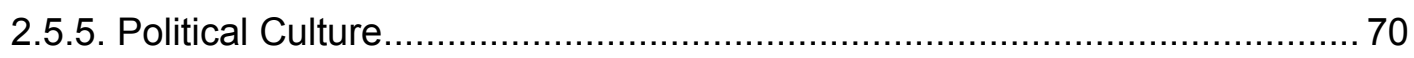

2.5.6. Relevant considerations for this study ............................................. 73

2.6. Characteristics of the Political Context of Brazil and Sweden.......................... 74

2.6.1. Organization of Political Institutions ..................................................... 75

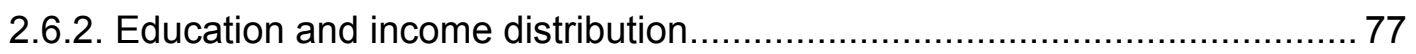

2.6.3. History of Democracy in Brazil and Sweden ..................................... 80

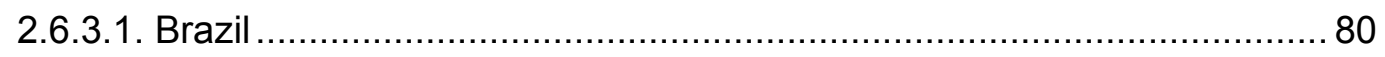

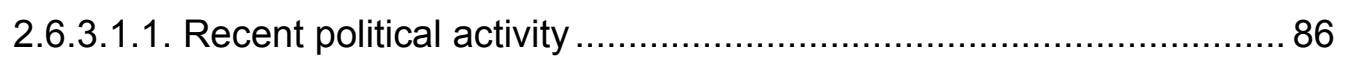

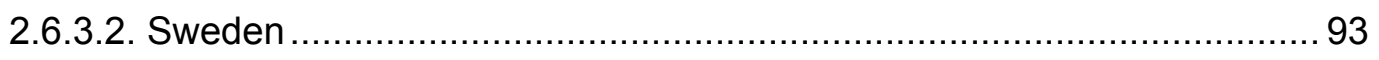

2.6.3.3.1. The Riksdag and the Swedish democracy .................................. 95

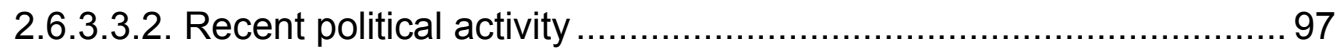

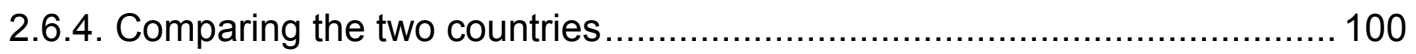

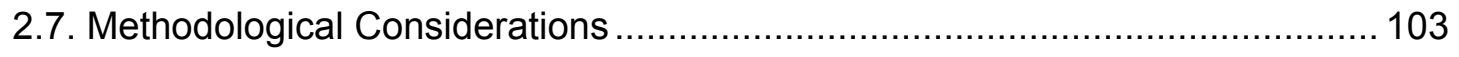

2.7.2. Considerations on Reliability .................................................... 104

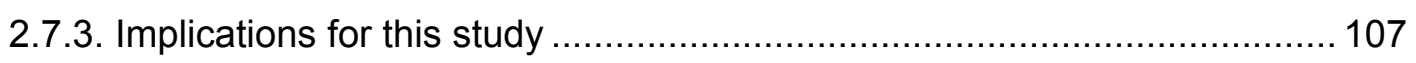

2.8. Theoretical Model and Research Objectives .......................................... 109

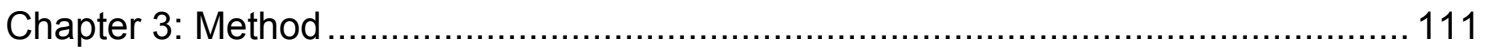

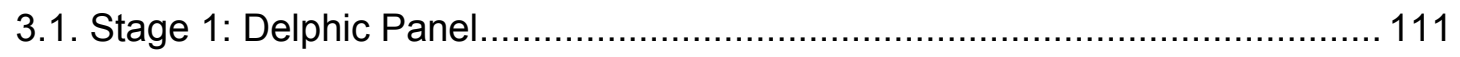

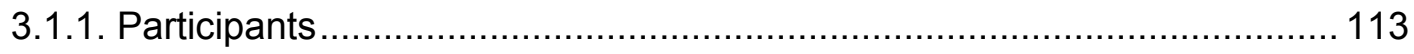


3.1.2. Procedures

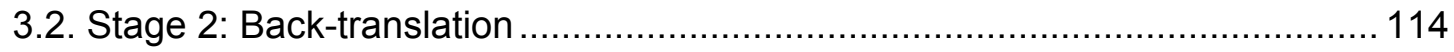

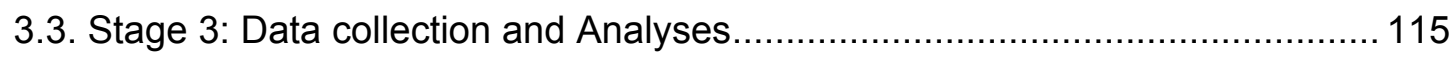

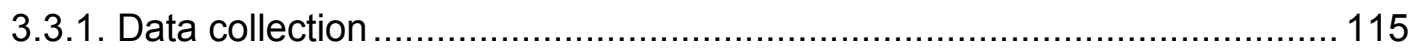

3.3.2. Participants and Missing Imputation .................................................... 116

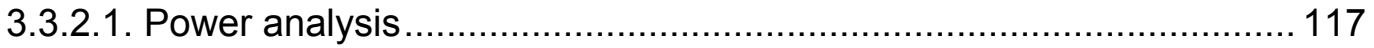

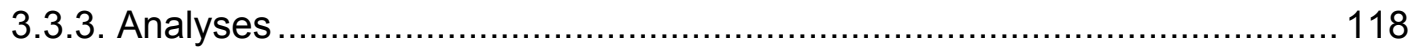

3.3.3.1. Exploratory Factor Analysis ...................................................... 118

3.3.3.2. Confirmatory Factor Analysis .................................................. 119

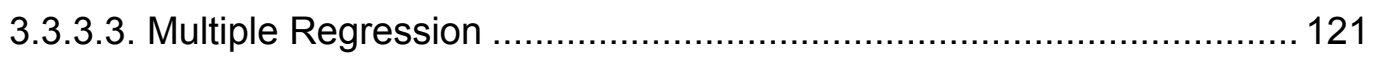

3.3.3.4. Structural Equation Modeling ................................................... 121

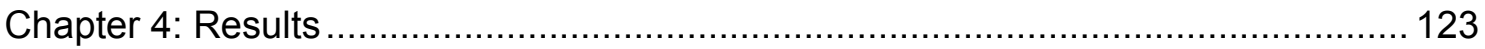

4.1. Exploratory and Confirmatory Factor Analyses (EFA and CFA) ................... 123

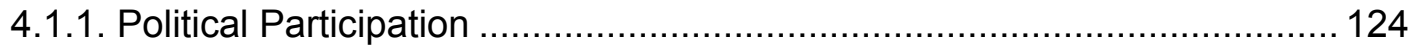

4.1.2. Stereotypes on Parliamentarians ........................................................ 137

4.1.2.1. Critical Information on Parliamentarians ...................................... 138

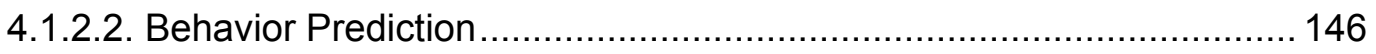

4.1.2.3. A General Model for Stereotypes on Parliamentarians..................... 152

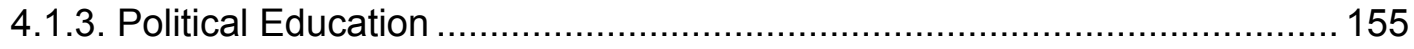

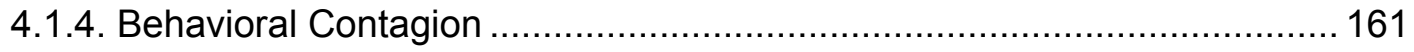

4.2. Variables' mean differences between Brazil and Sweden ............................. 164

4.3. Relationships among variables (Stepwise Multiple Regression and Structural

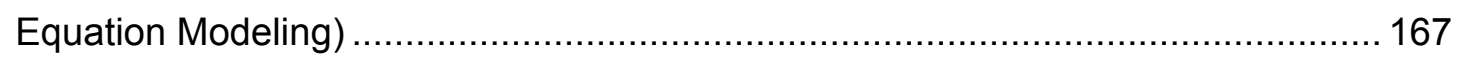

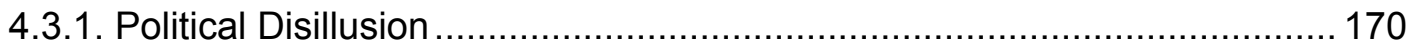

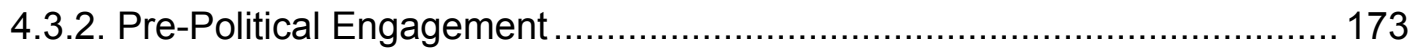

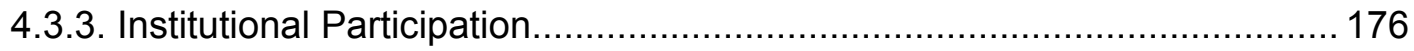

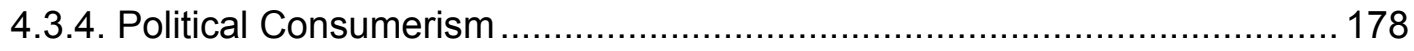




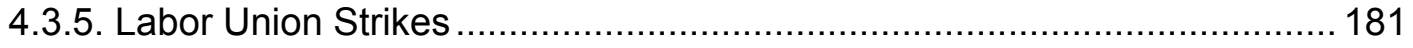

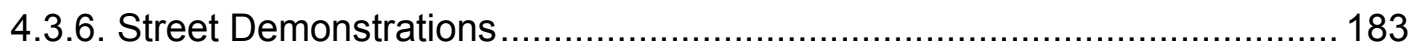

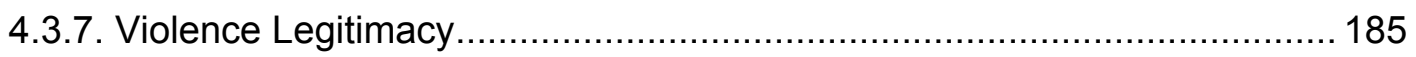

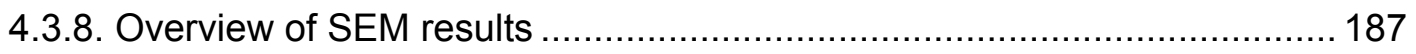

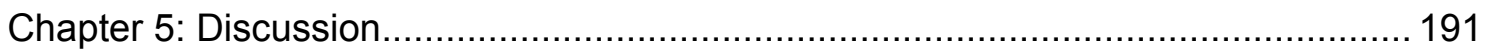

5.1. General Remarks on Factor Structure ................................................. 191

5.2. Understanding Political Participation: the Contribution of each Independent

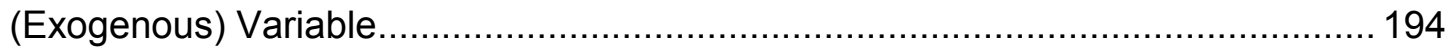

5.2.1. The effect of Stereotypes about Parliamentarians ............................... 194

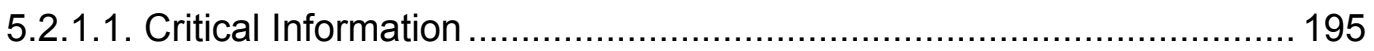

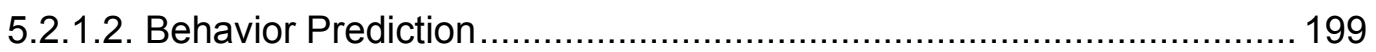

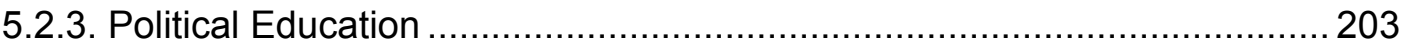

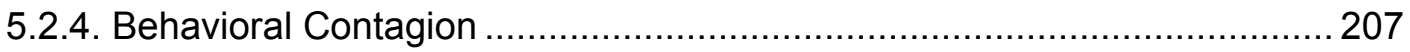

5.2.5. Party Preferences and Demographic Characteristics.......................... 213

5.3. The Different Types of Political Participation ............................................ 214

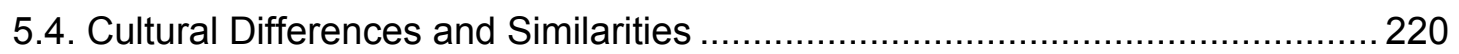

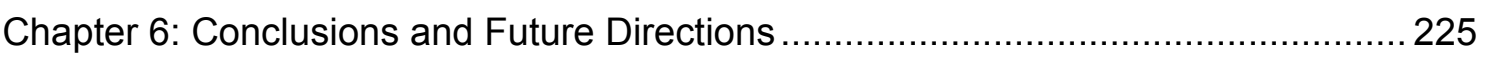

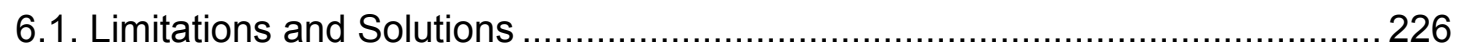

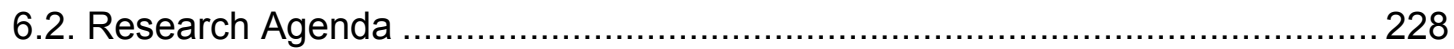

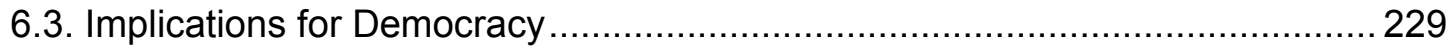

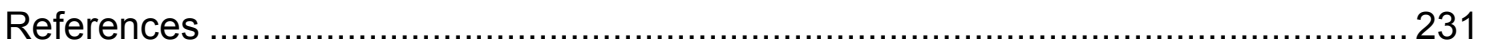

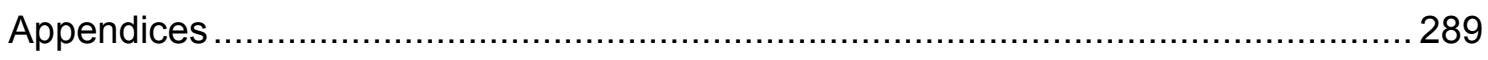

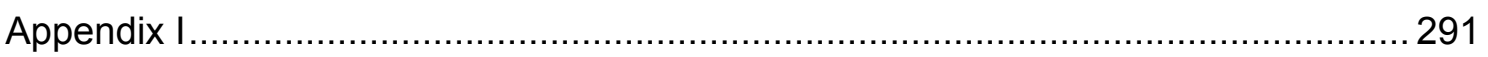

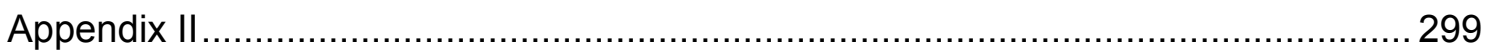

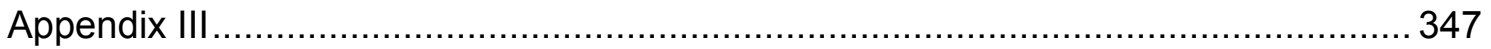

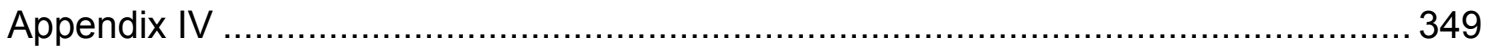

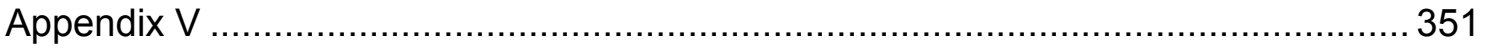




\section{List of Tables}

1. Categories of political participation according to Ekman e Amnå (2012)...........

2. Categories of political participation as proposed in this study

3. Comparison between the organization of political institutions in the investigated countries.

4. Comparison of indicators of education, income and quality of life in the countries surveyed.

5. Non-Participation (Political Attitudes) in Brazil and Sweden: EFA results

6. Political Participation (Past Behavior) in Brazil and Sweden: EFA results.

7. Participation and Political Disillusion in Brazil and Sweden: Goodness-of-Fit indices and Power Analysis.

8. Discriminant Validity, based on the Five Factor Model. Bold values indicate the Average Extracted Variance $\left(\mathrm{Rho}_{\mathrm{vc}}\right)$.

9. Political Participation and Political Disillusion, Final Model: Internal Consistency and Convergent Validity.....

10. Participation and Political Disillusion: Test of Equivalence.

11. Stereotypes on Parliamentarians (Critical Information): EFA Results.

12. Stereotypes on Parliamentarians, Critical Information, in Brazil and Sweden: Goodness-of-Fit indices and Power Analysis

13. Discriminant Validity for Critical Information factors. Bold values indicate the Average Extracted Variance (Rhovc); values in the ladder represent the square covariance between factors.

14. Stereotypes on Parliamentarians, Critical Information: Tests of Equivalence..

15. Critical Information: Internal Consistency and Convergent Validity....

16. Stereotypes on Parliamentarians (Behavior Prediction): EFA Results

17. Parliamentarians' Behavior Prediction: Goodness-of-Fit indices and Power Analysis.

18. Parliamentarians' Behavior Prediction: Internal Consistency and Convergent Validity. 
19. Discriminant Validity for Behavior Prediction factors. Bold values indicate the Average Extracted Variance (Rhovc); values in the ladder represent the square covariance between factors.

20. Stereotypes on Parliamentarians, Behavior Prediction: Test of Metric Equivalence.

21. General Model for Stereotypes on Parliamentarians: Goodness-of-Fit indices and Power Analysis.

22. General Model for Stereotypes on Parliamentarians: Internal Consistency and Convergent Validity....

23. General Model for Stereotypes on Parliamentarians: Test of Metric Equivalence.

24. Political Education: EFA Results

25. Political Education: Goodness-of-Fit indices and Power Analysis

26. Political Education: Test of Metric Equivalence.

27. Behavioral Contagion: EFA results

28. Behavioral Contagion: Goodness-of-Fit indices and Power Analysis.

29. Behavioral Contagion: Test of Metric Equivalence.

30. Goodness of Fit for prediction models on Political Disillusion.

31. Goodness of Fit for prediction models on Pre-Political Engagement

32. Goodness of Fit for models on Institutional Participation (2nd order factor)....

33. Goodness of Fit for models on Political Consumerism

34. Goodness of Fit for models on Participating in Labor Union Strikes

35. Goodness of Fit for models on Participating in Street Demonstrations.

36. Goodness of Fit for models on Political Violence Legitimacy.....

37. Summary of SEM models - predicting Political Participation factors and standalone items.

38. New categories for Political Participation. 


\section{List of Figures}

1.1. Reproduction of figure in Realo, Allik and Greenfield (2008, p. 456), crossing the scores of institutional collectivism practices (House, Hanges, Javidan, Dorfman \& Gupta, 2004) and the interpersonal trust score (Inglehart, Basanez, Diez-Medrano, Halman \& Luijkx, 2004).

2.1. Democratic Party's advertisement against, with an iconic representation of "noseband vote" (voto de cabresto).

2.2. Chances of winning presidential elections in Brazil, considering the three preferred candidates. Source: pollingdata.com.br, which compiled results from several election polls.

2.3. Hypothesized relations between the variables of the study

4.1. Participation and Political Disillusion factor structure for Brazil - Final Model.

4.2. Participation and Political Disillusion factor structure for Sweden - Final Model

4.3. Critical Information factor structure for Brazil, with Second-Order Factor.....

4.4. Critical Information factor structure for Sweden, with Second-Order Factor.

4.5. Behavior Prediction factor structure for Brazil.

4.6. Behavior Prediction factor structure for Sweden

4.7. General Model for Stereotypes on Parliamentarians - Brazil.

4.8. General Model for Stereotypes on Parliamentarians - Sweden

4.9. Political Education One-Factor Structure for Brazil.

4.10. Political Education One-Factor Structure for Sweden

4.11. Behavioral Contagion factor structure - Brazil.

4.12. Behavioral Contagion factor structure - Sweden.

4.13. Explaining Political Disillusion in Brazil: Structural Equation Modeling results.

4.14. Explaining Political Disillusion in Sweden: Structural Equation Modeling results.

4.15. Explaining Pre-Political Engagement in Brazil: Structural Equation Modeling results 
4.16. Explaining Pre-Political Engagement in Sweden: Structural Equation Modeling results

4.17. Explaining Institutional Participation in Brazil: Structural Equation Modeling results

4.18. Explaining Institutional Participation in Sweden: Structural Equation Modeling results

4.19. Explaining Political Consumerism in Brazil: Structural Equation Modeling results.

4.20. Explaining Political Consumerism in Sweden: Structural Equation Modeling results.

4.21. Explaining participation in Labor Union Strikes in Brazil: Structural Equation Modeling results

4.22. Explaining participation in Labor Union Strikes in Sweden: Structural Equation Modeling results

4.23. Explaining participation in Street Demonstrations in Brazil: Structural Equation Modeling results.

4.24. Explaining participation in Street Demonstrations in Sweden: Structural Equation Modeling results

4.25. Explaining Political Violence Legitimacy in Brazil: Structural Equation Modeling results

4.26. Explaining Political Violence Legitimacy in Sweden: Structural Equation Modeling results. 


\section{Resumo}

O objetivo geral desta pesquisa foi comparar a influência de Estereótipos sobre os Parlamentares, Educação Política e Contágio Comportamental sobre a Participação Política entre Brasil e Suécia, para construir um modelo teórico-explicativo e oferecer evidências de validade. A tipologia de Ekman e Amnå (2012) embasou o uso de um conceito abrangente de Participação Política, que varia da não participação, passando pela atenção (stand by) até a participação manifesta. Estereótipos sobre parlamentares foram definidos em duas esferas: Informação Crítica a que os eleitores prestam atenção e Predição de Comportamento, i.e., como os eleitores pensam que os parlamentares se comportam. Educação Política se refere ao quanto cada esfera da vida de uma pessoa contribui para sua aprendizagem política. Itens de Contágio Comportamental aferiam a influência do participante sobre outros e a influência exercida por outros sobre ele/ela. O questionário foi elaborado através do Painel Délfico, conduzido simultaneamente com especialistas brasileiros e suecos, tendo o inglês como língua comum. O questionário resultante foi retro-traduzido para o Português Brasileiro e Sueco. Estas duas versões foram administradas aos participantes, via internet. Participaram 984 brasileiros, $37,4 \%$ do sexo feminino e com idade média de 43,95 anos (DP 15,64). Suecos totalizaram 879 , sendo $46,5 \%$ mulheres e a idade média foi de 49,57 anos (DP 16,64). Análises Fatoriais Exploratórias e Confirmatórias foram realizadas. Médias das respostas de participantes brasileiros e suecos foram comparadas através de teste-t. Empregou-se a Modelagem de Equações Estruturais (MEE), precedida de regressão múltipla exploratória, a fim de determinar como as variáveis independentes (exógenas) poderiam predizer a Participação Política. Discutiram-se as implicações metodológicas. As equivalências de Estrutura Fatorial e Métrica foram alcançadas, entre Brasil e Suécia, para Participação Política, Estereótipos sobre Parlamentares e Contágio Comportamental. Os fatores de Educação Política não se mostraram consistentes, portanto seus itens foram considerados separadamente. Os testes-t indicaram que os brasileiros se envolvem em ação política mais frequentemente do que os suecos. Quanto aos Estereótipos, suecos percebem a Qualidade da Representação de seus parlamentares mais positivamente do que os brasileiros; a Corrupção, por outro lado, foi percebida como maior no Brasil. Suecos prestam mais atenção a informações críticas relacionadas a Partidos e Tendências de Representação dos parlamentares, enquanto os brasileiros se preocupam mais com Informações Pessoais do que os suecos. Os modelos de previsão SEM evidenciaram que, embora a corrupção seja uma preocupação primária para os brasileiros, ela não ajuda a prever Participação Política no Brasil, mas sim na Suécia. Embora suecos prestem mais atenção às diferenças entre Partidos e às Tendências de Representação, estes fatores tiveram maior importância para prever Participação Institucional no Brasil. Conclui-se que aquilo que é senso comum (como a corrupção no Brasil e diferenças entre partidos na Suécia) não ajuda a distinguir as pessoas que participam daquelas que não o fazem. Itens de Educação Política tiveram efeito muito pequeno. Contágio Comportamental desempenhou um papel central, a ponto de embaçar a fronteira entre ação política individual e coletiva. O engagamento político está, enfim, fortemente ligado ao envolvimento em uma rede politicamente ativa.

Palavras-chave: Participação Política, Estereótipos, Educação Política, Socialização Política, Contágio Comportamental, Parlamentares 


\section{Abstract}

The general objective of this research was to compare the influence of Stereotypes about Parliamentarians, Political Education and Behavioral Contagion on Political Participation between two countries (Brazil and Sweden) to build and offer evidence of validity for a theoretical-explanatory model. Ekman and Amnå's (2012) typology was the base for a comprehensive concept of Political Participation, as it ranges from nonparticipation, through attention (stand by) and manifest participation. Stereotypes about Parliamentarians were defined in two spheres: Critical Information to which voters pay attention and Behavior Prediction, i.e., how voters expect parliamentarians to behave. Political Education intended to assess how each sphere of a person's life contributes to his/her political learning. Behavioral Contagion assessed the influence the participant exerted on others and how much other people influenced him/her. The questionnaire was elaborated via Delphic Panel, ran simultaneously with Brazilian and Swedish experts, using English as a common language. The resulting questionnaire was backtranslated to Brazilian Portuguese and to Swedish. These two versions were administered to participants through electronic formularies, distributed via internet. Participants from Brazil numbered 984, 37.4\% women and the mean age was 43.95 (S.D. 15.64) years. Swedes numbered $879,46.5 \%$ women and the mean age was 49.57 (S.D. 16.64) years. Exploratory and Confirmatory Analyses were performed, in order to determine Factor Structures and to evaluate their equivalence between the two countries. Means from the Brazilian and Swedish participants were compared through t-test. Structural Equation Modeling (SEM), preceeded by exploratory Stepwise Multiple Regression, mas performed in order to stablish how the independent (exogenous) variables predicted Political Participation. Methodological implications are discussed. Factor Structure and Metric equivalences were met for Brazil and Sweden, for Political Participation, Stereotypes about Parliamentarians and Behavioral Contagion. Political Education factors were not consistent, so its items entered the prediction models as standalones. T-tests indicated that Brazilians engage political action more often than Swedes. Regarding Stereotypes, Swedes perceive the Quality of Representation of their parliamentarians as better than Brazilians evaluate theirs; Corruption, on the other hand, was perceived as higher in Brazil. Swedes pay more attention to Critical Information related to the Parties and Representation Trends of parliamentarians, while Brazilians worry more about Personal Information than Swedes. The SEM prediction models evidenced that, though Corruption was a major issue to Brazilians, it did not help predict Political Participation in Brazil, but it did in Sweden. Though Swedes pay more attention informations about Parties and Representation Trends, these had greater importance to predict Institutional Participation in Brazil. It is concluded that commonsense information (such as Corruption in Brazil and Party differences in Sweden) does not help to tell the difference between those people who participate and those who do not. Political Education items had disappointingly low effect. Behavioral Contagion played a pivotal role on explaining Political Participation. "Being influenced" and "influencing others" was so importantly related to Political Participation that it is considered that the boundaries of individual and collective action are blurred. Engaging politics is, at last, strongly intertwined to being a part of a politically active network.

Keywords: Political Participation, Stereotypes, Political Education, Political Socialization, Behavioral Contagion, Parliamentarians 


\section{Chapter 1: Introduction}

After a period when social scientists believed that people got disenchanted with democracy and became politically apathetic (Moisés \& Carneiro, 2008; Paxton, 1999; Putnam, 1995), Brazil is overwhelmed with demonstrations, in the year of 2013. Nearly two million individuals took on the streets of more than 400 cities protesting against the increase in bus fares, against political corruption, for freedom of speech, and a large list of claims (Estadão.com.br, 2013; Folha de S. Paulo, 2013a; G1, 2013; Leal, 2013). However, the apparent 'boom' of political participation in Brazil did not happen alone, neither in time, nor in space. In time, because the recent political demonstrations are linked to political movements started years before - e.g., Marches against Corruption (Marchas contra a Corrupção) and many other demonstrations promoted by Movimento Passe Livre (Zero Bus Fare Movement) (Colon \& Moura, 2011; Gomes \& Maheirie, 2011; Martins, 2012). And in space... political movements in many countries, organized by social media (or 'social networks' as the websites that enable massive communication among individuals are sometimes referred to) occurred all over the world. The Occupy Wall Street movement (in the United States and 82 other countries) was a reaction to the effects of the 2008 economic crisis, where protesters claimed for better distribution of wealth (López, 2011; Uchoa, 2013). The movements further known as Arab Spring (Tunisia, Egypt, Libya and 14 other countries) targeted the polydecennial dictatorships that toughly repressed popular political movements (Bellin, 2012). In Stockholm, Sweden, a controversial police action resulted on the killing of an immigrant, stirring protests (which were often violent) against racism and discrimination, in May 2013. In Turkey, during the same month, 2.5 million individuals took to the streets to protest for greater freedom of speech (Kuymulu, 2013). Other protests took to the streets of Greece, Indonesia, India and other countries driven by economic reasons and for greater freedom of speech (The Economist, 2013c). 
These huge demonstrations contrast the thesis of increased political apathy. Although this was the most prominent activity in the last decade, many other activities could be characterized as 'political participation' and have enticed attention from researchers (Anderson, 2010; Brussino, Rabbia \& Sorribas, 2008; Ekman \& Amnå, 2012; Hooghe \& Dejaeghere 2007; Inglehart \& Catterberg, 2002). All those movements challenge researchers that try to scientifically describe and analyze them based on the literature. How could one compare the many forms of political actions emerging in the world, considering cultural, historical and institutional framework variations? Could the concept applied to a context be generalized to another context? As this is such a complex and varied phenomenon, any social scientist who dares studying it must have good focus. It implies selecting a 'slice of reality' that allows the collection of information to subsidize the empirical analysis without damaging the scope of the phenomenon of political participation. The focus of this study is henceforth explained, delimitating one among the many potential approaches on the subject.

\subsection{The Focus of this Study}

'Participation' and 'politics' are inseparable in origin. Historically, the election of political representatives was an alternative to direct democracy, where citizens discussed the city affairs directly in the public arena (Borba \& Ribeiro, 2010; Friede, 2006). Therefore, the establishment of parliaments gave rise to a division of the roles assigned to citizens, whereas it created a class of representatives who were in charge of political activities, and another of represented individuals with the duty (under this study's scope) of monitoring and controlling the activities performed by the first ones (Borba \& Ribeiro, 2010; Friede, 2006; Merkel, 2004). The representative/represented relation is, therefore, in the heart of the debate about political participation in contemporary societies (Merkel, 2004; Moisés, 2010; Moisés \& Carneiro, 2008). Since the parliament is the functional substitute of the Greek Agora, and in an attempt to 
understand the mobilization around collective interests at national level, the 'slice of reality' to be studied herein is the political participation regarding the bodies of the National Legislative Power.

The national Legislative Houses basically serve as arenas of negotiation among groups of supporters of the sectorial interests of the country (Lima \& Santos, 2001; Ricci, 2003). Considering that the represented ones are in charge of monitoring and controlling representatives, the understanding of how electors 'read' the parliamentarian activity is crucial. After all, while representatives handle everyday with political activities, becoming experts with jargons specific to their activities (Pereira \& Mueller, 2000), the represented ones are at risk of becoming more and more alienated because of the difficulty in understanding the political language (Delli Carpini \& Keeter, 1996; Henrique, 2010; Merkel, 2004).

It might be tempting to suppose that from now on we should focus our efforts on the investigation of forms to draw the attention of the represented ones to political activity as a whole, so they can receive and rationally analyze the political information available before making a decision (as proposed by Delli Carpini \& Keeter, 1996; and Luskin, Fishkin \& Jowell, 2002). But we will not do that. The permanent attention on political life could make full sense to social scientists, but not necessarily to those who invested time studying to become good dentists, bakers, electricians, computer programmers. After all, these people do not make their livelihood on discussing politics... and they can, on the other hand, enjoy the peace promoted by the Social Contract to engage in their professions, raise their children, or share good moments with friends (Baier, 1986; Silva, Goyeneche \& Silva, 2009).

Carreirão (2002) points out the need for 'relaxing' the requirements of structuring the 'system of beliefs' of the electorate. On the other hand, it is important to analyze which are the best key informations to support the decisions of citizens who are not expert in politics (Arceneaux, 2008; Samuels, 1997; Samuels \& Zucco, 2014). 
Hence, it is supposed that citizens make their decisions without fully knowing details of political activity (Huckfeldt \& Sprage 1995; Lupia \& McCubbins, 2000 Samuels, 1997).

According to this proposition, the following research question was the starting point to this investigation: how do individuals make decisions about political participation in the real context, in their everyday lives, based on the information they have about parliamentarian politics? To answer it, I have sought for psychological processes that could explain the citizens' perception about the parliament. I have focused on processes used almost unconsciously, i.e., individuals should be able of using them without having to reflect about it. The psychological processes selected to the analysis should summarize (at least hypothetically) a large number of information and political influences a given individual receives. Ultimately, these processes should be observable in different cultures so that, through comparison between countries, one can identify the relations between these psychological processes and the forms of political participation adopted by citizens.

Assuming that the Legislative Houses accommodate competing groups of interest, selecting psychological processes that approach the citizen's reading about the groups of representatives' behavior seems to be useful. The variables $\underline{\text { Stereotypes }}$ about Parliamentarians, Political Education and Behavioral Contagion proved to be suitable for that purpose. Firstly, the concept of Stereotypes has to do with the interpretation made about the behavior of a group. Political Education, in turn, comes as variable of analysis because it could have great influence on the interpretation of the behavior of people holding political offices - interfering also on the formulation of stereotypes. Finally, the Behavioral Contagion could be useful to explain how some politics-related beliefs and behaviors become 'common sense', as it can explain how they are multiplied and encourage action. The relation between these variables and the objective of this study are explained in details in Chapter 2, where the literature is reviewed. 
The transnational comparative study was performed in order to check if the theoretical model built herein could be applied to different contexts, and still preserve the power of explaining the phenomenon of political participation. The comparison is even more relevant if contrasting countries are selected.

The decision for comparing Brazil and Sweden is explained by the contrasting representative/represented relation. Regarding trust in the political system, Brazilians complain about the malfunctioning of governmental institutions and the impunity of bad politicians (Moisés and Carneiro, 2008; Ribeiro, 2007). Moreover, Brazilian politics is marked by 'generalized' corruption, and it is hard to uphold the existence of 'good politicians' (Azevedo \& Chaia, 2008; Cunha, 2006; Wallin, 2014). In Sweden, on the other hand, surveilling institutions are agile, and politicians involved with corruption are seldom re-elected, mainly because electors do not accept voting for them (Wallin, 2014). While the Swedish politicians are quite frugal regarding the use of public funds, Brazilian politicians are granted quotas for transportation and other expenses, which makes the parliament an expensive and ineffective institution, in Brazilians' opinion (Moisés and Carneiro, 2008; Wallin, 2014). Swedes highly trust their system, which enabled a Welfare State that promotes social equality and experiences low corruption (Rothstein \& Uslaner, 2005). Brazilians, in turn, distrust public institutions and even advocate for the paradoxal 'democracy without National Congress' (Moisés, 2008).

Regarding cultural differences, Brazil and Sweden stand in extreme opposition. To Singelis et al. (1995) and Triandis and Gelfand (1998), Sweden is an iconic example of Horizontal Individualism, meaning that Swedes value individual sovereignty while praise equality. Brazilians, in the opposite direction, are very dependent on others in their nuclear groups (e.g. family) and accept that social hierarchy is natural - then Brazil is an example of Vertical Collectivism.

Hofstede's (1980; 1991) findings are similar. In Sweden, being independent, equal rights, and individual empowerment are praised. Swedes are egalitarian, seek balance between family/work lives, and strive from dominance and competition, while 
valuing solidarity. Sweden is then an Individualistic and Feminine society. Brazilians, oppositely, are loyal to their families in exchange for protection; they are intermediately guided to competition, and they respect hierarchy - as status symbols of power are very important in order to indicate social position. Brazil is, then, a Collectivistic / Power Distant society, with intermediate score in Masculinity.

These differences are reflected in political life. Swedes do not accept power distance with their representatives, while in Brazil it is taken as "natural". Swedes' preference for equality and individual sovereignty requires citizens to be self-sufficient and respect general rules. Brazilians act like they need protection from the "people outside family", and it is expected that "outside people" are not to be trusted. Rules can be broken, when surviving "outside people" disloyalty is more important.

Realo, Allik and Greenfield (2008) compared 45 countries, on interpersonal trust and civic involvement. They found that in countries with high interpersonal trust, people are more likely to engage into institutional collectivism practices, as they get greater social capital. In other words, they are more likely to trust people from outside their families (e.g. in neighbourhood or country level) and participate in institutions with community-oriented purposes or others, like political parties. Brazil and Sweden stand on very different positions, according to this comparison (Figure 1.1).

Brazil scores remarkably low in interpersonal trust (at the bottom of Figure 1.1), whereas Sweden scores very high. Regarding adhesion to institutional collectivism practices, Brazil again scores pretty low, while Sweden gets the highest score among the compared countries. This offers additional evidence that Brazil and Sweden are contrasting cases, making it a really valuable comparison. If results in this study are found to be valid to extremely contrasting cases, they might be useful to further research on other countries. 


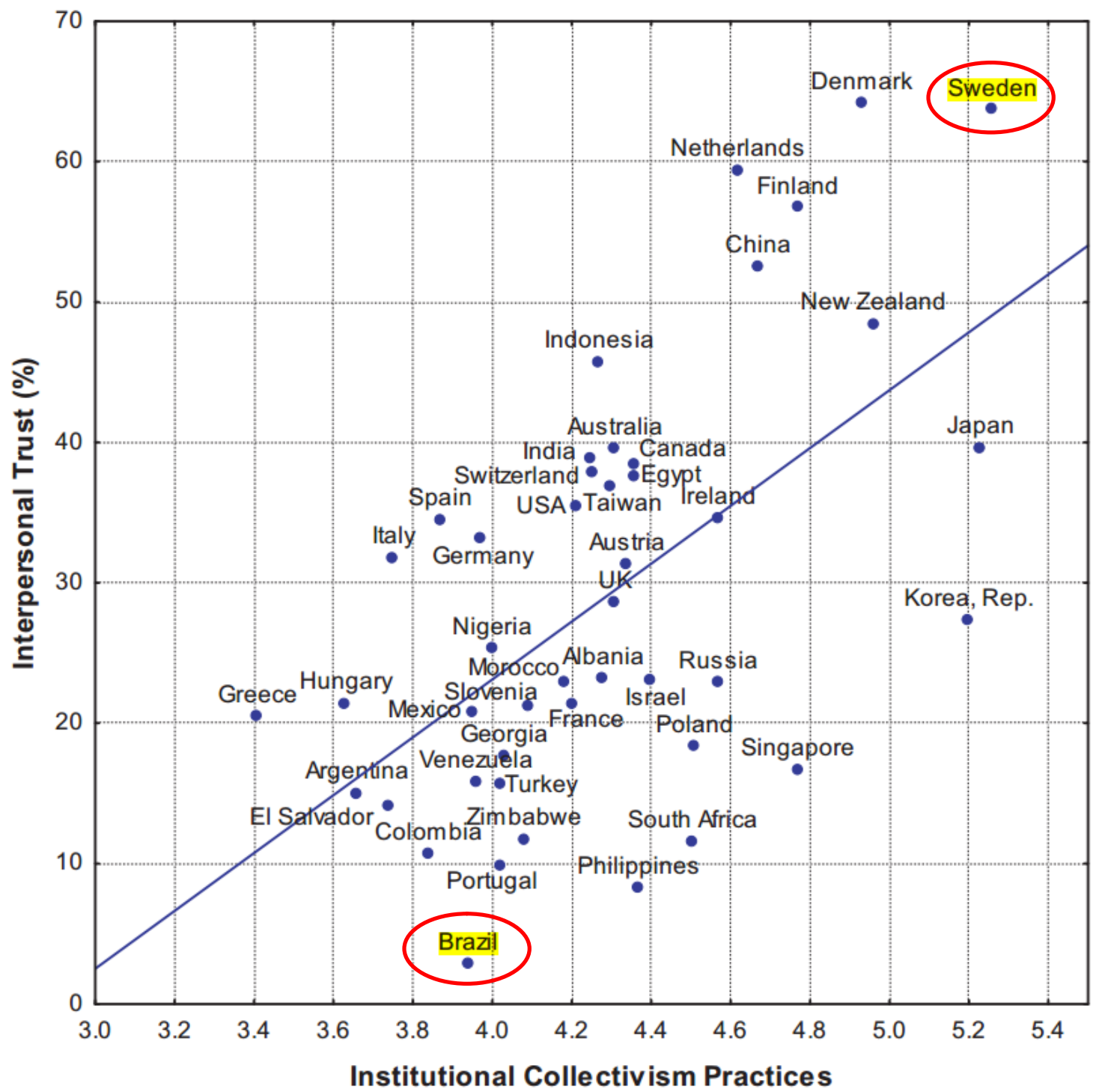

Figure 1.1. Reproduction of figure in Realo, Allik and Greenfield (2008, p. 456), crossing the scores of institutional collectivism practices (House, Hanges, Javidan, Dorfman \& Gupta, 2004) and the interpersonal trust score (Inglehart, Basanez, DiezMedrano, Halman \& Luijkx, 2004). Emphasis to Brazil and Sweden were added herein.

Such contrasts raise several questions. Are the Swedish parliamentarians perceived as 'more honest' than the Brazilian ones? And, regarding the quality of parliamentarian work, is there any difference between the countries? Does the perception about politicians influence on the political engagement of electors? 
Performing tests in such contrasting contexts could be useful to show which variable can better explain the political engagement.

\subsection{Study Objective and Relevance}

The general objective of the research proposed herein is as follows: Comparing the influence of the variables Stereotypes about Parliamentarians, Political Education and Behavioral Contagion on Political Participation between two countries (Brazil and Sweden) to build and offer evidence of validity for a theoretical-explanatory model.

The proposed research intends to contribute to the already existing literature on Political Participation (presented at Section 2.1) by submitting to empirical test the recent advances on the theoretical field. First, the concept of Political Participation has recently expanded to include newly found behaviors; the test of new a categorization is then tested via Factor Analysis. Moreover, the selection of independent variables is innovative; as such, empirical support is needed to state whether they can or cannot predict Political Participation. The comparison of the variables' factor structures and prediction power on two contrasting countries is useful to avoid limiting the study findings to one cultural context. Since culture shapes compatriots' preconceptions on politics, conclusions about one country are not directly replicable to other contexts.

The study is relevant in three perspectives: social, applied and academic. In the social perspective, the study is expected to identify the most effective psychological processes as predictors of political participation, in order to explain and help encouraging the increase of political action. In the applied perspective, it aims at providing feedback to institutions dealing with education, the media, and also the legislative houses, so they can develop strategies of education and communication to encourage political participation based on the psychological processes identified. In the academic perspective, it is a study oriented to produce innovative knowledge as no 
empirical study to evaluate the relations between the variables proposed herein has been found.

Chapter 2 details the theoretical framework for the concepts of Political Participation, Stereotypes about Parliamentarians, Political Education and Behavioral Contagion. Moreover, it makes a deeper analysis on the concept of culture, since the study crosses different cultural contexts - if we consider, at least, that there are two 'national' cultures produced in different political contexts, which potentially affects, each in their specific way, the results of the empirical study proposed herein. Yet, Chapter 2 very briefly presents the recent political history of Brazil and Sweden, notably a selection of events that could be more influent on the variables of the study.

Chapter 3 presents the study method. A questionnaire was prepared using the Delphic Panel Technique, i.e., with the participation of Brazilian and Swedish experts. The final version of the questionnaire, in English, was translated into Brazilian Portuguese and Swedish in a process of back-translation. Data were collected through the web panel (distribution of the research through the Internet). Results are presented in Chapter 4 and discussed in Chapter 5. Remarks about the research are disclosed in Chapter 6. 


\section{Chapter 2: Literature Review}

This chapter presents the state-of-the-art of the literature about the criterion (endogenous) variable, Political Participation and also about antecedent (exogenous) variables, Stereotypes about Parliamentarians, Political Education and Behavioral Contagion. Since this is a transnational study, it presents the concept of culture and a discussion about how a research should be developed in different cultural contexts. Next, it discloses a brief summary of the political history of Brazil and Sweden and, finally, a theoretical model for the relationships between the variables that will be statistically tested.

\subsection{Political Participation}

I refuse to live in a country like this. And I am not leaving. Michael Moore, 2009

The history of political participation merges with that of democracy. The first experiences of democracy took place at the assemblies in Athens, through the voted deliberations in Esparta and in the Roman Republic. The common grounds of these experiences were the strict concept of citizenship (excluding slaves, women and men who had no land tenure) and the traits of direct democracy, since politics used to be restricted to a relatively short number of inhabitants in those cities (Macedo, 1995). Thus, the political system was much more accessible to those included in it; however, it co-existed with the exclusion of most of the population.

Between the $18^{\text {th }}$ and the $19^{\text {th }}$ centuries, the political philosophers supported the liberal state as a way to constitutionally limit the powers of the monarch; this, however, did not imply the implementation of a 'democracy.' 
In the light of their historical experience, liberal political philosophers - e.g. Benjamin Constant - remained hostile to democracy, which would entail instability and disorder, thus showing the people's inherent inability of governing. Even Rousseau, who is typically associated with democracy, was not really in favor of modern democracy, i.e., representative democracy (Bresser-Pereira, 2011, p. 227).

The modern concept of democracy only emerged at the turn of the $19^{\text {th }}$ to the $20^{\text {th }}$ century, when the first societies implemented the universal suffrage - although democratization has been reached through non-linear processes, with the eventual return of totalitarian regimes (Huntington, 1991, Merkel, 2004). The advance of democratization in western countries was followed by a change on the discourse of political philosophers supporting the extension of citizenship to groups excluded up to then (Bresser-Pereira, 2011, Canfora, 2006; Lipset, 1993).

Participation was reached thanks to the pressure of groups excluded from the political system (women, slaves, men with no land tenure) and granted by the elite when they perceived there was no threat in granting the poorest layers with the right to voting (Bresser-Pereira, 2011). Following this zeitgeist transition favoring democracy, notably universal suffrage and equal access to decision-making spheres, social scientists of several areas started investigating what favors and what hinders the full exercise of citizenship (Canfora, 2006; Lipset, 1993; Merkel, 2004).

\subsubsection{Theoretical Perspectives on Political Participation}

The theoretical perspectives on political participation started by focusing exclusively on the citizen's act of selecting the political elite members (Dahl, 1956; Downs, 1957; Schumpeter, 1942). Schumpeter, in particular, emphasized the conduction of politics by leaders elected by citizens, as if citizens should be active only during elections (Miguel, 2002; Mitchel, 1984; Teorell, 2006). The attention for political behaviors not exclusively related to elections was fostered after the publication of works by Almond and Verba (1963, 1980), Milbrath (1965), Verba and Nie (1972), and 
Kaase and Marsh (1979). Since then, the thought about political participation has undergone an expansionist movement, as along the last 50 years new behaviors were investigated as exemplary political engagement (Teorell, 2006; Van Deth, 2001).

Engagement in community actions (Anderson, 2010), political consumerism (boycotts or buycotts - Stolle, Hooghe \& Micheletti, 2005), participation in organized social movements, participation in protests, organization of petitions or even getting involved in acts of political violence could also be considered to be forms of political participation (Brussino, Rabbia \& Sorribas, 2008; Dalton, 2008; Ekman \& Amnå, 2012; Hooghe \& Dejaeghere 2007; Lake \& Huckfeldt, 1998; Leighley, 1995; Paxton, 1999). The inclusion of these new behaviors expanded the concept of political participation (Berger, 2009) carries the risk of building a "theory of everything". According to Van Deth (2001), political participation started comprising "virtually any kind of activity, except for the clearly private behavior" (p. 8).

Amnå and Ekman (2014) added that political participation theories can be classified on "pessimistic" and "optimistic" interpretations on political passivity. Some pessimists consider the lack of participation a threat to democracy (like Putnam, 1995). However, on the past two decades, optimistic interpretations on political passivity arose, as they regard "passive" citizens as people who are attentive to politics and may get in action when needed (e.g. Norris, 1999; Dalton, 2004). Some of these optimists consider passivity as an asset to democracy. Yet according to Amnå and Ekman (2014), the pessimistic interpretation that citizens pay attention to politics as they distrust their elites (Rosanvallon, 2008; Theiss-Morse \& Hibbing, 2005) contrasts with the optimistic notion of monitorial citizens - those who critically observe the political context (Hooghe and Dejaeghere, 2007; Schudson, 1998).

Regardless the theoretical approach about political participation, Teorell (2006) points out that the question "which degree of participation should be considered satisfactory?" cannot be answered in absolute terms. The author proposes three core comparisons to understand if participation levels are higher or lower: a) to compare the 
occurrence of different kinds of participation in the same political context; b) to compare the same kind of political participation in different contexts; and, c) to compare the same kind of political participation in the same context, at different historic moments.

In face of the arguments by Teorell (2006) this study proposes to compare a given set of behaviors of political participation in different contexts - namely, the two countries selected for the study: Brazil and Sweden. It aims at understanding which characteristics of both the individual and the context favor their participation, notably in actions targeted to influence the parliamentarians' decisions.

\subsubsection{Downturn or mutation of Political Participation?}

Robert Putnam (1995) started a comprehensive discussion about the downturn of political participation in the United States with his essay "Bowling alone: America's declining social capital." Putnam emphasizes the drop of participation in elections, in political parties' activities, in the involvement with local committees or organizations, in demonstrations, additionally to increasing distrust of Americans in relation to their national government.

However, the thesis on political participation decay has been receiving reduced empirical support and it is criticized by authors who observe changes in the citizens' behaviors (Borba \& Ribeiro, 2010; Brussino, Rabbia \& Sorribas, 2008; Dalton, 2008; Ekman \& Amnå, 2012; Hooghe \& Dejaeghere 2007; Lake \& Huckfeldt, 1998; Leighley, 1995; Paxton, 1999; Stolle, Hooghe, \& Micheletti, 2005). The empirical evidences of those studies go against the thesis of reduced engagement of citizens in politics.

Based on studies of the historical series of 70 countries, Inglehart and Catterberg (2002) point out that democracies surveyed had undergone a period of disenchantment, a 'post-honeymoon' effect, and later resumed their participation. Hooghe and Dejaeghere (2007) investigate if citizens started adopting a posture of 'politics monitoring' and of getting involved with political actions at informal spheres, 
which are less connected to democratic institutions. These authors identified that in fact the 'monitorial citizens', notably the younger ones, became more critical in relation to democratic institutions, and moved away from the organized political activity like trade unions and political parties. Hooghe and Dejaeghere emphasize that the Scandinavian countries (Denmark, Finland, Iceland, Norway and Sweden) do not fit into this profile since in those countries the 'post-modern' citizens still participate in political activities through trade unions and political parties, and feel integrated to the political system.

Borba and Ribeiro (2010) point out the migration of interests away from 'conventional' forms of participation (related to elections and party affiliation) towards 'non-conventional' forms (demonstrations, protests and strikes). Norris, Walgrave and Van Aelst (2005) affirm that participants of public demonstrations are more likely to get involved in conventional political actions. Norris, Walgrave and Van Aelst's argument contradicts the thesis that demonstrations represented a feeling of distrust in the political system, and emphasize that those same citizens can present different forms of engagement (which is partially opposite to Borba and Ribeiro). Ekman and Amnå (2012), in turn, advocate that there was no effective decline in participation but, rather, a migration from 'manifest' forms of political participation (oriented to influence decisions made by political elites) to 'latent' forms of participation (paying attention to political activity or engaging in political activities that do not involve governmental institutions), which brings them closer to the thesis of 'monitorial citizens' by Hooghe and Dejaeghere (2007).

After the turn of millennium a wide array of studies identified a new trend. Citizens (notably the younger generations) started adopting a posture of being attentive politics and getting involved with political actions in informal spheres, less connected to political institutions, becoming 'monitorial citizens' (Brussino, Rabbia \& Sorribas, 2008; Ekman \& Amnå, 2012; Hooghe \& Dejaeghere, 2007). Those youngsters prefer mobilizations with no hierarchical organization and that could be started and concluded with great flexibility (Inglehart \& Catterberg, 2002). 
When it comes to the debate around the reduction or not of political participation, there is a high degree of disagreement among researchers about the meaning of 'participation' (Altman \& Pérez-Liñán, 2002; Berger, 2009) and about how to measure the phenomenon in a changing political world (Bollen, 1980; Diamond 1996; Huntington, 1991). Moreover, sometimes researchers fail when they restrict their conclusions about ups and downs of political participation to the countries where they perform their empirical investigations - in other words, they take the risk of showing off that decreased political participation is a global phenomenon, despite having investigated the matter only in their country or in a limited number of countries. The heart of the matter is the definition of clear parameters to compare and measure political participation in different countries, at different times (Altman \& Pérez-Liñán, 2002; Bollen, 1990).

In the historical perspective, talking about the increase or decrease of political participation implies comparing Moment A against Moment B (Bollen, 1980; Teorell, 2006). In this sense, it is risky to affirm that 'manifest' participation has decreased today. Furthermore, most countries have undergone democratic openness throughout the $20^{\text {th }}$ century (Huntington, 1991; Samuels \& Zucco, 2013), after periods when the rights to voting and freedom of speech were suspended (like Brazil, Chile, Ecuador, Peru, Nicaragua, Bolivia, Germany, Italy, Mozambique and others). Thus, one can hardly compare historic moments that are so different in terms of democratic freedoms (Bollen, 1990; Brussino, Rabbia \& Sorribas, 2008). Countries are apparently moving towards democratization; however, it is indeed possible that new totalitarian regimes may emerge - in other words, 'democratization waves' eventually bump into 'reversal waves' and history does not follow a linear path (Diamond 1996; Huntington, 1991).

Anyway, comparing political participation in different historic moments or countries demands clear definition of the phenomenon (Bollen, 1980). That definition must be applicable to different contexts under the historical and geographic perspectives (Seligson, 2002). Therefore, it is worth analyzing the definitions of political 
participation in line with the theoretical perspective of this study, in order to establish the conceptual framework to be used at the empirical investigation.

\subsubsection{Concept of Political Participation in this study}

The work of defining the phenomenon of political participation in operational terms requires, initially, an effort to comprise all kinds of behavior that could be classified as such, rather than to delimit political participation and exclude what does not fit into this concept. In this light, the definitions proposed by Verba and Nie (1972), Milbrath and Goel (1977) and Kaase and Marsh (1979) - which are frequently referred to in the literature on this matter - are analyzed herein, highlighting the theoretical advances produced between the 1970s and the 2010s. These authors from the 1970s define political participation as:

Actions performed by private citizens more or less intensively oriented to influence the selection of rulers and/or their actions (Verba \& Nie, 1972, p. 2).

Actions performed by private citizens to influence on or support governments or politics. (Milbrath \& Goel 1977, p. 2).

Any voluntary activity by individual citizens trying to directly or indirectly influence on the political decisions at different levels of the political system. (Kaase \& Marsh 1979, p. 42).

Those definitions are centered on the citizens' influence over governmental decisions, leaving aside other types of participation. Classification should be diversified to comprise other types of participation than those related to the institutional political process (Brussino, Rabbia \& Sorribas, 2008; Ekman \& Amnå 2012; Hooghe \& Dejaeghere, 2007).

Additionally to definitions, the categories created by authors in the 1970 s should be understood to classify the existing types of political participation. Kaase and Marsh (1979) created a dichotomized classification of political participation divided into 'conventional' forms (voting, affiliating to political party, contributing to campaigns and 
other forms of participation related to elections) and 'non-conventional' forms (protests, public demonstrations or takeover of buildings). However, in this classification even the 'non-conventional' forms are focused on influencing governmental decisions and, thus, are subject to the criticism by Ekman and Amnå (2012) and Brussino, Rabbia and Sorribas (2008). Moreover, although this classification has become fully accepted in the literature (according to Borba and Ribeiro, 2010), it generates a theoreticalmethodological controversy which is hard to be solved.

Those 'non-conventional' forms of participation are defined in terms of behaviors that do not fit into 'regulations, laws, rules and uses that govern political participation in a given regimen (Kaase \& Marsh, 1979, p. 41). Verba, Nie and Kim (1978) have also contributed to the controversy when they decided to include a reference to the legality of political participation, which was then defined as

"Legal actions carried by private citizens more or less directly oriented to influence the selection of governors and/or their actions " (Verba, Nie \& Kim, 1978 , p. 2 - emphasis added to the word inserted to the previous definition by Verba \& Nie, 1972).

When one highlights the duality between 'legal' or 'illegal' actions, there is the risk of building dependence on the status quo and, thus, being subject to changing social constraints (Brussino, Rabbia \& Sorribas, 2008; Sabucedo, 1984; Van Deth, 1986). In other words, political actions considered legal in some countries could be illegal in others (e.g., public demonstrations). Likewise, a political action could be either legal or illegal in the same country, depending on the historic moment being studied (like dictatorship or a democratic period). Therefore, the concept by Kaase and Marsh (1979) is not adequate to longitudinal or transnational studies, since legislation on political rights (notably freedom of speech) varies along time and between countries (Sabucedo, 1984). Even worse, it has the cumbersome effect of suggesting, by connotation of the terms selected, that 'conventional' type is more legitimate than the 'non-conventional' one (Van Deth, 1986). Thus, the 'non-conventional' category of 
political participation comprises several political behaviors that should be better differentiated and characterized (Brussino, Rabbia \& Sorribas, 2008; Van Deth, 2001).

Moving away from the 'vision of the problem' towards the 'vision of solution', it is worth analyzing the same literature in terms of progresses towards building consistent categories to the different forms of political participation, notably the cross-cultural perspective. In their classic study Verba and Nie (1972) identified four main forms of political participation among the United States citizens: a) voting; b) activism in electoral campaigns; c) involvement in cooperative activities (community); d) contacts initiated by citizens. It is a more complete and diversified classification than the focus on legality or 'conventionality', but it has not become hegemonic in literature (Borba \& Ribeiro, 2010), as it would happen with Kaase and Marsh (1979).

Brussino, Rabbia and Sorribas (2008) applied questionnaires to youngsters in Córdoba (Argentina). Through cluster and factorial analysis, these researchers identified three categories of political participation: a) Political party/trade union participation; b) Community activities; and, c) Protest actions. The classification of Brussino, Rabbia and Sorribas (2008), therefore, escapes from the frivolous debate about legality/illegality, conventionality/non-conventionality, and legitimacy/illegitimacy of political actions. Thus, three categories were produced, which just gather and describe behaviors, without assigning them labels that depend on the status quo of the country and its historic moment.

Ekman and Amnå (2012) support that too much attention was attached to the manifest forms of participation (e.g., voting, participating in demonstrations, writing petitions), while researches usually disregard the latent forms (e.g., paying attention to the news about politics and discussing with friends). Metaphorically, they affirm that the underwater part of the iceberg is what is actually missed. The authors propose reorganizing the categories of political participation. The classification proposed by the Swedish authors builds a spectrum that starts with political disengagement, going through latent forms of participation and concluding in manifest forms, differentiating 
individual and collective forms of action (please refer to Table 1). This study adopts the classification model proposed by Ekman and Amnå (2012), with some adjustments (please refer to Table 2; changes italicized); therefore, each category elaborated by these authors is described below in details.

For Ekman and Amnå (2012), the forms of non-participation or disengagement could be characterized in terms of anti-political or apolitical attitudes. People with antipolitical attitude practice active forms of disengagement (like manifesting their displeasure about politics or having an anti-political lifestyle), while people with apolitical attitude adopt passive forms of behavior, perceiving politics as something humdrum (Table 1). For this study, the names of subcategories were changed: more emphasis was assigned to the apolitical or anti-political posture, which could be read as "passive" and "active", (Table 2). The example of social exclusion as driver of collective anti-political actions was withdrawn, as social exclusion could be a driver to active political participation (Duriguetto, Souza \& Nogueira, 2009). 
Table 1. Ekman e Amnå's (2012) Political Participation Framework.

\begin{tabular}{|c|c|c|c|c|c|c|c|}
\hline & \multicolumn{2}{|c|}{$\begin{array}{l}\text { Non-participation } \\
\text { (disengagement) }\end{array}$} & \multicolumn{2}{|c|}{$\begin{array}{l}\text { Civil participation } \\
\text { (latent-political) }\end{array}$} & \multicolumn{3}{|c|}{ Political participation (manifest) } \\
\hline & \multirow{2}{*}{$\begin{array}{l}\text { Active forms } \\
\text { (antipolitical) }\end{array}$} & \multirow{2}{*}{$\begin{array}{l}\text { Passive forms } \\
\quad \text { (apolitical) }\end{array}$} & \multirow{2}{*}{$\begin{array}{l}\text { Social involvement } \\
\text { (attention) }\end{array}$} & \multirow{2}{*}{$\begin{array}{l}\text { Civic engagement } \\
\text { (action) }\end{array}$} & \multirow{2}{*}{$\begin{array}{l}\text { Formal political } \\
\text { participation }\end{array}$} & \multicolumn{2}{|c|}{$\begin{array}{l}\text { Activism (extra-parliamentary political } \\
\text { participation) }\end{array}$} \\
\hline & & & & & & Legal & Illegal \\
\hline $\begin{array}{l}\text { Individual } \\
\text { forms }\end{array}$ & $\begin{array}{l}\text { Non-voting } \\
\text { Actively avoiding } \\
\text { reading newspapers or } \\
\text { watching TV when it } \\
\text { comes to political issues } \\
\text { Avoid talking about } \\
\text { politics } \\
\text { Perceiving politics as } \\
\text { disgusting } \\
\text { Political disaffection }\end{array}$ & $\begin{array}{l}\text { Non-voting } \\
\text { Perceiving politics } \\
\text { as uninteresting and } \\
\text { unimportant } \\
\text { Political passivity }\end{array}$ & $\begin{array}{l}\text { Taking interest in politics } \\
\text { and society } \\
\text { Perceiving politics as } \\
\text { important }\end{array}$ & $\begin{array}{l}\text { Writing to an editor } \\
\text { Giving money to charity } \\
\text { Discussing politics and } \\
\text { societal issues, with } \\
\text { friends or on the Internet } \\
\text { Reading newspapers } \\
\text { and watching TV when it } \\
\text { comes to political issues } \\
\text { Recycling }\end{array}$ & $\begin{array}{l}\text { Voting in elections and } \\
\text { referenda } \\
\text { Deliberate acts of non-voting } \\
\text { or blank voting } \\
\text { Contacting political } \\
\text { representatives or civil } \\
\text { servants } \\
\text { Running for or holding public } \\
\text { office } \\
\text { Donating money to political } \\
\text { parties or organizations }\end{array}$ & $\begin{array}{l}\text { Buycotting, } \\
\text { boycotting and } \\
\text { political } \\
\text { consumption } \\
\text { Signing petitions } \\
\text { Handing out } \\
\text { political leaflets }\end{array}$ & $\begin{array}{l}\text { Civil disobedience } \\
\text { Politically motivated } \\
\text { attacks on property }\end{array}$ \\
\hline $\begin{array}{l}\text { Collective } \\
\text { forms }\end{array}$ & $\begin{array}{l}\text { Deliberate non-political } \\
\text { lifestyles, e.g. hedonism, } \\
\text { consumerism. } \\
\text { In extreme cases: } \\
\text { random acts of non - } \\
\text { political violence (riots), } \\
\text { reflecting frustration, } \\
\text { alienation or social } \\
\text { exclusion. }\end{array}$ & $\begin{array}{l}\text { "Non-reflected" non- } \\
\text { political lifestyles }\end{array}$ & $\begin{array}{l}\text { Belonging to a group with } \\
\text { societal focus } \\
\text { Identifying with a certain } \\
\text { ideology and/or party } \\
\text { Life-style related } \\
\text { involvement: music, group } \\
\text { identity, clothes, et cetera } \\
\text { For example: veganism, } \\
\text { right -wing Skinhead } \\
\text { scene, or left -wing } \\
\text { anarcho-punk scene }\end{array}$ & $\begin{array}{l}\text { Volunteering in social } \\
\text { work, e.g. to support } \\
\text { women's shelter or to } \\
\text { help homeless people } \\
\text { Charity work or faith- } \\
\text { based community work } \\
\text { Activity within } \\
\text { community based } \\
\text { organizations }\end{array}$ & $\begin{array}{l}\text { Being a member of a } \\
\text { political party, an } \\
\text { organization, or a trade } \\
\text { union. } \\
\text { Activity within a party, an } \\
\text { organization or a trade union } \\
\text { (voluntary work or attend } \\
\text { meetings). }\end{array}$ & $\begin{array}{l}\text { Involvement in new } \\
\text { social movements or } \\
\text { forums } \\
\text { Demonstrating, } \\
\text { participating in } \\
\text { strikes, protests and } \\
\text { other actions (e.g. } \\
\text { street festivals with a } \\
\text { distinct political } \\
\text { agenda) }\end{array}$ & $\begin{array}{l}\text { Civil disobedience } \\
\text { actions } \\
\text { Sabotaging or } \\
\text { obstructing roads and } \\
\text { railways } \\
\text { Squatting buildings } \\
\text { Participating in violent } \\
\text { demonstrations or } \\
\text { animal rights actions } \\
\text { Violence } \\
\text { confrontations with } \\
\text { political opponents or } \\
\text { the police }\end{array}$ \\
\hline
\end{tabular}


Table 2. Political Participation Framework, with adaptations for the present research (changes assigned in italic).

\begin{tabular}{|c|c|c|c|c|c|c|c|}
\hline & \multicolumn{2}{|c|}{$\begin{array}{c}\text { Non-participation } \\
\text { Disengagement }\end{array}$} & \multicolumn{2}{|c|}{$\begin{array}{c}\text { Latent Participation } \\
\text { (Pre-Political) }\end{array}$} & \multicolumn{3}{|c|}{ Political participation (manifest) } \\
\hline & \multirow{2}{*}{$\begin{array}{l}\text { Antipolitical } \\
\text { (Active forms) }\end{array}$} & \multirow{2}{*}{$\begin{array}{c}\text { Apolitical } \\
\text { (Passive forms) }\end{array}$} & \multirow{2}{*}{$\begin{array}{c}\text { Attention } \\
\text { (Involvement) }\end{array}$} & \multirow{2}{*}{$\begin{array}{c}\text { Action } \\
\text { (Engagement) }\end{array}$} & \multirow{2}{*}{$\begin{array}{l}\text { Institutional political } \\
\text { participation }\end{array}$} & \multicolumn{2}{|c|}{ Extra-institutional activism } \\
\hline & & & & & & Non-violent & Violent \\
\hline $\begin{array}{l}\text { Individual } \\
\text { forms }\end{array}$ & $\begin{array}{l}\text { Non-voting } \\
\text { Actively avoiding } \\
\text { reading newspapers or } \\
\text { watching TV when it } \\
\text { comes to political issues } \\
\text { Avoid talking about } \\
\text { politics } \\
\text { Perceiving politics as } \\
\text { disgusting } \\
\text { Political disaffection }\end{array}$ & $\begin{array}{l}\text { Non-voting } \\
\text { Perceiving politics as } \\
\text { uninteresting and } \\
\text { unimportant } \\
\text { Political passivity }\end{array}$ & $\begin{array}{l}\text { Taking interest in politics } \\
\text { and society } \\
\text { Perceiving politics as } \\
\text { important } \\
\text { Reading newspapers } \\
\text { and watching TV when it } \\
\text { comes to political issues }\end{array}$ & $\begin{array}{l}\text { Writing to an editor } \\
\text { Giving money to charity } \\
\text { Discussing politics and } \\
\text { societal issues, with } \\
\text { friends or on the Internet } \\
\text { Recycling }\end{array}$ & $\begin{array}{l}\text { Voting in elections and } \\
\text { referenda } \\
\text { Deliberate acts of non- } \\
\text { voting or blank voting } \\
\text { Contacting political } \\
\text { representatives or civil } \\
\text { servants } \\
\text { Running for or holding } \\
\text { public office } \\
\text { Donating money to } \\
\text { political parties or } \\
\text { organizations }\end{array}$ & $\begin{array}{l}\text { Buycotting, } \\
\text { boycotting and } \\
\text { political } \\
\text { consumption } \\
\text { Signing petitions } \\
\text { Handing out } \\
\text { political leaflets } \\
\text { Civil disobedience }\end{array}$ & $\begin{array}{l}\text { Politically } \\
\text { motivated attacks } \\
\text { on property } \\
\text { Escracho- } \\
\text { physically or } \\
\text { morally attacking } \\
\text { politicians }\end{array}$ \\
\hline $\begin{array}{l}\text { Collective } \\
\text { forms }\end{array}$ & $\begin{array}{l}\text { Deliberate non-political } \\
\text { lifestyles, e.g. hedonism, } \\
\text { consumerism. } \\
\text { In extreme cases: } \\
\text { random acts of non - } \\
\text { political violence (riots), } \\
\text { reflecting frustration or } \\
\text { alienation }\end{array}$ & $\begin{array}{l}\text { "Non-reflected" non- } \\
\text { political lifestyles }\end{array}$ & $\begin{array}{l}\text { Belonging to a group } \\
\text { with societal focus } \\
\text { Identifying with a certain } \\
\text { ideology and/or party } \\
\text { Life-style related } \\
\text { involvement: music, } \\
\text { group identity, clothes, } \\
\text { et cetera For example: } \\
\text { veganism, right -wing } \\
\text { Skinhead scene, or left - } \\
\text { wing anarcho-punk } \\
\text { scene }\end{array}$ & $\begin{array}{l}\text { Volunteering in social } \\
\text { work, e.g. to support } \\
\text { women's shelter or to } \\
\text { help homeless people } \\
\text { Charity work or faith- } \\
\text { based community work } \\
\text { Activity within } \\
\text { community based } \\
\text { organizations }\end{array}$ & $\begin{array}{l}\text { Being a member of a } \\
\text { political party, an } \\
\text { organization, or a trade } \\
\text { union. } \\
\text { Activity within a party, an } \\
\text { organization or a trade } \\
\text { union (voluntary work or } \\
\text { attend meetings). }\end{array}$ & $\begin{array}{l}\text { Involvement in new } \\
\text { social movements or } \\
\text { forums } \\
\text { Demonstrating, } \\
\text { participating in } \\
\text { strikes, protests and } \\
\text { other actions (e.g. } \\
\text { street festivals with a } \\
\text { distinct political } \\
\text { agenda) } \\
\text { Civil disobedience } \\
\text { actions }\end{array}$ & $\begin{array}{l}\text { Sabotaging or } \\
\text { obstructing roads } \\
\text { and railways } \\
\text { Squatting } \\
\text { buildings } \\
\text { Participating in } \\
\text { violent } \\
\text { demonstrations or } \\
\text { animal rights } \\
\text { actions } \\
\text { Violent } \\
\text { confrontations with } \\
\text { political opponents } \\
\text { or the police }\end{array}$ \\
\hline
\end{tabular}


Regarding what Ekman and Amnå (2012) call "Civil Participation" (please refer to Table 1), it comprises behaviors that could be classified in terms of "Social Involvement" (typically oriented to attention to politics) and "Civic Engagement" (actions that produce political impact external to the context of governmental institutions, like voluntary social works). Among the adjustments proposed herein, the name of the category was changed to 'Latent Participation (pre-political)' complying with the terminology used by the Swedish authors, but inverting the emphasis placed to nomenclature (Table 2). The words 'civil', 'civic' and 'social' were excluded from the names of categories and subcategories - in this context, there is such a big semantic overlapping among the words that they could be considered to be interchangeable. Subcategories were renamed to 'Attention (Involvement)' and 'Action (Engagement)' so that emphasis is attached to terms that help differentiating these. Finally, the behavior 'Reading newspapers and watching TV when it comes to political issues' migrated from the subcategory 'Action' to 'Attention' as it is basically the consumption of political information.

The manifest Political Participation comprises the participation in the formal political system (actions compliant to the rules of political institutions) and the extraparliamentarian participation, which was divided into legal and illegal forms of demonstration (Ekman \& Amnå, 2012). Thus, the problematic duality between legality and illegality, which seemed to have been overcome (Brussino, Rabbia \& Sorribas, 2008), has not been abandoned in the classification by Ekman and Amnå. Despite that, the classification allows a more sophisticated understanding of the phenomenon than the taxonomies proposed in the past. Adaptations proposed to this category aim at solving the issue of 'legality'. The word 'formal' was replaced by 'institutional' in the subcategory that gathers behaviors that use the political system according to their rules - thus, avoiding a complex debate about the dialectics of formality or informality of the political action (Duriguetto, Souza, \& Nogueira, 2009). The subcategory that 
characterizes activism was renamed to "Extra-Institutional Activism" replacing the expression "extra-parliamentarian", as activism could be oriented to influence nonparliamentarian institutions - e.g., bodies of the Executive or Judiciary Powers (Campilongo, 1994; Cittadino, 2004; Fuks \& Perissinotto, 2006). Instead of classifying activism in terms of legality or illegality, it is proposed to differentiate violent and nonviolent acts (Table 2). The behaviors classified by Ekman and Amnå (2012) remain unchanged, except for the item 'Civil Disobedience' as it is of non-violent nature (Silva, 1998) and the inclusion of escracho (public attacks to politicians - Mocca, 2005).

The conceptual framework outlined by Ekman and Amnå (2012) can provide a comprehensive overview on the types of political participation practiced in a nation, and allows for comparing countries and producing historical series. The changes proposed aimed at facilitating the application of the model, avoiding difficulties arising from classifying political action in terms of legality or illegality.

The classification by Ekman and Amnå (2012) was proposed in a theoretical perspective, based on the literature review, and it is being subjected to the first empirical tests; Amnå and Ekman (2014) have tested different degrees of "political passivity” (i.e., focused on the 'Non-participation' column); Talò and Mannarini (2014) have created a political participation scale ${ }^{1}$; likewise, this study proposes a test to this classification.

Besides testing the verisimilitude of Ekman and Amnå's (2012) classification, it is necessary to investigate which variables could determine the occurrence of each category of participation. Therefore, it is worth discussing theoretical considerations that point out the predictive potential of the other variables listed here.

1 When the study by Talò and Mannarini (2014) was published, this study had already concluded the data collection stage. Therefore, it could not use the article as input to draft the questionnaire presented in this Thesis. 


\subsubsection{Antecedent Variables of Political Participation}

What could explain the stronger tendency of some people toward participating in political activities? Information and cognition play a core role that should be deepened.

Delli Carpini and Keeter (1996) note that the political system works well to wellinformed citizens, while it is far from being democratic to uninformed citizens. Luskin, Fishkin and Jowell (2002) noted that, after receiving information from experts, the participants of a quasi-experimental program presented less extreme attitudes and more open to dialogue. Both studies conclude that well-informed citizens better enjoy the opportunities to operate the political system.

On the other hand, Lupia and McCubbins (2000) and Huckfeldt and Sprage (1995) establish that electors do not need to get an exhaustive amount of information to make a political decision. Moreover, sometimes information is not structured, as it could be generated by the mutual influence people practice. In opposition to the aforementioned authors, Lupia and McCubbins (2000) and Huckfeldt and Sprage (1995) do not start from the premise that "more information is better." Instead of pursuing an ideal of 'well-informed citizen', these authors try to know reality as it is, i.e., how people seek for information about politics in their everyday lives.

Lupia and McCubbins (2000) argue that, either in the political arena or not, people usually have few information on the decisions they are about to make (corroborated by Carlin \& Love, 2013; Druckman, 2001; Garzia, 2013; Henrique, 2010). Usually, people decide to pay attention to information that could serve as a shortcut to the decision, i.e., they prefer information that demands reduced effort of interpretation and analysis (corroborated by Huckfeldt \& Sprage, 1995). The underlying questions are: 'how much is the minimum amount of information enough to take a decision similar to a deeply informed decision?' and 'which information provides reliable shortcuts to decision?' 
For Huckfeldt and Sprage (1995) the sources of political information are necessarily biased, and that bias is out of the control of the receiver. Furthermore, the information received more recently concurs with the information previously assimilated. The authors try to respond the question 'how do information influence on the personal political preferences?' investigating social learning and behavioral contagion. In that sense, Huckfeldt and Sprage (1995) support the need for observing the transmission of political information in a district, city or small regional circumscription - after all, what is most relevant to them is to understand the phenomenon of communication by word of mouth, which happens very discreetly.

In brief, while some researchers (from the school of Cambridge) argue that "more information is better", other researchers (from the school of Michigan) support that people make decisions based on the poor information they have. It is worth mentioning that, according to the classification used in this study, the interest for political information fits into the subcategory 'attention', i.e., it is a form of latent participation. However, Ekman e Amnå (2012) state that latent forms of participation could lead to manifest forms. The authors argue for the need of outlining items to evaluate latent participation in combination with readiness for manifest political action.

Here, nonetheless, the selection of manifest forms of participation would depend on how citizens understand the information they get. Brussino, Rabbia and Sorribas (2008) explain how that would take place:

People can work both at electoral and non-electoral levels to promote their symbolic or material interests. Notwithstanding, due to resources available, the institutional context and the cognitive dimensions underlying the 'political' dimension, they would tend to conceive as 'possible', 'legitimate' or 'effective' only some of those specific practices, in detriment to others (Brussino, Rabbia \& Sorribas, 2008; p. 300).

In other words, the decision on the political action through which citizens expect to get the best results takes into consideration their concept of 'political'. In that sense, the citizen's interpretation about the behavior of governmental agent is a relevant 
issue. In this study this phenomenon is translated in terms of stereotype (with no pejorative judgment, since stereotype could have either negative or positive bias on the target) as it could summarize several pieces of information about the politician, following the line of argument of Huckfeldt and Sprage (1995) and Lupia and McCubbins (2000). Moreover, it is worth evaluating if the political education delivered to citizens in Brazil and Sweden contributes or not to nurture citizens attentive to politics and tending to act whenever necessary (Frazer, 2000; Henderson \& Chatfield, 2011; Henrique, 2010; Mayer, 2011; Persson, 2012). Finally, the behavioral contagion will be discussed as the process through which beliefs and behaviors are transmitted in a crowd, leading the transformation of individual behavior into collective behavior (Cho \& Rudolph, 2008; Lake \& Huckfeldt, 1998).

The next sessions deepen the debate about stereotypes about parliamentarians, political education and behavioral contagion. Then, the considerations about researches in different cultural contexts are presented, how are the two countries surveyed, and the processes of building democratic institutions and political participation in Brazil and Sweden are briefly depicted. 


\subsection{Stereotypes about Parliamentarians}

Every day, citizens are exposed to an avalanche of political information. Newspapers, TV, radio, social media, blogs, websites, chats in bars, etc. A wide range of information could be used to understand the interaction of groups in the parliamentarian arena: parties, interests of the sectors they represent, profession (previous to that as parliamentarian), political offices previously held, etc. (Carlin \& Love, 2013; Druckman, 2001; Garzia, 2013, Kam, 2007, Koch, 2003, Pietryka \& Boydstum, 2012). However, politically lay citizens, with short time to analyze information, may have to ignore several pieces of information and build their opinions based on the information they consider to be more relevant (Arceneaux, 2008; Druckman, 2001, Lau \& Redlawsk, 2001). Which information, then, do they consider to be relevant? To which conclusions does that information lead?

This study employs the concept of Stereotypes about Parliamentarians as it understands that stereotypes summarize a large amount of information about a group (e.g., parliament members) and could be useful to differentiate groups (e.g., members of different political parties); this is supported by the literature (Haslam, Turner, Oakes, McGarty, \& Reynolds, 1997; Koch, 2003; Lau \& Redlawsk, 2001; Schneider \& Bos, 2011). Based on 'relevant' information, citizens can try to predict the behavior of parliamentarians (Arceneaux, 2008; Carlin \& Love, 2013; Samuels \& Zucco, 2013). Moreover, this study tests if citizens can select their form of political participation based on how they perceive the behavior of parliamentarians (Kinder \& Sears, 1985; Sacchi, Carnaghi, Castellini \& Colombo, 2013).

The exercise of applying stereotypes as independent (exogenous) variable of political participation implies a conceptual analysis to reconfigure its meaning. Next, attitudes, stereotypes, prejudice and discrimination are distinguished to clarify the use of those concepts herein. 


\subsubsection{Relations among concepts}

The concept of 'stereotype' has its origin in the concept of attitudes, prejudice and discrimination. Fishbein and Ajzen (1975) understand "attitude" as a long-lasting organization of beliefs and cognitions in general, endowed with emotional charge pro or against a defined social object which predisposes to an action that is coherent with the cognitions and affections related to that object. These are "predispositions learned to favorably or unfavorably respond to a given object' (Fishbein \& Ajzen, 1975, p. 6). The three elements underlined above are found in the tripartite organization proposed four decades before by Allport (1935), to whom Attitude bears:

a) An affective (or evaluative) component that reflects if the person likes or dislikes an object or situation;

b) A cognitive component which consists in the beliefs people have about an object or situation; and

c) A behavioral component which represents the behavioral tendencies in relation to an object or situation.

When reviewing the literature, Ajzen and Fishbein (2005) point the inexistence of empirical evidence regarding a clear separation among the three abovementioned components; even Allport (1935) had affirmed that this is a 'didactic' division, since those components are in fact intertwined. However, even applying that tripartite and didactic division, Eagly and Chaiken (1998) point out that, by analogy, the stereotype corresponds to the cognitive component, while prejudice corresponds to the affective component and discrimination corresponds to the behavioral component (and Fiske, 1998 reaffirms it). In other words, up to now the attitudes towards a group could be described in terms of the following components: 'stereotype', 'prejudice' and ‘discrimination’. 
Prejudice and discrimination are concepts of intrinsically negative bias. These refer, respectively, to disliking, fearing, feeling anger or envying a group and acting in an aggressive way in relation to it (Brewer \& Brown, 1998). The consulted literature does not even propose nomenclatures to express positive affections or behaviors in relation to a group. By extension, the concept of stereotype, previously considered to be neutral (Ryan, 2003), is implicitly 'contaminated' by such negativity, and is usually considered to be the baseline for prejudice and discrimination (like did, e.g., Allport, 1954; and Katz \& Braly, 1933). The effect is that it contaminates, likewise, the researches about attitudes in relation to groups as it assumes that thoughts, affections and actions among groups always bear negative biases (Jussim, McCauley \& Lee, 1995; Mackie, 1973; Ryan, 2003).

This study accepts the possibility of ambivalent attitudes in relation to groups (i.e., positive and/or negative) which contradicts the prevailing trend of studies in this area (Ryan, 2003; Ryan \& Bogart, 2001). Therefore, the following paragraphs are devoted to: a) Dissociating 'stereotype' from the negative burden typically assigned to it; and, b) proposing alternative concepts to 'prejudice' and 'discrimination' to allow investigations about positive and negative behaviors in intergroup relations. Finally, it discusses the application of those concepts in the context of interaction between citizens and parliamentarians.

\subsubsection{Stereotypes as a system to classify groups}

The content of stereotypes may bear positive or negative valence (Cuddy et al., 2009; Jussim, McCauley \& Lee, 1995; Ryan \& Bogart, 2001). It is a simple description of a group. Therefore, it works as a schema to classify people as belonging to this or that group (Brewer \& Brown, 1998; Haslam et al., 1997; Mackie, 1973; Torres, \& 
Neves, 2013). By the way, a schema ${ }^{2}$ is nothing but that: a structured pooling of concepts 'used to represent events, a sequence of events, precepts, situations, relations and even objects' (Eysenck \& Keane, 1994, p. 245).

The formulator (the one who creates the stereotype) assumes there are no significant differences between the members of the out-group ${ }^{3}$; in their view, a member of a group, in isolation, would behave like the remainder members (Brewer \& Brown, 1998; Fiske, 1998). The formulator can use stereotypes to describe the common behavior of the members of an out-group like, e.g.: 'Japanese are organized', 'Mexicans add too much pepper in food" or 'Brazilians arrive late.'

For a long time in the $20^{\text {th }}$ century, Social Psychology researchers have investigated stereotypes based on the assumption that these were 'inaccurate' or even 'fake' interpretations about groups, ethnics, gender, age, religions, etc. (Allport, 1954; Brigham, 1971; Hartley, 1946; Katz \& Braly,1933; Richter, 1956). Those researchers tried to demonstrate that individuals who based their perceptions on stereotypes often distorted reality. The out-group behaviors would always be construed in such a way as to prove stereotypes (Jost \& Banaji, 1994; Richter, 1956). Stereotypes would be 'Siamese twins' of prejudice. Researchers felt obliged to produce knowledge about the matter; that knowledge would be used to deconstruct the stereotypes as they were 'evil' (Jussim, McCauley \& Lee, 1995; Ryan, 2003). If researches could fulfill that objective, the individuals would no longer use stereotypes as the basis for their

2 The notion of schema as organized structure of thought was introduced by Immanuel Kant, and further re-elaborated and introduced to psychology and pedagogy through the works by Frederic Bartlett and Jean Piaget (according to Duarte, Nunes \& Kristensen, 2008).

${ }^{3}$ Out-group is understood as the 'social unit with which the individual does not identify or to which he/she does not belong', and the in-group is exactly the opposite, i.e., the 'social unit with which the individual identifies or to which s/he belongs' (James, 1986). The terms outgroup and in-group are used to respectively designate the group that formulates and the target-group of the stereotype, prejudice or discrimination. 
interpretation about group behaviors and would 'see' the characteristics of individuals that used to be stereotyped (Ryan, 2003).

Jussim, McCauley and Lee (1995), in the countercurrent of that reasoning, answered the 'charges' (as they called it) that stereotypes would be something necessarily evil and unrealistic. They argue that the assumption that stereotypes are 'fake' and 'inaccurate' is a conceptually problematic one and is not empirically justified. Here it is worth summarizing those arguments, as they contradict the trend of some researches about stereotypes still in our days ${ }^{4}$.

Before rebutting the 'charges' Jussim, McCauley and Lee (1995) explained that one should distinguish the stereotypes of the 'all or nothing' type (according to which all members of a group are presumed to be equal) and the 'probabilistic' stereotypes (according to which some members are more and others are less 'typical' of a group). Thus, when one says that stereotypes are factually incorrect (first accusation), the affirmation is based on the 'all or nothing' type (e.g., 'Japanese are efficient'), which is demonstrated at the review by Ryan (2003). However, those authors claim to be unaware of any study on stereotypes where participants employ the 'all or nothing' type; participants usually employ the 'probabilistic' type. In other words, people usually accept that some members of a group can "break" the stereotype (e.g., there could be one inefficient Japanese person). So, stereotypes could effectively be factually right, provided these are grounded on information that properly describes the target-group and accept exceptions.

The authors use the same argument to refute the accusation that stereotypes are irrationally resistant to new information. If valid stereotypes are of the 'probabilistic' kind, so it would not be irrational if such stereotype resisted to the confrontation with an atypical member of the group. After all, if the information about the group remains valid,

\footnotetext{
${ }^{4}$ The study will not present all arguments used by the authors. For further details, please read the original text. The chapter referred herein is available at http://psycnet.apa.org/books/10495/.
} 
there is no sense in disregarding it just because you suddenly knew someone different (Ryan \& Bogart, 2001).

Jussim, McCauley and Lee (1995) consider the criticisms to stereotypes made by Levine and Campbell (1972, as quoted by Jussim, McCauley \& Lee, 1995) to be more 'sophisticated'. Those critics advocate for the idea that stereotypes: a) are exaggerations about the true intergroup differences; b) are ethnocentric; and c) assume genetic origins to intergroup differences. Jussim, McCauley and Lee (1995) argue there is no empirical evidence to any of the three criticisms, which should be managed as hypotheses to be tested. Finally, there is the criticism that stereotypes establish unrealistic vision of the out-group homogeneity, i.e., out-groups are perceived as less diverse than what they effectively are (as supported by Richter, 1956). According to Jussim, McCauley and Lee (1995), it should also be considered to be a hypothesis to be tested, as one cannot say it is a proven fact (this idea is supported by Mackie, 1973 and Ryan, 2003).

For Jussim, McCauley and Lee (1995) there is no functional difference between stereotype and other kinds of categorization. It is a cognitive need, required to deal with the large amount of information about people (Brewer \& Brown, 1998; Lau \& Redlawsk, 2001). After all, handling information about each individual in isolation would demand a huge capacity of processing and storage from memory; on the other hand, human cognition tends to work with simplifications of reality (Allport, 1954; Fiske, 1998). Categorization allows the formulation of expectations about the object being categorized, driving the agent's behaviors (Brewer \& Brown, 1998; Ottati \& Lee, 1995).

In different situations, stereotypes bear a kernel of truth (Ottati \& Lee, 1995) or reach high degrees of consensus (Haslam et al., 1997), except for those created to endorse prejudices and discrimination (Allport, 1954; Cuddy et al., 2009; Ryan \& Bogart, 2001). That makes sense as stereotypes fit into several models used in social psychology to explain the cognitive processes. 
This study is interested in verifying if participants are sensitive to the variability of the group of parliamentarians. It aims at evaluating which critical information participants use to differentiate parliamentarians, as well as what participants expect from parliamentarians, using a measure of behavior prediction. Considering that stereotypes bear probabilistic nature, it makes sense asking how often participants pay attention to each piece of critical information and in the participants' view, which proportion of parliamentarians behave according to some descriptions presented (behavior prediction). By testing those measures and the categories of political participation disclosed in the previous section, we aim at evaluating if there is any link between the interpretation about parliamentarians and the political actions undertaken by citizens.

\subsubsection{Stereotypes about Parliamentarians in, Prejudice}

\section{and Discrimination out}

When the stereotypical description is judged as 'good' or 'bad', we are entering the affective sphere. Although Eagly and Chaiken (1998) affirm that prejudice corresponds to the affective component of attitude, it should be noted that prejudice refers only to negative affections in relation to a group. The literature referred to herein does not present any words to define positive affects in relation to a group leaving no other option than using this underlined expression.

While it might be accepted that there is prejudice against any group, the concept imbues the existence of a relation of power where one group subjugates other group (Rottenbacher, Espinosa \& Magallanes, 2011). Usually the prejudiced individual holds a position of power over the object of prejudice - after all, the behavioral component 'discrimination' (which also bears negative sense) occurs when the agent has the conditions to oppress the target (Bohmer \& Briggs, 1991; Brewer \& Brown, 
1998). Therefore, if there is prejudice (in strictu sensu, negative affections in relation to the group) from the elector against parliamentarians, the first is disadvantaged as they cannot humiliate or subjugate the later (i.e., they could not 'discriminate') except under extremely atypical and historically relevant conditions (Van der Hulst, 2000).

The study of stereotypes about parliamentarians should accept the ambivalence of attitudes; therefore, there is no use in approaching prejudice and discrimination herein. What is relevant to this study is to understand how stereotypes could be useful to classify parliamentarians (serving as a schema) to predict their behaviors and to guide the interaction between represented individuals and representative.

Likewise, an alternate concept to 'discrimination' should be proposed, as the study does not aim at investigating the oppression exercised by electors on the parliamentarians. Here comes the question: which behaviors could electors assume in face of beliefs and affections regarding parliamentarians? Protesting, voting, lobbying, commenting on newspapers, using political violence or even distrusting politics as a response to parliamentarians are some examples of the behaviors categorized by Ekman and Amnå (2012) as political participation. Therefore, this study intends to verify how stereotypes about parliamentarians are related to the categories of political participation preferred by citizens.

\subsubsection{Can stereotypes predict behavior?}

According to Fishbein and Ajzen (1975), attitude results from an interaction of beliefs about a behavior with the evaluation of the result to be achieved. The intention of acting results from the confrontation of the individual's attitudes with their subjective rules (established by what the individual believes to be the social rule and his/her motivation to being adjusted to it). Behavior can take place as a result of the intention to act. However, the relation of causality between attitudes (including stereotypes and 
affects) and behavior is very fragile as one single behavior is also influenced by many other factors (LaPiere, 1934; Neiva \& Mauro, 2011). Then, additionally to investigating if stereotypes about parliamentarians could predict or not the occurrence of given categories of political participation, it is also important investigating other variables that could predict behaviors of political participation. Next, we discuss how stereotypes could be measured to be applied to the objective of this study. The influence of other variables on political participation will be discussed further.

\subsubsection{Measuring stereotypes}

Recalling the example of 'political information avalanche', the choice for the variable 'stereotypes' can be explained now. Instead of investigating if citizen is exposed to all types of political information available (Colling, 2007; Haslam et al., 1997; Lyons \& Kashima, 2003; Macedo \& Baccega, 2012; Rosa, 2012; Rottenbacher, Espinosa \& Magallanes, 2011), for parsimony this study investigates what citizens decide to receive (what is the critical information) and how they appraise parliamentarians (how the participant predicts parliamentarians' behavior).

Some indications point out that stereotype-based classification can be useful to understand the parliamentarian politics. People capable of identifying the difference between parties can recognize, with higher probability of success, stereotypic or counter-stereotypic information in the experimental context, but could also be misled as they trust in stereotypes (Arceneaux, 2008; Carlin \& Love, 2013; Koch, 2003; Kuklinski \& Hurley, 1994; Samuels \& Zucco, 2013). In other words, if a left-wing Socialist candidate employs arguments that do not fit in his/her stereotype (e.g., advocating nonintervention of the State on economy,), electors recognize the disparity and point out that 'there is something wrong' in that discourse (Kinder \& Sears, 1985; Lau \& Redlawsk, 2001 Sacchi, Carnaghi, Castellini \& Colombo, 2013). 
On the other hand, trusting in stereotype as a cue to construe a political fact could lead citizens to make mistakes in face of counter-stereotypic actions - as illustrated by the episode when the Partido dos Trabalhadores [Workers' Party] (PT, which has strong links to trade unions) in Brazil proposed a minimum wage lower than that proposed by the opposition - Partido da Social Democracia Brasileira [Brazilian Social Democracy Party] (PSDB), which surprised citizens who believed the contrary would happen - PT would establish a minimum wage higher than PSDB would (Samuels \& Zucco, 2013). Other studies also point out the risk of exaggeratedly trusting in stereotypes (Arceneaux, 2008; Kuklinski \& Hurley, 1994). The evaluation of misleading potential, like the abovementioned, extrapolates the objectives of this study. However, it intends to observe if some pieces of information monitored by participations could be associated to higher or lesser degree of political engagement (considering Ekman \& Amnå's framework).

Analogous to the formulation of stereotypes by individuals, this study proposes the comparison of stereotypes formulated about parliamentarians in two countries, namely Brazil and Sweden. At collective level, the Brazilian and Swedish citizens may differ regarding critical information perceived by participants and the prediction of behaviors of parliamentarians.

This study or stereotypes in politics brings about other questions. Could formal education influence on the citizens' appraisal of parliamentarians (including stereotypes about them)? Could the stereotypes disseminated in an in-group (here, citizens) become collective political action? In this sense, the next sessions approach political education and behavioral contagion. 


\subsection{Political Education}

We can only transform humanity and create a happier more compassionate world through education.

Tenzin Gyatso (Dalai Lama) on twitter, 06.01.2014

As this is a study that approaches stereotypes as a form of appraising the parliamentarian politics, it presumes education plays a significant role. After all, the way how citizens are educated is presumably the ground for their understanding about their country's politics (Benevides, 1996). Education can bring important effects on the citizens' understanding about politics which, in turn, influences on the elaboration of stereotypes about politicians. Education can also have direct effect on the political participation - this, however, is a quite controversial subject in literature.

The link between education and politics was broadly discussed in the fields of philosophy and pedagogy, which could have definitely influence the zeitgeist in this sense. Since the sophists Socrates, Plato and Aristotle, the organization of the polis (City-State) was articulated to the paideia - an ideal view of education to form citizens (Galston, 2001; Oliveira, 2008). According to the reviews by Oliveira (2008) and Gondim and Rodrigues (2010), Kant underlined that education predominantly contributes to the moral constitution of the person as an autonomous and equal being before the society. That thought became common sense among thinkers of the Modern Age - John Dewey, Jürgen Habermas, Hilary Putnam, Noam Chomsky, Jean Piaget and Lawrence Kohlberg. Benevides (1996) emphasizes that the implementation of a citizen-forming education builds up an amazing political inversion: it is an initiative by the State 'but aims at strengthening the people in face of the State, rather than the contrary' (p. 228).

John Rawls (2000) argues that education plays a core role to train citizens to the public debate, recognizing themselves and the others as rational, equal and free 
individuals (Gondim \& Rodrigues, 2010; Gamarnikow, 2013). Paulo Freire (2001) believes that education holds a crucial role to raise individuals' awareness about their political reality and historical moment. According to him, education should place the individuals as persons that puts themselves in face of reality in an autonomous and free way (argument that approximates Freire to John Rawls) and that is continuously involved in the political domain. According to Ignacio Martín-Baró $\left(1996^{5}\right)$, education must contribute to make individuals aware about their condition of oppressed being, so to respond to unfair situations and become protagonists of their histories (Martín-Baró, 1996; Schlösser, 2013). Anísio Teixeira (1936) criticizes the 'patronizing' education focused on preparing the governed ones to obey, in opposition to the elites who are trained to govern (Benevides, 1996).

Although, as aforementioned, the zeitgeist is favorable to accepting the inextricable connection between education and politics, the empirical studies diverge on the topic. Therefore, it would be relevant to discuss how this relation has been tested and its findings.

\subsubsection{Does Education predict the Political Participation?}

The argument that education has positive impacts on the political participation was subjected to countless empirical studies (e.g., Berinsky \& Lenz, 2011; Børhaug, 2008; Henderson \& Chatfield, 2011; Henrique, 2010; Mayer, 2011) - this means affirming that, as individuals progress in scholarship, greater are their chances of

\footnotetext{
${ }^{5}$ This text is a posthumous translation of a conference by the author delivered in 1985. MartínBaró was a psychologist and Jesuit priest, activist in defense of Human Rights and Social Justice in El Salvador. He became an influent academic in Latin American countries and headed the department of Psychology and Education at the Universidad Centroamericana "José Simeón Cañas" (UCA). He was killed by the El Salvador Armed Forces soldiers on November 16, 1989, charged with being a Communist-terrorist that supported guerrillas of resistance against the government (Oliveira \& Guzzo, 2013).
} 
getting interested in participating in the political life of their countries (Elkins, 2000; Verba, Scholzman \& Brady, 1995; Wachelke \& Hammes, 2009). However, there is no consensus about how education influences participation (Frazer, 2000; Mayer, 2011; Persson, 2012) or even about if there is any causal relation between both (Berinsky \& Lenz, 2011; Kam \& Palmer, 2008).

The arguments that support the relation between education and political participation indicate multi-causality. Advances in education levels facilitate the development of cognitive skills required to understand relevant political information (Delli Carpini \& Keeter 1996; Frazer, 2000; Galston, 2001; Oliveira, 2008; Henrique, 2010; Hooghe, \& Dassonneville, 2011; Michaud, Carlisle, \& Smith, 2009); and the development of civil skills in the school environment facilitates political engagement (Pring, 1999; Verba, Schlozman, and Brady 1995), and also the attention on political institutions, the distribution of power and the opportunities to participate (Emler \& Frazer, 1999). Moreover, 'increased scholarship affects several psychological variables, among which are political efficacy, political interest, civil obligations and political sophistication' (Elkins, 2000, p. 115) and others directly related to political participation like intention to vote, declared interest for politics and for debating politics with family and friends (Emler \& Frazer, 1999).

Other studies, however, indicate no causality relation between education and participation. Education would be a proxy measure of other variables that could explain participation (Kam \& Palmer, 2008; Kam \& Palmer, 2011; Persson, 2012). For Kam and Palmer (2008) the factors that lead individuals to pursue higher education level (characteristics of their parents, individual skills and other predispositions) could also lead them to participate in politics. Therefore, those authors define education as a criterion (endogenous) variable in their empirical test. Results support the hypothesis that political participation does not result from education itself, but from other variables - like mimicking the example of parents who appraise education as much as political 
participation, or the better social positioning enabled by education, which increases the chances of interaction with other political actors. This issue became a disputation arena with Mayer (2011) and Henderson and Chatfield (2011), who pointed methodological flaws in Kam and Palmer's (2008) work. Persson (2012), when comparing Swedish students taking junior high school (equivalent to secondary education in Brazil), university students and those who decided for vocational training, concluded that differences in terms of political participation can be found among students even before they join each education modality.

Other studies feed the debate either supporting the proxy effect (Berinsky \& Lenz, 2011; Highton, 2009) or the causal effect of education on the political participation (Dee, 2004; Sondheimer \& Green, 2010). In brief, one could say that, considering the current state-of-the-art, there is no consensus about the relation between those variables.

However, this study does not intend to discuss the causality or proxy effect between education (as the reached educational level) and participation, as the test of this hypothesis requires longitudinal data. On the other hand, as this study intends to perform a transnational comparison, other aspects of that relation could be observed even if these are not enough to establish if the effect is causal or proxy.

\subsubsection{Political Education formally included in the School}

\section{Curriculum}

Typically, scientific education is not focused on forming citizens (Freire, 2001) and, therefore, the relation with political participation probably is an indirect one. This brings about a debate around the relevance of having in school curricula a specific subject on political education (Emler \& Frazer, 1999; Frazer, 1999; Parry, 1999). 
Finkel and Smith (2011) report that the participants of the Kenyan National Civic Education Programme - NCEP became opinion leaders, and disseminated their knowledge through the social media. Groves (2011) noted that the adoption of Paulo Freire's pedagogy by Spanish teachers, early in the 1970s, have encouraged teachers to act in a political way and prepare their students (specially adults) to participate in the Spanish politics (Groves, 2011).

In Brazil, the closest and most recent experiences of insertion of politics at school in Brazil were the disciplines Organização Social e Politica Brasileira (Social Organization and Brazilian Politics) and Educação Moral e Cívica (Civic and Moral Education). These disciplines were implemented during the 1964-1985 military dictatorship (by Decree-Laws issued in 1968 and 1969), with a blatant intention of preventing alleged social disorder risks to the Brazilian society. Values such as nationalism, seen as love of country and obedience to its rulers were placed as these disciplines' main purpose (Menin, 2002). In 1996, these two disciplines were removed from schools curricula by the new Lei de Diretrizes e Bases da Educação (Law of Education Guidelines and Bases), under the justification that they were impregnated with a "negative character of indoctrination" (Menezes \& Santos, 2002). The reinsertion of politics in elementary and secondary schools faces resistance of those afraid of the indoctrination return.

Børhaug (2008) evaluated the results of the political education curriculum through interviews with Norwegian students, and concluded that students are oriented to identify which party is better in line with their ideological standing. This works as a training of voters, but has some constraints since it does not encourage students to assume a critical posture before the political system of the country.

Nevertheless, the incentive to critical posture among students is object of another irresolute discussion. According to Parry (1999), education could serve to reproduce socially established practices and values or to redress practices and values, 
correcting flaws perceived by previous generations (corroborated by Paulo Freire, 2001). As Parry says, the imbroglio emerges when we perceive that some adults want their children to challenge the values in force, while others fear the dismantling of traditions. Parry suggests that schools should be free to outline their political education curriculum (either to preserve or to challenge traditions) and parents should decide on the kind of education that will be provided to their children.

Frazer (2000) reports that the British Government plan of introducing citizenship-oriented education at schools brought about the antipathy from both the right and left wings. The opposition's arguments show that 'politics is optional' and individuals were not obliged to be familiar with governmental institutions. Moreover, political activity involves contact between groups that support opposite ideas, and little is known about people's preparedness to manage this reality (Emler \& Frazer, 1999). As Frazer (1999) explains:

Yet, 'politics' is non-optional. [The right and left wings] must be prepared to defend their individual and collective rights to follow their own ways of life, to claim when necessary recognition of their social and political identities. Such claims involve encountering fellow citizens (or subjects) who are 'strangers' both in the sense of being not of ones hitherto acquaintance, and also (much of the time) 'different' with different voices, different values, ways of life and modes of conduct. (...)

[To deal with these differences] would involve education in the structures of power - both formal political institutions and arrangements, and the informal. (Frazer, 2000, p. 100)

The main dilemma is the co-existence of the desire of having impartial political education, and the recognition that, when put in practice, it will not be impartial (Parry, 1999, Frazer, 1999). Moreover, the results achieved by political education models may vary according to context and historical nuances like, e.g., greater interest of students for politics during periods of crisis (Davies, 1999).

However, it is important to admit the existence of regularities resulting from public policies on education in each country. Even if students are not presented to a 
discipline about politics, the political debate in classrooms could produce noticeable effects in terms of political behavior. In a transnational comparison, the differences resulting from education are expected to be detectable. Therefore, the use of that variable in a model of empirical test could explain relevant aspects of the different political participation between countries.

On the other hand, caution is needed to prevent assuming the causal relation between education and political participation in the light of the considerations by researchers that identify a proxy effect. Among others, it must be taken into account the possibility that political education does not take place exclusively through formal school education, but also through other institutions or social networks in which the individual participates. One can assume that institutional frameworks and opportunities of building of social networks vary between the countries studied, thus reinforcing the interest in comparing them.

Adopting an extended perspective of the word 'education', to comprise also learning in non-school environments (family, friends, groups, churches, associations, communities, newspapers, TV programs, etc.), is necessary to understand where people usually learn about politics. Even more, when it comes to political education in non-school environments, there is a thin line between education and political socialization.

\subsubsection{Political Education or Political Socialization?}

Additionally to school, other institutions could foster political participation working place, church, non-governmental organizations, trade unions, political parties, etc. (Kam \& Palmer, 2008; Wyatt, Katz, \& Kim, 2000). Usually, the political culture is built in informal debates, at the spheres of collective decision or discussion with political opponents (Huckfeldt \& Sprage, 1995; Lupia \& McCubbins, 2000; Wyatt, Katz, 
\& Kim, 2000). As the same individual may participate in several spheres, it is unlike that one can clearly establish the contribution by each activity on their political view (Luskin, Fishkin \& Jowell, 2002). Therefore, researchers today face the challenge of studying several contexts simultaneously to evaluate how these influence one another (Amnå, Ekström, Kerr, \& Stattin, 2009)

For the purposes of this study, political socialization is understood in terms of learning about politics out of the context of formal education. 'Formal education', in turn, is understood as the acquisition of knowledge by citizens at schools and higher education institutions that are part of the educational system of the country. This study tries to identify if the political education of participants takes place at spaces of formal education or out of it (through political socialization) to compare the contribution of each context to the political participation.

Some authors consider the school environment as a room of political socialization as important as other spaces (Dudley \& Gitelson, 2002; Jennings, Stoker \& Bowers, 2009; Niemi \& Hepburn, 1995; Pring, 1999). However, this investigation insists on the differentiation between formal education and other forms of socialization. If on one hand the causal relation between formal education levels and political participation is being challenged, on the other hand the specific curricula on politics could prevent students from remaining ignorant of this matter (Frazer, 2000).

This study intends to evaluate, based on participants' self-perception, the contribution provided by each context to their knowledge about politics (regardless if the school or other areas of life). Testing the correlation among that self-perception and other variables allows checking if given contexts, in given countries, favor different kinds of political participation. 


\subsection{Behavioral Contagion}

La politique est une religion

remise sur ses pieds ${ }^{6}$

Serge Moscovici, 1985

The classic work by Gustave Le Bon (2008 [1895]), The Crowd: a study of the popular mind is considered to be an important milestone in the understanding of collective action. His work is appraised for the plausible description of the processes of collective action and decision and, at the same time, criticized for the pessimistic and even anti-democratic bias of the author's rationale (Consolim, 2008; McGuire, 1987; Moscovici, 1985).

This section discusses studies about the behavior of crowds and individuals organized in collective actions. It starts by Le Bon's work, discussing his contributions to the phenomena of collective action, the criticisms to his work, and the theoretical consequences to recent researches. The decision for starting with such a controversial work is due to its influence on further theories. Moreover, the study on behavior of crowds is not consolidated under a prevailing theory, although the following theories share a large common ground.

\subsubsection{Le Bon's Ideas}

Le Bon (2008) starts The Crowd by asserting that, underlying the apparent causes of the great changes of civilization, there is a deep change in peoples' ideas -

\footnotetext{
${ }^{6}$ Literally translated, Moscovici affirms that 'politics is a religion back to its feet', which cannot be directly translated into English. In a semantically sensitive translation, Moscovici means that 'politcs is a new form of religion' or, in other words, that 'politcs was built on the same place previously occupied by religion, using the same foundations (its 'feet')'.
} 
their opinions, concepts and beliefs. The author notes that, by the time he was writing the book, crowds were becoming aware of their huge power, as a consequence of the 'dissemination of some ideas gradually implemented in spirits' (p. 21). He adds that, prior to such awareness-building, civilizations were created and sustained by a small intellectual aristocracy, but 'never by crowds' (p. 23).

Adopting a really pessimistic tone, Le Bon affirms that crowds are impulsive, little skilled to reasoning, but very skilled for action; moreover, crowds have power only to destroy, never to build. The author suggests that powerful leaders (Le Bon uses the expression 'lords of the world', p. 24) bear instinctive knowledge about the crowds' souls, being capable of mastering them and leading them to a stated objective.

The main criticism to the thesis of crowds' irrationality is due to the clear intention of Le Bon of condemning popular movements, democratic institutions and collective aspirations (Margot-Duclos, 1961, quoted by McGuire, 1987). Jesus (2013) affirms that 'this outdated racialist vision of the masses could be one of the explanations to the malaise caused by the discussion about crowds to this date, and to the lack of researches applied to the Brazilian reality' (p. 500). Zimmermann (1992) affirms that the unsustainable defense by Le Bon regarding the Anglo-Saxon superiority in relation to the 'Latin race', merely due to hereditary factors, provided arguments to several researchers and politicians of anti-democratic tendency.

Reading the The Crowd demands from readers a sharp relativism to acknowledge that what seems strange in the book is rooted in the zeitgeist of the time when it was written (McGuire, 1987). In fact, Le Bon's ideas were not dissonant to the ideas of other thinkers late in the $19^{\text {th }}$ century and early in the $20^{\text {th }}$ century, like Hippolyte Taine (1885), Herbert Spencer, Friedrich Nietzsche and Gabriel Tarde (Jesus, 2013; McGuire, 1987; Miguel, 2002; Nye, 1973. Zimmermann, 1992). The common ground shared by those authors is that they were influenced by social Darwinism, which proclaimed that some human beings had benefited from better 
genetic evolution or gains at social level, and they should build the driving elites of society (Consolim, 2008; Miguel, 2002; Ribeiro, 2001). The authors were notably concerned about the 'mass uprisings' that would establish 'immoral' equality and annihilate the respect to 'natural' hierarchy (Miguel, 2002). In a more sophisticated way, Max Weber presents the unavoidable emergence of professional politician as something necessary to the efficiency of bureaucracy (Borchert, 2003). According to Joseph Schumpeter (who refers to Le Bon), masses cannot define what is the common good, neither select their representatives in a rational way; therefore, the elites should compete for the vote of citizens in a game that will decide which leader will prevail (Miguel, 2002).

Despite criticisms, the issues raised by Le Bon fostered the outlining of hypotheses to be subjected to scientific tests along the $20^{\text {th }}$ century. Some researchers provided continuity to the aristocratic ideas of Le Bon's, but it also others objected that reasoning and tried to provide more 'impartiality' to his analysis (Jesus, 2013; McGuire, 1987; Nye, 1973; Sandoval, 1997; Zimmermann, 1992). Subsequent scientific findings support and refine the author's concepts. However, no study disclosing vehement and firm refusal to the phenomena described by Le Bon could be found. Considering its importance, the main concepts outlined by the author should be briefly stated.

Le Bon uses the term 'the mind of the crowds' to emphasize that crowds behave very differently from the sum of individual behaviors. Furthermore, crowds are not limited to a random agglomerate of people; their collective 'mind' is what enables them to be identified as a crowd.

Le Bon formulates a law of mental unit of crowds pointing out that under specific conditions the conscious personality of individuals disappears; their feelings and ideas are oriented to the same direction. Thus, a psychological crowd is assembled:

The disappearance of conscious personality and the convergence of feelings and thoughts to the same direction, first traits of the crowd about to get organized, sometimes do not imply the simultaneous presence of several individuals on the same site. Thousands of individuals spread over can, in a given moment and 
under the influence of violent feelings, emerged from an important national happening, for example, acquire characteristics of a psychological crowd. Any chance that gathers them is enough (...) to [converse into] the specific form of acts of crowds [emphasis added] (Le Bon, 2008, p. 30).

The explanation for intellectually different persons to gather around a collective mind is, according to Le Bon, the similitude of their instincts, passions, feelings including their moral, affections, antipathies, and political and religious beliefs. That could explain, for example, the flood of rejection that led crowds to fight for the impeachment of President Fernando Collor de Melo in 1991, as demonstrators had deep antipathy for him due to the failure of his economic plans and the scandalous cases of corruption during his mandate (Bertoncelo, 2009; Bethell, 2008; Borges Filho, 2010; Gohn, 2009). In May 2013, in Sweden, a wave of violent demonstrations after the killing of an immigrant with indications of police brutality and racial prejudice (Hansson, Cars, Ekenberg \& Danielson, 2013; Schierup, Ålund \& Kings, 2014). In June 2013, demonstrators all over Brazil joined demonstrators in São Paulo asking for reduction of bus fares, criticizing the brutal police repression, and the biased coverage of the 'mainstream media' against demonstrations (Damasceno, 2013; Lima, 2013; Vion-Dury, 2013).

In the examples above there were great national happenings that confronted the crowds' beliefs, mobilizing individuals towards collective action. Sweden is a peculiar case, as in the first sight the episode is not qualified as a great national happening. However, as Le Bon explains, much more intensively than statistic data, an image or some words can give rise to a crowd:

The facts themselves do not affect the popular imagination, but the way they are presented. By condensation, if I could say that, the facts should produce an impacting image capable of fulfilling and afflicting the soul. (Le Bon, 2008, p. 70).

So, the conditions surrounding the death of the immigrant may have changed that episode, which is statistically insignificant, into a 'great happening' to immigrants living in Sweden (this idea is corroborated by Schierup, Ålund \& Kings, 2014). Similarly, 
the dissemination of shocking images of the demonstrations in São Paulo through the social media may have contributed to the assembling of a nationwide psychological crowd (corroborated by Damasceno, 2013; Fernandes, 2013; Lima, 2013; Ranthum, 2013).

Le Bon also emphasizes that the core ideas of a people are slowly and consistently changing; in that sense, revolutions express the abandonment of old beliefs on behalf of new ones, marking moments of important change and consolidation of a new vision of world. This corroborates the reasoning of Bertoncelo's (2009) who affirms that the huge public demonstrations for direct elections in Brazil (Diretas Já in 1983 and 1984) had an effect of a rite of passage, expressing the refusal to the discourse that supported the military dictatorship that started with the military coup in 1964 , and paving the way to the throbbing democratic beliefs.

Not only context-related factors can explain the assembling of the soul of crowds. Le Bon lists three potential causes that lead to the assembling of a psychological crowd, related to human characteristics:

a) The author considers suggestibility as the main cause. According to him, individuals in crowd are in a state quite similar to hypnosis, and easily act on suggestions of others. The individual loses consciousness of their acts and is guided by the streaming flow created by the others.

b) The feeling of invincible power resulting from the fact of being part of a group that is numerically large. Crowd becomes anonymous and irresponsible, and individuals give in to some instincts that, in other times, would be promptly curbed.

c) Mental contagion comes from the hypnotic effect of participating in a crowd. There 'every act is contagious; and contagious to the point of leading individuals to easily sacrifice their personal interest on behalf of the collective interest' (p. 35). 
Le Bon's arguments regarding suggestibility are quite controversial due to their links to hypnosis (Consolim, 2008; Jesus, 2013; McGuire, 1987; Nye, 1973). Recent researches do not approach the notion of hypnosis, but point out that, in a group, people tends to repeat the behavior of someone who serves as a model, with reduced self-criticism (Aarts, Gollwitzer \& Hassin, 2004; e Bono \& Ilies, 2006; Cacioppo \& Hawkley, 2009; Dik \& Aarts; 2007; Freedman \& Perlick, 1979; Krassa, 1988). The feeling of invincible power is corroborated by Reicher (2008). The empirical verification of these arguments should be done through experimental tests or qualitative approach, as survey-type researches on this topic could be biased by social desirability (Pasquali, 2010).

The concept of mental contagion provides relevant insights to the objectives of this study. This study keeps distance from the author's pessimism, in an attempt to understand contagion in a non-pejorative sense. It is indeed worth questioning if there is a multiplying effect that could increase the chances of an individual to participate in a collective action - even if by imitation of friends or other close persons. It is possible that feelings shared during a great national happening can mobilize crowds to a demonstration or any other form of political action. The example provided by someone else's behavior could make an individual move from intention towards action. Rather than 'mental contagion', this study employs the expression 'behavioral contagion' which emphasizes the imitation of actions and reduces the terminological ambiguity (Nicol, 1995), avoiding the unproductive debate around a dualistic (mind-body) or a monist (only body) concept of human being (Ryle, 1951).

Cialdini and Trost (1998) raised an interesting question: after all, why should individuals accept the influence of others? In a naïve perspective, being 'victim' of influence apparently brings no gains; however, the authors support there are indeed effective gains. In the first place, the influenced ones have their uncertainty about the 
behavior to be adopted in a given situation reduced, thus gaining their acceptance as a member of a group. The raising of the influenced ones' self-esteem also works as a way of compensation for the agreement to the objectives of the influencer or group (corroborated by Simon et al., 1998; and by Van Stekelenburg \& Klandermans, 2013).

Sandoval (1997) critically says that Sociology started from the assumption that individuals would be passively guided by the ideologies of the dominant class, through the learning of social rules and values, while Social Psychology - as a legacy of Le Bon - placed the collectivity under suspicion. In the psychological interpretation, the individuals' creativity would be inhibited thus leading them to conformism in exchange for their acceptance by the group. Sandoval emphasizes that both sociology and psychology presuppose the individuals' irrationality in their contact with social environment. Still according to him, the study of political behavior used to refuse the individual's capacity of being an agent in the political setting.

Concluding in an optimistic tone, Sandoval (1997) observes a change of the researchers' focus which is now addressed to understand individuals as social actors and how they articulate it with collective action. McGuire (1987) suggests the possibility of developing a pro-social version of the psychology of crowds, i.e., it could accept situations of mass behavior where participants are aware about their actions and deliberately make the decision of participating or not in the crowd. In this sense, the study will now analyze the recent theoretical advances and, then, will delimit how the subject will be approached herein.

\subsubsection{Recent Theoretical Advances}

Most of the times, the aristocratic bias of Le Bon is refused by the researchers after him (Jesus, 2013; McGuire, 1987). However, many subsequent theories still considered the irrational motivation - with new outlines - as a component of the 
behaviors of crowds. McGuire (1987) explains that Freud (1921), in Group Psychology and the Analysis of the Ego replaced the 'hypnotic state' of Le Bon's crowd for impulses of the libido driven by the identification with the collective; Wilfred Trotter (1921), in Instincts of the herd in peace and war replaces the crowd's suggestibility for the aggregation instinct of the herd, affirming that individual rationality could be considered to be an impairment to the herd integration; William McDougall (1927), in The group mind points out telepathy (which lacks empirical verification) and collective consciousness of big groups, emphasizing that individuals renounce their cognition and control of actions when they are in a group; Neil Smelser (1965), in Theory of collective behavior efforts to keep distance from Le Bon, but corroborates that collective behavior is moved by 'general beliefs' of hysterical nature and, therefore, suggestible; Serge Moscovici (1985), in L'age des foules (Age of Crowds) admits that collectivity overcomes the individual's rationality, and says that Le Bon's theory is uncomfortable to modern readers but, nonetheless, that he had anticipated the theoretical advances noted in the $20^{\text {th }}$ century.

Jesus (2013) classifies the post-1950 advances around four major modern theories: theory of deindividuation; theory of social identity; theory of convergence; and, emerging norms model.

The theory of deindividuation suggests that individuals become more uninhibited and impulsive when mixed to the group, thus building a sense of anonymity (Diener, 1980; Festinger, Pepitone \& Newcombe, 1952; Reimann, \& Zimbardo, 2011). Reicher (2008), on the other hand, disagrees with the explanation about anonymity and suggests that the sense of empowerment and identification with the group rules explain the individual's behavior in the crowd.

The emergent norm model (Turner, 1964, as quoted by Jesus, 2013) establishes that crowds get organized around shared social cognitions, preserving the individual traits. Norms emerge from symbolic interactions among the parties involved, 
just like the roles of leaders and followers that also emerge. Fehr and Fischbacher (2004) also add that little is known about how norms are built, but note that sanctions spontaneously practiced by the group members can lead individuals to non-selfish objectives and facilitate cooperation.

The theory of social identity (Tajfel \& Turner, 1979) assumes that people share beliefs and feelings with the group, and get committed to the collective action. The existence of out-groups ${ }^{7}$ (like the police in confrontation with crowds) and of discourses formulated by representative members of the in-group ends up by building the notions of 'we' in contrast to 'they' (Drury \& Reicher, 1999). That is how sympathy with the group is built, notably when collective identity is more prominent than the personal identity (Simon et al., 1998; Turner, Brown \& Tajfel, 1979). For Van Stekelenburg and Klandermans (2013), when the experience of deprivation or injustice of the group becomes important to the individual, the motivation for protesting raises.

The theory of convergence assumes that people wanting to be part of a crowd decide to abandon the cognition and behaviors that clash with the majority. This argument is based on Festinger's (1975) theory of cognitive dissonance. According to that theory, in face of two incompatible beliefs of the same relevance, the individual tends to select one and reject the others and, after selecting one (usually the majority's thinking, in this case), seeks for reasons to justify the selected belief and reasons to disqualify the belief that was rejected.

While the theory of deindividuation supports Le Bon's theory on the irrationality of the crowd, the theories of social identity and convergence acknowledge that individuals decide for participating in the crowd and perform cognitive evaluations on that participation. The theory of emergent norm avoids the discussion about

7 Here, for clarification purposes, is repeated the concept of out-group: 'social unit with which the individual does not identify or to which he / she does not belong', and the in-group is exactly the opposite, i.e., the 'social unit with which the individual identifies or to which he / she belongs' (James, 1986). 
rationality/irrationality and suggests a 'natural path' to crowds, resulting from the symbolic interaction of individuals (in the cognitive plan, emphatically).

Additionally to the theories pointed out above by Jesus (2013), there are the experimental studies on Goal Contagion. Dik and Aarts (2007) argue that, when an individual $A$ infers the effort of $B$ towards an objective, that facilitates the occurrence of A's behavior towards the same (inferred) objective. That is what authors call Goal Contagion. The authors concluded that objectives-oriented activities can be transmitted from a person to another during every day social interactions, in a careless way (corroborating Bargh, Gollwitzer, LeeChai, Barndollar \& Trötschel, 2001).

For its positive bias on the study of influences among members of the same group, the work by Gomes and Maheirie (2011) is worth of mentioning. Through interviews, the authors have investigated the influence exercised among participants of the Movimento Passe Livre (Zero-Fare Movement) in Florianópolis. They conclude that participants are mutually influenced, build friendly relationships and match militancy and everyday activities with friends. Moreover, some of the respondents reported that their parents, teachers and friends serve as models of political activity (corroborating McClurg, 2003; and McFarland \& Thomas, 2006). The movement participants feel happy for being part of something that goes beyond them, 'participating in the lives of other people, changing subjects and contexts, bearing meaning, taking their creation and themselves to the world' (Gomes \& Maheirie, 2011; p. 370). Therefore, the study points out the effect of the collectively organized political participation on the psychological constitution of the individual; it highlights that individuals assign conscious meaning to what he/she does as member of the group (corroborated by McClurg, 2003).

The empirical evidences for the behavioral contagion are found in scattered studies. Typically with the use of experimental methodology, the behavioral contagion is related to laughing at a joke (Freedman \& Perlick, 1979), expressing positive or 
negative emotions (Bono \& llies, 2006) or formulating opinions (Krassa, 1988), getting involved with criminal or risky activities (Jones \& Jones, 1995), even solitude (Cacioppo, \& Hawkley, 2009), but literature is not limited to these examples. Evidences on the implication of contagion on the political participation have been also identified through researches like, e.g., those performed by Djupe and Grant (2001), McClurg (2003), McFarland and Thomas (2006).

Participation in the same community or organized movement seems to strengthen the links between members and facilitate contagion (Djupe \& Grant, 2001; Gomes \& Maheirie, 2011; Harrigan, Achananuparp \& Lim, 2012; Jones \& Jones, 1995; McClurg, 2003). By investigating processes of contagion with the use of spatial econometric methods in a geo-coded dataset, Cho and Rudolph (2008) affirm that one can intuitively imagine that neighbors positively influence one another on behalf of the engagement in a political action...

However, what surely is not intuitive neither obvious is that this dissemination process exists regardless our measures of social involvement, political engagement, interpersonal trust, [education, income, age], race and gender. (...) In brief, social context is relevant, regardless the variable included in or excluded from our model (Cho \& Rudolph, 2008; p. 286).

The several concepts created by each theoretician referred to in this section show the same way: individuals tend to adjust their behaviors according to the surrounding crowd or group either for political actions or in other areas of life. Each theory proposes a different explanation to the same behaviors; these explanations are not mutually exclusive, but reveal the different potential views on a given episode of collective action, either spontaneous or organized. Therefore, it is worth defining how the "behavioral contagion" phenomenon will be approached in this study. 


\subsubsection{Behavioral Contagion as approached in this study}

For the present study, Behavioral Contagion is understood as the influence exerted from one individual to another, either by encouraging, convincing or by following other people's examples. It is here investigated without Le Bon's aristocratic bias. This contagion - whether of cognitive, affective or instinctive nature - can be considered an important element to understand the collective action, notably to explain the recent episodes of crowds assembled with notable degree of spontaneity and, many times, without any well-defined leadership. Nonetheless, beyond the popular demonstrations on the streets, behavioral contagion can be important and required to other forms of collective action, with different degrees of organization like engaging in community works with political implications (Djupe \& Grant, 2001), donate cash to or vote for a candidate (Shachar \& Nalebuff, 1999), run to a political office (Matland, 2005; Matland \& Studlar, 1996) or just to increase the chances of getting involved into new opportunities of political actions (Cho \& Rudolph, 2008; Gomes \& Maheirie, 2011; McClurg, 2003; McFarland \& Thomas, 2006).

Behavioral Contagion blurs the boundaries between individual and collective behaviors (Lake \& Huckfeldt, 1998). That is supported by the criticism by Cho and Rudolph (2008) on the 'individualistic school', highlighting that political participation should be understood in the light of collectivities (corroborating Gomes \& Maheirie, 2011; McFarland \& Thomas, 2006; and Moscovici, 1985). Behavioral contagion would be minimally required to enable the organized political action - after all, political actions take place mainly through the mobilization of collective interests, seldom by an individual's interest in isolation.

In brief, the purpose is to evaluate if when an individual A observes individual B participating in a political action, the changes for $A$ to participation in the same action can vary. Furthermore, possibly a larger number of politically active individuals close to A could lead him to even higher chances of participation. In essence, questionnaire 
items regarding behavioral contagion in this study aim at assessing if 'influencing people' or 'following the influence of someone' increase or not the chances for the individual to get engaged in a political action.

This study is not aimed at developing neither an experiment nor a qualitative investigation and, thus, it cannot evaluate the degree of rationality of the political actions object of the investigation. The answer to the questionnaires items is inexorably subjected to cognitive filters (Caprara et al., 2000; Pasquali, 2010); thus, it would be naïve to expect a participant to impartially answer items intended to measure to which extent their decision of participating in a collective action was irrational. Rather, the study aims to evaluate if the participant finds in their social network examples of persons engaged in political actions. 


\subsection{Researching in Different Cultures}

The nature of man is always the same; it is their habits that separate them. Confucius, $4^{\text {th }}$ a.C.

Researches on Social Psychology directly or indirectly handle with the phenomenon of culture (Smith \& Bond, 1999; Torres \& Neves, 2013). Even when a study focuses on the population of one single country, unique traits of that nation hinder data collection instruments and procedures from other countries to be directly 'translated' to it (Smith, Fischer, Vignoles \& Bond, 2013). Considering the stated intention of comparing behaviors of citizens in two countries (Brazil and Sweden) in this research, it is worth making some remarks about the important role played by culture.

The next subsections present a brief analysis of the concept of culture, followed by some considerations about cross-cultural researches. Then relevant aspects of the culture of each country which could impact this study are described.

\subsubsection{What is Culture?}

The concept of culture has brought about - and still brings about - intensive discussions in the field of social sciences (notably anthropology, which is considered to be the science of Culture - Geertz, 1973; Murdock, 1932; White, 1959). Researchers that review literature are careful about proposing a definitive concept (Keesing, 1974; Kroeber \& Kluckhohn, 1952). Laraia (1997) states that understanding the concept of culture will be 'a perpetual theme of the restless human reflection' (p. 65).

The classical definition of Culture denotes the opposition to the idea of biological transmission of given human characteristics. Edward Tylor (1920 [1871]) defined culture as 'that complex whole which includes knowledge, belief, art, morals, 
law, custom, and any other capabilities and habits acquired by man as a member of society' (p.1). This definition leaves a strong imprint on the learning nature of culture and its social transmission, in opposition to the transmission through biological mechanisms (Laraia, 1997; Murdock, 1932; White, 1959; Wright, 1998).

The sharing/dissemination of 'cultural things' is considered to be a core element to understand cultures, and it receives attention and support by many authors (Heller, 1995; Keesing, 1974; Kroeber \& Kluckhohn, 1952; Laraia, 1997; Tylor, 1920; White, 1959), and this could be considered an harmonic understanding in the study of cultures.

The harmonic understandings, listed up to now, point out that culture:

a) Refers to human capacities transmitted through learning rather than just by biological mechanisms (Keesing, 1974; Laraia, 1997; Murdock, 1932; Tylor, 1920; White, 1959);

b) Is adaptive and dynamic, reaffirmed and rebuilt through the experience of the encultured ones (Geertz 1973; Keesing, 1974; Kroeber \& Kluckhohn, 1952; Laraia, 1997);

c) Is shared, disseminated or transmitted (the term varies depending on the author) in public spaces (Heller, 1995; Geertz, 1973; Laraia, 1997; Oyserman, Sorensen, Reber \& Chen, 2009; Tylor, 1920);

d) Tells the encultured ones which events are interconnected (Geertz, 1993; Kroeber \& Kluckhohn, 1952; Smith et al., 2013).

In an attempt to find converging aspects among the different studies, culture is defined herein as follows: a system of knowledge and beliefs made up by symbols, rules, language and habits historically constituted and socially shared. Such definition certainly disregards several cultural elements approached by the aforementioned researchers, but it is enough to discuss the variables investigated in this study. 
Thus, could we say that the findings of this research will explain the cultural differences between Brazil and Sweden? That is not so simple and is the topic approached in the next section. Beyond conceptual considerations, Social Psychology researchers accumulate theoretical and methodological recommendations to approach cross-cultural issues (Fiske, Kitayama, Markus \& Nisbett, 1998; Smith et al., 2013). The next section discusses the advances made and their relevance to this study.

\subsubsection{Cross-cultural Studies in Social Psychology}

For Social Psychology, culture is a phenomenon that comprises all others - in other words, all phenomena studied in this field of knowledge are closely linked to culture (Fiske, Kitayama, Markus \& Nisbett, 1998; Kroeber \& Kluckhohn, 1952). The main contribution expected from cross-cultural studies in social psychology is the identification of the dimensions in which cultural groups vary (Soares, Farhangmehr \& Shoham, 2007). Those studies seek universalisms comparing the meaning of the concepts studied and how these are manifested in each nation (Smith et al., 2013).

The phenomena referred to be autochthon (i.e., specific to a culture) can be expressed at different degrees of intensity in different cultural contexts (Smith \& Bond, 1999; Torres \& Neves, 2013). The discovery of related or quasi-equivalent phenomena between cultures allows extracting, from particular cases, evidences of universalism of the psychological concepts studied. According to the terms coined by Pike (1967, quoted by Smith et al., 2013 and by Harris, 1976) it is about extracting evidences of 'Etic' phenomena from 'Emic' studies. It is worth explaining those terms.

Pike created the terms 'Etic' and 'Emic' by analogy to the fields of Phonetics and Phonemic, which try to track the sounds universally produced by the human beings and the sounds typical to a given idiom, respectively. So, Pike's 'Etic' refers to the study of universal cultural phenomena (by analogy to the term PhonETICs) that can be 
found in different cultures, while 'Emic' (by analogy to PhonEMIC) refers to specific traits of a people (Smith et al., 2013; Harris, 1976).

Here mention should be made to two examples. Hofstede and Bond (1988) found an emic trait of Chinese people: the long-term view that was even called Confucianism as it would be related to the thinker Confucius (Kung $F u T z u$ ). This trait, which had not been identified in previous studies - as these did not include China drew the authors' attention and raised questions about if it would be typical just to the Chinese or if it would be manifested in other peoples (an etic question) in further studies (Chen \& Chung, 1994; Franke, Hofstede \& Bond, 1991; Johnson \& Lenartowicz, 1999; Yeh \& Lawrence, 1995). Likewise, the curiosity about forms of informal influence like the "Brazilian way" ("jeitinho brasileiro", an emic phenomenon) motivated Smith, Huang, Harb e Torres (2012) to make a comparison between similar behaviors observed in other cultures like the pulling strings (in England), the wasta (in Lebanon) and the guanxi (in China). Similarities and differences are found among the four cases, pointing out that informal influence is common in those cultures (therefore, is an indication of an etic phenomenon), although being manifested differently in each country.

Smith, Fischer, Vignoles and Bond (2013) disclose the care required when performing cross-cultural studies due to the nuances of the cultures studied that put researcher on a kind of 'sandy' soil. The interpretation of the studied phenomenon can be contaminated by the researcher's pre-concepts based on his/her own culture. According to Smith et al. (2013), this kind of mistake is called 'imposed etic', i.e., the researcher presumes that an emic trait of his/her culture is an etic phenomenon and tries to measure it in other cultures without any adjustment. Thus, the comparability between cultures depends on strict attention to the nuances of each people being studied. 
The validity of a cross-cultural study also depends on the clear distinction between the levels of individual and national analysis to avoid hypotheses from being tested at a level while, in fact, they refer to other (Smith et al., 2013). When analyzing data, cross-cultural researchers should avoid making inferences with the vice of ecological fallacy, i.e., assign to an individual a characteristic found in his/her group (Gelfand, Erez \& Aycan, 2007; Smith \& Bond, 1999). In practice, it is about paying attention to the fact that individuals participate in different ways in their culture (Keesing, 1974; Kroeber \& Kluckhohn, 1952; Laraia, 1997). For instance, if the United States bear the trait of individualism and Guatemala is marked by collectivism, it does not mean that any single American individual is more individualist than any Guatemalan individual.

To avoid vices during the application of questionnaires to different cultures, Smith, et al., (2013) recommend a careful translation of the research instruments. It should undergo a back-translation, i.e., after the first translation into the target language (e.g., from German to Burmese) the instrument should be 'de-translated' to the original language (from Burmese to German) to check if the meaning of all items remain unchanged (Brislin, 1970). At the same time, the procedure should consider the semantic specificity of the languages involved, what means to avoid literal translation and privilege the translation into something that expresses the same meaning in each culture (Smith et al. refer to it as 'decentralized translation', as it cannot be made by one single translator). In practical terms, it means paying attention to the different meanings of the same expression in the different languages involved. For instance, in English 'to kick the bucket' means 'to die'; if its literally translated into Portuguese, 'chutar o balde', Brazilians would understand the same expression as 'to be revolted'. So, the best translation into Portuguese would be 'bater as botas' (literally, 'to bump the boots') even if the literal interpretation makes no sense. 
Cross-Cultural Psychology has advanced through the gradual shaping of concepts through empirical tests and comparison of cultural differences (Betancourt \& Lopez, 1993; Smith et al. 2013). Next subsection discusses the specific usage of statistics to assess cross-cultural differences. The following considerations seem to be relevant in the present context, as those analyses are not common in other fields of expertise.

\subsubsection{Interpreting Cross-Cultural Statistics}

Advances in statistical techniques allowed a very strict evaluation of measure equivalence across cultures. Confirmatory Factor Analysis (CFA), processed through Structural Equation Modeling (SEM), is useful to verify Factor Structure, Metric and Scalar Equivalence among different cultural groups (Hair, Black, Babin, Anderson \& Tatham, 2009; Brown, 2006). CFA tools allow the introduction of constraints (like forcing factor loadings and items' intercepts to be equal across groups) for comparison. These procedures are meant to ensure that variables are useful to compare the groups enrolled.

Factor Structure Equivalence is found when the same factor structure offers good fit for each group (i.e., Brazilians and Swedes, here) separately and also on a simultaneous test. In this simultaneous test, two covariance matrices are created, and Goodness-of-Fit indices indicate how well the estimates are adjusted to both, simultaneously (or, if there are more groups, Goodness-of-fit indicates the good adjustment to all covariance matrices).

Metric Equivalence indicates that items have identical relationships with factors in all cultural groups; this allows the researcher to infer that scale points have the same meaning among groups (Smith, Fischer, Vignoles \& Bond, 2013). To perform this test, factor loadings are constrained to be equal across groups, by indicating this desired 
constraint on any SEM software. This is considered a rigorous test on the majority of comparisons (Hair et al., 2009). Therefore, it is usually enough to demonstrate partial metric equivalence, given by the existence of at least two equivalent factor loadings for each factor (Brown, 2006; Byrne, Shavelson, \& Muthén, 1989; Hair et al., 2009). Chisquare and $\mathrm{CFI}$ discrepancies $\left(\Delta \mathrm{X}^{2}\right.$ and $\left.\Delta \mathrm{CFI}\right)$ are usually considered the main indicators of equivalence. Non-significant $\Delta \mathrm{X}^{2}$ (considering the chi-square table) is usually considered to indicate equivalence across groups (Hair et al., 2009). When $\triangle$ CFI remains below 0.01 (Cheung \& Rensvold, 2000), this is an evidence of equivalence.

Scalar Equivalence refers to the situation where the scores can be directly compared between two or more cultural groups. Scalar Equivalence cannot be tested directly, because the researcher does not have access to measure the real expression of the factor (Smith et al., 2013). To perform this test, the intercepts of each item for the comparison group(s) is constrained to be equal to the reference group. The evidence of Scalar Equivalence also considers $\Delta \mathrm{X}^{2}$ or $\Delta \mathrm{CFI}$.

Metric and Scalar Equivalence are very rigorous tests (Brown, 2006; Hair et al., 2009, Thompson, 2004). Smith et al. (2013) warn that very few cross-cultural studies tested these levels of equivalence. On Metric Equivalence, Thompson (2004) states that, in practice, researchers usually hope that the same constructs are measured across groups but do not expect factor loadings pattern to be completely invariant. Scalar Equivalence is the most difficult to establish (Smith et al., 2013), as intercept constraints actually narrows group responses to very strict limits. It is actually to be criticized that the use of rigorous interpretation parameters for Scalar Equivalence may make cross-cultural comparisons unfeasible, as it is expected that, on realistic collected data, people from different cultures use scales points somewhat differently. Scalar Equivalence is often disregarded (Smith et al., 2013); its seldom demonstration 
might be considered an evidence of its oversensitivity (see words of caution by Brown, 2006; Caprara, Barbaranelli, Bermúdez, Maslach \& Ruch, 2000).

Chi-square and CFI discrepancy tests $\left(\Delta \mathrm{X}^{2}\right.$ and $\left.\Delta \mathrm{CFI}\right)$ are usually regarded in the search of Metric and Scalar Equivalence evidences. Chi-square tests, however, are oversensitive to sample size, and there is little agreement among researchers on the adequacy of using it (Bollen, 1989; Brown, 2006; Byrne and Campbell, 1999; Hayduk, 1987; Scott-Long, 1983). Therefore, $\Delta X^{2}$ may lead to reject good models, especially on large samples (Caprara et al., 2000). The use of $\Delta$ CFI $<0.01$ threshold has not still reached agreement (Brown, 2006). Caprara et al. (2000) considered that strict cutoffs of CFA tests of equivalence might be oversensitive, as tests with the Big Five personality test showed adequate Factor Structure Equivalence and differences among countries could be actually an effect of cultural differences. The effect of cultural differences is also accepted by Byrne and Campbell (1999) and Olatunji et al. (2009), who also reported negative results on equivalence tests. These authors consider that it seems reasonable that factor loadings vary across those different populations. Thompson (2004) states that, if constrained model's Goodness-of-Fit is inside the acceptance parameters, it is a good evidence of Metric Equivalence.

Smith et al. (2013) explain that the interpretation of cross-cultural data sometimes involves handling with non-equivalent results. In practical terms, to this study it means that different factor structures ${ }^{8}$ can be found in each country observed. The interpretation of those non-equivalent results forces researchers to decide for one of the three methodological options:

a) To consider that different structures indicate measurement bias, so they should not be used;

\footnotetext{
${ }^{8}$ Pooling of the questionnaire items calculated through statistical analyses that summarize a construct or variable investigated (Thompson, 2005).
} 
b) To assume that non-equivalence ("the bias") is of some relevance, because it shows that cultures operate differently. Therefore 'bias' becomes a variable of interest. This can offer insights into how the context influences psychological realities;

c) To assume that any bias found is a kind of evidence of the existence of cultural differences.

The first methodological option is excessively strict as it implies discarding virtually all the content researched. Boehnke et al. (2014) warn that, when using the criterion of strict equivalence between the cultures investigated,

fairly narrow kernel of a psychological construct will be included in cross-cultural research, namely, the one for which semantic identity can be proven via showing the equivalence of covariances (Boehnke et al., 2014, p. 1658 a).

Consequently, the researcher fails in finding 'emic' aspects, i.e., disregards the cultural differences. Cross-cultural research abounds in non-equivalent results (please refer to Rossier, 2014; Spencer, Fitch, Grogan-Kaylor \& Mcbeath, 2005) or, on the other hand, partial equivalences are found (Hui \& Triandis, 1983; Smith et al., 2014).

The third methodological option is pretty much lenient and could lead to conclusions about Emic phenomena without a deep analysis. This study decided to consider, in the light of the second option, that non-equivalence is indeed important and should be observed as an indication of cultural differences; however, it recognizes that a binational study cannot draw assertive conclusions about the typical cultural features of the phenomena studied. Sound and consistent conclusions about cultural differences are only achievable through the replication of studies in several countries (like Caprara et al., 2000; Olatunji et al., 2009), which could not be done here. On behalf of the originality of this Doctoral Thesis, we tried to investigate unexplored relations between the variables selected, using a questionnaire designed exclusively for this study. Therefore, the conclusions of this research are expected to foster new 
cross-cultural studies about political participation, stereotypes about parliamentarians, political education and behavioral contagion, to observe the consistence of differences found regarding such phenomena herein.

And that brings up a new question: How could culture be translated into empirically relevant variables? Those variables should allow benchmarking the people's studies, in exercises to simplify reality. If culture resembles a 'package' that wraps virtually everything, it should be 'unpacked' (Smith \& Bond, 1999).

\subsubsection{Unpacking Culture}

The complexity of culture-related phenomena is in direct opposition to the inexorable need of defining the research focuses. Unavoidably, researchers will disregard some important element, on behalf of parsimony (Briley, Morris \& Simonson, 2000). As culture is an extremely broad phenomenon to be scientifically investigated (Soares, Farhangmehr \& Shoham, 2007), it should be unpacked, i.e., researchers should identify constructs related to behavior, like beliefs, values, motivation etc. (Smith \& Bond, 1999) to enable the research. Such constructs should be quantifiable so to allow placing an individual in a 'universal' dimension, i.e., whose validity is not restricted to his/her cultural group (Thomas, 2008; Torres \& Neves, 2013).

It cannot be pointed with absolute certainty who would have pioneered the culture unpacking. Among the oldest ones, Kluckhohn (1951) proposed a differentiation between objective culture (concrete objects produced by the group like flags, jars, clothes) and subjective culture (traditional ideas and values transmitted among members). Hall $(1966 ; 1998)$ proposed the analysis of differences based on four principles: a) time; b) space; c) context; and, d) regarding the message flow.

Studies that delimit variables for scientific investigation purposes have provided relevant contributions to identify cultural differences (Soares, Farhangmehr \& Shoham, 
2007) as they enable operating the concept of culture to study attitudes and behaviors (Smith, Dugan \& Trompenaars, 1996). The most prominent examples of unpacking in literature are the works by Geert Hofstede and Shalom Schwartz (quoted by Betancourt \& Lopez, 1993; Briley, Morris \& Simonson, 2000; Oyserman \& Sorensen, 2009; Smith, Fischer, Vignoles \& Bond, 2013; Soares, Farhangmehr \& Shoham, 2007; Thomas, 2008; Torres \& Neves, 2013).

Hofstede (1980; 1983; 1984a; 1984b; 1991; 1993) identified cultural variations in the dimensions Masculinity/Femininity, Avoidance of Uncertainties, Distance of Power and Individualism/Collectivism, additionally to the Chinese Confucianism discovered by Hofstede and Bond (1988), as mentioned in the previous section. The Individualism/Collectivism axis produced a multitude of subsequent studies, and it is probably the most used dimension in social psychology to analyze cultural differences Gelfand, Erez \& Aycan, 2007).

Schwartz (1992; 1994), in turn, identified 56 values categorized in 10 motivational types thatare organized in four basic values. Inglehart and Welzel (2010) categorized countries according to their position on a scatter plot which crosses two axis (or dimensions). The first is the traditional versus secular values dimension, which represents the extent to which one country's people has replaced religion-based traditions by science and rational thinking. The second axis represents the survival versus self-expression values, i.e. to which extent one country's people worry about physical and economic security or to subjective well-being and tolerance. Additionally to the consistency acknowledged, similitudes between Schwartz's, Hofstede's and Inglehart and Welzel's findings could point out the existence of systems of common meaning between different cultures (Smith et al., 2013; Torres \& Neves, 2013).

The abovementioned studies proposed several concepts (dimensions) to analyze culture. The works by Hofstede and Schwartz are especially influent regarding the use of surveys to measure cultural differences, having influenced the subsequent 
studies in Social Psychology both in theoretical and methodological terms. Researchers trying to unpack culture have identified and systematized dimensions that enabled searching for universal characteristics of humanity, with large replication in further studies (Schwartz, 2011; Smith \& Bond, 1999).

Culture unpacking is also subject to criticisms. Briley, Morris and Simonson (2000) warn that cultures cannot be simply limited to a combination of dimensions, as this would strongly disregard their complexities. Gelfand, Erez and Aycan (2007) point out that efforts to unpack culture in organizational behavior researches have focused virtually exclusively on the Individualism/Collectivism axis; the same authors highlight the need for seeking new variables to produce new advances on unpacking of culture. The criticism by Briley, Morris and Simonson (2000) points out that unpacking could lead to neglect some important aspects of culture.

Gelfand, Erez and Aycan (2007) and Oyserman and Sorensen (2009) suggest expanding the approach of unpacking so it can reach a wider variety of situations. This study accepts the unpacking as a valid and very useful methodological proposal to compare cultural differences. Both unpacking and other different approaches (like ethnography, for instance) are subject to limited scope due to the choices that researchers must make to delimit their studies. So, instead of ruling over a technique due to its limitations, it starts from the assumption that different techniques could supplement one another - after all, despite the clear difference in terms of generalization and deepening of data, ethnography can raise questions to be explored through the unpacking, and vice-versa.

\subsubsection{Political Culture}

The Civic Culture by Almond and Verba (1963) is considered to be the pioneer work in the study of political culture (Capistrano \& Castro, 2010, Henrique, 2013; 
Kuschnir \& Carneiro, 1999). Almond and Verba classified societies following three kinds of political culture: parochial, subjection or participant. The parochial political culture would be characteristic to simple societies with incomplete differentiation between religious and political structures, and of low level of political and associative participation. The political culture of subjection would happen in societies where citizens do not feel to be apt to participate, and leave decisions to the centralizing administrative apparatus. Finally the political culture of participation would characterize the systems that integrate conscious individuals, somehow linked to the political system and willing to participate. This classification was subject to severe criticisms by anthropologists that highlighted the need for more careful theoretical formulations about political culture.

According to Kuschnir and Carneiro (1999), Almond and Verba (1963) have classified societies according to their proximity or not to the democratic political culture (or civic culture) of the western society. Moreover, Almond and Verba tried to '[on one hand] reinforce and justify the understanding of the supremacy of the North-American society as a model to be followed [in opposition to the Soviet socialism] and, on the other hand, to promote and justify the North-American politics (...)' (Castro, 2000, p. 17 , as quoted by Borba, 2005, pp. 148-149). This strongly normative and ethnocentric appeal found in the works by Almond and Verba (1963), as well as others that followed them in the study of political culture, eventually removed anthropologists from this debate (Borba, 2005; Capistrano \& Castro, 2010; Jackman \& Miller, 1996; Kuschnir \& Carneiro, 1999). Almond and Verba (1980) were responsive to the criticism, and diminished their work's prescribing character.

Therefore, the studies about political culture remained limited to the scope of political science (Kuschnir \& Carneiro, 1999). However, there are no apparent reasons for the debate about its results to remain restrict to that discipline, or to abandon the efforts to understand it (Fuks, Perissinoto \& Ribeiro, 2003; Inglehart, 1988; Jackman \& 
Miller, 1996). The study of political culture should serve as an analytical tool to research beliefs, values and identities of different groups existing in the society, in order to explain the political behavior of individuals (Borba, 2005; Inglehart, 1988; Putnam, 1996; Lane, 1992). The political culture analysis should consider the relation between citizens and the institutional and historic context where they are formed, including several determinants of the public support to the form of political organization in the societies studied (Capistrano \& Castro, 2010; Jackman \& Miller, 1996; Kuschnir \& Carneiro, 1999).

Several works investigate the link between political culture and trust in democratic institutions, in face of the cultural tradition (Catterberg \& Moreno, 2006; Henrique, 2010 and 2013; Hibbing \& Patterson, 1994; Moisés, 2008; Patterson, 1968; Putnam, Leonardi, Nanetti, \& Pavoncello, 1983; Rennó, 2001; Van Der Meer, 2010). Those studies bear a prescriptive trait as they search for solutions to the crisis of distrust in the Legislative Power (Henrique, 2013; Teorell, 2006), to the point of a significant share of citizens advocate for a paradoxal 'democracy without National Congress' (Moisés, 2008, p.31), or of mistrusting other public institutions (Fuks, Perissinoto \& Ribeiro, 2003; Mishler, \& Rose, 2005; Putnam, 1996).

It should be recognized that those studies about political culture help understanding the problems found in the relation between representatives and represented ones, with the ultimate purpose of improving the performance of institutions. In conclusion, the attempt to understand several political cultures should avoid the ethnocentric (to assume that the practices of a nation should be 'copied' by other nations) and prescriptive character, recognizing that there is no "one best way" to the effective functioning of democracies.

Up to now, this study has discussed the concept of culture, the required care for cross-cultural research, the unpacking of culture (changing it into empirically measurable dimensions) and the tendencies of studies about political culture. Those 
considerations are important to define the decisions on the investigation being outlined. The next section summarizes the implications of the past theoretical remarks about the subject studied herein.

\subsubsection{Relevant considerations for this study}

In face of the abounding understandings about what is culture and how it could be studied, some considerations should be made regarding the study proposed here. As explained in the Section 2.5.4, when 'unpacking culture', one cannot, a priori, state that the investigated variables are cross-cultural dimensions to the point of being used to unpack the culture of both selected countries. However, this initial incursion is necessary to build a reasonably consistent measure that could be tried in other countries. The purpose here is to compare variables that could be related to behavior (political participation).

At the same time, stereotypes could be viewed as cultural products and as 'culturally produced syntheses about a specific group (for this study, about parliamentarians of their countries). In other words, stereotypes are built, rebuilt and become common through sharing (term employed by Heller, 1995) or dissemination (term used by Laraia, 1997) at public spaces (Geertz, 1973) just like the other cultural codes (Jussim, McCauley \& Lee, 1995). Therefore, these could be observed as part of the knowledge system (term used by Keesing, 1974) of a given culture, configuring relevant indications about the culturally built form how people relate to their parliamentarians.

If each individual knows only part of their social codes (as stated by Keesing, 1974 and Laraia, 1997) and if education and socialization are means for cultural transmission, the efficiency of that transmission should be evaluated. The study is 
focused on learning how social codes about politics are transmitted and if that influences political participation.

As culture is a phenomenon that comprises all the others (Smith et al., 2013) the variables in this study are not only influenced by culture, being integral part of it. Due to the cross-cultural nature of this study, participants are expected to provide different answers, to the point that it will be possible to assemble groups according to nationality. These differences can provide indications about the interference of cultural elements on the variables selected to the study.

This study does not intend to make an exhaustive cultural mapping, or searching for correlations between cultural traits and the variables of interest listed in the previous sections. It aims at identifying differences and similarities with comparative tests among the variables already listed and the demographic data surveyed through questionnaire.

On the other hand, this investigation cannot avoid describing the historical process of the social-political-cultural constitution of the Brazilian and Swedish peoples. To avoid the risk of faulty generalization or imposed etic, the cross-national research should start with, at least, reasonable knowledge about the history of each country and their main sub-cultural dimensions like, for example, the existing political conflicts. In the next section, the socioeconomic differences between Brazil and Sweden are explained, with a brief summary of their histories, which must be considered when regarding the response to the items of this research.

\subsection{Characteristics of the Political Context of Brazil and}

\section{Sweden}

Summarizing the information that characterizes the political context of the countries selected implies electing some pieces of information that are presumed to be 
more relevant to the objectives of the research. The following section is a summary of the political context of Brazil and Sweden, noting that it is not an exhaustive analysis.

\subsubsection{Organization of Political Institutions}

This analysis starts by describing Brazil and Sweden, regarding their political institutional arrangement (Table 3). Brazil is organized in the Republican Form of Government, Presidential System, Federate Form of State, the national parliament has a bicameral structure, and voting is mandatory. Sweden differs in all items, being a Parliamentarian Monarchy in a Unit State, unicameral parliament and voluntary voting. A common ground between both countries is the tripartite division of powers: Executive, Legislative and Judiciary.

The Brazilian deputies and the Swedish Riksdag ${ }^{9}$ members hold 4-year mandates. In Brazil, all members of the Chamber of Deputies are replaced through elections at every four years; the same happens to the Riksdag members in Sweden. The senators in Brazil hold 8-year mandates, with alternate renewal of one third and two third in every election. Table 3 summarizes these data.

Both countries have a multiparty system, which is entailed from the configuration of their electoral rules (as explained by Chauhan, 2013; Duverger, 1980; Enander, 2013; Fleischer, 2004; Nicolau \& Schmitt, 1995; Tella, 2010). The number of political parties represented in the parliament illustrates the fragmentation of political party organization in both countries and the laxness of electoral laws regarding the creation of new parties (Duverger, 1980; Tavares, 1994). Roughly comparing, one could say that between these countries, the Brazilian law allowed the entry of larger

\footnotetext{
9 "Riksdag" means, in a free translation, 'the meeting of kingship' or 'meeting of nobles'. The parliament acquired democratic traits early in the $20^{\text {th }}$ century, as further explained in this chapter, being not restricted to the nobility. However, the name remained and started referring to the national parliament. It can also be written Riksdagen, which means 'The Riksdag', i.e., the suffix '-en' corresponds to the definite article ('the', in English).
} 
number of political parties in the national parliament (18 being the higher amount, at the Chamber of Deputies), while in Sweden eight parties entered the parliament.

Table 3. Comparison between the organization of political institutions in the investigated countries.

\begin{tabular}{ccc}
\hline & Brazil & Sweden \\
\hline Form of Government & Republic & Monarchy \\
Government System & Presidential & Parliamentary \\
Form of State & Federate & Unit \\
& (26 States and one Federal & (21 counties with administrative \\
& autonomy)
\end{tabular}

This table was prepared based on a compilation of information from official websites of the parliaments and electoral authorities of the countries:

Brazil:- www.camara.leg.br | www.senado.leg.br | www.tse.jus.br

Sweden: http://www.val.se | http://www.riksdagen.se

The larger number of political parties participating in elections with real chances of achieving a seat in the parliament, for some political science researchers (e.g., Carreirão, 2002; Dalton \& Anderson, 2011), is an indication of poor political party organization, thus increasing the complexity of the parliamentarian game and, therefore, reducing the possibility of the lay voter to understand how politics work in their countries. However, in a different light, the fragmentation of political parties' 
organization could show and represent the several political trends found in the country (Kinzo, 2004; Nicolau \& Schmitt, 1995; Sáez \& Freidenberg, 2002). In countries with reduced number of political parties, those trends could be hidden under the same party label. The latter would be the case for the United States of America (USA) where there are two prevailing parties in the federal arena (Republicans and Democrats); nonetheless, they comprise several trends and political tensions internally (Delli Carpini \& Keeter, 1996; Duverger, 1980; Embaixada Americana, 2008).

As this is a study about stereotypes about parliamentarians, the political party could be considered to be a critical information (or not) to identify the opposing subgroups in the plenary (Arceneaux, 2008; Brewer \& Brown, 1998; Carreirão, 2002; Huckfeldt \& Sprage, 1995). That is why the items about 'critical information about parliamentarians' (one of the measures of stereotypes) should enable comparing the importance of political parties against other information that citizens could receive about the parliamentarians. It allows assessing if voters perceive or not any difference between the parties. If voters pay less attention to parties, it is worth checking which other piece of information they use to understand the parliament organization.

Additionally to the organization of political institutions, the social-economic indicators could offer an overview on the problems faced and the political priorities of each country. The next section analyzes the main indicators and briefly compares the countries surveyed.

\subsubsection{Education and income distribution}

Every year, the United Nations (United Nations Development Programme UNDP, 2013) calculates the Human Development Index (HDI) based on an inventory of questions about health (measured by life expectancy), education (according to the average years of schooling of people of more than 25 years old and the expectation for 
children to conclude school) and income (according to the per capita Gross National Income on the purchase power). Put simply, the HDI provides an overview on the quality of life in a given region, based on the aforementioned aspects. The index ranges from zero to one; the closer to one, the better are the living conditions. In 2013's Human Development Report (UNDP, 2013) the HDI of 186 countries was evaluated: the index ranged from 0.304 (Nigeria) to 0.955 (Norway). For comparison purposes, results are organized in the form of a ranking, although the ranking of a country does not allow, per se, any qualitative inference about the lives of citizens.

Brazil and Sweden widely differ, regarding HDI. As shown in Table 5, Sweden reports better conditions of health, education and income than Brazil. The Nordic country is close to the highest score in the scale and is ranked in $7^{\text {th }}$. Brazil is ranked in $85^{\text {th }}$ (Table 4).

Table 4. Comparison of indicators of education, income and quality of life in the countries surveyed

\begin{tabular}{ccc}
\hline Indicators $^{*}$ & Brazil & Sweden \\
\hline Human Development & & 0.916 \\
2013 HDI SCORE & $\left(85^{\text {th }}\right)$ & $\left(7^{\text {th }}\right)$ \\
(ranking for 186 countries) & & $25[2000]$ \\
Income Inequality & $54.7[2009]$ & $\left(3^{\text {rd }}\right)$ \\
Gini score [year of measurement] & $\left(144^{\text {th }}\right)$ & \\
(ranking among 156 countries) & & 478 \\
Education & 391 & $\left(38^{\text {th }}\right)$ \\
Average score in the 2012 PISA & $\left(58^{\text {th }}\right)$ & \\
(ranking among 65 countries) & &
\end{tabular}

\footnotetext{
* This table was made based on information available at the websites of the rankings organizers. The name of each indicator and the website addresses to access the documents that served as input to this table are as follows:
}

HDI - Human Development Index measured by the United Nations (UN). Available at: http://hdr.undp.org/en/reports/global/hdr2013/

Gini - developed by the Italian Statistician Corrado Gini is calculated by the World Bank. The UN uses the Gini index measured by the World Bank to adjust the HDI calculation. Source: http://data.worldbank.org/indicator/SI.POV.GINI

PISA - Programme for International Student Assessment, measured by the Organization for Economic Cooperation and Development (OECD): http://www.oecd.org/pisa/keyfindings/pisa-2012-results-volume-i.htm 
The Gini (named after the Italian statistician Corrado Gini) is calculated by the World Bank. An important limit of the Gini is that it is not measured at regular intervals, resulting in a table made up with data measured in different years among countries. However, the World Bank database is the only one open to the public and, despite that limitation, it is used by the UN to adjust the HDI calculation. The Gini measures income inequality (Gini, 1921); ranges from zero (no inequality) to 100 (full inequality).

PISA, in turn, is made up by several scores calculated by the Programme for International Student Assessment. Its evaluations take place at every three years and comprise three areas of knowledge (reading, mathematics and sciences) and every edition of the program put more emphasis to one of those areas (Organization for Economic Co-operation and Development [OECD], 2013). The 2012 edition, used in the table, placed more emphasis on mathematic and was applied in 65 countries. Students that complete 15 years old participate in the program.

Regarding the Gini, Sweden is ranked the third country with less inequality, while Brazil reports high inequality. In terms of education, pursuant to the PISA index, Sweden is also in a much better position than Brazil (Table 4).

The discrepancy among the HDI, Gini and PISA indices of both countries can serve as useful inputs to understand the results to be collected. If significant differences between both countries are identified to stereotypes about parliamentarians, political education, behavioral contagion and/or political participation, the relation between these and the aforementioned socioeconomic indicators will be evaluated. It is worth mentioning this is a first comparative incursion between these countries; thus, the merit of these inferences would be to raise questions to be deeply investigated in further studies.

The characteristics of Brazil and Sweden presented above provide an overview of the context-related differences of their citizens' living conditions. Such differences can directly or indirectly influence on the responses to the questionnaire - and this 
should be verified in the empirical test. The historical context of both countries is analyzed next, in face of its importance to understand the current institutional organization and the conditions for popular participation.

\subsubsection{History of Democracy in Brazil and Sweden}

Despite the existing controversies about the concept of Democracy, the two countries selected currently present the traits of a Democratic State of Law (Bresser Pereira, 2011; Duverger, 1980; Merkel, 2004; Moisés, 2010): universal suffrage, assurance of civil rights, freedom of speech and of association (including the creation of political parties) and constitutionalism (the State abides by the rules imposed in a Constitution prepared by representatives of the people). In this current configuration, these countries are described as democracies, in spite of the differences in their institutional organization (Bethell, 2008; Diamond, 1996; Huntington, 1991; Linz \& Stepan, 1999; Scobbie, 2010; Scott, 1988). However, their histories present differences that deserve attention.

The construction of democracy followed different paces in Brazil and Sweden, and it was determined by pressures of sectors of the society that gained political power in different moments (Huntington, 1991). The following sections approach the paths followed by each country. Moreover, it discusses the latest political movements that could have influenced the political participation today in the two selected countries.

\subsubsection{Brazil}

Brazil remained colony of the Portuguese crown since it was discovered in 1500. To escape from Napoleon Bonaparte's invasion in Portugal, the Portuguese Royal Family moved to Rio de Janeiro in 1808, transferring the Portuguese Empire headquarters to that city, bringing in its ships all the administrative paraphernalia and 
government staff. That had relevant impact on the emergence of political institutions in Brazil, which were firstly administered by the Portuguese crown (Bethell, 1985, Gomes, 2007). In 1921 the King D. João VI went back to Portugal, leaving his son D. Pedro I as the Regent Prince of Brazil (Bethell, 1985; Gomes, 2010).

In 1822, the Portuguese bourgeoisie pressured the crown to return Brazil to its status of colony. José Bonifácio, who was very influent in the politics by that time, believed that continuing monarchy would be the only way for maintaining social stability and the unity of Brazil during the transition to an independent State. He was concerned about the attempts of Portugal to impose commercial and political restrictions to Brazil. Bonifácio advised D. Pedro I to disobey the orders issued by Portugal (Bethell, 1985). On September 7, 1822, D. Pedro I received documents from Lisbon revoking his acts as Regent Prince and accusing his supporters of treason (Bethell, 1985). On that day, Pedro I declared independence from the Portuguese crown. The advices of José Bonifácio and the pressure exercised by the Brazilian aristocracy that wanted to preserve the commercial autonomy they had conquered have contributed to the declaration of independence (Gomes, 2010).

Even after the declaration of independence on September 7, 1822 the constructing of political institutions and democracy in Brazil ran a long way. The Empire of Brazil - instituted by D. Pedro I - counted on a political class drastically divided about how the independent country should be governed (Bethell, 1985). Through all this pressure, D. Pedro I instituted the first constitution of Brazil in 1823, providing for the creation of the Senate (50 lifetime members selected by the Emperor) and the House of Representatives (100 member elected indirectly for 4-year mandates). The criteria of income for active electoral capacity (the power of voting) and passive (the right of being candidate) kept the power restricted to aristocracy (Gomes, 2010).

Although Brazil has flourished in the second half of the $19^{\text {th }}$ century, the tensions between aristocracy and the emperor did not cease. Succeeding Pedro I, 
Pedro II affirmed that slavery was a national shame, and sustained his intention of abolishing it (Barman, 1999). His daughter Isabel - who eventually assumed the Empire Regency when Pedro II had to leave for medical care - took that responsibility for herself (Gomes, 2013). In May 1888, taking advantage of the political effervescence about the topic, she signed the Golden Law [Lei Áurea] that abolished slavery in Brazil. Farmers considered that act a seizure of their 'goods' (the slaves) and started supporting the movements for the republic (Barman, 1999). The overthrow that overturned the Empire and instituted the Republic was headed by the military, supported by the rural aristocracy, and took place on November 15, 1889 (Bethell, 1985; Gomes, 2013).

On the first anniversary of the Republic Proclamation, a Constituent Assembly was established and defined the independence between the Executive, Legislative and Judiciary Powers (during the Empire times, the three powers were subjected to the crown). The lifelong mandates of senators were replaced by 9-year mandates, and the number of seats for Deputies would be defined according to the population of each State, with at least four deputies to the smallest States. The 1891 Constitution ensured the secrete optional male vote for those of more than 21 years old, excluding beggars, illiterates, soldiers and congregants of monastic orders (Gomes, 2013). In practice only $2.2 \%$ of the Brazilian population were entitle to voting (Tribunal Superior Eleitoral [TSE], 2013).

Law No. 426 of December 7, 1896 granted voters the option of publicly expressing their votes, and defined that fiscals should give voters a receipt stating on whom they had voted. That was used by the farmers to control the vote of their employees, what was then named "voto de cabresto" ("noseband vote", see Figure 2.1) (TSE, 2013). That ensured the alternation of military and land owners in the Presidency of the Republic until the apogee of the 1930 revolution. The period started in 1894 (first election after the Republic Proclamation) was named as 'Old Republic', 'Age of Dark' or 
'milk and coffee politics' as the power was alternated by coffee growers from São Paulo and milk producers from Minas Gerais (Bethell, 2008; Fleischer, 2004; TSE, 2013). During the Old Republic, the political parties were considered to be inefficient and unnecessary; thus, they were not mentioned in legislation.

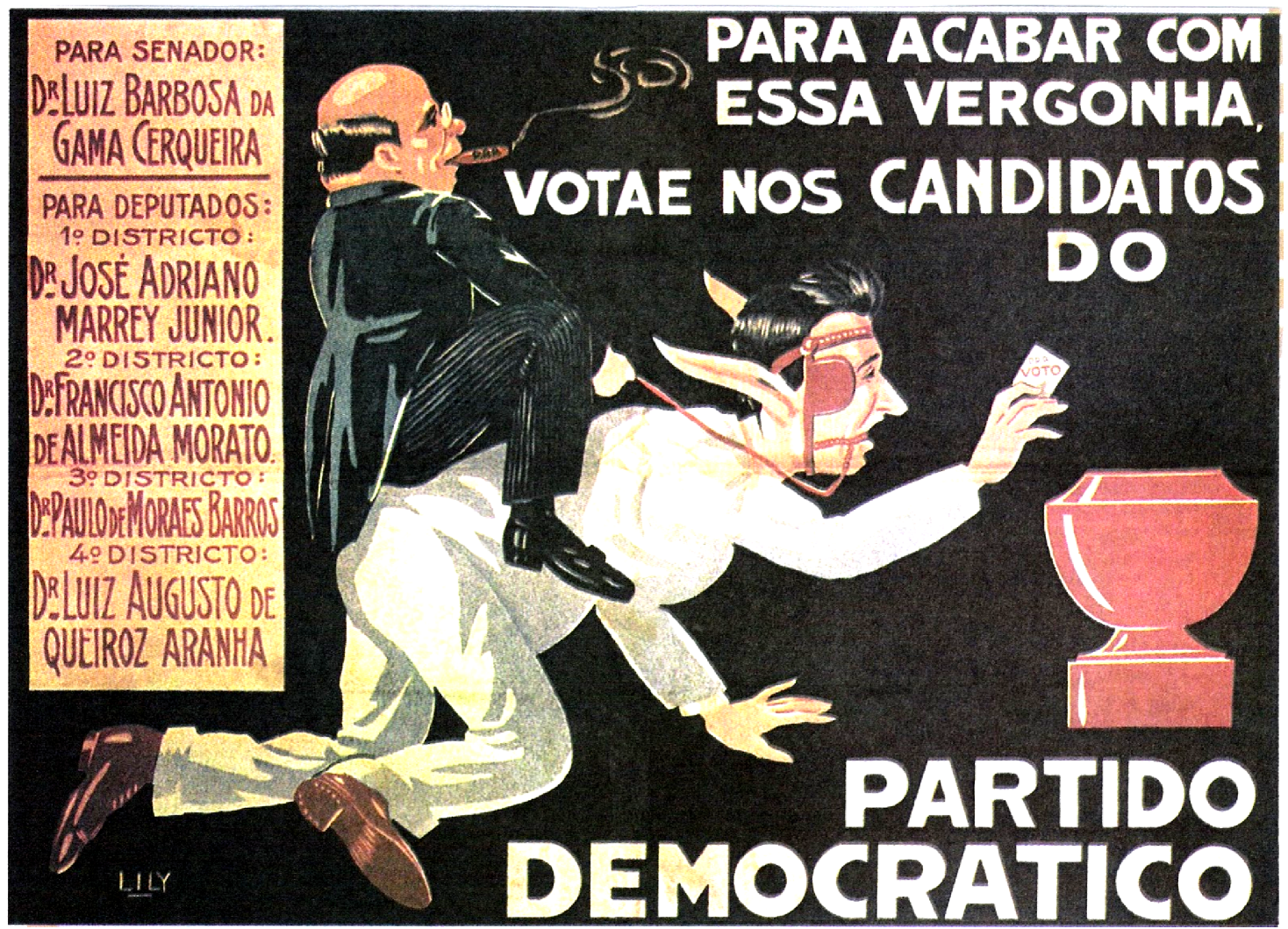

Figure 2.1. Democratic Party's advertisement, with an iconic representation of "noseband vote" (voto de cabresto).

The year of 1930 was the apex of several pressures for reforms in the Brazilian state. Among the claims that would speed up revolution, one could mention the moralization of elections, with mandatory secrete universal voting, including women's vote. The revolution that brought Getúlio Vargas to the power took place. In 1932, Vargas enacted an electoral code that established secrete and universal ballot (including women), but still left aside beggars, illiterates and military (garrisons Bethell, 2008). For the first, time there was a reference to the possibility of political 
parties registering their candidates to run to elections. The 1934 constitution would enforce these rights, but kept illiterates severed from electoral participation (TSE, 2013).

The new rules were valid to the 1933 Constituent Assembly election. However, no presidential election happened in Brazil until 1945. Since 1930, Getúlio Vargas headed the Provisional Government that promised reforms to expand social rights and consolidate democracy. In 1934, through indirect elections, the National Congress members granted Vargas an additional four-year mandate. In 1937 Vargas got the support of the military to cope with a threat of overthrow and made himself a coup which would keep him on the Presidency until 1945 (Camargo, Hippolito, D'Araújo \& Flaskman, 1986). Still in 1937, Vargas closed the National Congress and imposed a new constitution whereby the Executive Power would have total control and appoint interveners to the federate states. Political parties were extinguished and there would be no new elections until a new military coup in 1945, which forced Vargas to resign. José Linhares, president of the Federal Highest Court by the time, assumed the interim presidency, and called elections in December 1945. Elected with the support of Getúlio, Eurico Gaspar Dutra took office in January 1946.

Getúlio Vargas remained very influent on the Brazilian political arena, and was elected Senator in 1946, without even deciding to run. In 1950 he was elected President of the Republic. His mandate ended on August 24, 1954 when, once again pressured by the military to resign, he killed himself in Palácio do Catete (the president's official residence). His gesture caused great national commotion. Historicists point out that Vargas' suicide hampered the organization of the military that would still try to avoid (in 1955) Juscelino Kubitschek to take office and João Goulart to take on the presidency (in 1961) (Bethell, 2008). The military coup would be successful in April 1964. 
Soon after the coup, on April $9^{\text {th }}$ the "supreme command of the revolution" issued the Institutional Act No. 1, an instrument that had no constitutional ground, concentrating power in the hands of the Executive power, persecuting dissidents and starting the cassation of mandates of parliamentarians that opposed to the regimen. Two days later, General Castelo Branco was elected through indirect voting in the National Congress (Bethell, 2008). During the military regimen (from 1964 to 1985), presidential elections were indirect (the National Congress members voted for president) and the electoral rules changed every election, so that winners would always be the parliamentarians from the party that supported the regimen (Aliança Renovadora Nacional - Arena) who would surely elect presidents allied to the military (Fleischer, 2004; TSE, 2013).

Subsequent institutional acts authorized the Executive to decree the Congress recess (which was closed throughout the year of 1966), to govern through decrees and to censor the media. Political parties were dissolved in October 1965. One month later, a supplementary act established new rules to organize political parties, allowing the assembling of only two parties: the Aliança Renovadora Nacional (ARENA, the party that supported the regimen) and the Movimento Democrático Brasileiro (MDB) that offered weak opposition (Bethell, 2008).

Popular demonstrations early in the 1980s drove the 'Diretas Já' movement, that claimed for the passing of the Proposal of Constitutional Amendment 'Dante de Oliveira' (named after the deputy who proposed it), which would reestablish the direct ballot for choosing the President of the Republic. Demonstrations became more frequent and gathered more people every month - there were nearly 50 mass rallies in several Brazilian cities, most of which gathering more than 30,000 people; the major ones took place in Rio de Janeiro (1 million people) and in São Paulo (1,5 million) (Bethell, 2008; Bertoncelo, 2009). In April 1984, the Amendment Proposal was defeated due to a maneuver of the military government, which did not allow the 
Amendment supporters to attend the plenary to vote for it (Bethell, 2008). However, the movement for direct elections had already driven a wedge among the government supporters in the parliament, who started influencing the scenario for political openness (Bertoncelo, 2009; Fleischer, 2004, TSE, 2013).

In 1985, the civilian Tancredo Neves was elected President of the Republic through indirect voting. Tancredo deceased soon after the election; his substitute, José Sarney, was tasked of organizing a new constitution (enacted in 1988) and the first direct presidential elections after the military regimen, which happened in 1989 (Bethell, 2008; TSE, 2013). Since then, the presidential and parliamentarian elections have taken place regularly, and this would be called a period of democracy consolidation in Brazil (Bethell, 2008).

Some researchers (Bethell, 2008; Fleischer, 2004; Linz \& Stepan, 1999) consider that democracy in Brazil has effectively occurred only in the period between the dictatorships (from 1945 to 1964) and after the political openness in 1985. In that sense, the Brazilian democratic experience is historically short, which could have impacts on the country's political culture (Moisés, 1992; Moisés, 2008; Ribeiro, 2007). There has been little trust in political institutions, a trend towards detachment and antipolitical postures (Baquero, 2001; Moisés \& Carneiro, 2008; Sallum Júnior, Graeff \& Lima, 1990; Shildo, 1990).

\subsection{Recent political activity}

Focusing on the period from the 1980s until today, three main popular political activities should be highlighted: The Diretas Já! movement (1983 and 1984), the Impeachment of President Fernando Collor de Mello (1992) and the demonstrations of June 2013.

The Diretas Já! movement, briefly described in the previous section, became a relevant hallmark of political participation in Brazil. It was of utmost relevance to the 
closure of a 21-year period of military dictatorship with fierce repression against freedom of speech and association, and of presidents elected indirectly by a National Congress with clearly weakened opposition (Kinzo, 2001). By that time, the public opinion detached from hegemonic news agencies, which had a pro-regimen bias and reduced the importance of demonstrations (Miguel, 2001; Palha, 2011). Demonstrations increased, pressuring for a change in the media speech, which started supporting direct elections (Bertoncelo, 2009). The campaigns for direct elections for president produced a memory of political power of the masses that resulted in a significant change on the Brazilian government regimen (Bertoncelo, 2009; Montes \& Meyer, 1984). Bertoncelo (2009) emphasizes that the campaign for 'direct' elections served as a rite of passage representing the de-constructing of symbolic standards that sustained the political structure until those days.

The perception of the capacity of changing government through mass movements was reinforced in 1992, in the episode of the Impeachment of President Fernando Collor de Melo (Bertoncelo, 2009; Borges Filho, 2010; Gohn, 2009). First president democratically elected after the military regimen, Fernando Collor de Melo took office in a time when the country was experiencing uncontrolled inflation $(84 \%$ per month, reaching $2,000 \%$ a year). On his first day as president, Collor decreed wage freeze and seizure of savings accounts as some measures to control inflation (Sallum Júnior \& Casarões, 2011; Silveira, 2013). That package of economic measures, named Collor I, was a disaster and it was followed by plan Collor II, which set out prices freeze and was another failure. Those fiascos drastically brought Collor's popularity down (Bethell, 2008). The then Minister of Economy, Zélia Cardoso de Mello, who designed the first plans, was replaced by Marcilio Marques Moreira, who conceived the Plan Marcilio, that matched high interest rates and restrictions to the public budget (Silveira, 2013). 
Inflation remained uncontrolled and things got worse to the president: corruption scandals destroyed his weak remaining popularity (reaching meager $9 \%$ of popular approval); additionally to the increasing opposition he faced in the National Congress (Bethell, 2008; Sallum Júnior \& Casarões, 2011). Without support, Collor faced an impeachment process that would culminate on the night of September 29, 1992 during a busy plenary session of the Chamber of Deputies. With 441 ayes, 38 nays, 1 abstention and 23 absentees, the Chamber passed the investigation of liability crimes attributed to Collor (Câmara dos Deputados, 2012). In the Senate, the impeachment was passed on December 30, by 76 ayes and 3 nays.

In the night when the impeachment was voted at the Chamber of Deputies, the lawn in front of the National Congress was crowded with the 'caras-pintadas' ('paintedfaces'): youngsters (mostly university students) that painted their faces with the colors of the Brazilian flag and black (symbolizing their disapproval at the president), chanting watchwords (Borges Filho, 2010; Gohn, 2009). That was the apex of several demonstrations for ethics in politics and the removal of Collor, catalyzed by the dissatisfaction with the economic measures adopted in his mandate (Bethell, 2008). According to Bethell (2008), 'for the very first time in the history of the Republic a president was removed from his office through legal and constitutional means and, for the first time, without the direct involvement of the military' (pp. 254-255), which could have contributed to strengthen the image of popular power against government. The 'caras-pintadas' stood for an aesthetic movement for ethics in politics, and have symbolically stamped an impression on the popular memory (Borges Filho, 2010). This record would represent the popular power, notably the university youth's power of organization to express their disapproval in relation to rulers (Gohn, 2009).

In June 2013; university students in São Paulo, mainly the members of the Movimento Passe Livre [Zero-Fare Movement] (MPL) started several protests against the increase of bus fares from $R \$ 3.00$ to $R \$ 3.20$ (Pires, 2013). They were fiercely 
repressed by the police, while media coverage was frankly against the demonstrations (Damasceno, 2013; Lima, 2013; Vion-Dury, 2013). Demonstrators started to criticize the media to the point of expelling or attacking journalists who were covering the marches (Fernandes, 2013; Ramos, 2013; Ranthum, 2013).

Throughout the month, there were many other confrontations among demonstrators, the police and the media (Andrade, Affonso \& Bianchi, 2013; BBC Brasil, 2013; Favero \& Diniz, 2013; G1, 2013; Guimarães, 2013; Paes \& Antunes, 2013; UOL Notícias, 2013). The debate moved away from the $\mathrm{R} \$ 0.20$ raise on the bus fare, towards the curtailment of freedom of speech (Carta Capital, 2013, Macedo, 2013), thus forcing attenuation of police action and of the media discourse (Fernandes, 2013; Ranthum, 2013; Secco, 2013; Spigariol, Shiomoda, Felizatte \& Bonici, 2013). The contrast between the social media stories (usually supporting demonstrations) and the discourse of the 'mainstream media' (usually contrary to demonstrations) sparked the required tension to spread the demonstrations all over the country (Damasceno, 2013; Fernandes, 2013; Ranthum, 2013; Lima, 2013).

New items were incorporated to the agenda of claims, like the end of secret voting for parliamentarian decisions; rejection of the Constitution Amendment Proposal (PEC, in Portuguese) 37, that was known as 'PEC of impunity'; continuity to the projects on Political Reform (changes to the electoral rules); public transport improvement; increased investments in public education and health; more transparency in public expenditures and punishment to politicians involved in embezzlement of public funds; rejection of police violence, among others (Abreu \& Medeiros, 2013; Ranthum, 2013). The items related to transparency and punishment of politicians involved with corruption had also been claimed by the Marches against Corruption in 2011 and 2012 (Colon \& Moura, 2011; Diário do Nordeste, 2011; Estadão.com.br, 2011; Lima, 2012; Martins, 2012). 
The number of demonstrators grew day after day, in more and more cities, reaching its apex on June $20^{\text {th }}$ (Estadão.com.br, 2013; Folha de S. Paulo, 2013; Leal, 2013). The response by the governmental agencies lagged behind the increased number of demonstrations (Chagas, 2013; Instituto Humanitas Unisinos, 2013; Moraes, 2013; Ranthum, 2013). Nonetheless, several measures were announced. As Ranthum (2013) summarizes:

(...) the mayor of São Paulo decided to reject the increase of $R \$ 0.20$. Coincidentally, in that same day the mayor of Rio de Janeiro, Eduardo Paes also decided to withdraw the increase on bus fares in the city. Other 15 cities, among which Goiânia and Cuiabá, have also reduced the bus fares.

After the bus fare reduction in several capitals, the focus moved to the federal government and the National Congress. (..). On the $21^{\text {st }}$, the President of the Republic made a statement to the nation which, per se, deserved an analysis. In the statement Dilma expressed support to demonstrations and showed some harmony to the movement that is still taking the streets (...) In brief, the President condemned violence in demonstrations, urged the 'heads of other powers' to 'add efforts' and signalized some actions, among which the elaboration of the National Urban Mobility Plan and the proposal of allotting $100 \%$ of the oil resources for education (Ranthum, 2013).

The Brazilian demonstrations apparently outline a systematic progression of the intended democratic objective. Diretas Já! aimed at establishing democratic rules to vote for the chief of the State (Bertoncello, 2009; Camargo, Hippolito, D'Araújo \& Flaskman, 1986; Montes \& Meyer, 1984); the caras-pintadas have impeached an elected president in rejection to corruption and inefficient economic measures (Baquero, 2001; Borges Filho, 2010; Sallum Júnior \& Casarões, 2011; Silveira, 2013). From Diretas Já to the impeachment of Collor the political participation and public contempt have been significantly expanded (Bethell, 2008; Kinzo, 2001). On the other hand, these episodes have not produced long-lasting effects on the democratic institutions that remain hostage to the vulnerability of their legitimacy (Baquero, 2001).

The demonstrations in June 2013 urged ethical work of rulers and the due use of public funds; moreover, the latter took freedom of expression to a new level, causing 
changes to media discourse and police repression (Leal, 2013; Ranthum, 2013; Spigariol, Shiomoda, Felizatte \& Bonici, 2013; Terra Notícias, 2013; Vion-Dury, 2013).

If culture is made up through sharing (Smith et al., 2013) and the demonstrations serve a ritualistic effect (Bertoncelo, 2009; Montes \& Meyer, 1984), then June's demonstrations could indeed be considered a relevant episode to the Brazilian political culture. These also offer a cue about the importance of sharing to build mass movements, reinforcing the need for this empirical research to investigate the effect of behavioral contagion suggested by Le Bon (2008) for political participation.

The 2014 elections were preceded by heated discussions on the Internet, strong engagement of candidates' supporters and debates on TV (Castro, 2014; Martín, 2014; Missau Ruviaro \& Missau Ruviaro, 2014). Eleven parties presented candidates, with Dilma Roussef (Workers' Party, Partido dos Trabalhadores, PT) Aécio Neves (Social Democracy Party, Partido da Social Democracia Brasileira, PSDB) and Eduardo Campos (Socialist Party, Partido Socialista Brasileiro, PSB) with the most feasible chances of winning (Barcellos, 2014; G1, 2014; Limongi \& Guarnieri, 2014).

On August $13^{\text {th }}$, Eduardo Campos died as his airplane crashed in the city of Santos, from the state of São Paulo. His associate Marina Silva, formerly a PT member, became the head candidate for presidency (Balzaretti, Silva, Rech, \& Da Sois, 2014; Limongi \& Guarnieri, 2014). Silva, Roussef and Neves took turns on voters' preference (see Figure 2.2). It was considered the most disputed elections in the last 20 years in Brazil (Bentes, 2014; Richard, 2014). The voters' engagement on political discussions was remarkable, so that some friendships were menaced political disagreement, which was not "normal" for the Brazilian standards (Castro, 2014; Martín, 2014; Missau Ruviaro \& Missau Ruviaro, 2014).

Dilma Roussef was reelected by a narrow advantage against Aécio Neves, who disputed the second round with her (Bentes, 2014). The parliament composition represents marginal advantage to Roussef, though parties that supported her during 
elections are not really faithful to her policies (Lima, 2014; Neher, 2014). Marina Silva, who supported Neves at the second round, announced that she would try to found a new party and leave PSB (Lima \& Frota, 2014). Aécio Neves promised to make a hard opposition (UOL, 2014).

\section{Brazilian 2014 presidential election}

Probability of candidates winning, $\%$

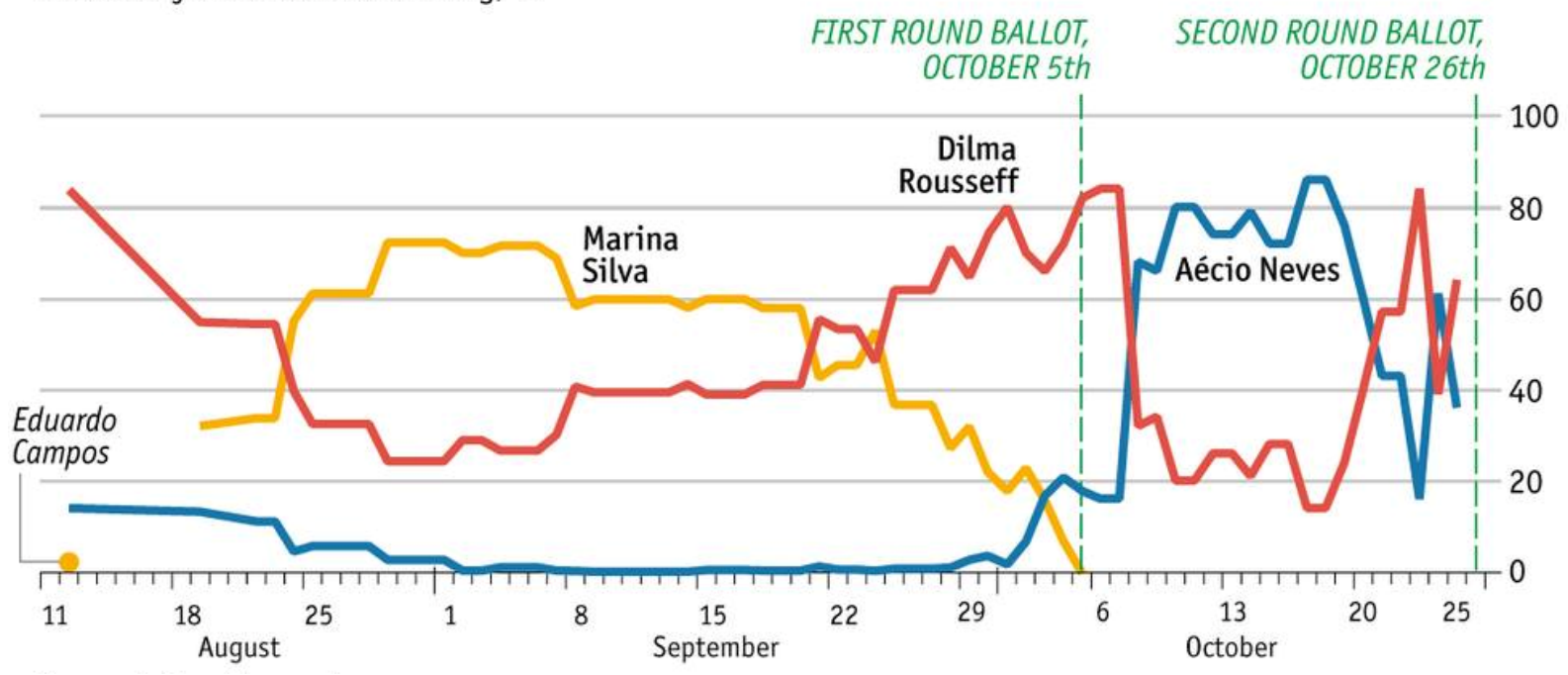

Figure 2.2. Chances of winning presidential elections in Brazil, considering the three preferred candidates. Source: pollingdata.com.br, which compiled results from several election polls.

Protesters dissatisfied with Roussef's reelection claimed military intervention and wrote an online petition to the government of the United States of America, asking President Barack Obama to intervene in Brazil - which was regarded as an attempt to revive the military dictatorship (Costa, 2014). A major corruption scandal involving the state-owned Petrobrás is pointed as evidence of bad public management and motivates requests of impeachment against Roussef (Alencar, 2015). Brazil faces economic slowdown, and recession is a major preoccupation to the re-elected president; moreover, the choice of a right-wing economy minister, Joaquim Levy, displeased politicians and voters who support PT (Rizério, 2015). The beginning of her 
new mandate is evaluated as a very delicate situation to president Roussef and to the country (Alencar, 2015).

\subsubsection{Sweden}

The rise of Sweden as a unified country and the delimitation of its territory have gone through different movements of tribes that lived in the region and fought for land (Barnes, 2003). Between the $8^{\text {th }}$ and the $11^{\text {th }}$ century, the territory currently occupied by Sweden was the home of the Vikings who invaded and inhabited countries northward Europe but, nonetheless, did not establish a unified State (Grimberg, 1935). Eric, the Winner (Erik Segersäll) is considered to be the first king of Sweden, welcomed by the Svear and Götar peoples that lived around the current Stockholm; his reign lasted from 970 to 995 (Lindkvist, 2003).

Feudalism and slavery were not developed in Sweden like in the continental Europe. From the $11^{\text {th }}$ to the $15^{\text {th }}$ centuries, farming by free farmers prevailed (Grimberg, 1935). Birger Jarl (who governed the peoples in that region between 1248 and 1266) is pointed out as the responsible for the creation of the first national laws of Sweden, while the reforms promoted by him favored the unification work performed by his successors (Lindkvist, 2003).

In 1435, the first meeting of kingship (Riksdag) was held, attended by nobility, clerics and the bourgeoisie in the city of Arboga, to offer opposition to the restrictions imposed by King Erik XIII, which damaged imports, exports and the interests of the Church. The meeting would lead to the ousting of King Erik, and the taking over by the leader of the opposition to the king, Engelbrekt Engelbrektsson, as provisional regent (Grimberg, 1935; Orrman, 2003). Then, Sweden would face nearly one century of political instability with a weakened monarchy, with alternating regents chosen by the representatives of the Riksdag (Schück, 2003). In 1523, the elected king Gustav Vasa I came into power. From 1527 on, convened by Gustav Vasa I, the kingship meeting 
(Riksdag) included representatives of farmers that occupied the lands granted by the reign, thus building up a "4-layer" representation: kingship, Church, bourgeoisie and peasants (mainly owners of small lands) (Scott, 1988). This would be the embryo of the Swedish parliament. The next subsection deepens the discussion on this topic.

In the $17^{\text {th }}$ century, Sweden emerged as an imperialist power, taking over parts of the lands from Russia, Poland and Lithuania washed by the Baltic Sea, additionally to Finland, which had been dominated late in the $16^{\text {th }}$ century. The Swedish territorial expansionist campaign was weakened by the defeat for the Russian army, in the Battle of Poltava in 1709, and another defeat for Norway in 1716. Throughout the $13^{\text {th }}$ century, Sweden failed to keep the territories external to the Scandinavian Peninsula. In 1809 , after being defeated by Russia, Sweden lost the territory that today houses Finland (Grimberg, 1935; Scott, 1988).

In 1814, King Charles XIII signed the Kiel Treaty with the ally Napoleon Bonaparte, whereby Sweden would attach Norway to its territory, in exchange for lands conquered in Germany. Norway tried to reestablish itself as a sovereign State, but was defeated in a confrontation with Sweden in July 1814 . That would be the last time that Sweden got involved in an armed conflict. Norway remained subordinated to Sweden until 1905 (Grimberg, 1935; Scott, 1988).

In the $19^{\text {th }}$ century, Sweden experienced expressive population growth and modernization of agriculture through government-sponsored initiatives. The weakening of agriculture in neighboring countries increased the importance of the Swedish agriculture. Nonetheless, the turn to the $20^{\text {th }}$ century marked the beginning of industrialization in the country (Gustavson, 1986). Still in that period the country experienced intensive migration of rural populations to urban areas, where popular movements started claiming the expansion of political rights (Chauhan, 2013; Enander, 2013). 
The expansion of political rights should be explained associated to the history of the Riksdag - which would further become the Swedish parliament, keeping the same name until these days. The next section deepens this historical view focusing on the modern age of the parliament, in an attempt to understand the building of the Swedish democracy.

\subsection{The Riksdag and the Swedish democracy}

Although Sweden is now considered to be a democracy, the preservation of monarchy in the country could bring about some doubts about the scope of the Swedish political rights (Hoppe, 2001). On the other hand, the history of the Riksdag accompanies the reduction of the Monarch powers and the building of the Swedish institutional framework, as well as the expansion of the political rights of the Swedish citizens (Scott, 1988).

Between the $16^{\text {th }}$ and the $19^{\text {th }}$ centuries, the Riksdag experienced empowerment in face of the weakened Monarchs, and lost power to strengthened Monarchs. Throughout that period, the permanence of a Monarch in power largely depended on the approval of the Riksdag members; crisis periods were followed by coups against the Monarch or the election of a temporary regent among the nobility members (Schück, 2003; Scobbie, 2010; Scott, 1988).

From 1844 to 1859 King Oscar I carried out several liberal reforms like the introduction of free enterprise (1846), equal rights to inheritance for men and women (1845), rights for divorced women (1858), religious freedom (1860) and autonomous local governments (1862). When his son Charles $\mathrm{XV}$ took the government, the power had been largely transferred to the Riksdag. In 1866, the four-layer representation (nobility, Church, bourgeoisie and peasants) was abolished and replaced by a bicameral parliament. The High Chamber members were elected through indirect voting, resulting in a membership virtually exclusively of big land owners, big industry 
and trade entrepreneurs. The Low Chamber members were elected through direct voting, and voters were men with assets, thus giving advantage to farmers. Disagreements between members of both chambers regarding the army organization and the taxes levying, took Sweden to a political slowdown period that would last until early in the $20^{\text {th }}$ century (Enander, 2013).

The right to voting was extended to all men in 1909 and to women in 1919, in response to popular pressures for equalitarian vote (Sveriges Riksdag, 2012; Tilton, 1974). The right to run for elections had already been granted to all citizens qualified for voting and, therefore, in the 1921 elections five women won seats (Scott, 1988). By that time many other popular movements (mainly linked to independent religious groups and trade unions) claimed for the adoption of democratic principles (Chauhan, 2013).

The parliamentarian system was most welcomed, and ministries were established, reporting directly to the parliament. Gustav V, the Sweden King by that time, unsuccessfully tried to appoint a First Minister opposite to most of the parliament in 1917; in response, the great majority of the parliament made him backtrack (Scobbie, 2010). The parliament command was then assigned to Nils Éden, who started several reforms that reduced the Monarchy's chances of intervening on the parliament decisions (Chauhan, 2013; Tilton, 1974).

In 1974 a new constitution comes into force, reestablishing the unicameral system, with 349 seats, and institutionalizing the parliamentarian system (Sveriges Riksdag, 2012). The king could no longer get involved with political activities; his role is strictly ceremonial, as the head of state. The parliament members elect a speaker that, in turn, indicates the Prime Minister (Statsminister). The Prime Minister is in charge of assembling the government team (Scobbie, 2010). That is the current regimen, which could be considered to be a democracy in face of its political decision-making process, universal suffrage, and free candidacy for political offices (Lindvall \& Rothstein, 2006). 


\subsection{Recent political activity}

Similarly to its Scandinavian neighbors Norway, Denmark and Finland, Sweden is considered to be country of stable democracy and economy. Such stability is directly reflected on the quality of life and well-being of its citizens (Bergman, 2011; Calmfors, 2012; Eger, 2010; The Economist, 2013a). The Swedish economic model is considered to be very successful, attracting the interest of countries wanting to 'learn' from Sweden, like the United States (Bergsten, 2013) and England (The Economist, 2013b). Economy grows in good pace since 1968, having suffered the last economic crisis in 1991, and resisting to the economic crises that affected the USA and the European Union since then (Bergman, 2011; Calmfors, 2012). The Swedish Welfare State undergoes efficient adjustments due to the domestic and international economic pressures, which guarantees its force (Bergsten, 2013; Chung \& Thewissen, 2011; Hofstad, 2013). The national policies on education and health, passed and sustained with the support of the majority of political parties, have enabled matching the partial privatization of services with state cost-sharing and, therefore, citizens can freely decide for the services they consider to be the best (Bergsten, 2013; Calmfors, 2012).

However, some economic problems afflict Sweden. The Swedish Crown has kept strong quotation, thus creating difficulties for exports; economy experiences slowdown since 2013 and the unemployment among the youth increases (Davidsson \& Marx, 2013; Lorentzen, Angelin, Dahl, Kauppinen, Moisio, \& Salonen, 2014; The Economist, 2013d).

Immigration seems to be the matter with greater capacity of mobilizing citizens in Sweden. The extreme-right political parties have accused government of keeping very flexible immigration policies, and of granting asylum to a large number of refugees, thus creating demand for jobs (Hirvonen, 2013; The Economist, 2013d). Moreover, the country experienced a wave of protests flared up by violent episodes involving racism and xenophobia (Malmberg, Andersson, \& Östh, 2013), although most 
of the public opinion in Sweden remains favorable to the inclusion of immigrants in social programs (Artiles \& Meardi, 2014).

In May 2013, several violent protests were started in the district of Husby, Stockholm, after the publicizing of an episode where the local police invaded the apartment of a 69 years old immigrant and killing him. There were controversial versions about the reasons why the police invaded the apartment, and about the episode itself (The Local, 2013a). The blog Megafonen described the episode by emphasizing the police brutality, linking it to racist feelings, as the district is inhabited mainly by immigrants (Malmberg, Andersson \& Östh, 2013; Schierup, Ålund \& Kings, 2014; The Local, 2013b).

The riots started on May $19^{\text {th }}$, spreading to other districts in Stockholm and to other cities on the following days (Deutsche Welle, 2013; Schierup, Ålund \& Kings, 2014). Peace was restored on May $28^{\text {th }}$ (The Huffington Post, 2013). During the period of conflict, comments were posted at the Internet either supporting or rejecting the Husby youth, disclosing the public opinion division and the different political views on the migratory affair (Hansson, Cars, Ekenberg \& Danielson, 2013; Hirvonen, 2013).

The episode put light on the discussion about the effective access of immigrants to public services, racial discrimination and youth unemployment, notably regarding Muslim immigrants (Hansson, Cars, Ekenberg \& Danielson, 2013; Schierup, Ålund \& Kings, 2014). According to Hirvonen (2013), that reaction against the immigration of Arab or Islamic refugees is translated in the terms 'Islamophobia' (used by supporters of the Swedish openness to immigration, pointing out the irrationality of rejecting immigrants), by contrast with the pejorative 'EuRabbia' (contraction of Europe and ARabbia, in reference to the 'settlement' of Europe by Arab immigrants, this term is used by those against opening the country to immigration).

Beyond the prejudice issues, the debate around immigration brings questions about the limits of the successful Swedish Welfare State. Opponents to the opening to 
immigration say that the Swedish economy already suffers setbacks considering that benefits like unemployment protection are extended to immigrants (Eger, 2010; Davidsson \& Marx, 2013; Schierup, Ålund \& Kings, 2014). Affirming to be favorable or against immigration is now a core point to define the political positioning of parties in Sweden, as it instills the issue of state funds allotment in social wellbeing (Eger, 2010). At the parliament arena, the Social Democratic Party (Sveriges socialdemokratiska arbetareparti) had dominated the Swedish political system for a long time. In recent elections, however, the formation of a Centre-right coalition (Allians för Sverige, or simply 'the Alliance') has entailed a change in Swedish politics (Svallfors, 2011). To describe the present situation, a brief background is called for.

The Swedish elections in 2010 entailed something of a disaster for the Social Democrats. The once dominant party was defeated for the second time in a row by the remodeled 'new Moderates' (De Nya Moderaterna, a neo-liberal/conservative party) and the Center-right coalition 'the Alliance' (Svallfors, 2011) headed by former Prime Minister Fredrik Reinfeldt (in office from 2006 to 2014). After two years of internal instability, the Social Democrats leadership was attained in 2012 by former trade union leader Stefan Löfven, which resulted in a temporal boost of support for the Social Democrats.

The Center-right coalition headed by Reinfeldt included the Christian Democrats (Kristdemokraterna), the Center Party (Centerpartiet), and the Liberal People's Party (Folkpartiet). In the 2014 elections, this ruling coalition came to an end, and the Social Democrats tried to form a new minority government, with the help of the Green Party (Miljöpartiet), leaving the Left Party (Vänsterpartiet) out in the cold (Pollard \& Johnson, 2014).

However, the right-wing anti-immigration Sweden Democrats (Sverigedemokraterna, SD) did very well in the 2014 elections, and emerged with almost 13 per cent of the votes as the third largest party in the Swedish parliament 
(BBC, 2014a; Hirvonen, 2013). In December 2014, together with the Alliance parties, SD defeated the budget proposed by the Löfven government, causing him to call for extraordinary elections, to be held on 22 March 2015 (Olsen, 2014). In the end, the Alliance parties struck a deal with the Social Democrats, which made it possible for the minority government to remain in power (Dickson \& Senero, 2014). There will be no elections until the regular four years have passed; but the situation remains somewhat uneasy.

\subsubsection{Comparing the two countries}

The former section briefly presented the institutional framework, political history and recent activities in both countries studied. One should recognize that the institutional framework imposes some constraints that should be considered in the research; however, the investigation about causality between the institutional framework and the variables listed herein exceeds the objectives of this study.

In Brazil, the political institutions emerged as a prêt-à-porter solution brought by the Royal Family that was escaping from Napoleon. After independence, Brazil became an Empire with a parliament assembled according to the Portuguese experience (Bethell, 1985; Gomes, 2010). The transition to republic was surrounded by convulsions of the elite of land owners and dissatisfaction of the military (Bethell, 1985; Gomes, 2013). The right to voting was limited, notably during the Vargas and the Military dictatorship times, resulting in reduced democratic experience for Brazil (Bethell, 2008; Fleischer, 2004; Linz \& Stepan, 1999). For the last 25 years, Brazil has attempted to consolidate its democracy and, at the same time, the governmental institutions are little trusted by citizens who, to a large extend, show anti-political attitudes (Baquero, 2001; Moisés \& Carneiro, 2008; Sallum Júnior, Graeff \& Lima, 1990; Shildo, 1990). 
Sweden did not experience being a colony, nor extensive feudalism or slavery. The emergence of the Riksdag is connected to the opposition of bourgeois and farmers against the King, claiming for the establishment of a decision-making instance that has been gradually empowered (Enander, 2013). Most of the kings needed the nobility support to remain on the throne, which resulted in frequent removals of Monarchs who many times have not passed the throne to their heirs (Schück, 2003; Scobbie, 2010; Scott, 1988). The discontinuity of the royal lineage may have been a major factor to strengthen the parliament and build the Swedish democracy in parallel to monarchy (Tilton, 1974). Having built a renowned model of Welfare State, Sweden is now experiencing a political division regarding the migratory issue and the maintenance of state investments on policies focusing on Social Welfare (Eger, 2010; Davidsson \& Marx, 2013; Schierup, Ålund \& Kings, 2014).

Popular demonstrations unveil the dissatisfaction with the poor quality of public services and restrictions to freedom of speech in Brazil (Abreu \& Medeiros, 2013; Ranthum, 2013), and with sharing benefits of a Welfare State with immigrants in Sweden (Eger, 2010; Hirvonen, 2013; Schierup, Ålund \& Kings, 2014). However, although the street demonstrations express strong discontentment, these are just the tip of icebergs, as Ekman \& Amnå (2012) stated. Maybe each nation employs different forms of conversing discontentment into political action, notably when it comes to refer it to the parliamentarian arena.

This study aims at investigating those differences, without disregarding their contexts. Up to now, it has presented the theoretical frameworks about the variables investigated, i.e., Political Participation (the dependent/ endogenous variable), as well as Stereotypes about Parliamentarians, Political Education and Behavioral Contagion (the independent / exogenous variables). The concept of culture and the caution required when carrying out a cross-national research was discussed. Finally, political institutions in Brazil and Sweden were described, as well as their socioeconomic 
indicators and political history. Then, this content is articulated as a proposal of research establishing the links between those variables and objectives, which are to be investigated, that allow for exploring the differences between both countries. 


\subsection{Methodological Considerations}

This study was based on the wide assessment of each variable. Ekman and Amnå's (2012) framework on Political Participation intends to comprise the whole spectrum, from Non-Participation, through Latent to Manifest Participation, with 42 different behaviors originally cataloged. Stereotypes on Parliamentarians items intended to embrace the most relevant Critical Information on parliamentarians (considering those which voters pay attention to) and the most relevant typical politicians' behaviors (for the Behavior Prediction scale). Political Education and Socialization encompassed very different contexts where people can learn about politics. Behavioral Contagion is a complex construct, and the items created tried to represent a few of the most important social influence trends.

This endeavour of "painting a landscape picture" of the studied phenomena posed difficulties for the study. First, because politics is not always considered an interesting issue to keep people answering long questionnaires (Carneiro \& Torres, 2012; Pasquali, 2010). Therefore, in spite of the interest to ask many questions to assess each variable, the number of items was forced to be as few as possible.

Second, when those items are submitted to Factor Analysis, those "landscape scales" suffer from a trade-off issue known as the Bandwidth-Fidelity Dilemma (Cronbach, 1990; Cronbach \& Gleser, 1965; Hogan \& Roberts, 1996). Putting it simple, to achieve high Fidelity (assessed by "reliability" indices like Cronbach's Alpha or Jöreskog's Rho, for example) it is necessary to ask several questions on the same construct; however, due to limited time, achieving high fidelity implies shortsighting the phenomena (i.e., reducing bandwidth) (Vasilopoulos, Cucina \& Hunter, 2007). Metaphorically, instead of landscapes, one will paint close portraits to achieve fidelity. On the opposite direction, to widely explore constructs on length-limited surveys, it is 
necessary to compromise fidelity. Understanding the implications of this dilemma requires a deeper comprehension of reliability mechanics.

\subsubsection{Considerations on Reliability}

It is necessary to emphasize the difference between the reliability of measures and internal consistency reliability. Internal consistency reliability indicates that a set of items tap the same underlying concept (Hair et al., 2009; Pasquali, 2012; Tremblay, 2001). Reliability of measures concerns its utility on predicting the criterion variable, as discussed ahead.

Challenging the connotative interpretation of the commonly used short term "reliability", statistical reliability does not mean that measures accurately represent phenomena as they really appear in nature (Boyle, 1991). The numbers don't remember where they come from, i.e., statistics softwares will not have access to reality to check if measures are good (Cohen, 1990). Softwares "consider" that the dataset contains all the available information about the studied universe. Hence, buzzwords should be used with care, to avoid being trapped on misconceptions.

Tremblay (2001) explains the Bandwidth-Fidelity Dilemma as he sheds light on what affects internal consistency reliability:

a) The similarity of the content of the items. It is possible to increase reliability by writing items that are very similar to each other. The resulting factor will reach a very high alpha. However, these very redundant items will only predict a very narrow range of behaviors (they will have a low criterion validity). Not-so-similar items may increase the prediction obtained from a scale.

b) The number of items. Tremblay states that it is a classical test theory principle that internal consistency increases as the number of items 
increases, assuming that they all assess the same construct. Commonalities among items are considered additions of evidence (therefore, by inference, it is claimed that they add consistency) (Boyle, 1991; Pasquali, 2012). On the other hand, items' peculiarities are averaged out (Tremblay, 2001).

c) The number of dimensions underlying the measure. Multiple dimensions tend to reduce the scale's internal consistency. If more than one factor is found in Exploratory Factor Analysis (EFA), the items should be split according to the dimensions they represent.

In a harder criticism, Hattie (1985) asserts that a one-dimensional scale is not necessarily reliable, internally consistent or homogeneous, even if a high Cronbach's alpha is found (corroborated by McDonald, 1981). The similarity of items may increase internal consistency indices (as they consider items inter-correlations), but it is not enough to demonstrate the existence of an underlying dimension (Boyle, 1991).

Boyle (1991) and Cattell (1982) state that rephrasing the same question several times may result on a "bloated specific factor", i.e., a group of items that give the impression of a substantive factor, despite its lack of practical significance. Both authors sustain that high internal consistency (or internal homogeneity) can be antithetical to high validity. Cattell (1973) suggests that item diversity is crucial to enable the sampling of a wide range of behaviors, thus allowing participants to respond to items that represent various expressions available in life. High internal homogeneity (hence, high alphas) can be regarded as evidence of redundancy or narrowness of a scale (Boyle, 1991, McDonald, 1981).

In practical terms, internal consistency reliability indices (like Cronbach's alpha or Jöreskog Rho) do not indicate if items are reliable. They indicate that, if you put two or more items together, their resulting compound will represent a functional aggregation of the original items (Hair et al., 2009; Pasquali, 2012). This aggregation 
could then be used as a substitute of the items, to make statistical tests simpler. To achieve "real" reliability, it is a pre-requisite that the original items are precise and valid.

There is another tricky buzzword that may lead to misconceptions. When combining items into factors, researchers usually name "error" the part of variance that remains unshared among items. It would be more precise to name it "unique factors" (as Pasquali, 2012) or "uniqueness" (as Brown, 2006). The whole item's measure is a composition of their "uniqueness" (their peculiarity that is usually discarded on factor analysis) and their commonalities (their shared variance with other items). Therefore, if an item does not share variance with other items, it does not mean that it is unreliable. It just means that it is a standalone item. Trying to assess this sole item's internal consistency would be nonsense, as internal consistency is an attribute of item compounds (such as factors). If a standalone item is precise and valid (considering its adequate wording), its uniqueness should not be treated as "error", as its whole variance may be considered for hypotheses testing. Items in factors, otherwise, have their unique variances ignored.

Reliability of the measures, differently from internal consistency, refers to the possibility of predicting the dependent (endogenous) variable (Tremblay, 2001, corroborated by Boyle, 1991 and Hogan \& Roberts, 1996). Measures (factors or standalone items), if reliable, will add significant prediction power to the statistical test. Tremblay (2001) refers to this prediction augmentation as Incremental Validity. Putting it in a simple example, if measures are added into a stepwise multiple regression, the addition of explained variance for each item or factor may be considered an evidence of incremental validity. If the addition of a new item is not accompanied by a relevant increase on explanation, either the item is redundant with other tested measures (it should hence be submitted to factor analysis) or its measure is probably unreliable. Boyle (1991) adds that this increase of criterion variable prediction is an advantage of scales with "moderate to low homogeneity", as they maximize the breadth of 
measurement. Moreover, Boyle asserts that reduced item homogeneity facilitates the maintenance of validity across different cultures, as broader measures may reduce the chance of measurement errors due to cultural differences.

Tremblay's (2001) argument on incremental validity neglects, however, some possibilities:

a) If a given item does not add variance explanation, it is possible that it is still reliable, and the negative result is actually the correct result.

b) If the newly added item adds a good piece of variance explained, it is still possible that it is a "wrong" result, given by spurious correlations.

In both cases above, the solution is to discuss the theory support or the logics of the hypothesized correlations (Brown, 2006; Cohen, 1990; Hair et al., 2009). Likewise, the quality of item's wording should be debated (especially regarding its precision). Reliability of measures is also evaluated by the avoidance of errors Type I and Type II (Cohen, 1992) and the significance of prediction indicators (correlations, covariances, etc.).

The reliability of the measures depends on the interpretation of the actual meaning of the statistical results, considering its non-numeric qualities - theoretical or logical support, precision of items (Boyle, 1991; Cohen, 1990; Tremblay, 2001). According to Cattell (1973), to obtain a broad but valid, behaviorally based rather than semantically based scale, the researcher has to sift hundreds of items to find those with high validity despite their high diversity.

\subsubsection{Implications for this study}

Boyle (1991) and Tremblay (2001) assert that for exploratory research it is recommended to go for more bandwidth at the cost of lowering internal consistency. 
For this study, Cronbach's alpha and Jöreskog's Rho above 0.60 were accepted, considering that this is an exploratory study (Bagozzi \& Yi, 1988; Farid, 2014). Factors with internal consistency below 0.60 were considered unacceptable for analysis.

Factors with low internal consistency (below 0.60) should be "disentangled", i.e., its items should become standalones. Standalone items enter Multiple Regression and Structural Equation Models disputing variance with factors and other variables (e.g., Age, Gender, Education Level, etc.). If they have significant participation on models, they are kept; otherwise, they are removed - just as it happens with factor scores entering these statistical tests.

The mainstream literature (e.g. Hair et al., 2009; Marôco, 2010; Pasquali, 2012) suggests that if the mean of correlations between items lays below 0.50 , that is an evidence of bad convergence. The same parameter is applied to the Average Variance Extracted (Rho $\mathrm{vc}_{\mathrm{vc}}$, or Rho for convergent validity) on Confirmatory Factor Analysis. However, Boyle (1991, supported by Kline, 1979) suggests that the mean of correlations among items stay between 0.30 and 0.70 , to avoid too low convergence (hence an evidence of bad consistency) or too high convergence (an evidence of bloated factor, with redundant items). These parameters were adopted for the present study. The operationalization of these implications is presented in the following Method and Results Chapters. 


\subsection{Theoretical Model and Research Objectives}

The dependent (endogenous) variable in this study was established, Political Participation, as well as the three independent (exogenous) variables whose influence will be tested: Stereotypes about Parliamentarians, Political Education and Behavioral Contagion. Such influence will be observed by means of exploratory empirical testing.

The purpose of this study is to describe these variables in Brazil and Sweden, for comparison purposes. Why is this comparison so important? Because stereotypes, political education and behavioral contagion may be relatively stable inside one country, as citizens are subject to the same context. Comparing stereotypes that Brazilians create about their parliamentarians with stereotypes about Swedish parliamentarians may enlighten traces about Emic or Etic nature of phenomena. The same goes for political education and behavioral contagion. Research can only identify what is typical of a culture when cross-cultural comparisons highlight what is different (Smith et al., 2013).

For these reasons, the choice of Sweden as a case study takes place primarily by their contrasting characteristics with Brazil. As explained, the historical processes of the two countries led to two very different forms of democracy functioning, and the issues that mobilize citizens are very different. The Swedish political system does not seem to suffer a crisis of legitimacy such as that of the Brazilian system. The Swedish political system appears to be stable, and political movements are not directed to question the system structures, but to which group should be given more power, within the rules established (Rothstein \& Uslaner, 2005; Wallin, 2014).

Given the purpose of the study, the scheme in Figure 2.3 is proposed as a bottom line. This organization was developed a priori, before starting data collection. 


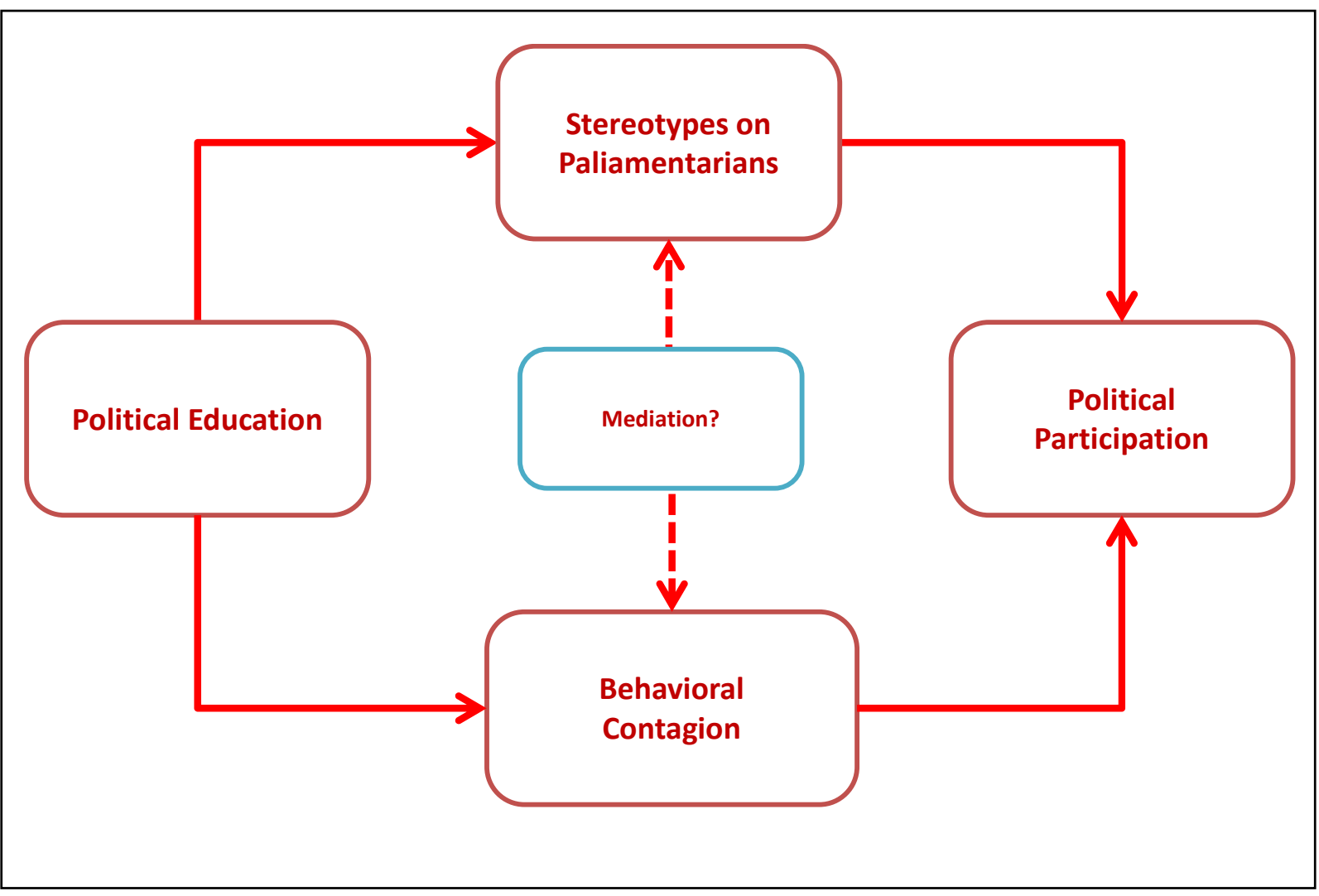

Figure 2.3. Hypothesized relationships between the study variables.

The test of the relationship between the variables will be conducted according to the following specific objectives:

1. To identify the factor structure of the variables;

2. To evaluate factor structure equivalence and metric equivalence;

3. To calculate differences in means between the factors observed in Brazil and Sweden;

4. To test the influence of stereotypes about parliamentarians, political education and behavioral contagion on the categories of political participation. This includes the verification of possible mediation among Stereotypes about Parliamentarians, Political Education and Behavioral Contagion.

The objectives above will be pursued in a study divided into three stages. These steps will be explained in Chapter 3: Method. 


\section{Chapter 3: Method}

The empirical investigation was carried out in 3 stages. First, a questionnaire was elaborated in English, with the use of a Delphic Panel gathering Brazilian and Swedish experts onto the task, so the questions would be valid for both contexts. Then, the questionnaire underwent a decentralized back-translation, resulting in Brazilian Portuguese and Swedish versions. Lastly, data was collected with the use of web panels on the Internet, and statistical tests were applied to assess the differences between the two countries.

\subsection{Stage 1: Delphic Panel}

The intent of the Delphic Panel is to engage experts into the construction of instruments to be used for data collection (Linstone \& Turoff, 1975). In order to reach this goal, it is necessary to ensure the experts' exemption until the end of this stage for this reason, the judgment of each panelist is not displayed to others (Hsu \& Sandford, 2007; Powell, 2003). This procedure seeks the experts' 'pure opinion', that is, without the informal influence that can occur in a synchronous meeting, like a focus group (Okoli \& Pawlowski, 2004). This is a recommended procedure when there is little prior empirical evidence about the investigated phenomena (Powell, 2003), which is the present study's case. Also, it helps to overcome geographical distances at low cost (Jones, Sanderson \& Black, 1992; Hsu \& Sandford, 2007; Okoli \& Pawlowski, 2004), such as the $10,000 \mathrm{~km}$ between Brazil and Sweden. On cross-country studies, it is recommended that the constructs formulation be conducted by a group of people from the nations involved (Bohenke et al., 2014). Therefore, this Delphic Panel convened Brazilian and Swedish experts into collaboration, which allowed constructing a questionnaire with items representing both cultures. 
Although Delphic Panel traditionally starts with an open-ended questionnaire, it is acceptable to use a literature-review-based structured questionnaire at the first round (Brooks, 1979; Custer, Scarcella \& Stewart, 1999; Cyphert \& Gant, 1971; Hsu \& Sandford, 2007; Okoli \& Pawlowski, 2004). A questionnaire draft was elaborated by this research's author. Items related to dependent (endogenous) variable, Political Participation, were taken from previous researches (Brussino, Rabbia \& Sorribas, 2009; Carneiro \& Torres, 2012; Caprara, Vecchione, Capanna \& Mebane, 2009; Ekman \& Amnå, 2012; Stolle, Hooghe, \& Micheletti, 2005).

Ekman and Amnå's (2012) framework does not contain questionnaire items, but its taxonomy cites various behaviors that can be converted into items - which in this case was made. Items referring to Non-Participation and to independent (exogenous) variables, Stereotypes on Parliamentarians; Political Education and Behavioral Contagion, were sparsely found in previous studies. Therefore, issues frequently found on previous researches were transformed into items. Non-Participation items reflected already reported negative attitudes (Anderson, 2010; Azevedo \& Chaia, 2008; Caprara, et al., 2009; Gomes, 2010; Miguel, 2003; Zimmerman \& Zahniser, 1991).

For Stereotypes, items were created considering what is the possible critical information on parliamentarians and what are commonly predictable behaviors of parliamentarians (Arceneaux, 2008; Blanc-Noel, 2013; Carlin \& Love, 2013; Garzia, 2013; Golebiowska, 2003; Koch, 2003; Jorge, 2003; Kam, 2007; Lau \& Redlawsk, 2001; Moisés, 2008; Rahn, 1993). Items on Political Education aim to assess how each context contributes to the learning by participants on the subject (Amnå, Ekström, Kerr \& Stattin, 2009; Castro, 2010; Resende \& Dionísio, 2005; Wyatt, Katz \& Kim, 2000). As for the Behavioral Contagion, the created items sought to assess if the participant exerted influence on others or if he/she followed someone else's influence (Caprara et al., 2009; Gomes \& Maheirie, 2011; Jesus, 2013; Le Bon, 2008; Moscovici, 1985; Zimmerman \& Zahniser, 1991). Items were based on the cited studies, but their 
wording was adapted to maintain harmony between different items and to adjust them to question headings. Delphic Panel experts were allowed to add new items and to criticize the whole questions wording and structure.

\subsubsection{Participants}

Twelve Brazilian and nine Swedish experts accepted the invitation to participate on the Delphic Panel. All of them are social science researchers, on politics-related fields, mostly master-degreed, PhD Students or PhD Professors. They had published studies on political issues or were working on research programs. A summary of their experience is presented on Appendix I.

\subsubsection{Procedures}

The Delphic Panel's number of rounds is not previously determined, and it depends on the achievement of agreement among experts. Nevertheless, 3 to 5 iterations (rounds) are usually enough, since it has to be considered that "perfect agreement" is uncommonly obtained (Stewart et al., 1999; Hsu \& Sandford, 2007). This study's Delphic Panel required three rounds. Experts could not have access to each other's comments and they were given one week to report their feedback. Warranting anonymous answers is essential to achieving Delphi's purpose (Hsu \& Sandford, 2007; Powell, 2003; Okoli \& Pawlowski, 2004). On the first round, the questionnaire draft (written in English, containing 87 items) was sent to Brazilian and Swedish experts by e-mail, simultaneously. Using a standardized form, experts could change question headings, add new items, assign items to be removed, change the item wording or add a relevant comment to it. The processing of the feedback was a craftwork analysis, as it was necessary to deal with very different, sometimes contradictory suggestions. At 
the second round, the newly processed questionnaire (containing 96 items) was presented to experts, with emphatic instructions to indicate items for removal. The resulting questionnaire was more consistent, and smaller - 68 items. A third round was held, with the possibility to re-include some essential items that could have been unfairly removed. The final English version (with 74 items) was achieved (see Appendix II). It was the raw material for the next stage: back-translation.

\subsection{Stage 2: Back-translation}

Back-translation was employed to ensure the same interpretation of items by Brazilian and Swedish citizens, considering cultural and linguistic differences (Brislin, 1970). Translators were explicitly instructed to perform a decentralized translation, i.e., to use expressions that express the meaning of the item according to the cultural nuances of each country (as explained in Section 2.5.2). For the present research, the procedure occurred according to the following steps:

a) The Delphic Panel's final questionnaire (written in English) was translated to Brazilian Portuguese and to Swedish, by professional bilingual translators.

b) The translated (Brazilian / Swedish) versions were then back-translated to English, by other two professional bilingual translators. These "backtranslators" did not have access to the original English version.

c) Three Brazilian Portuguese native-speakers and three Swedish nativespeakers played the role of translation judges. Judges did not have access to the translated version (Brazilian / Swedish version); they had access only to the original English version and to the back-translated English version. By comparing differences between these two English versions, they pointed items that needed correction. 
d) The judges' feedbacks were then presented to the Brazilian and the Swedish revisers (also native-speakers, chosen among the Delphic Panel experts). Revisers had access to all versions, and implemented the corrections the judges demanded to the Brazilian and Swedish versions.

e) The revised Brazilian and Swedish versions were then presented to the professional back-translators. The cycle then re-started from step "b".

It took three back-translation rounds for each version (Brazilian / Swedish) to achieve acceptable quality, considering the judges' opinions. The last Brazilian and Swedish versions were then presented to the judges, who demanded minor corrections to revisers. After those last revisions, Brazilian and Swedish versions were considered approved for data collection (see Appendix II, for the final translated versions).

\subsection{Stage 3: Data collection and Analyses}

\subsubsection{Data collection}

Brazilian and Swedish questionnaires were inserted into data collection web panel platforms (websites that offered resources to build data-collection forms). Both platforms were chosen for their respect to participants' privacy (SurveyMonkey and Solvero's Nebu). In Brazil, the link to the questionnaire was distributed through social media (Facebook paid advertisement and Twitter) and multi-thematic mailing lists. In Sweden, the questionnaire was distributed, a Swedish research company, to a randomized list of participants. Data collection occurred in the year 2014, between June 25 and August 31 in Brazil, and between August 05 and August 18 in Sweden.

In both countries, the informed consent was presented prior to the questionnaire, and it was necessary to agree with those terms before proceeding. 
Informed consent emphasized that the participant's privacy was going to be preserved and that the participant could leave the questionnaire at any time. The uncompleted questionnaires were not considered into analysis.

\subsubsection{Participants and Missing Imputation}

Under a tolerance threshold of up to $10 \%$ of missing answers, 984 Brazilians were considered for analysis. The mean age was 43.95 (S.D. 15.64), and $37.4 \%$ are women. Regarding educational level, $71.3 \%$ had completed University Education, from which $48.5 \%$ were post-graduated.

After removing the ones above the $10 \%$ threshold, 879 Swedish participants were considered for analysis. Swedish participants were 49.57 years old on average (S.D. 16.64), and $46.5 \%$ were women. On education, $27.9 \%$ had completed University Education, from which $5.1 \%$ were post-graduated.

Swedish sample was achieved considering age, education and regional distributions to be similar to the Statistiska Centralbyrån's 2013 summary of population ${ }^{10}$. People from the lower-educated cohort (incomplete elementary school) were under-represented; considering that participation was voluntary, this indicates that the questionnaire might be too sophisticated for people at this education level. Brazilian sample fetched the same criteria (age, education and regional distribution), considering the most recent population statistics from Instituto Brasileiro de Geografia e Estatística [Brazilian Institute for Geography and Statistics] (IBGE) ${ }^{11}$ and Tribunal Superior

\footnotetext{
${ }^{10}$ Retrieved from: http://www.scb.se/en /Finding-statistics/Statistics-by-subject-area/ Population/Population-composition/Population-statistics/Aktuell-Pong/25795/Yearly-statistics-The-whole-country/26040/

${ }^{11}$ Retrieved from: http://www.ibge.gov.br/apps/populacao/projecao/index.html
} 
Eleitoral [Election Superior Court] $(\mathrm{TSE})^{12}$, but it resulted in an over-representation of Center-West region and highly educated voters $(48,5 \%$ had completed university, against $5,27 \%$ as predicted by TSE).

This study did not have the intention to achieve a precise representation of each country population, though. Yet, data collected should be enough to run statistical analysis for testing interactions among variables. At first sight, for the adequate use of Factor Analysis, it is recommended that the sample contains 10 to 20 participants per questionnaire item (Pasquali, 2012; Thompson, 2005); so, in Brazil this ratio represented 16.4 participants per factorable item and in Sweden this ratio was 14.6. However, a more precise assessment of the sample size adequacy is given by Power Analysis.

\subsubsection{Power analysis}

Statistical Power assessment is useful for avoiding the risk of rejecting erroneously the alternative hypothesis $\left(\mathrm{H}_{1}\right)$ (Type II error, or " $\beta$ ") (Mayr, Erdfelder, Faul \& Buchner, 2007) or accepting a false null hypothesis $\left(\mathrm{H}_{0}\right)$ (Type I error, or " $\alpha$ "). In practical terms, Power Analysis indicates if the sample size was adequate or not for the employment of the statistical analyses like Multiple Regression or Structural Equation Modeling (Cohen, 1992; Mayr, Erdfelder, Faul \& Buchner, 2007). Assessed Power (1 $\boldsymbol{\beta}$ ) over $\mathbf{0 . 8 0}$ indicates that the risk of Type II error is removed satisfactorily (Cohen, 1992). For the calculation of statistical power, it is necessary to establish a set of parameters according to the type of test to be performed (in the present study, Multiple Regression and Goodness of Fit, a criterion for Structural Equation Modeling - SEM):

${ }^{12}$ Retrieved from: http://www.tse.jus.br/eleicoes/estatisticas/estatistica-do-eleitorado-por-sexoe-faixa-etaria 
- Effect size (calculated in terms of probability of $\mathrm{H}_{0}$ ): 0.15 for Multiple Regression; 0.30 for SEM.

- Maximum Tolerance to Type I error: $\alpha=0.01$.

- Sample size: 984 participants in Brazil, 879 in Sweden.

The actual effect size of phenomena usually cannot be estimated beforehand, so it is necessary to follow the rule-of-the-thumb from similar studies. Effect sizes mentioned above were the commonly recommended conventions to each statistical technique, considering a "medium" effect size (Cohen, 1992). The risk of Type I error is tolerated up to $1 \%(\alpha=0.01)$, which is rigorous but recommended when multiple tests are made upon the same data, yet according to Cohen. Degrees of freedom and number of predictors (also required parameters) can vary, according to each test design. Power Analyses results are presented and discussed together with Multiple Regression and Structural Equation Modeling (SEM) results.

For the given parameters, the Power obtained was of 1.00 for the Multiple Regression. For the CFAs, power ranged ${ }^{13}$ from 0.96 to 1.00 , and from 0.91 to 1.00 for the SEMs. Therefore, it was considered that the sample sizes supplied fairly well the power estimates recommended in the literature. The specific sample for the CFAs and SEMs are presented in the respective tables, in the Results Chapter.

\subsubsection{Analyses}

\subsubsection{Exploratory Factor Analysis}

Exploratory Factor Analysis (EFA) was used to the examination of patterns or relationships in a large set of variables in order to decide if they can be condensed into

${ }^{13}$ Power for Confirmatory Factor Analysis (CFA) and Structural Equation Modeling (SEM) may vary according to the number of degrees of freedom in each model. For this reason ranges are presented here. 
factors (latent variables) (Hair et al., 2009). A set of indicators are used to ensure that factors are consistent - they are summarized in Appendix III. Principal Axes Factoring (PAF) was employed to estimate the factor structure, combined with Oblimin rotation. Horn's (1965) Parallel Analysis was performed in order to confirm if the Factor Structure found is not an effect of random correlations (Hayton, Allen \& Scarpello, 2004; Thompson, 2005).

This study employed EFA as a preliminary analysis, in order to identify the factor structures that should be tested with CFA. Hence, EFA results are shortly presented and discussed; Confirmatory Factor Analysis (CFA), which provides a more sophisticated evaluation, deserved greater attention.

\subsubsection{Confirmatory Factor Analysis}

On Confirmatory Factor Analysis (CFA), a good factor structure is achieved when a good fit is reached and construct validity is demonstrated. Goodness-of-Fit indices ( $X^{2} /$ d.f., RMSEA, SRMR, CFI, TLI, see details on Appendix IV) usually punish the presence of items that do not contribute to their factors - and the researcher is usually forced to remove those items or to find its correct place into the factor structure (Brown, 2006; Hair et al., 2009; Thompson, 2005). Construct validity, in turn, is composed by:

a) Convergent Validity: indicates that different items of theoretically similar or overlapping constructs are indeed interrelated (Brown, 2006). As explained in Section 2.7.3, this study adopted the parameter of Average Variance Extracted (Rho $\left.{ }_{\mathrm{vc}}\right)$ between 0.30 and 0.70 (Boyle, 1991; Kline, 1979).

b) Discriminant Validity: indicates that items of theoretically distinct constructs are not highly intercorrelated (Brown, 2006). It is evaluated by comparing the extracted variance with the square construct correlations. If extracted variance is higher than the square structure correlations, it is an evidence of 
discriminant validity (Fornell \& Larcker, 1981; Hair et al., 2009). In addition, small or statistically nonsignificant factor covariances are usually not problematic and are typically retained in the solution (i.e., they provide evidence that the discriminant validity of the factors is good). However, if factor correlations exceed 0.80 or 0.85 , there is evidence to question that the latent factors represent distinct constructs, thus indicating poor discriminant validity (Brown, 2006).

Low discriminance indicates the need of forcing the reduction of the number of factors or gathering them on a Second-Order Factor. Factors with low Convergent Validity $\left(\mathrm{Rho}_{\mathrm{vc}}<0.50\right)$ may be kept unchanged, for this study, if the same factors pass the Discriminant Validity test or if the Second-Order Factor solution is admissible.

It is also important that factor structures allow comparisons between Brazilians and Swedes. For the present study, it is considered satisfactory that Factor Structure Equivalence is found between Brazilian and Swedish participants, regarding the adequacy of Goodness-of-Fit indices (Brown, 2006; Caprara et al., 2000). Metric Equivalence tests are reported, also considering the adequacy of Goodness-of-Fit as enough evidence (Thompson, 2005). The finding of $\Delta \mathrm{CFI}<0.01$ was considered additional evidence of equivalence; however, the significance of $\Delta X^{2}$ was disregarded, for its known oversensitivity to large samples (see Section 2.5.3).

Scalar Equivalence is disregarded, especially considering that no transformations were made onto data to reduce skewness nor were outliers removed. These are considered sources of equivalence weaknesses (Byrne \& Campbell, 1999; CanelÇınarbaş, Cui \& Lauridsen, 2011), but they were not changed, since the use of the rawest data possible was fetched. 


\subsubsection{Multiple Regression}

After factor structures were defined by CFA, factor scores (mean of composing items of each factor) were calculated. The effect of Independent variables' scores (Stereotypes, Political Education and Behavioral Contagion) on Political Participation (dependent variable) was tested through Stepwise Multiple Regression. This was used only as an interim analysis; therefore, its results are presented in Appendices and will not be discussed. Structural Equations Models started by reproducing Multiple Regression results.

\subsubsection{Structural Equation Modeling}

Structural Equation Modeling (SEM) examines the inter-relations structures given by a series of multiple regression equations. These equations describe all relationships among constructs (i.e. latent variables, or factors) enrolled (Hair et al., 2009). Criteria to accept a structural equation model as valid are similar to CFA, and they are presented in Appendix IV.

The main difference between SEM and CFA is that CFA is intended to identify good-fitted factor structures, while SEM is applied to test causal relationships among independent (exogenous) and dependent (endogenous) variables (Bollen, 1998; Hair et al., 2009; Hu \& Bentler, 1999). So, factors found in CFA are now tested under causal models, graphically represented by a path diagram.

Considering that SEM is strictly missing-unfriendly, Multiple Imputation (Allison, 2003; Brown, 2006; Schafer \& Graham, 2002; Wolf, Harrington, Clark \& Miller, 2013) was used to estimate the missing data. This approach uses all available data (both missing and missingless cases). It is similar to the use of Maximum Likelihood to produce parameter estimates, but with some improvements. The imputation method is based on iterated linear regressions in which each variable with missing data is 
regressed on other observed variables. The main advantage of this method is to prevent underestimates of variances and overestimates of correlations among the variables, produced by classical techniques, such as mean or regression imputation (Allison, 2003). Multiple Imputation solves those problems by introducing random variation into the process (Brown, 2006). 


\section{Chapter 4: Results}

As discussed before, the Delphic Panel achieved a reasonable agreement on questionnaire adequacy for both Brazilian and Swedish contexts. Back-translation provided Brazilian Portuguese and Swedish with items with similar meanings.

The following results start with a variable-by-variable explanation of Exploratory and Confirmatory Factor Analyses' (EFA and CFA) conclusions. Secondly, relationships among variables, calculated by Stepwise Multiple Regression and Structural Equation Modeling (SEM), are presented. Chapter 5 discusses these results as enlighten by theory. Conclusion remarks are presented into Chapter 6 .

\subsection{Exploratory and Confirmatory Factor Analyses}

\section{(EFA and CFA)}

For each variable (Political Participation, Stereotypes on Parliamentarians, Political Education and Behavioral Contagion), Exploratory Factor Analysis (EFA) was employed prior to Confirmatory Factor Analysis (CFA). EFAs' empirically defined factors were then submitted to CFA. Item-factor relationships were graphically represented into the software AMOS (version 21.0.0), which calculates Goodness of Fit indices to evaluate the quality of that structure. CFA allows the evaluation of Factor Structure and Metric Equivalence, to ensure that indicators are useful to the comparison of different countries.

The following sub-sections show conclusions for each variable, starting from the dependent (endogenous) variable, Political Participation. Independent (exogenous) variables factor structures are subsequently presented. 


\subsubsection{Political Participation}

The two sets of Political Participation items (political attitudes and past behavior) were separately tested into Exploratory Factor Analysis (EFA). Results for Brazil and Sweden were slightly different, as shown in Tables 5 and 6.

Table 5. Non-Participation (Political Attitudes) in Brazil and Sweden: EFA results.

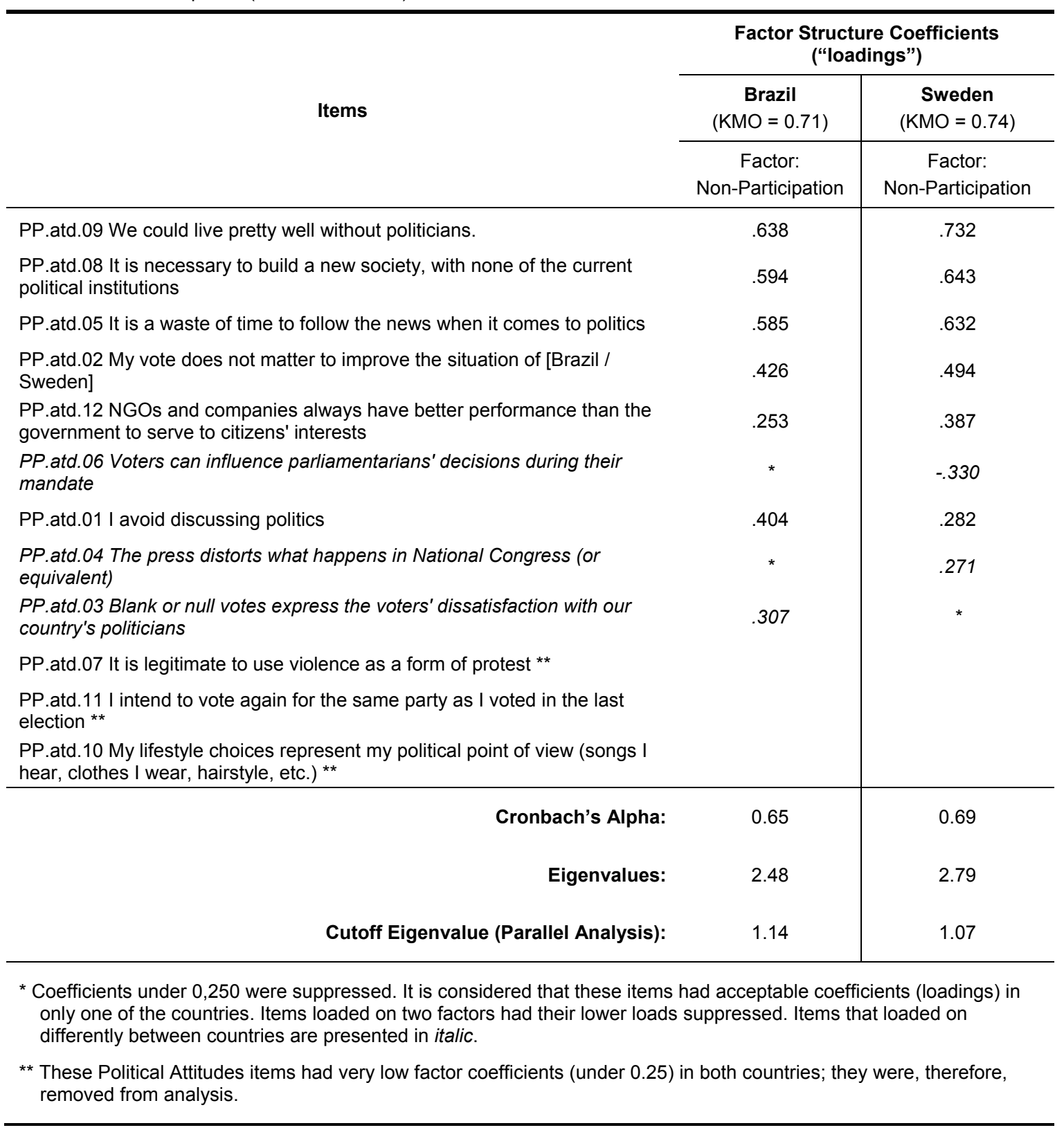


Table 6. Political Participation (Past Behavior) in Brazil and Sweden: EFA results

\begin{tabular}{|c|c|c|c|c|c|c|}
\hline \multirow{3}{*}{ Items } & \multicolumn{6}{|c|}{ Factor Structure Coefficients ("Ioadings")* } \\
\hline & \multicolumn{3}{|c|}{$\begin{array}{c}\text { Brazil } \\
(\mathrm{KMO}=0,86)\end{array}$} & \multicolumn{3}{|c|}{$\begin{array}{c}\text { Sweden } \\
(\mathrm{KMO}=0,88)\end{array}$} \\
\hline & $\begin{array}{l}\text { Factor 1: } \\
\text { Action }\end{array}$ & $\begin{array}{l}\text { Factor 2: } \\
\text { Attention }\end{array}$ & $\begin{array}{l}\text { Factor 3: } \\
\text { Pre-Political } \\
\text { Engagement }\end{array}$ & $\begin{array}{l}\text { Factor 1: } \\
\text { Action }\end{array}$ & $\begin{array}{l}\text { Factor 2: } \\
\text { Attention }\end{array}$ & $\begin{array}{l}\text { Factor 3: } \\
\text { Pre-Political } \\
\text { Engagement }\end{array}$ \\
\hline $\begin{array}{l}\text { PP.beh. } 10 \text { I have participated in events } \\
\text { organized by political parties }\end{array}$ & ,795 & & &, 580 & & \\
\hline $\begin{array}{l}\text { PP.beh. } 13 \text { I have handed out political } \\
\text { leaflets }\end{array}$ & 692 & & & 671 & & \\
\hline $\begin{array}{l}\text { PP.beh.05 I have participated in } \\
\text { institutional meetings (forums, seminars, } \\
\text { public hearings) about political issues }\end{array}$ &, 557 & & & & ,440 & \\
\hline $\begin{array}{l}\text { PP.beh.01 I have contacted } \\
\text { parliamentarians directly (by meeting, } \\
\text { telephone or through the Internet) }\end{array}$ & ,421 & & & &, 554 & \\
\hline $\begin{array}{l}\text { PP.beh. } 04 \text { I contacted the written press, } \\
\text { radio or TV station to communicate } \\
\text { something politically important }\end{array}$ & ,381 & & & & ,491 & \\
\hline $\begin{array}{l}\text { PP.beh. } 09 \text { I have participated in street } \\
\text { demonstrations }\end{array}$ & ,340 & & &, 562 & & \\
\hline $\begin{array}{l}\text { PP.beh. } 08 \text { I took part in strikes } \\
\text { organized by labor unions }\end{array}$ & ,332 & & & ,392 & & \\
\hline $\begin{array}{l}\text { PP.beh. } 07 \text { I took part in discussions } \\
\text { about political issues }\end{array}$ & & ,617 & & & ,438 & \\
\hline $\begin{array}{l}\text { PP.beh. } 02 \text { I have used social networks } \\
\text { on Internet (Facebook, Twitter, } \\
\text { YouTube, others) to engage into political } \\
\text { action }\end{array}$ & & 607 & & &, 542 & \\
\hline $\begin{array}{l}\text { PP.beh.06 I signed petitions on public } \\
\text { issues }\end{array}$ & &, 603 & & & & ,377 \\
\hline $\begin{array}{l}\text { PP.beh. } 03 \text { I looked up for information } \\
\text { about the performance of } \\
\text { parliamentarians }\end{array}$ & &, 545 & & &, 522 & \\
\hline $\begin{array}{l}\text { PP.beh. } 12 \text { I have chosen or refused } \\
\text { products for political, ethical or } \\
\text { environmental protection reasons }\end{array}$ & & ,356 & & & & ,489 \\
\hline $\begin{array}{l}\text { PP.beh. } 11 \text { I have helped an association } \\
\text { not linked to parties or government } \\
\text { (labor union, social minority } \\
\text { organization, church, NGO etc.) }\end{array}$ & & & ,722 & & & ,663 \\
\hline $\begin{array}{l}\text { PP.beh. } 14 \text { I have worked as a volunteer } \\
\text { (for my kids school church } \\
\text { neighbourhood other) }\end{array}$ & & & 622 & & & ,470 \\
\hline Cronbach's Alpha: & 0,77 & 0,72 & 0,66 & 0,73 & 0,71 & 0,63 \\
\hline Eigenvalues: & 4,56 & 1,40 & 1,25 & 4,78 & 1,42 & 1,16 \\
\hline Cutoff Eigenvalue (Parallel Analysis): & & 1,06 & & & 1,10 & \\
\hline
\end{tabular}

* Coefficients under 0,250 were suppressed. Items loaded on two factors had their lower loads suppressed. Items that loaded on different factors between countries are presented in italic.

Political attitudes items were organized on an one-factor structure, named Nonparticipation, with acceptable Kaiser-Meyer-Olkin (KMO) and Cronbach's alpha ( $\alpha$ ) 
indices for both Brazil $(\mathrm{KMO}=0.71, \alpha=0.65)$ and Sweden $(\mathrm{KMO}=0.74, \alpha=0,69)$. Two items had weak loadings in Sweden (PP.atd.01 and PP atd.04), but as they helped improving Cronbach's alpha, they were kept. Three items (PP.atd.07; PP.atd.11; PP.atd.10) were removed from analysis, as they did not reach acceptable loadings (>0.25) for both Brazil and Sweden.

Past behavior items analyses resulted in a three-factor structure, for both countries (see Table 6). Considering Ekman and Amnå's (2012) adapted framework,

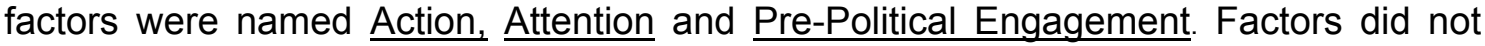
correspond exactly to the theoretical prediction (they were somewhat different from the columns at Table 2, in section 2.1.3). The three-factor structure was consistent for Brazil $(\mathrm{KMO}=0.86$, Cronbach's alphas of $0.77,0.72$ and 0.66$)$ and for Sweden $(\mathrm{KMO}$ $=0.88$, Cronbach's alphas of $0.73,0.71$ and 0.63$)$. Putting it simple, these factors had enough consistency to be used as substitutes to their respective questionnaire items, making easier the interpretation of results.

There was, however, a notable mixture of items between "Attention" and "Action" in the two countries, and "Pre-Political Engagement" was also different between Brazil and Sweden. Those differences in factor structures indicate that, in Brazil, behaviors like participating in institutional meetings (PP.beh.05), contacting parliamentarians (PP.beh.01) and contacting the press (PP.beh.04) are more typical of people who are engaged on Institutional Participation. In Sweden, these same behaviors are typical of people who pay Attention to politics. Pre-Political Engagement in Sweden gathered more behaviors (PP.beh.06, PP.beh.11, PP.beh.12 and PP.beh.14) than in Brazil (PP.beh.11 and PP.beh.14).

Differences between Brazilian and Swedish factor structures could make it difficult to establish comparisons. In Confirmatory Factor Analysis (CFA), an equivalent factor structure was fetched. Three concurrent CFA models were necessary to find it. 
CFA started by reproducing the common item-to-factor relationships in Brazil and Sweden found in EFA (Tables 5 and 6). Three scenarios were designed to perform this test: a) Brazil only, b) Sweden only, and c) Simultaneous test (Brazil and Sweden where the fit is calculated considering both countries at the same time). Non-common items were hence removed from this first CFA model, which was named "Minimal Model" (see Model A in Table 7). Besides removing the non-common items, other items were removed from the Non-participation factor to improve Goodness-of-Fit.

Non-participation factor was reduced to a three-item factor (PP.atd.05, PP.atd.08 and PP.atd.09). Given that any trial to re-insert items to Non-Participation resulted on the reduction of internal consistency, this three-item factor solution was admitted as the best possible. The resulting factor was renamed "Political Disillusion", as its items represent carelessness for politics, however without suggesting action. All other political attitude items were removed from analysis.

Regarding past behavior items, the removal of items reduced the scope of factors. Moreover, the following items were removed from the Minimal Model:

a) PP.beh.01. I have contacted parliamentarians directly (by meeting, telephone or through the Internet).

b) PP.beh.04. I contacted the written press, radio or TV station to communicate something politically important.

c) PP.beh.05. I have participated in institutional meetings (forums, seminars, public hearings) about political issues.

d) PP.beh.06 I signed petitions on public issues.

e) PP.beh.08. I took part in strikes organized by labor unions.

f) PP.beh.12. I have chosen or refused products for political, ethical or environmental protection reasons. 
Table 7. Participation and Political Disillusion in Brazil and Sweden: Goodness-of-Fit indices and Power Analysis

\begin{tabular}{|c|c|c|c|c|c|c|c|c|c|c|c|}
\hline Model & Scenario & $x^{2}$ & d.f. & $x^{2} /$ d.f. & RMSEA & SRMR & CFI & TLI & AGFI & $\begin{array}{c}\text { Achieved } \\
\text { Power } \\
(1-\beta)^{*}\end{array}$ & $\begin{array}{l}\text { Type I } \\
\text { error } \\
\text { alpha }\end{array}$ \\
\hline & Acceptance Criteria: & -- & -- & $\begin{array}{c}\text { between } \\
1 \text { and } 5\end{array}$ & $<0.07$ & $<0.08$ & $>0.92$ & $>0.92$ & $>0.90$ & $>0.80$ & $\begin{array}{l}\text { fixed at } \\
.01\end{array}$ \\
\hline \multirow{3}{*}{$\begin{array}{l}\text { A) "Minimal Model" } \\
\text { Based on common item-to-factor } \\
\text { relationships between countries. } \\
\text { Redundant items were removed } \\
\text { from Non-Participation to } \\
\text { improve fit }\end{array}$} & Brazil & 186.12 & 38 & 4.90 & .063 & .057 & .93 & .90 & .94 & .99 & .01 \\
\hline & Sweden & 121.24 & 38 & 3.19 & .050 & .049 & .96 & .94 & .96 & .99 & .01 \\
\hline & $\begin{array}{l}\text { Brazil and Sweden } \\
\text { simultaneously }\end{array}$ & 307.36 & 76 & 4.04 & .040 & .045 & .95 & .92 & .95 & 1.00 & .01 \\
\hline \multirow{3}{*}{$\begin{array}{l}\text { B) "Four-Factor Model" } \\
\text { Important items were re-inserted }\end{array}$} & Brazil & 504.11 & 115 & 4.38 & .059 & .050 & .91 & .88 & .92 & .99 & .01 \\
\hline & Sweden & 442.40 & 115 & 3.85 & .057 & .051 & .92 & .89 & .92 & .97 & .01 \\
\hline & $\begin{array}{l}\text { Brazil and Sweden } \\
\text { simultaneously }\end{array}$ & 946.51 & 230 & 4.12 & .041 & .051 & .91 & .89 & .92 & .99 & .01 \\
\hline \multirow{3}{*}{$\begin{array}{l}\text { C) "Final Model" } \\
\text { Second-order factor for } \\
\text { Institutional Participation was } \\
\text { introduced }\end{array}$} & Brazil & 574.11 & 120 & 4.78 & .062 & .054 & .89 & .86 & .91 & .98 & .01 \\
\hline & Sweden & 488.52 & 120 & 4.07 & .059 & .054 & .91 & .89 & .92 & .96 & .01 \\
\hline & $\begin{array}{l}\text { Brazil and Sweden } \\
\text { simultaneously }\end{array}$ & 1062.63 & 240 & 4.43 & .043 & .054 & .90 & .87 & .91 & .99 & .01 \\
\hline
\end{tabular}


These items, however, were considered too theoretically relevant to be suppressed. They refer to behaviors which importance is mentioned in several studies (Amnå, Ekström, Kerr \& Stattin, 2009; Bertoncelo, 2009; Brussino, Rabbia \& Sorribas, 2008; Dalton, 2008; Ekman \& Amnå, 2012; Gomes \& Maheirie, 2011; Hansson, Cars, Ekenberg, \& Danielson, 2013; Stolle, Hooghe \& Micheletti, 2005). Additionally, PP.atd.07 ("It is legitimate to use violence as a form of protest") was the only measure available for political violence. The exclusion of those items could limit the interpretation of subsequent analyses to a very narrow range of political behaviors. It was decided, then, to bring them back in, at the risk of lowering Goodness-of-Fit.

In other words, the insertion of non-common item-to-factor connections could be statistically interpreted as a distortion to the organization of items. Nonetheless, since Brazilians and Swedes act differently when it comes to politics, it is worth the risk: Goodness-of-Fit indices (which provide a general evaluation of model's quality) may weaken, but the re-inserted items add important information to this research's purposes.

The items PP.beh.08 ("strikes") and PP.beh.12 ("political consumerism") did not settle in any factor, and PP.beh.09 ("street demonstrations") had to be moved out of "Action" for the achievement of acceptable fit. Item PP.atd.07 ("political violence") was also kept as a standalone. A Four-Factor Model was met, achieving good fit in all three scenarios (see Model B in Table 7).

It was then necessary to test if factors found were indeed different, or if there was a "hidden" major factor connecting some of them. It is said that factors converge when their items are strongly interconnected. This connection strength must resist to the test of discriminance, that is, items from one factor should not be "attracted" to other factors. If factors stay clearly separate, it is said that they are convergent and discriminant, that is, they actually represent distinct facts in the real world. However, if 
two or more factors are "attracted" to each other, it means that they are part of a bigger phenomenon - the hidden factor (technically speaking, a "second-order factor").

That Four-Factor Model was submitted to tests of Convergent and Discriminant Validity. Convergent validity is met when factor's Average Extracted Variance (or Rho for Convergent Validity, $\mathrm{Rho}_{\mathrm{vc}}$ ) is above 0.30 . Discriminant Validity is found when the square covariances among factors remain below each factor's $\mathrm{Rho}_{\mathrm{vc}}$. On the contrary, square covariances above factors' Rho $\mathrm{vc}_{\mathrm{vc}}$ indicate the possible existence of a secondorder factor (Hair et al., 2005; Marôco, 2010).

Square covariances between Attention and Action stood above these factors' Rho $\mathrm{vc}_{\mathrm{v}}$, indicating low discriminance (see Table 8). These factors were hence grouped into a second-order factor, named Institutional Participation. The "Final Model" is presented in Figures 4.1 and 4.2. The inclusion of a Second-order factor slightly compromised Goodness-of-Fit (see Model C in Table 7). However, this solution was kept, because it solves the low discriminance Attention and Action. Adequacy of RMSEA, SRMR and AGFI indicate that the model is parsimonious (unnecessary estimations were removed). CFI and TLI below threshold indicated that some relationships among variables (paths in the diagram) were forcedly omitted (Brown, 2006). 
Table 8. Discriminant Validity, based on the Five Factor Model. Bold values indicate the Average Extracted Variance (Rho ${ }_{\mathrm{vc}}$ ); values in the ladder represent the square covariance among factors and/or standalone items. Values in italics indicate low discriminance (they are above Rhovc for each factor).

\begin{tabular}{|c|c|c|c|c|c|c|c|c|c|}
\hline & & $\begin{array}{l}\text { Political } \\
\text { Disillusion }\end{array}$ & $\begin{array}{l}\text { Pre-Political } \\
\text { Engagement }\end{array}$ & Attention & Action & $\begin{array}{l}\text { PP.atd.07 } \\
\text { Violence }\end{array}$ & $\begin{array}{c}\text { PP.beh.08 } \\
\text { Strikes }\end{array}$ & $\begin{array}{c}\text { PP.beh.09 } \\
\text { Demonstrations }\end{array}$ & $\begin{array}{c}\text { PP.beh.12 } \\
\text { P. Consumerism }\end{array}$ \\
\hline & Rho $_{\mathrm{vc}}$ & .408 & .512 & .405 & .422 & & & & \\
\hline & \multicolumn{9}{|l|}{ Political Disillusion } \\
\hline & $\begin{array}{l}\text { Pre-Political } \\
\text { Engagement }\end{array}$ & .004 & & & & & & & \\
\hline & Attention & .078 & .194 & & & & & & \\
\hline \multirow[t]{5}{*}{ Brazil } & Action & .036 & .203 & .548 & & & & & \\
\hline & PP.atd.07 Violence & .029 & $\mathrm{~ns}^{*}$ & .023 & .008 & & & & \\
\hline & PP.beh.08 Strikes & $\mathrm{ns}^{*}$ & .032 & .048 & .123 & .026 & & & \\
\hline & $\begin{array}{c}\text { PP.beh.09 } \\
\text { Demonstrations }\end{array}$ & $\mathrm{ns}^{*}$ & .058 & .144 & .160 & .068 & .168 & & \\
\hline & $\begin{array}{c}\text { PP.beh.12 } \\
\text { P. Consumerism }\end{array}$ & .012 & .137 & .160 & .044 & $\mathrm{~ns}^{*}$ & .014 & .032 & \\
\hline
\end{tabular}

${ }^{*}$ Not significant, removed from model. 
Table 8 (cont.). Discriminant Validity, based on the Five Factor Model. Bold values indicate the Average Extracted Variance (Rhovc); values in the ladder represent the square covariance among factors and/or standalone items. Values in italics indicate low discriminance (they are above Rhovc for each factor).

\begin{tabular}{|c|c|c|c|c|c|c|c|c|c|}
\hline & & $\begin{array}{l}\text { Political } \\
\text { Disillusion }\end{array}$ & $\begin{array}{l}\text { Pre-Political } \\
\text { Engagement }\end{array}$ & Attention & Action & $\begin{array}{l}\text { PP.atd.07 } \\
\text { Violence }\end{array}$ & $\begin{array}{l}\text { PP.beh.08 } \\
\text { Strikes }\end{array}$ & $\begin{array}{c}\text { PP.beh.09 } \\
\text { Demonstrations }\end{array}$ & $\begin{array}{c}\text { PP.beh.12 } \\
\text { P. Consumerism }\end{array}$ \\
\hline \multirow{9}{*}{ Sweden } & $\mathbf{R h o}_{\mathrm{vc}}$ & .472 & .496 & .361 & .448 & & & & \\
\hline & \multicolumn{9}{|l|}{ Political Disillusion } \\
\hline & $\begin{array}{l}\text { Pre-Political } \\
\text { Engagement }\end{array}$ & .017 & & & & & & & \\
\hline & Attention & .006 & .303 & & & & & & \\
\hline & Action & .004 & .230 & .533 & & & & & \\
\hline & PP.atd.07 Violence & .096 & $\mathrm{~ns}^{*}$ & .026 & .036 & & & & \\
\hline & PP.beh.08 Strikes & $\mathrm{ns}^{*}$ & .040 & .044 & .096 & .017 & & & \\
\hline & $\begin{array}{c}\text { PP.beh.09 } \\
\text { Demonstrations }\end{array}$ & $\mathrm{ns}^{*}$ & .144 & .281 & .325 & .044 & .123 & & \\
\hline & $\begin{array}{c}\text { PP.beh.12 } \\
\text { P. Consumerism }\end{array}$ & .017 & .176 & .176 & .044 & $\mathrm{~ns}^{*}$ & .008 & .053 & \\
\hline
\end{tabular}

* Not significant, removed from model. 
The examination of Modification Indices indicated that covariance between the uniqueness of "Attention" and "Political Consumerism" (standalone item) had been omitted ( $\operatorname{cov}=0.35$ for Brazil; $\operatorname{cov}=0.40$ for Sweden). This suggests that people who are attentive to politics are likely to engage into Political Consumerism. Other omitted connections suggest (possibly cultural) differences between Brazil and Sweden. For Brazil, discussing politics (uniqueness [uniq] of PP.beh.07) was negatively related to the Political Disillusion factor $(\operatorname{cov}=-0.20)$. For Sweden, handing out political leaflets (uniq.PP.beh.13) is negatively connected to the uniqueness of "Attention" (cov = -0.52); but in Brazil it was connected to participating in events organized by political parties (uniq.PP.beh.10) (cov = 0.42). For Brazil, the feeling that following the news is a waste of time (uniq.PP.atd.05) is negatively connected to "Attention" (cov $=-0.39$ ). Most of those connections are made between different factors, then complicating interpretation and the calculation of factor scores.

The addition of those omitted paths to the model could improve fit $\left(X^{2} /\right.$ d.f. $=$ 3.17; $\mathrm{RMSEA}=0.034, \mathrm{SRMR}=0.048 ; \mathrm{CFI}=0.94 ; \mathrm{TLI}=0.92 ; \mathrm{AGFI}=0.94$ for the simultaneous scenario). However, it was decided to keep them omitted, so the model would be easier to interpret and also to put to test on Multiple Regression and SEM. It has to be considered that EFA showed different factor structures for Brazil and Sweden. Differences may reflect Brazilians' and Swedes' different political mindsets or context-dependent issues (such as the engagement on massive political action in Brazil, in 2013, for example). The internal consistency and convergence of the factors were satisfactory (Table 9). The Final Model (Model C in Table 7) was then tested for factor structure equivalence and metric equivalence. 
Table 9. Political Participation and Political Disillusion, Final Model: Internal Consistency and Convergent Validity

\begin{tabular}{|c|c|c|c|c|}
\hline & Jöreskog's Rho & $\begin{array}{c}\text { Convergent Validity } \\
\text { Rhovc }\end{array}$ & Jöreskog's Rho & $\begin{array}{c}\text { Convergent Validity } \\
\text { Rhovc }\end{array}$ \\
\hline Acceptance Criteria & $>0.60$ & $>0.30$ & $>0.60$ & $>0.30$ \\
\hline $\begin{array}{l}\text { Pre-Political } \\
\text { Engagement }\end{array}$ & .68 & .52 & .66 & .50 \\
\hline $\begin{array}{l}2^{\text {nd }} \text { order factor: } \\
\text { Institutional } \\
\text { Participation }\end{array}$ & .85 & .74 & .84 & .73 \\
\hline Action & .78 & .42 & .80 & .45 \\
\hline
\end{tabular}

Regarding equivalence, the achievement of acceptably fitted models on all three scenarios (each country separately and simultaneously, see Table 7) is an evidence of Factor Structure Equivalence (Brown, 2006; Hair et al., 2009; Thompson, 2005).

A Metric Equivalence test was performed by constraining factor loadings so they were equal between Brazil and Sweden. A significant chi-square difference between constrained and baseline model was found $(p<0.001)$, but it was disregarded, for its known oversensitivity (see Section 2.5.3). Considering Goodness-of-Fit, the constrained model was acceptable, regarding RMSEA, SRMR and AGFI. CFI and TLI deterioration made these indices distant from their respective cutoffs (Table 10); nonetheless, it must be recalled that fit was intentionally compromised with the reinsertion of important items. Thus, considering that CFI and TLI were already compromised on the baseline model, and that RMSEA, SRMR and AGFI had slight deterioration, evidence of Metric Equivalence was found. Also, $\Delta \mathrm{CFI}=-0.09$, below the 0.10 cutoff, offered additional evidence of equivalence. 


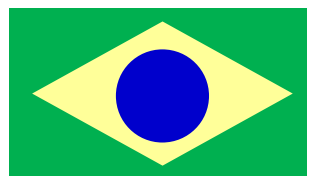

Brazil
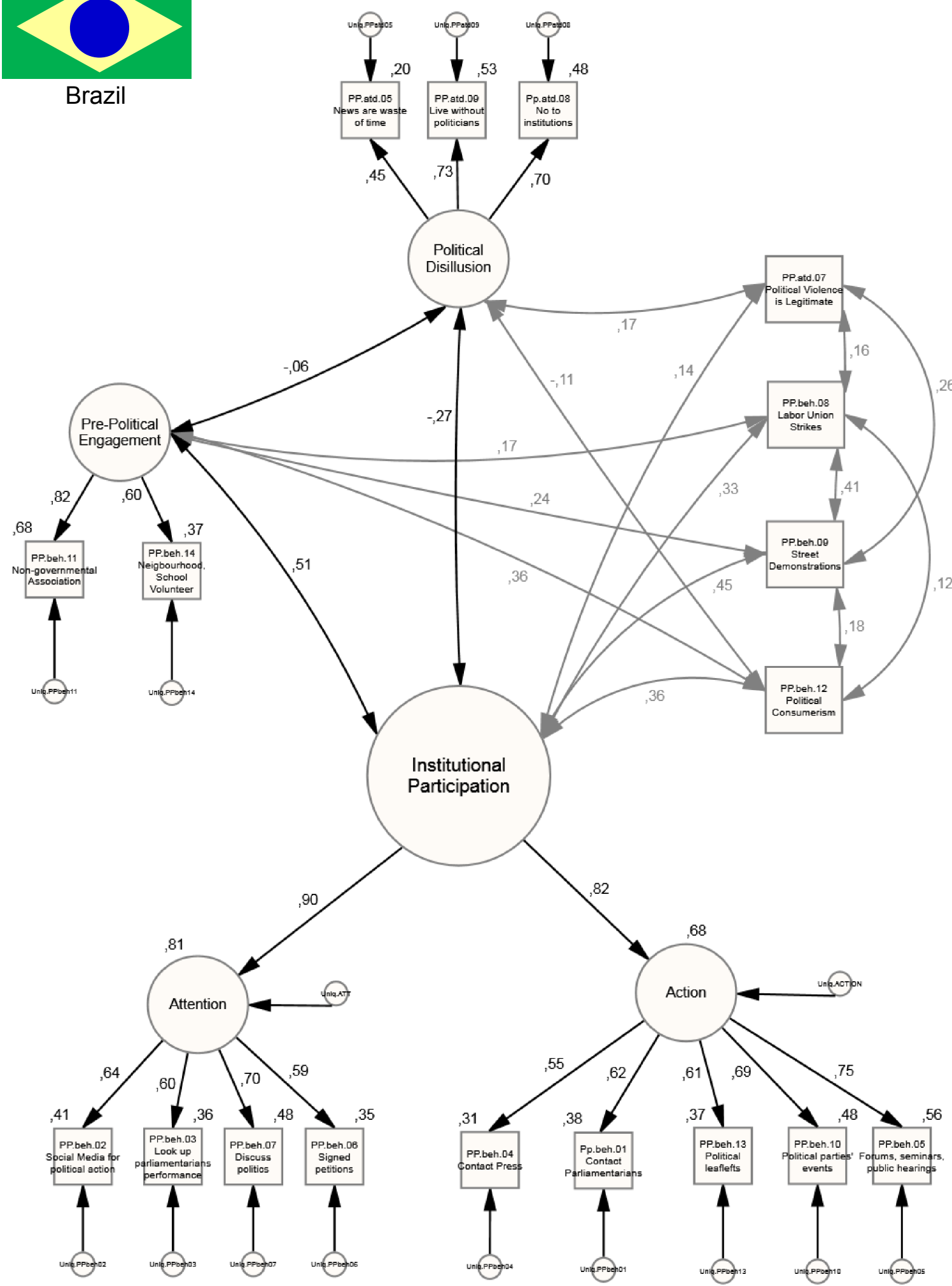

Figure 4.1. Participation and Political Disillusion factor structure for Brazil - Final Model. 


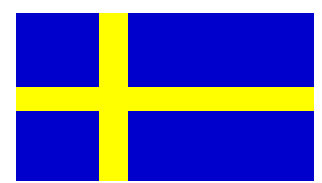

Sweden

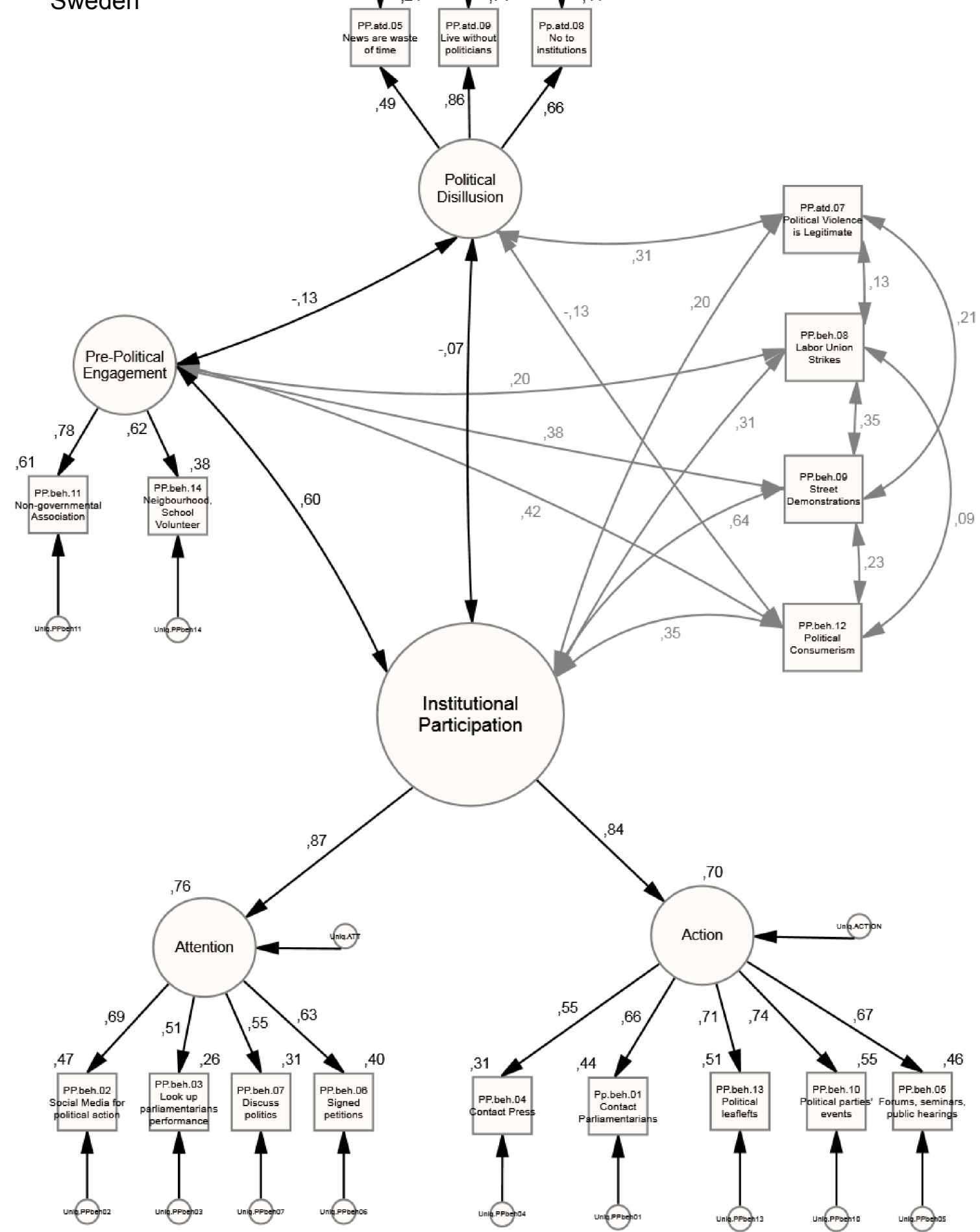

Figure 4.2. Participation and Political Disillusion factor structure for Sweden - Final Model. 
Table 10. Participation and Political Disillusion: Test of Equivalence.

\begin{tabular}{|c|c|c|c|c|c|c|c|c|c|c|c|}
\hline Model & Scenario & $x^{2}$ & d.f. & $x^{2} /$ d.f. & RMSEA & SRMR & CFI & TLI & AGFI & $\Delta X^{2}\left({ }^{*}\right)$ & $\Delta \mathrm{CFI}^{*}$ \\
\hline Accel & tance Criteria: & -- & -- & $\begin{array}{c}\text { between } \\
1 \text { and } 5\end{array}$ & $<0.07$ & $<0.08$ & $>0.92$ & $>0.92$ & $>0.90$ & $p>0.0 .05$ & $<|0.01|$ \\
\hline Unconstrained & $\begin{array}{l}\text { Brazil } \\
\text { ₹Sweden }\end{array}$ & 1062.63 & 240 & 4.43 & .043 & .0539 & .901 & .874 & .911 & & \\
\hline $\begin{array}{l}\text { Metric } \\
\text { Equivalence: } \\
\text { Constrained } \\
\text { factor loadings }\end{array}$ & $\begin{array}{l}\text { Brazil = } \\
\text { Sweden }\end{array}$ & 1151.01 & 250 & 4.60 & .044 & .0566 & .892 & .868 & .907 & $p<0.001$ & -.009 \\
\hline
\end{tabular}

Stereotypes on Parliamentarians, Political Education and Behavioral Contagion are the independent (exogenous) variables, i.e., those variables that may explain what leads people into Political Participation. Their factor structures are presented on the following three subsections.

\subsubsection{Stereotypes on Parliamentarians}

The items from Stereotypes about Parliamentarians (the first exogenous, independent variable) were presented to participants in two groups: a) Critical Information - participants were asked to which information they usually paid attention, when watching parliamentarians discuss some important subject; and b) Behavior Prediction - participants informed how big a share of parliamentarians usually behaved as described on the list of items. These two groups were separately submitted to EFA; it was not considered to test them altogether, as they are different dimensions, with different natures (information relevance versus described behaviors). EFA could then mix those two types of items into a non-interpretable solution. After deciding the factor structures, however, a general CFA model for Stereotypes on Parliamentarians was 
made. On CFA, the risk of mixing items is absent, as the researcher can decide which items compose each factor.

\subsubsection{Critical Information on Parliamentarians}

Critical Information resulted in different arrangements between Brazil and Sweden, even though Parallel Analysis recommended a two-factor structure for both countries (Table 11). The Swedish factor structure was clearly a two-factor compound, with fairly good consistency $(\mathrm{KMO}=0.87$, Cronbach's alphas of 0.88 and 0.77 , all loadings above 0.55). The first factor was named Party-Oriented View, as it gathered items related to traditional party information. The second factor was named Representation Trends, as it mostly encompassed items related to the politician links to groups of interest he/she tended to represent.

Brazilian factor structure for Critical Information was a bit more complex, but also with good consistency $(\mathrm{KMO}=0.88$, Cronbach's alphas of $0.88,0.84$ and 0.62 , all loadings above 0.533$)$. The first factor structure obtained was a three-factor compound, with the third factor's Eigenvalue (1.02) marginally below the cutoff Eigenvalue estimated by Parallel Analysis (1.07). The first factor was mostly similar to the Swedish Party-Oriented View (the only different item was ST.inf.04 - His/her area of expertise...) and Representation Trends was also mostly similar. The remarkable difference is that two items migrated, creating a "Personal Information" composite, the third ("new") factor. Personal Information assessed if participant was attentive to the politician gender and religion. Forcing a two-factor solution (as recommended by Parallel Analysis) resulted in the maintenance of "Personal Information", and all other items grouped on the first factor (thus making a mix of Party-Oriented View and Representation Trends). This solution makes it nearly impossible to establish a comparison with the Swedish solution, and it precludes telling apart those two relevant constructs. The two-factor compound reduced, hence, the possible explanations on 
participant's view about parliamentarians. Therefore, the Brazilian three-factor solution was kept. These factor structures were submitted to CFA.

Table 11. Stereotypes on Parliamentarians (Critical Information): EFA Results

\begin{tabular}{|c|c|c|c|c|c|c|}
\hline \multirow{3}{*}{ Items } & \multicolumn{6}{|c|}{ Factor Structure Coefficients ("Ioadings") } \\
\hline & \multicolumn{3}{|c|}{$\begin{array}{c}\text { Brazil } \\
(\mathrm{KMO}=0,88)\end{array}$} & \multicolumn{3}{|c|}{$\begin{array}{c}\text { Sweden } \\
(\mathrm{KMO}=0,87)\end{array}$} \\
\hline & $\begin{array}{l}\text { Factor 1: } \\
\text { Party- } \\
\text { Oriented } \\
\text { View }\end{array}$ & $\begin{array}{l}\text { Factor 2: } \\
\text { Politician } \\
\text { History }\end{array}$ & $\begin{array}{l}\text { Factor 3: } \\
\text { Personal } \\
\quad \text { Info }\end{array}$ & $\begin{array}{l}\text { Factor 1: } \\
\text { Party- } \\
\text { Oriented } \\
\text { View }\end{array}$ & $\begin{array}{l}\text { Factor 2: } \\
\text { Politician } \\
\text { History }\end{array}$ & $\begin{array}{l}\text { Factor 3: } \\
\text { Personal } \\
\quad \text { Info }\end{array}$ \\
\hline $\begin{array}{l}\text { ST.inf. } 02 \text { If he/she is left-winged or right- } \\
\text { winged }\end{array}$ & .841 & & & .821 & & \\
\hline $\begin{array}{l}\text { ST.inf.03 If he/she represents the } \\
\text { governing party(ies), the opposition or a } \\
\text { neutral position }\end{array}$ & .772 & & & .824 & & \\
\hline ST.inf.01 His/her political party & .700 & & & .836 & & \\
\hline $\begin{array}{l}\text { ST.inf.10 His/her former political } \\
\text { positions (ex.: Minister, Secretary etc.) }\end{array}$ & & .700 & & & .551 & \\
\hline $\begin{array}{l}\text { ST.inf.04 His/her area of expertise (ex.: } \\
\text { environment, foreign affairs, economic } \\
\text { development, human rights etc.) }\end{array}$ & & .671 & & .592 & & \\
\hline $\begin{array}{l}\text { ST.inf.09 If he/she has been involved in } \\
\text { scandals }\end{array}$ & & .619 & & & .457 & \\
\hline $\begin{array}{l}\text { ST.inf.05 The groups of interest in which } \\
\text { he/she takes part (labor unions, } \\
\text { entrepreneurs associations, } \\
\text { environmental protection institutions, } \\
\text { farmers associations etc.) }\end{array}$ & & .608 & & & .498 & \\
\hline $\begin{array}{l}\text { ST.inf.06 If he/she represents some } \\
\text { minority (ex.: indians/native people, } \\
\text { immigrants, gays/LGBT, disabled people } \\
\text { etc.). }\end{array}$ & & .422 & & & .586 & \\
\hline ST.inf.07 His/her religion & & & .807 & & .649 & \\
\hline $\begin{array}{l}\text { ST.inf.08 The parliamentarian's gender } \\
\text { (male/female) }\end{array}$ & & & .533 & & .558 & \\
\hline Cronbach's Alpha: & .88 & .84 & 0.62 & .88 & .77 & \\
\hline Eigenvalues & 1.16 & 1.11 & 1.02 & 4.56 & 1.37 & \\
\hline Cutoff Eigenvalue (Parallel Analysis) & & 1.07 & & & 1.08 & \\
\hline
\end{tabular}

CFA started with a dilemma: which factor structure to test? The Brazilian threefactor, or the Swedish two-factor solution? Both were tested. Table 12 presents a Goodness-of-Fit comparison between those two models. Just like Political 
Participation, each factor structure was tested in three scenarios: one for Brazil, one for Sweden and one with the two countries simultaneously.

For all models, the item ST.inf.09, "[I pay attention...] if he/she has been involved in scandals", though important, had to be removed for the achievement of acceptable fit. For subsequent analyses, the evaluation of corruption henceforth relied on the "corruption" factor, explained on the next section. Also, the item ST.inf.04, "[I pay attention to...] His/her area of expertise (...)", was removed. This item had loaded differently on Brazilian and Swedish EFA structures, and it badly compromised fit, especially for the Swedish group. Its removal was considered acceptable, as other items covered information's on parliamentarians' "résumé".

The first two-factor structure resulted on unacceptable RMSEA and chi-square over degrees of freedom ratio (Model $A$ in Table 12). After removing ST.inf.07 ("religion") and ST.inf.08 ("gender") from the Representation Trends factor, acceptable Goodness-of-Fit was achieved for a new model (see Model B in Table 12). CFI, TLI and AGFI were excellent for all scenarios. The three-factor models had poorer RMSEA and $X^{2} /$ d.f. ratio, but were still acceptable, considering that all other indices were pretty good. It is actually possible to choose between both factor structures, regarding their adequate Goodness-of-Fit. The three-factor structure was chosen, as it provides more information: ST.inf.07 and ST.inf.08 are kept, as they compose the "Personal Information" factor. This factor could be useful to predict one or more Political Participation factors - which indeed it was, as presented on Section 5.2.1.1. 
Table 12. Stereotypes on Parliamentarians, Critical Information, in Brazil and Sweden: Goodness-of-Fit indices and Power Analysis.

\begin{tabular}{|c|c|c|c|c|c|c|c|c|c|c|c|}
\hline Model $^{*}$ & Scenario & $x^{2}$ & d.f. & $x^{2} /$ d.f. & RMSEA & SRMR & CFI & TLI & AGFI & $\begin{array}{c}\text { Achieved Power } \\
(1-\beta)^{* *}\end{array}$ & $\begin{array}{l}\text { Type I error } \\
\text { alpha }\end{array}$ \\
\hline & Acceptance Criteria & -- & -- & $\begin{array}{c}\text { between } \\
1 \text { and } 5\end{array}$ & $<0.07$ & $<0.08$ & $>0.92$ & $>0.92$ & $>0.90$ & $>0.80$ & fixed at .01 \\
\hline \multirow{3}{*}{$\begin{array}{l}\text { A) } 2 \text { factors } \\
\text { Considering the Swedish factor } \\
\text { structure in EFA } \\
\text { (ST.inf.07 and ST.inf.08 loaded } \\
\text { on Representation Trends) }\end{array}$} & Brazil & 228.98 & 19 & 12.05 & .106 & .057 & .94 & .91 & .89 & .99 & .01 \\
\hline & Sweden & 140.97 & 19 & 7.42 & .086 & .049 & .96 & .94 & .93 & .99 & .01 \\
\hline & $\begin{array}{l}\text { Brazil and Sweden } \\
\text { simultaneously }\end{array}$ & 369.95 & 38 & 9.73 & .069 & .057 & .95 & .92 & .91 & 1.00 & .01 \\
\hline \multirow{3}{*}{$\begin{array}{l}\text { B) } 2 \text { factors } \\
\text { Considering the Swedish factor } \\
\text { structure in EFA } \\
\text { (removed ST.inf.07 and } \\
\text { ST.inf.08) }\end{array}$} & Brazil & 24.66 & 8 & 3.08 & .046 & .015 & .99 & .99 & .98 & 1.00 & .01 \\
\hline & Sweden & 37.80 & 8 & 4.73 & .065 & .031 & .99 & .98 & .96 & .99 & .01 \\
\hline & $\begin{array}{l}\text { Brazil and Sweden } \\
\text { simultaneously }\end{array}$ & 62.47 & 16 & 3.90 & .040 & .015 & .99 & .98 & .97 & 1.00 & .01 \\
\hline \multirow{3}{*}{$\begin{array}{l}\text { C) } 3 \text { factors } \\
\text { Considering the Brazilian factor } \\
\text { structure in EFA }\end{array}$} & Brazil & 87.49 & 17 & 5.15 & .065 & .029 & .98 & .97 & .95 & .99 & .01 \\
\hline & Sweden & 81.99 & 17 & 4.82 & .066 & .031 & .98 & .96 & .95 & .99 & .01 \\
\hline & $\begin{array}{l}\text { Brazil and Sweden } \\
\text { simultaneously }\end{array}$ & 169.48 & 34 & 4.98 & .046 & .029 & .98 & .97 & .95 & 1.00 & .01 \\
\hline \multirow{3}{*}{$\begin{array}{l}\text { D) Second-order factor is } \\
\text { introduced }\end{array}$} & Brazil & 105.53 & 18 & 5.86 & .070 & .037 & .97 & .96 & .95 & .99 & .01 \\
\hline & Sweden & 119.91 & 18 & 6.66 & .080 & .046 & .97 & .95 & .94 & .99 & .01 \\
\hline & $\begin{array}{l}\text { Brazil and Sweden } \\
\text { simultaneously }\end{array}$ & 225.45 & 36 & 6.26 & .053 & .037 & .97 & .95 & .95 & 1.00 & .01 \\
\hline
\end{tabular}

* None of the models contained items ST.inf.04 and ST.inf.09, as they compromised fit.

** Post-Hoc Power Analysis calculated with software G-Power (version 3.1.9), considering Effect Size $=0.30$. 
There was evidence of low discriminance between Representation Trends and Party-Oriented View in Brazil (see Table 13). In Sweden, the same happened between Representation Trends and Personal Information (Table 13). This can be explained under the light of EFA's decision process. It loaded Representation Trends and Personal Info items on the same factor, in Sweden. In Brazil, when a 2-factor structure was forced on EFA, Personal Information remained intact and all other items loaded on a general "politicians' résumé" factor. This might be an effect of cultural differences, as discussed on Section 5.2.1.1. Anyway, for both countries, a hidden (second-order) factor could be underlying this proximity among factors.

\begin{tabular}{|c|c|c|c|c|}
\hline & & $\begin{array}{c}\text { Party- } \\
\text { Oriented View }\end{array}$ & $\begin{array}{c}\text { Representation } \\
\text { Trends }\end{array}$ & $\begin{array}{c}\text { Personal } \\
\text { Information }\end{array}$ \\
\hline \multirow{4}{*}{ Brazil } & Rho $_{v c}$ & 0.715 & 0.524 & 0.507 \\
\hline & Party-Oriented View & & & \\
\hline & Representation Trends & 0.6561 & & \\
\hline & Personal Information & 0.1936 & 0.3249 & \\
\hline \multirow{4}{*}{ Sweden } & Rho $_{v c}$ & 0.746 & 0.469 & 0.43 \\
\hline & Party-Oriented View & & & \\
\hline & Representation Trends & 0.4624 & & \\
\hline & Personal Information & 0.1681 & 0.5776 & \\
\hline
\end{tabular}

A Second-Order Factor model was tried (Model D in Table 12; Figures 4.3 and 4.4). Chi-square ratio laid out of recommended parameters. RMSEA was acceptable for Brazil, marginally bad for Sweden and good for the simultaneous scenario. Chisquare and RMSEA maladjustment is attributed to the increase of model complexity. On the other hand, SRMR, CFI, TLI and AGFI stood comfortably inside parameters, indicating that the existing paths truly contribute to the model. At last, there is enough evidence of Second-Order Factor model adequacy. Furthermore, the introduction of the 
second-order factor allows a more parsimonious explanation, concerning the extent of attention the participants pay to information about parliamentarians. A low score on that "Critical Information" factor would indicate that the participant usually ignores information about politicians; on the opposite direction, a high score would indicate that the participant really tries to understand the politician's profile.

The well-fitted Second-order factor model (Model D in Table 12) on the simultaneous scenario is an evidence of Factor Structure Equivalence. When factor loadings were constrained to be the same for both countries, all Goodness-of-Fit indices remained inside the acceptance parameters (except chi-square, which was already out of parameters on the baseline model - see Table 14). This is considered enough evidence of Metric Equivalence, as explained at Section 3.3.3.2. The CFI deterioration $(\triangle \mathrm{CFI})$ was -0.003 , inside 0.01 cutoff criteria - hence, an additional evidence of Metric Equivalence. Chi-square discrepancy test $\left(\Delta X^{2}\right)$ showed significant deterioration, but it was disregarded - as explained on Section 2.5.3, this is an oversensitive test, and it tends to reject even good models. In conclusion, Metric Equivalence was achieved, considering the evidence of good fit, as previously explained.

Table 14. Stereotypes on Parliamentarians, Critical Information: Tests of Equivalence.

\begin{tabular}{|c|c|c|c|c|c|c|c|c|c|c|c|}
\hline Model & Scenario & $x^{2}$ & d.f. & $X^{2} /$ d.f. & RMSEA & SRMR & CFI & TLI & AGFI & $\Delta X^{2}\left({ }^{*}\right)$ & $\Delta \mathrm{CFI}^{*}$ \\
\hline \multicolumn{2}{|c|}{ Acceptance Criteria: } & -- & -- & $\begin{array}{c}\text { between } \\
1 \text { and } 5\end{array}$ & $<0.07$ & $<0.08$ & $>0.92$ & $>0.92$ & $>0.90$ & $p>0.05$ & $<|0.01|$ \\
\hline Unconstrained & $\begin{array}{l}\text { Brazil } \\
\text { \#Sweden }\end{array}$ & 225.45 & 36 & 6.26 & .053 & .0366 & .971 & .955 & .946 & & \\
\hline $\begin{array}{l}\text { Metric } \\
\text { Equivalence } \\
\text { Constrained } \\
\text { factor loadings }\end{array}$ & $\begin{array}{l}\text { Brazil = } \\
\text { Sweden }\end{array}$ & 254.28 & 43 & 5.91 & .051 & .0414 & .968 & .958 & .948 & $p<0.001$ & -.003 \\
\hline
\end{tabular}

* Comparing to the Unconstrained model. 


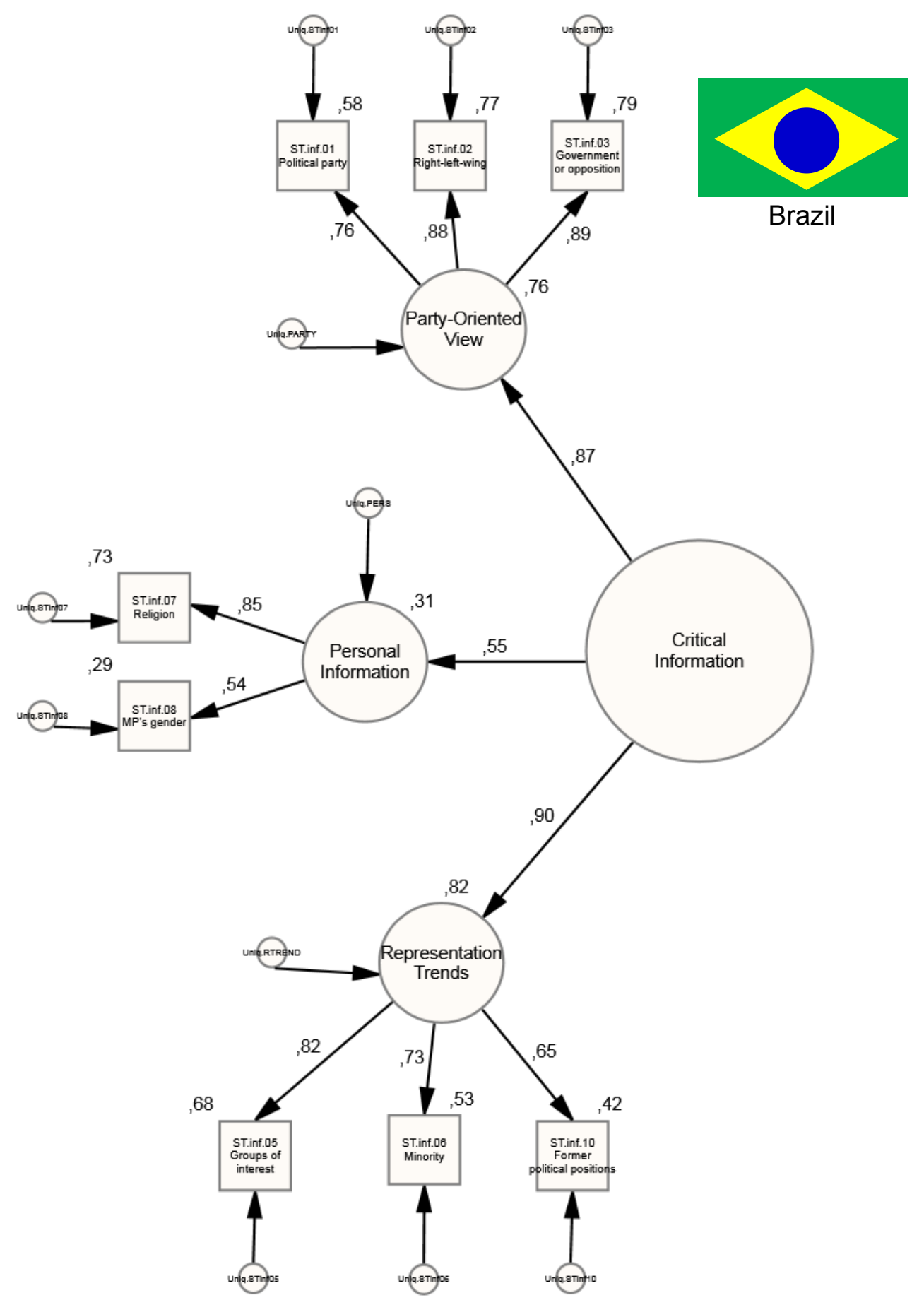

Figure 4.3. Critical Information factor structure for Brazil, with Second-order factor (Model D in Table 12). 


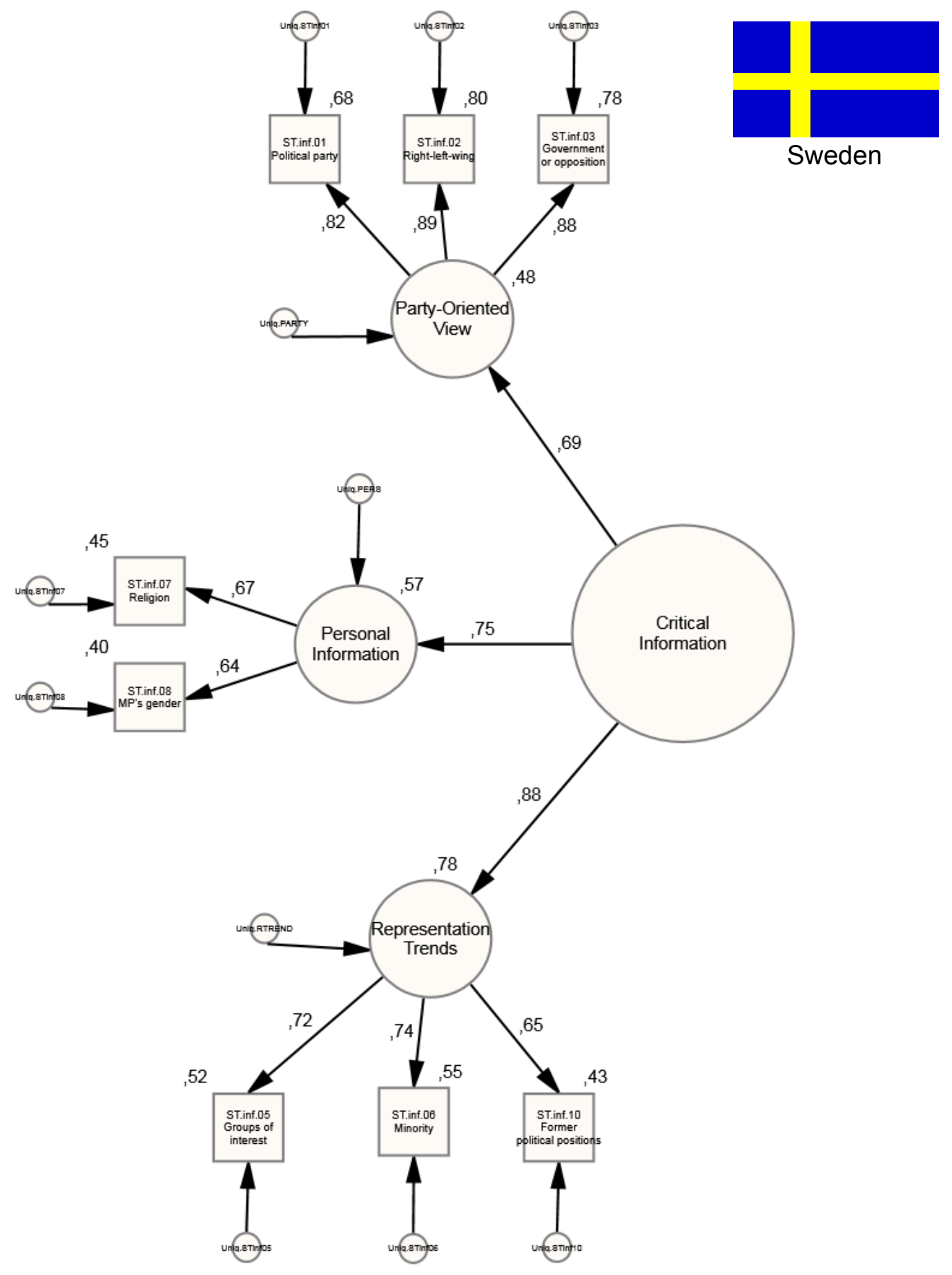

Figure 4.4. Critical Information factor structure for Sweden, with Second-order factor (Model D in Table 12). 
Internal consistency (Jöreskog's Rho column in Table 15) was good for all factors, for both countries (ranging from 0.60 to 0.90 ). Convergent validity as met for all factors (see Rhovc columns at Table 15).

Table 15. Critical Information: Internal Consistency and Convergent Validity

\begin{tabular}{lcccc}
\hline & \multicolumn{2}{c}{ Brazil } & \multicolumn{2}{c}{ Sweden } \\
\hline & $\begin{array}{c}\text { Jöreskog's } \\
\text { Rho }\end{array}$ & $\begin{array}{c}\text { Convergent } \\
\text { Validity } \\
\text { Rhovc }\end{array}$ & $\begin{array}{c}\text { Jöreskog's } \\
\text { Rho }\end{array}$ & $\begin{array}{c}\text { Convergent } \\
\text { Validity } \\
\text { Rhovc }\end{array}$ \\
\hline $\begin{array}{l}\text { Acceptance Criteria } \\
\text { Critical Information }\end{array}$ & 0.60 & $>0.30$ & $>0.60$ & $>0.30$ \\
$\begin{array}{l}\text { Second-Order) } \\
\text { Party-Oriented View }\end{array}$ & .83 & .62 & .82 & .60 \\
$\begin{array}{l}\text { Representation Trends } \\
\begin{array}{l}\text { Personal Information } \\
\text { Rer }\end{array}\end{array}$ & .78 & .71 & .90 & .75 \\
\hline
\end{tabular}

\subsubsection{Behavior Prediction}

The composition of the Behavior Prediction factor was exactly the same for Brazil and Sweden, with very good factorability $(\mathrm{KMO}=0.91$ for both countries, see Table 16). A two-factor solution was met, just as recommended by Parallel Analysis. The first factor was named Quality of Representation, as it grouped items that evaluated parliamentarians' work, with a positive trend. Cronbach's alpha for this factor was 0.89 for Brazil and 0.91 for Sweden; very good in both cases. The second factor

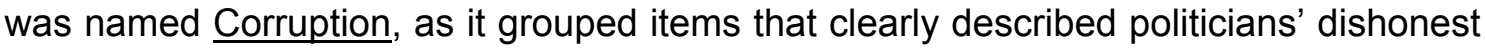
actions. Cronbach's alpha for this factor was acceptable for Sweden $(\alpha=0.74)$, but low for Brazil $(\alpha=0.56)$. This inflicted the decision to keep the Corruption factor or to force a one-factor solution for Brazil. 


\begin{tabular}{|c|c|c|c|c|}
\hline \multirow{3}{*}{ Items } & \multicolumn{4}{|c|}{ Factor Structure Coefficients (“loadings”)* } \\
\hline & \multicolumn{2}{|c|}{$\begin{array}{c}\text { Brazil } \\
(\mathrm{KMO}=0,91)\end{array}$} & \multicolumn{2}{|c|}{$\begin{array}{c}\text { Sweden } \\
(\mathrm{KMO}=0,91)\end{array}$} \\
\hline & $\begin{array}{c}\text { Factor 1: } \\
\text { Quality of } \\
\text { Representation }\end{array}$ & $\begin{array}{l}\text { Factor 2: } \\
\text { Corruption }\end{array}$ & $\begin{array}{c}\text { Factor 1: } \\
\text { Quality of } \\
\text { Representation }\end{array}$ & $\begin{array}{l}\text { Factor 2: } \\
\text { Corruption }\end{array}$ \\
\hline $\begin{array}{l}\text { ST.beh.08 They create laws beneficial to } \\
\text { the country (They adopt laws beneficial } \\
\text { to the country) }\end{array}$ & .786 & & .780 & \\
\hline $\begin{array}{l}\text { ST.beh. } 11 \text { They work for a fairer income } \\
\text { distribution among [Brazilians/Swedes] }\end{array}$ & .751 & & .617 & \\
\hline $\begin{array}{l}\text { ST.beh. } 05 \text { They make good use of } \\
\text { budget to improve services (schools, } \\
\text { hospitals, police) for the people }\end{array}$ & .740 & & .743 & \\
\hline $\begin{array}{l}\text { ST.beh.06 They accomplish the } \\
\text { promises they make while in electoral } \\
\text { campaign }\end{array}$ & .705 & & .714 & \\
\hline $\begin{array}{l}\text { ST.beh. } 09 \text { They do a good job on } \\
\text { representing [my country] }\end{array}$ & 699 & & .753 & \\
\hline $\begin{array}{l}\text { ST.beh. } 12 \text { They represent their } \\
\text { constituents }\end{array}$ & 690 & & .766 & \\
\hline $\begin{array}{l}\text { ST.beh. } 01 \text { They represent my interests } \\
\text { as a citizen }\end{array}$ & .677 & & .740 & \\
\hline $\begin{array}{l}\text { ST.beh. } 04 \text { They contribute for the } \\
\text { sustainable development }\end{array}$ & .641 & & .697 & \\
\hline $\begin{array}{l}\text { ST.beh. } 07 \text { They behave coherently to } \\
\text { their parties }\end{array}$ & .565 & & .542 & \\
\hline $\begin{array}{l}\text { ST.beh.03 They help their own friends } \\
\text { and family to achieve important positions } \\
\text { (they practice nepotism) }\end{array}$ & & .653 & & .890 \\
\hline $\begin{array}{l}\text { ST.beh. } 02 \text { They favor companies over } \\
\text { the interests of citizens }\end{array}$ & & .508 & & 692 \\
\hline $\begin{array}{l}\text { ST.beh. } 10 \text { They use public money for } \\
\text { their private interests }\end{array}$ & & .487 & & .443 \\
\hline Cronbach's Alpha: & .89 & .56 & .91 & .74 \\
\hline Eigenvalues & 5.13 & 1.55 & 5.96 & 1.41 \\
\hline Cutoff Eigenvalue (Parallel Analysis) & \multicolumn{2}{|c|}{1.10} & \multicolumn{2}{|c|}{1.10} \\
\hline
\end{tabular}

\footnotetext{
* Items loaded on two factors had their lower loads suppressed.
}

It was decided to keep the Corruption factor, considering that it is extremely important to assess participants' impressions on the parliamentarians' behavior - using a "positive" and a "negative" evaluation factor would certainly be more useful than just using a single-factor evaluation. This factor structure was then submitted to CFA, as explained below. 
CFA started by reproducing the two-factor structure found with EFA. The examination of Modification Indices and Standardized Residual Covariances suggested the exclusion of these items, in order to improve Goodness-of-Fit:

a) ST.beh.02 They favor companies over the interests of citizens

b) ST.beh.06 They accomplish the promises they make while in electoral campaign

c) ST.beh.07 They behave coherently to their parties

d) ST.beh.09 They do a good job on representing [my country]

Re-insertion attempts for these items have failed, as they unacceptably compromised fit. An adequate two-factor model for Brazil and for Sweden was found (see Figures 4.5 and 4.6). Goodness-of-Fit indices showed that the model is strongly consistent, as RMSEA and SRMR were far below and CFI, TLI and AGFI were far above the cutoff criteria for Brazil, Sweden and for the Combined model (see Table 17). Chi-square over degrees of freedom ratio was also very adequate in all three conditions.

Table 17. Parliamentarians' Behavior Prediction: Goodness-of-Fit indices and Power Analysis.

\begin{tabular}{lcccccccccc}
\hline \multicolumn{1}{c}{ Scenario } & $\boldsymbol{X}^{2}$ & d.f. & $\boldsymbol{X}^{2} /$ d.f. & RMSEA & SRMR & CFI & TLI & AGFI & $\begin{array}{c}\text { Achieved } \\
\text { Power } \\
(\mathbf{1}-\boldsymbol{\beta})^{*}\end{array}$ & $\begin{array}{c}\text { Type I } \\
\text { error } \\
\text { alpha }\end{array}$ \\
\hline $\begin{array}{l}\text { Acceptance } \\
\text { Criteria }\end{array}$ & -- & -- & $\begin{array}{c}\text { between } \\
1 \text { and } 5\end{array}$ & $<0.07$ & $<0.08$ & $>0.92$ & $>0.92$ & $>0.90$ & $>0.80$ & $f i x e d$ at \\
$\begin{array}{l}\text { Brazil } \\
\text { Sweden }\end{array}$ & 34.07 & 13 & 2.62 & .041 & .022 & .99 & .98 & .98 & .99 & .01 \\
$\begin{array}{l}\text { Brazil and } \\
\text { Sweden }\end{array}$ & 37.84 & 13 & 2.91 & .047 & .020 & .99 & .98 & .97 & .99 & .01 \\
Simultaneously & 71.91 & 26 & 2.77 & .031 & .020 & .99 & .98 & .98 & 1.00 & .01 \\
\hline
\end{tabular}

* Post-Hoc Power Analysis calculated with software G-Power (version 3.1.9), considering Effect Size = 0.30.

"Quality of Representation" factor showed very good internal consistency (Table 18) and convergence for Brazil (Jöreskog's Rho $=0.84 ;$ Rhovc $=0.51$ ) and for Sweden (Jöreskog's Rho $=0.86$; Rhovc $=0.56$ ). "Corruption" also showed very good internal consistency and convergence for Sweden (Jöreskog's Rho $=0.81 ;$ Rhovc $=$ 
0.68), but acceptable consistency (Jöreskog's Rho $=0.62)$ and convergence $($ Rhovc $=$ 0.48) for Brazil.

Table 18. Parliamentarians' Behavior Prediction: Internal Consistency and Convergent Validity

\begin{tabular}{lcccc}
\hline & \multicolumn{2}{c}{ Brazil } & \multicolumn{2}{c}{ Sweden } \\
\hline & $\begin{array}{l}\text { Jöreskog's } \\
\text { Rho }\end{array}$ & $\begin{array}{c}\text { Convergent } \\
\text { Validity } \\
\text { Rhovc }\end{array}$ & $\begin{array}{c}\text { Jöreskog's } \\
\text { Rho }\end{array}$ & $\begin{array}{c}\text { Convergent } \\
\text { Validity } \\
\text { Rhovc }\end{array}$ \\
\hline $\begin{array}{l}\text { Acceptance Criteria } \\
\begin{array}{l}\text { Quality of } \\
\text { representation }\end{array}\end{array}$ & $>0.60$ & $>0.30$ & $>0.60$ & $>0.30$ \\
\begin{tabular}{l} 
Corruption \\
\hline
\end{tabular} & .84 & .51 & .86 & .56 \\
\hline
\end{tabular}

Brazil
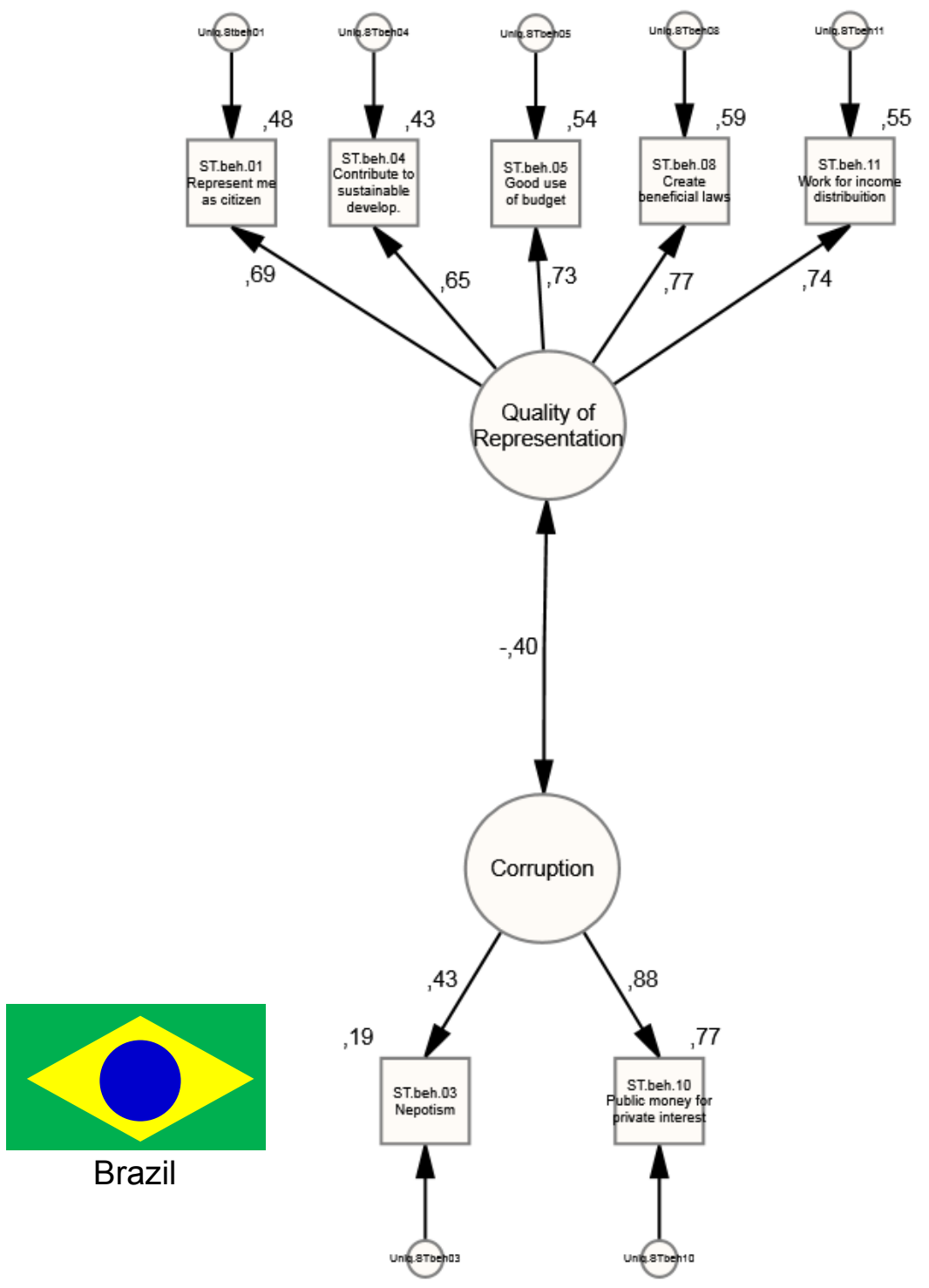

Figure 4.5. Behavior Prediction factor structure for Brazil. 


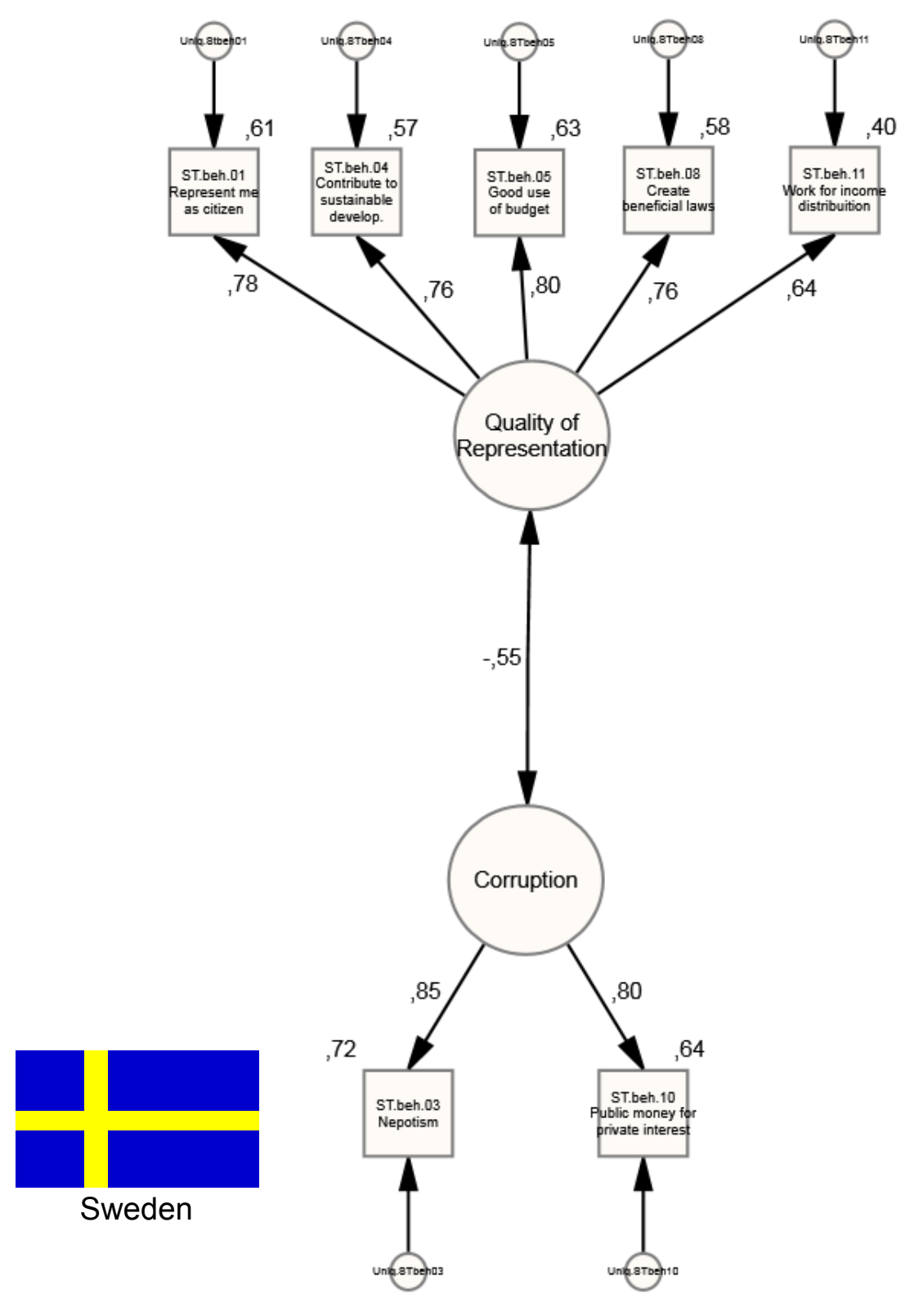

Figure 4.6. Behavior Prediction factor structure for Sweden.

It is noteworthy that there is a negative covariance between the two factors, which emphasizes that they have opposite trends - Quality of Representation stands for a positive evaluation of parliamentarians' behaviors, Corruption stands for a negative evaluation. This negative covariance had a considerable value (-.40 for Brazil, - .55 for Sweden), but discriminance validity test showed adequate separation between 
these two factors (see Table 19 and Figures 4.5 and 4.6). Hence, it would be inadequate to test a second-order factor.

Table 19. Values in italics indicate low discriminance (they are above Rho $\mathrm{vc}_{\mathrm{vc}}$ for each factor).

\begin{tabular}{cccc}
\hline & & Quality of Representation & Corruption \\
\hline \multirow{2}{*}{ Brazil } & Quality of Representation & .514 & .480 \\
& Corruption & & \\
\hline \multirow{2}{*}{ Sweden } & Rho & .680 & \\
& Quality of Representation & .563 & \\
\hline & Corruption & .302 & \\
\hline
\end{tabular}

Table 20. Stereotypes on Parliamentarians, Behavior Prediction: Test of Metric Equivalence.

\begin{tabular}{|c|c|c|c|c|c|c|c|c|c|c|c|}
\hline Model & Scenario & $x^{2}$ & d.f. & $X^{2} /$ d.f. & RMSEA & SRMR & CFI & TLI & AGFI & $\Delta X^{2}(*)$ & $\Delta \mathrm{CFI}^{*}$ \\
\hline \multicolumn{2}{|c|}{ Acceptance Criteria: } & -- & -- & $\begin{array}{c}\text { between } \\
1 \text { and } 5\end{array}$ & $<0.07$ & $<0.08$ & $>0.92$ & $>0.92$ & $>0.90$ & $p>.0 .05$ & $<|0.01|$ \\
\hline Unconstrained & $\begin{array}{l}\text { Brazil } \\
\text { \#Sweden }\end{array}$ & 71.91 & 26 & 2.77 & .031 & .0205 & .990 & .984 & .976 & & \\
\hline $\begin{array}{l}\text { Metric } \\
\text { Equivalence, } \\
\text { Constrained } \\
\text { factor loadings }\end{array}$ & $\begin{array}{l}\text { Brazil = } \\
\text { Sweden }\end{array}$ & 106.61 & 31 & 3.44 & .036 & .0258 & .984 & .978 & .971 & $p<0.001$ & -.006 \\
\hline
\end{tabular}

* Comparing the Unconstrained model.

The well-fitted model on the simultaneous scenario suggests Factor Structure Equivalence between Brazil and Sweden (Table 17). Constraining all factor loadings to be equal for both countries resulted on a still adequate model (see Constrained Factor Loadings model in Table 20). Chi-square deterioration $\left(\Delta X^{2}\right)$ was significant $(p<$ 0.001 ), but it was disregarded for its known oversensitivity. Enough evidence of Metric Equivalence was found, since Constrained Factor Loadings model achieved good fit. CFI deterioration $(\triangle \mathrm{CFI}=-.006)$ was below the 0.01 threshold, which was considered an additional evidence of Metric Equivalence. The achievement of Factor and Metric 
equivalences indicates that these items' compounds are adequate to comparative test between Brazil and Sweden.

\subsubsection{A General Model for Stereotypes on Parliamentarians}

After solving the factor structure for Critical Information and Behavior Prediction, a general model for Stereotypes on Parliamentarians was made (see Figures 4.7 and 4.8). The General Model for Stereotypes on Parliamentarians achieved excellent fit on all scenarios: Brazil, Sweden and Combined models (see Table 21). Power Analysis indicated that it is highly unlikely to commit Type II error. The Corruption Factor showed little improvement on Internal consistency and Convergent validity at the general model (see Table 22).

The simultaneous model's very good fit indicates Factor Structure Equivalence. When all factor loadings were constrained to be equal for Brazil and Sweden (see Table 23), all Goodness-of-Fit indices were comfortably adjusted to parameters. CFI deterioration $(\triangle \mathrm{CFI}=-0.005)$ laid inside the 0.01 threshold, offering additional evidence of Metric Equivalence. Chi-square resulted significant $(p<0.001)$, but it was disregarded, for its oversensitivity. At last, the General Model for Stereotypes about Parliamentarians was considered satisfactory for the subsequent analysis.

Table 21. General Model for Stereotypes on Parliamentarians: Goodness-of-Fit indices and Power Analysis.

\begin{tabular}{|c|c|c|c|c|c|c|c|c|c|c|}
\hline Scenario & $x^{2}$ & d.f. & $x^{2} /$ d.f. & RMSEA & SRMR & CFI & TLI & AGFI & $\begin{array}{c}\text { Achieved } \\
\text { Power } \\
(1-\beta)^{*}\end{array}$ & $\begin{array}{l}\text { Type I } \\
\text { error } \\
\text { alpha }\end{array}$ \\
\hline $\begin{array}{l}\text { Acceptance } \\
\text { Criteria }\end{array}$ & -- & -- & $\begin{array}{c}\text { between } \\
1 \text { and } 5\end{array}$ & $<0.07$ & $<0.08$ & $>0.92$ & $>0.92$ & $>0.90$ & $>0.80$ & $\begin{array}{c}\text { fixed at } \\
.01\end{array}$ \\
\hline Brazil & 234.67 & 85 & 2.76 & .042 & .039 & .97 & .97 & .96 & .99 & .01 \\
\hline Sweden & 245.80 & 85 & 2.89 & .046 & .041 & .97 & .96 & .95 & .99 & .01 \\
\hline $\begin{array}{l}\text { Brazil and } \\
\text { Sweden } \\
\text { simultaneously }\end{array}$ & 480.48 & 170 & 2.83 & .031 & .039 & .97 & .97 & .95 & .99 & .01 \\
\hline
\end{tabular}

${ }^{*}$ Post-Hoc Power Analysis calculated with software G-Power (version 3.1.9), considering Effect Size = 0.30. 


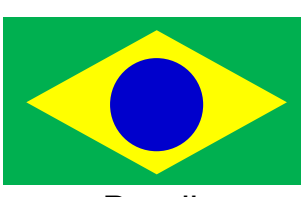

Brazil

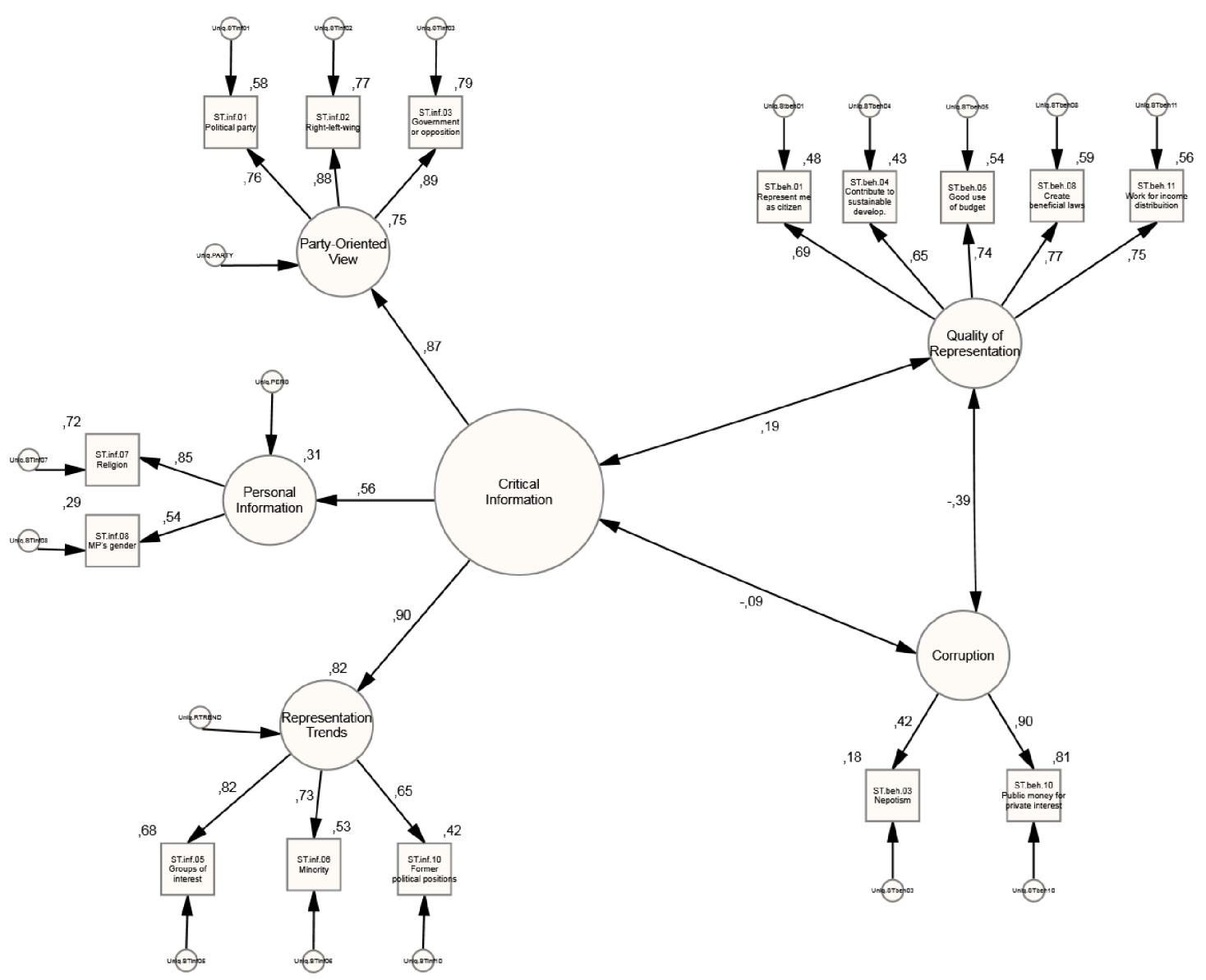

Figure 4.7. General Model for Stereotypes about Parliamentarians - Brazil. 

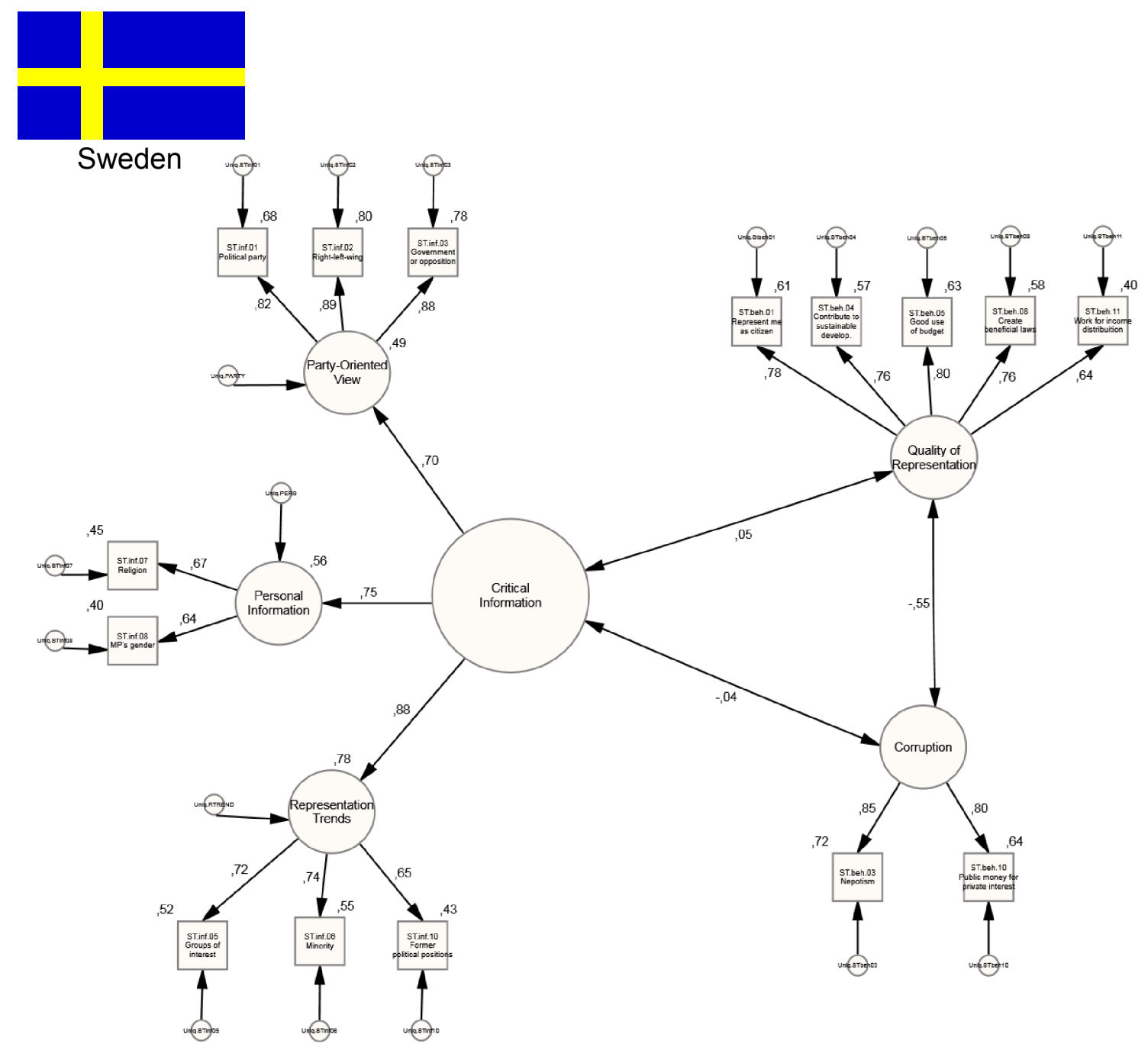

Figure 4.8. General Model for Stereotypes about Parliamentarians - Sweden. 
Table 22. General Model for Stereotypes on Parliamentarians: Internal Consistency and Convergent Validity

\begin{tabular}{|c|c|c|c|c|c|}
\hline \multirow[t]{2}{*}{$\begin{array}{l}\text { Stereotype } \\
\text { Component }\end{array}$} & Factor & $\begin{array}{c}\text { Jöreskog's } \\
\text { Rho }\end{array}$ & $\begin{array}{l}\text { Convergent } \\
\text { Validity } \\
\text { Rhovc }\end{array}$ & $\begin{array}{c}\text { Jöreskog's } \\
\text { Rho }\end{array}$ & $\begin{array}{c}\text { Convergent } \\
\text { Validity } \\
\text { Rhovc }\end{array}$ \\
\hline & Acceptance Criteria & $>0.60$ & $>0.30$ & $>0.60$ & $>0.30$ \\
\hline \multirow{2}{*}{$\begin{array}{c}\text { Critical } \\
\text { Information }\end{array}$} & Party-Oriented View & .88 & .71 & .90 & .75 \\
\hline & Personal Information & .66 & .51 & .60 & .43 \\
\hline \multirow{2}{*}{$\begin{array}{l}\text { Behavior } \\
\text { Prediction }\end{array}$} & $\begin{array}{l}\text { Quality of } \\
\text { Representation }\end{array}$ & .84 & .52 & .86 & .56 \\
\hline & Corruption & .63 & .49 & .81 & .68 \\
\hline
\end{tabular}

Table 23. General Model for Stereotypes on Parliamentarians: Test of Metric Equivalence.

\begin{tabular}{|c|c|c|c|c|c|c|c|c|c|c|c|}
\hline Model & Scenario & $x^{2}$ & d.f. & $X^{2} /$ d.f. & RMSEA & SRMR & CFI & TLI & AGFI & $\Delta X^{2}\left(^{*}\right)$ & $\Delta \mathrm{CFI}^{*}$ \\
\hline \multicolumn{2}{|c|}{ Acceptance Criteria: } & -- & -- & $\begin{array}{c}\text { between } \\
1 \text { and } 5\end{array}$ & $<0.07$ & $<0.08$ & $>0.92$ & $>0.92$ & $>0.90$ & $p>.0 .05$ & $<|0.01|$ \\
\hline Unconstrained & $\begin{array}{l}\text { Brazil } \\
\text { (baseline) }\end{array}$ & 480.48 & 170 & 2.826 & .031 & .0388 & .973 & .966 & .955 & & \\
\hline $\begin{array}{l}\text { Constrained } \\
\text { factor } \\
\text { loadings }\end{array}$ & Brazil & 543.58 & 182 & 2.987 & .033 & .0428 & .968 & .963 & .952 & $p<0.001$ & -.005 \\
\hline
\end{tabular}

* Comparing to the baseline model - Brazil

\subsubsection{Political Education}

Seven items in the questionnaire asked participants where they had learned about politics. This is actually a self-evaluation on how much each sphere of their lives had contributed to their understanding about politics. The main purpose was to compare Formal Education (learning about politics at school) with socialization 
(learning from friends, workmates etc.), to answer the question: which of these have greatest impact on Political Participation?

EFA results surprisingly added family education to Formal Education items (learning at School and at University), for both Brazil and Sweden (see Table 24). The Socialization factor was sufficiently consistent for Brazil and Sweden (Cronbach's alpha $=0.65$ in both countries). This Formal (+Home) Education factor achieved acceptable Cronbach's alpha for Brazil (0.63) and but low for Sweden (0.53). Also, Eigenvalues for Formal (+home) Education in Sweden (0.98) was below recommended by Parallel Analysis (1.07).

\begin{tabular}{|c|c|c|c|c|}
\hline \multirow{3}{*}{ Items } & \multicolumn{4}{|c|}{ Factor Structure Coefficients (“loadings")* } \\
\hline & \multicolumn{2}{|c|}{$\begin{array}{c}\text { Brazil } \\
(\mathrm{KMO}=0,79)\end{array}$} & \multicolumn{2}{|c|}{$\begin{array}{c}\text { Sweden } \\
(\mathrm{KMO}=0,80)\end{array}$} \\
\hline & $\begin{array}{l}\text { Factor 1: } \\
\text { Socialization }\end{array}$ & $\begin{array}{l}\text { Factor 2: } \\
\text { Formal (+home) } \\
\text { Education }\end{array}$ & $\begin{array}{l}\text { Factor 1: } \\
\text { Socialization }\end{array}$ & $\begin{array}{l}\text { Factor 2: } \\
\text { Formal (+home) } \\
\text { Education }\end{array}$ \\
\hline PE.06 ... from friends & .709 & & .693 & \\
\hline PE.04 ... from coworkers & .649 & & .710 & \\
\hline $\begin{array}{l}\text { PE. } 05 \text {... from members of an } \\
\text { association / trade union / party in which } \\
\text { you are a member }\end{array}$ & .473 & & .795 & \\
\hline $\begin{array}{l}\text { PE. } 07 \text {... on your own (reading books, } \\
\text { newspapers, Internet, watching TV, } \\
\text { radio, etc.). }\end{array}$ & .364 & & .414 & \\
\hline $\begin{array}{l}\text { PE.01 ... at school (primary school - 1st } \\
\text { grade, or high school - 2nd grade) }\end{array}$ & & 695 & & .876 \\
\hline PE.02 "...at University" & & .524 & & .545 \\
\hline PE.03 ... from your family & & .454 & & .552 \\
\hline Cronbach's Alpha: & .65 & .63 & .65 & .53 \\
\hline Eigenvalues & 2.70 & 1.08 & 2.74 & .98 \\
\hline Cutoff Eigenvalue (Parallel Analysis) & \multicolumn{2}{|c|}{1.03} & \multicolumn{2}{|c|}{1.07} \\
\hline
\end{tabular}


In order to perform CFA, the Swedish factor structure was kept unchanged, as it was directly comparable to the Brazilian one. Also, it would be primarily relevant to maintain these two factors separate (instead of forcing a one-factor solution), as they are useful to compare the influence of different learning contexts on Political Participation. The two-factor structure was tested in CFA. Goodness of Fit indices indicated adequate fit for all scenarios (Model A in Table 25). However, improvements were needed, concerning low internal consistency and convergent/discriminant validity.

At CFA, Formal (+Home) Education had low internal consistency and low convergence for Brazil (Jöreskog's Rho $=0.55 ;$ Rho $\left._{v c}=0.29\right)$ and Sweden (Jöreskog's Rho $\left.=0.50 ; R o_{v c}=0.25\right)$. Socialization showed adequate internal consistency and acceptable convergence (Jöreskog's Rho $=0.67 ;$ Rho $_{\mathrm{vc}}=0.35$ for Brazil; Jöreskog's Rho $=0.68 ;$ Rho $_{v c}=0.42$ for Sweden), after PE.07 (“...on your own [...]”) was made a standalone item, for the improvement of the factor's internal consistency. Low convergence compromised discriminant validity, which was also low for both countries (square covariance between factors of 0.50 for Brazil, 0.61 for Sweden, above factors' Rho $_{\mathrm{vc}}$ ). Attempts to improve Formal (+Home) Education internal consistency, by removing weakly loaded items, failed.

Considering Formal (+Home) Education's low internal consistency and convergence (Jöreskog's Rho below 0.60; Rho ${ }_{\mathrm{vc}}$ below 0.30) for Brazil and Sweden, additionally with its low eigenvalue for Sweden, this factor was disentangled, and its items were considered standalones. It was considered that all three contexts grouped under this factor were empirically too different to be considered in the same compound. In other words, this factor was not consistent enough to function as a substitute of its items; therefore, for further analyses items will be considered separately. 
Table 25. Political Education: Goodness-of-Fit indices and Power Analysis

\begin{tabular}{|c|c|c|c|c|c|c|c|c|c|c|c|}
\hline Model & Scenario & $x^{2}$ & d.f. & $x^{2} /$ d.f. & RMSEA & SRMR & CFI & TLI & AGFI & $\begin{array}{c}\text { Achieved } \\
\text { Power } \\
(1-\beta)^{*}\end{array}$ & $\begin{array}{l}\text { Type I } \\
\text { error } \\
\text { alpha }\end{array}$ \\
\hline & Acceptance Criteria: & -- & -- & $\begin{array}{c}\text { between } \\
1 \text { and } 5\end{array}$ & $<0.07$ & $<0.08$ & $>0.92$ & $>0.92$ & $>0.90$ & $>0.80$ & $\begin{array}{l}\text { fixed at } \\
.01\end{array}$ \\
\hline \multirow{3}{*}{$\begin{array}{l}\text { A) Two-Factor, } \\
\text { Removed PE.07 }\end{array}$} & Brazil & 51.84 & 12 & 4.32 & .058 & .033 & .96 & .93 & .97 & 1.00 & .01 \\
\hline & Sweden & 55.80 & 12 & 4.65 & .064 & .036 & .95 & .92 & .96 & 1.00 & .01 \\
\hline & $\begin{array}{l}\text { Brazil and Sweden } \\
\text { simultaneously }\end{array}$ & 107.64 & 24 & 4.48 & .043 & .036 & .96 & .93 & .96 & 1.00 & .01 \\
\hline \multirow{3}{*}{ B) One Factor } & Brazil & 23.93 & 8 & 2.99 & .045 & .021 & .98 & .96 & .98 & 1.00 & .01 \\
\hline & Sweden & 34.53 & 8 & 4.32 & .061 & .027 & .97 & .93 & .96 & 1.00 & .01 \\
\hline & $\begin{array}{l}\text { Brazil and Sweden } \\
\text { simultaneously }\end{array}$ & 58.46 & 16 & 3.65 & .038 & .027 & .98 & .94 & .97 & 1.00 & .01 \\
\hline
\end{tabular}



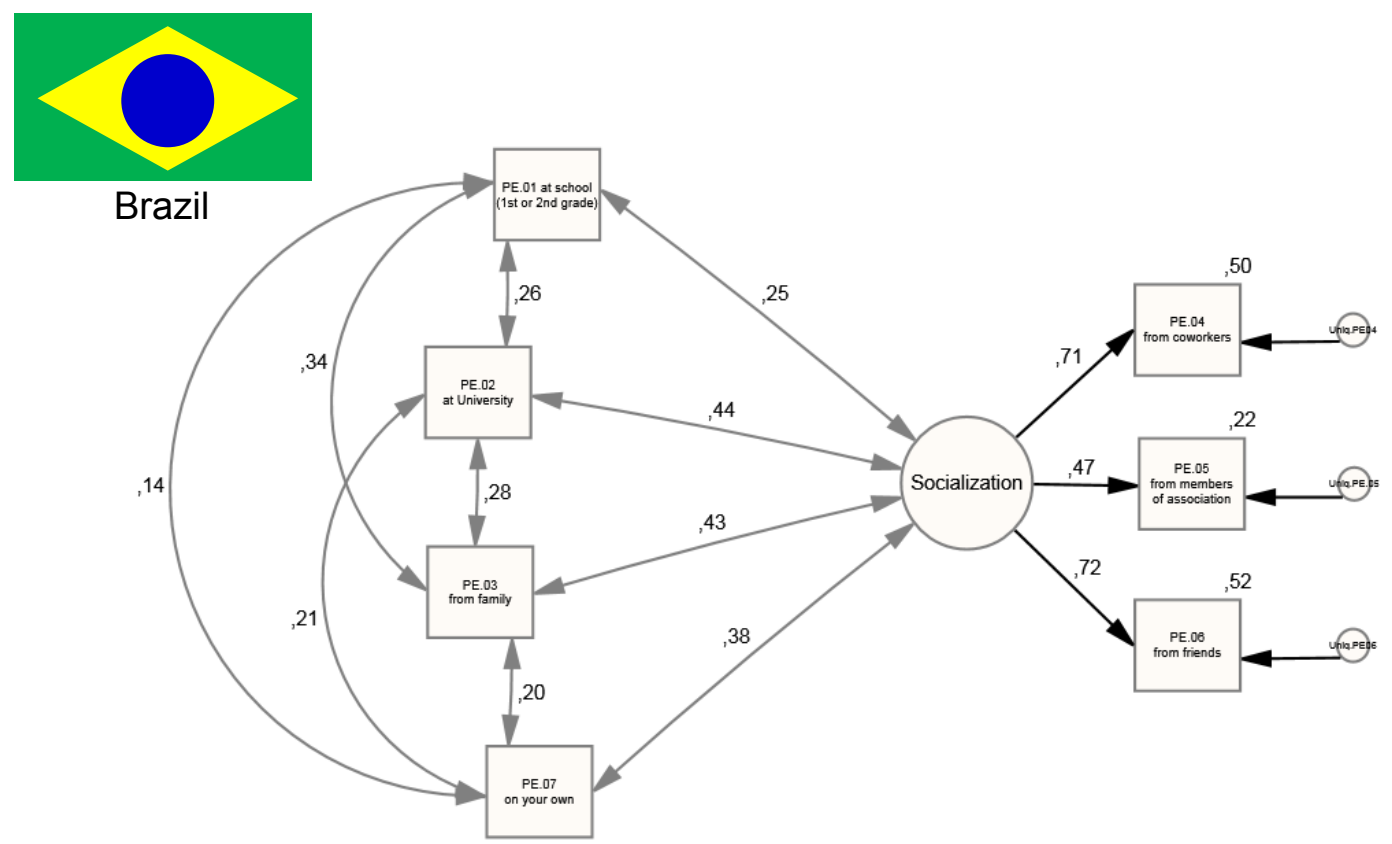

Figure 4.9. Political Education One-Factor Structure for Brazil (Model B in Table 25).

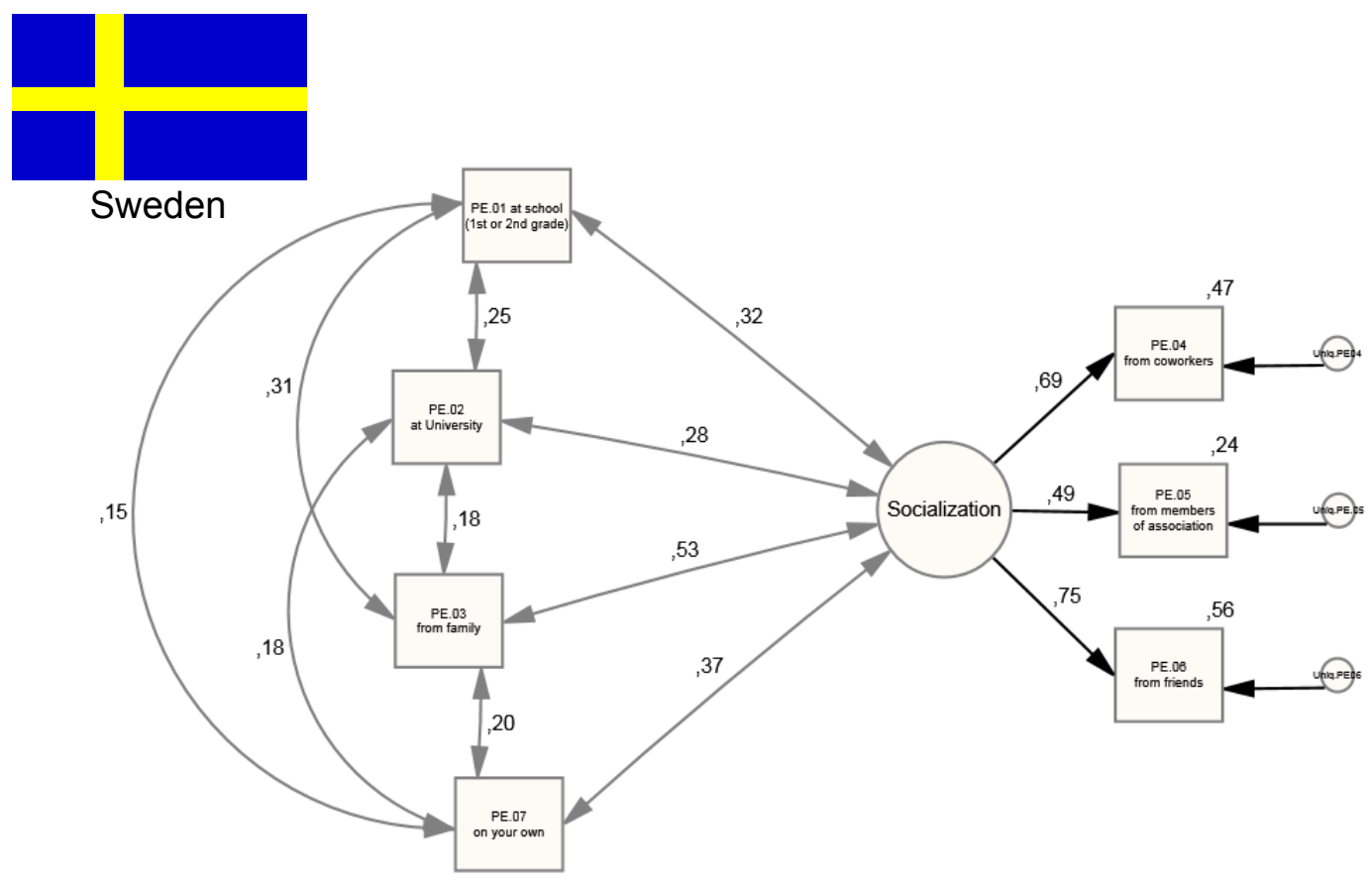

Figure 4.10. Political Education One-Factor Structure for Sweden (Model B in Table 25). 
A final model for Political Education was tested, with Socialization factor alone (Model B in Table 25, Figures 4.9 and 4.10). CFI, TLI and AGFI indicated very good fit to all scenarios, as did SRMR (below 0.030). RMSEA was pretty good for Brazil (0.045) and simultaneous (0.038), and acceptable for Sweden (0.061). Socialization's internal consistency slightly improved (Jöreskog's Rho $=0.67 ; \mathrm{Rho}_{\mathrm{vc}}=0.41$ for Brazil; Jöreskog's Rho $=0.69 ; \mathrm{Rho}_{\mathrm{vc}}=0.43$ for Sweden). The Discriminance Validity test was ignored, since this is a one-factor solution.

The simultaneous scenario's good fit (Model B in Table 25) indicates Factor Structure Equivalence. When factor loadings were constrained to be equal between groups, $X^{2} / D$.F. ratio slightly improved, as the addition of degrees of freedom (the denominator) was not accompanied by a big rise on chi-square (Table 26). This difference was not significant $(p=0.244)$. This may be explained by the "small" size of the model, as it is a one-factor solution with 3 items (hence there are not many factor loadings to constrain). Other Goodness-of-Fit indices shortly rose, as an effect of the chi-square ratio increase, which is regarded as good evidence of Metric Equivalence. The CFI variation $(\triangle \mathrm{CFI}=-0.001)$ presented extra evidence. At last, this one-factor solution is statistically adequate.

Table 26. Political Education: Test of Metric Equivalence.

\begin{tabular}{cccccccccccc}
\hline Model & Scenario & $\boldsymbol{X}^{2}$ & d.f. & $\boldsymbol{X}^{2} /$ d.f. & RMSEA & SRMR & CFI & TLI & AGFI & $\Delta \boldsymbol{X}^{2}\left(^{*}\right)$ & $\Delta$ CFI $^{*}$ \\
\hline \multicolumn{1}{c}{ Acceptance Criteria: } & -- & -- & $\begin{array}{c}\text { between } \\
1 \text { and } 5\end{array}$ & $<0.07$ & $<0.08$ & $>0.92$ & $>0.92$ & $>0.90$ & $p>0.05$ & $<|0.01|$ \\
\hline Unconstrained & $\begin{array}{l}\text { Brazil } \\
\text { FSweden }\end{array}$ & 58.46 & 16 & 3.65 & .038 & .027 & .979 & .944 & .969 & \\
$\begin{array}{l}\text { Constrained } \\
\text { factor } \\
\text { loadings }\end{array}$ & $\begin{array}{l}\text { Brazil }= \\
\text { Sweden }\end{array}$ & 61.29 & 18 & 3.40 & .036 & .028 & .978 & .949 & .971 & $p=.244$ & -.001 \\
\hline
\end{tabular}

* Comparing to the Unconstrained Model. 


\subsubsection{Behavioral Contagion}

Behavioral Contagion items intended to assess how much the participants followed someone else's influence or tried to influence others into Political Participation. It also assessed how many people close to the participant were usually engaged on Political Participation. EFA returned a one-factor structure for both countries (see Table 27), just as recommended by Parallel Analysis. It is fairly consistent $(\mathrm{KMO}=0.74$, Cronbach's alpha $=0.71$ for Brazil; $\mathrm{KMO}=0.78$, Cronbach's alpha $=0.77$ for Sweden) .

\begin{tabular}{|c|c|c|}
\hline \multirow{3}{*}{ Items } & \multicolumn{2}{|c|}{$\begin{array}{l}\text { Factor Structure Coefficients } \\
\text { ("Ioadings") }\end{array}$} \\
\hline & $\begin{array}{c}\text { Brazil } \\
(\mathrm{KMO}=0,74)\end{array}$ & $\begin{array}{c}\text { Sweden } \\
(\mathrm{KMO}=0,78)\end{array}$ \\
\hline & $\begin{array}{c}\text { Factor: } \\
\text { Behavioral } \\
\text { Contagion }\end{array}$ & $\begin{array}{c}\text { Factor: } \\
\text { Behavioral } \\
\text { Contagion }\end{array}$ \\
\hline BC.01 I usually try to convince friends to participate in political action & .72 & .70 \\
\hline BC.04 I am encouraged by people close to me to participate in politics. & .62 & .81 \\
\hline BC.02 I understand the politics of my country better than most of my friends & .54 & .61 \\
\hline $\begin{array}{l}\text { BC.03 I pay attention to the opinion of friends who are more politically active } \\
\text { than I am }\end{array}$ & .52 & 63 \\
\hline $\begin{array}{l}\text { BC. } 05 \text { How big a share of your friends/relatives usually take part in political } \\
\text { activities (approximately)? }\end{array}$ & .46 & .43 \\
\hline Cronbach's Alpha: & .71 & .77 \\
\hline Eigenvalues: & 2.31 & 2.63 \\
\hline Cutoff Eigenvalue (Parallel Analysis): & 1.04 & 1.04 \\
\hline
\end{tabular}

The one-factor structure was confirmed at CFA. However, the item BC.02 "I understand the politics of my country better than most of my friends" was removed (Figures 4.11 and 4.12). It was intended to assess if knowing about politics had something to do with influencing people or following their influence (Delli Carpini \& Keeter, 1996; Luskin, Fishkin \& Jowell, 2002). This item dramatically compromised fit. 
Theoretical reasons why this item dropped out of the factor are discussed on Section 5.3.4.

This factor structure without BC.02 achieved very good fit in all scenarios (Brazil, Sweden and Combined, see Table 28), notably an almost perfect fit for Sweden. Power Analysis strongly removed the possibility of Type II error. Behavioral Contagion showed acceptable internal consistency (Jöreskog's Rho $=0.67$ for Brazil, 0.75 for Sweden) and Convergent Validity (Rhovc $=0.35$ for Brazil, 0.44 for Sweden). The Discriminant Validity test was ignored, as this is a one-factor structure.

Table 28. Behavioral Contagion: Goodness-of-Fit indices and Power Analysis.

\begin{tabular}{|c|c|c|c|c|c|c|c|c|c|c|}
\hline Scenario & $x^{2}$ & d.f. & $X^{2} /$ d.f. & RMSEA & SRMR & CFI & TLI & AGFI & $\begin{array}{c}\text { Achieved } \\
\text { Power } \\
(1-\beta)^{*}\end{array}$ & $\begin{array}{l}\text { Type I } \\
\text { error } \\
\text { alpha }\end{array}$ \\
\hline Acceptance Criteria & -- & -- & $\begin{array}{c}\text { between } 1 \\
\text { and } 5\end{array}$ & $<0.07$ & $<0.08$ & $>0.92$ & $>0.92$ & $>0.90$ & $>0.80$ & $\begin{array}{c}\text { fixed at } \\
.01\end{array}$ \\
\hline Brazil & 9.64 & 2 & 4.82 & .062 & .022 & .99 & .96 & .97 & 1.00 & .01 \\
\hline Sweden & 2.49 & 2 & 1.24 & .017 & .011 & .99 & .99 & .99 & 1.00 & .01 \\
\hline $\begin{array}{l}\text { Brazil and Sweden } \\
\text { simultaneously }\end{array}$ & 12.12 & 4 & 3.03 & .033 & .022 & .99 & .98 & .98 & 1.00 & .01 \\
\hline
\end{tabular}

* Post-Hoc Power Analysis calculated with software G-Power (version 3.1.9), considering Effect Size = 0.30.

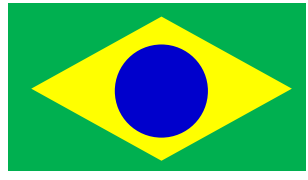

Brazil

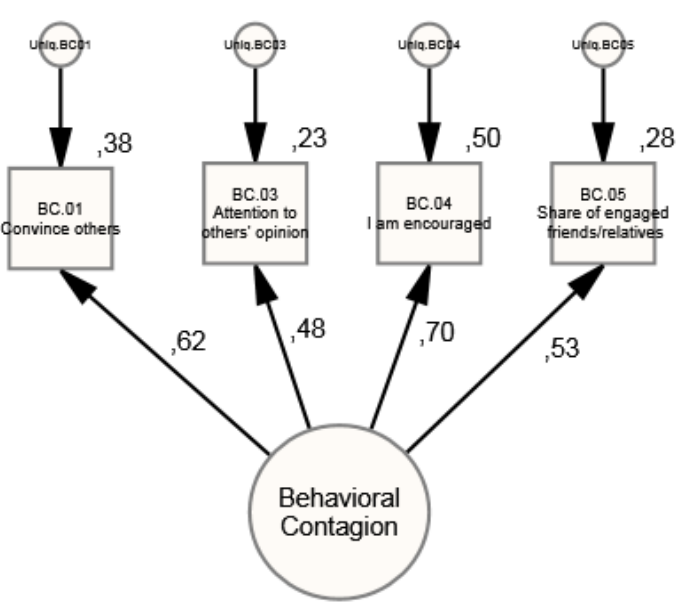

Figure 4.11. Behavioral Contagion factor structure - Brazil. 


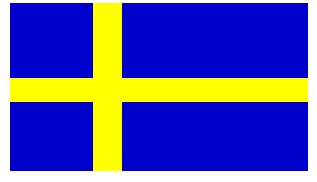

Sweden

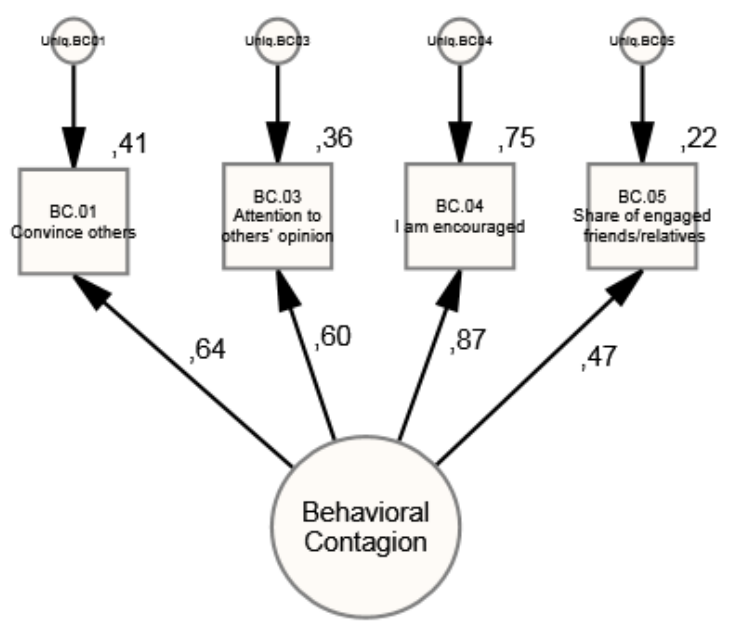

Figure 4.12. Behavioral Contagion factor structure - Sweden.

Simultaneous scenario's good fit (Table 28) indicates Factor Structure Equivalence. Factor loadings were constrained to be equal for both countries, to perform the Metric Equivalence test. It was found that the item BC.03 ("I pay attention to the opinion of friends who are more politically active than I am") compromised equivalence, thus it was left unconstrained. According to Hair et al. (2009), Metric Equivalence test is actually rigorous, and demonstrating partial equivalence - by constraining at least two items per factor - is adequate. All constrained model's Goodness-of-Fit indices were comfortably adjusted (see Table 29), suggesting Metric Equivalence. The significant result of Chi-square deterioration $\left(\Delta X^{2}\right)$ was unheeded for its oversensitivity. $\mathrm{CFI}$ deterioration $(\triangle \mathrm{CFI}=-0.01)$ offered additional evidence of equivalence. Therefore, partial Metric Equivalence was met for Behavioral Contagion. 
Table 29. Behavioral Contagion: Test of Metric Equivalence.

\begin{tabular}{|c|c|c|c|c|c|c|c|c|c|c|c|}
\hline Model & Scenario & $x^{2}$ & d.f. & $X^{2} /$ d.f. & RMSEA & SRMR & CFI & TLI & AGFI & $\Delta X^{2}\left(^{*}\right)$ & $\Delta \mathrm{CFI}^{*}$ \\
\hline \multicolumn{2}{|c|}{ Acceptance Criteria: } & -- & -- & $\begin{array}{c}\text { between } \\
1 \text { and } 5\end{array}$ & $<0.07$ & $<0.08$ & $>0.92$ & $>0.92$ & $>0.90$ & $p>.0 .05$ & $<|0.01|$ \\
\hline Unconstrained & $\begin{array}{l}\text { Brazil } \\
\text { fSweden }\end{array}$ & 12.12 & 4 & 3.03 & .033 & .0216 & .994 & .982 & .983 & & \\
\hline $\begin{array}{l}\text { Metric } \\
\text { Equivalence } \\
\text { Constrained } \\
\text { factor } \\
\text { loadings }\end{array}$ & $\begin{array}{l}\text { Brazil = } \\
\text { Sweden }\end{array}$ & 27.59 & 6 & 4.60 & .044 & .0346 & .984 & .968 & .976 & $p<0.001$ & -.010 \\
\hline
\end{tabular}

Behavioral Contagion's one-factor structure gathered items on influencing others, following others' influence and the amount of politically engaged people nearby the participant. It can be regarded as a measure of how much the individual is integrated to a politically active network.

\subsection{Variables' mean differences between Brazil and}

\section{Sweden}

As Factor Structure Equivalence and Metric Equivalence were demonstrated on CFAs, differences between Brazil and Sweden can now be assessed. Factor scores were calculated, considering the factor structure for each variable, as explained on the previous section. This research's variables are henceforth referred to as compounds of their factor structures and standalone items. Independent samples t-test was conducted to compare means between Brazil and Sweden.

Regarding Stereotypes about Parliamentarians, there is no significant difference on the general attention Brazilians $(M=4.61, S D=2.37)^{14}$ and Swedes $(M=4.59,2.69)$

\footnotetext{
${ }^{14}$ Mean and Standard Deviation. Scores range from zero to 10 ; the same goes for their means.
} 
pay to the Critical Information, considering its second-order factor scores; $t(1861.59)=0.17, p=0.866^{15}$. However, they differ on the specific factors. Swedes $(M=5.96, S D=3.04)$ pay more attention than Brazilians $(M=5.63, S D=3.34)$ to Partyrelated information (considering Party-Oriented View factor score); $\mathrm{t}(1860.35)=2.20$, $\mathrm{p}=0.028$. Otherwise, Brazilians $(\mathrm{M}=5.64, \mathrm{SD}=3.01)$ pay more attention to Representation Trends than Swedes $(M=4.07, S D=2.59) ; t(1858.83)=-12.06, p<$ 0.001. Participants from both groups seldom pay attention to Personal Information, but Brazilians $(M=2.52, S D=2.81)$ do that more often than Swedes $(M=1.93, S D=2.28)$; $t(1844.63)=5.00, p<0.001$

Quality of Representation is close to the mid-point of the scale in Sweden ( $M=$ 4.68, $S D=1.77$ ), which is significantly higher than the low quality perceived by Brazilians $(M=2.02, S D=1.36) ; t(1642.36)=36.05, p<0.001$. Corruption, on the other hand, is perceived as higher in Brazil $(M=7.41, S D=2.24)$ than in Sweden $(M=4.08$, $S D=2.62) ; t(1737.21)=29.22, p<0.001$.

Socialization is a more important locus of political learning for Brazilians ( $M=$ 4.09, $S D=2.43)$ than for Swedes $(M=3.72, S D=2.24) ; t(1858.77)=3.41, p=0.001$. Swedes $(M=5.10, S D=3.13)$ are more likely to learn about politics in elementary or secondary education than Brazilians $(M=3.05, S D=3.15) ; t(1839.39)=14.04, p<0.001$. On the other hand, Brazilians $(M=5.27, S D=3.41)$ give more importance to the learning of politics at the University than Swedes $(M=4.12, S D=3.29) ; t(1184)=-5.48, p<0.001$. On what concerns the importance of learning politics from the family, participants from Brazil $(M=4.81, S D=3.27)$ and Sweden $(M=4.79, S D=2.93)$ do not significantly differ, $t(1860.98)=0.13, p=0.899$.

The loci of political learning on the previous paragraph had moderate to low importance, when regarding their means. Learning politics on one's own (reading

\footnotetext{
${ }^{15}$ Number in parenthesis represent the degrees of freedom, followed by the result of t-test and significance ( $p$-value).
} 
books, newspapers, Internet, watching TV, radio. etc.) had bigger importance for both groups, with Brazilians $(M=7.89, S D=2.61)$ giving it more importance than Swedes $(M=$ 7.25, $\mathrm{SD}=2.60) ; \mathrm{t}(1839.15)=-5.31, \mathrm{p}<0.001$

Regarding Behavioral Contagion as a measure of belonging to a politically engaged network, Brazilians $(M=4.01, S D=2.14)$ are significantly more involved than Swedes $(M=2.49, S D=1.97) ; t(1859.13)=15.95, p<0.001$. Effects of Behavioral Contagion and the other aforementioned variables on Political Participation are discussed on the next section.

Political Disillusion is below the midpoint for both groups, but Brazilians ( $M=$ 3.19, $S D=2.75)$ are more disillusioned than Swedes $(M=2.60, S D=2.23) ; t(1843.48)=$ 5.09, $\mathrm{p}<0.001$. Participants from Brazil $(M=1.90, S D=3.07)^{16}$; more often than those from Sweden $(M=0.60, \quad S D=1.95)$, engaged in street demonstrations; $t(1687.83)=11.04, p<0.001$. The same goes for the involvement in labor union strikes (Brazil: $M=1.09, S D=2.48$; Sweden: $M=0.25, S D=1.15 ; t[1417.22]=9.55, p<0.001$ ). Political violence legitimation was remarkably low in both countries, but it received greater support in Brazil $(M=1.49, S D=2.85)$ than in Sweden $(M=0.75, S D=1.90)$; $t(1726.70)=6.67, p<0.001$.

Pre-Political Participation (volunteering for a non-governmental association, neighbourhood or kids school, for example) was more frequent in Brazil ( $M=4.22$, $\mathrm{SD}=3.63)$ than in Sweden $(\mathrm{M}=2.45, \mathrm{SD}=3.19) ; \mathrm{t}(1860.48)=11.16, \mathrm{p}<0.001$. Brazilians $(M=5.27, S D=4.28)$ and Swedes $(M=4.98, S D=4.43)$ do not differ on the engagement on Political Consumerism; $\mathrm{t}(1821.52)=1.41, \mathrm{p}=0.158$

When it comes to Institutional Participation, as assessed by the homonym Second-Order Factor, Brazilians $(M=3.11, S D=2.29)$ are more often engaged then Swedes $(M=1.46, S D=1.70) ; t(1799.64)=17.79, p<0.001$. Brazilians are more

${ }^{16}$ Original scale for past behavior concerning Policial Participation ranged from "zero" to " 5 or more times". It was converted to a zero to 10 scale, in order to enable comparison with other scales on this study. 
attentive (assessed by the "Attention" factor score, Brazil: $M=5.64, S D=3.04$; Sweden $M=2.73, S D=2.49 ; t[1846.80]=22.71, p<0.001$ ), and more active than Swedes (as assessed by the "Action" factor score, Brazil: $M=1.82, S D=2.31$; Sweden $M=0.85$, $S D=1.67 ; t[1783.51]=10.45, p<0.001)$

These results present a first overview on political thinking differences between Brazil and Sweden. The understanding of these variables relationships is crucial to the comprehension of their systemic functioning in both countries.

\subsection{Relationships among variables (Stepwise Multiple Regression and Structural Equation Modeling)}

After defining factor structures (as explained in Section 4.1), factor scores were calculated. These factor scores were submitted to Stepwise Multiple Regression, to test which predictor (exogenous) variables (Stereotypes on Parliamentarians, Political Education and Behavioral Contagion) could better predict Political Participation (the criterion, endogenous variable). Relationships found through Stepwise Multiple Regression were further tested under Structural Equation Modeling (SEM).

Stepwise Multiple Regression results are briefly mentioned here, as they were a preliminary stage and they are strongly redundant with the SEM analyses. Why, then, the two statistical techniques were used? Why not rely on one of them?

Stepwise Multiple Regression is useful to perform a first exploratory approach. In practical terms, all exogenous variables are inserted into that Regression, and only those with significant prediction effect over the endogenous variable are kept. Structural Equation Modeling (SEM), on the other hand, demands theoretical support or previous empirical evidence - therefore, it is not an adequate tool for exploratory testing. For this reason, Stepwise Multiple Regression was performed to provide the 
first empirical evidence. Exogenous variables that "survived" Stepwise Regression then entered the first model for the SEM analysis.

SEM provides deeper and more rigorous analyses, as it discloses a number of additional indicators (such as Goodness of Fit and Modification Indices - Hair et al., 2009; Marôco, 2010). Through the examination of Modification Indices and covariances' significance, it is possible to identify relationships among exogenous variables that have impact on the prediction of the endogenous variable. It is also possible to test mediation between exogenous variables, and the quality of explanation is assessed by Goodness-of-Fit indices. Structural Equation Modeling (SEM) usually results on more parsimonious models than Multiple Regression, as non-significant covariances are removed from the models, as well as exogenous variables with low prediction power.

Factors and standalone items for Stereotypes about Parliamentarians, Political Education and Behavioral Contagion entered the Stepwise Multiple Regression as predictor (exogenous) variables. Demographic information - gender, age, education (highest school level achieved), party membership, sympathy with a party, party rejection, political orientation (left-wing or right-wing), and wealth (assessed by the possession of goods, see Appendix III) also entered the regression as predictor variables.

Regarding Stereotypes about Parliamentarians, Critical Information is a secondorder factor, composed by Party-Oriented View, Representation Trends and Personal Information. It was considered that either the first-order factors or the second-order factor could help explain each type of Political Participation differently. Hence, the second-order factor and the first-order factors entered the Stepwise Multiple Regression concurrently, so this exploratory test could indicate if each type of Political Participation is better explained by the whole compound (the second-order factor) or specifically by some of its components (first-order factors). 
It was also serendipically found that the items for the Socialization factor (from Political Education), though positively inter-correlated, had different effects over variables when inserted on SEM models to explain Political Participation. How did it happen? Through the examination of Modification Indices, it was observed that two items from the Socialization Factor could have opposite and significant effects on the explanation of some types of Political Participation. For example, when used to predict Pre-Political Engagement in Sweden (presented in Section 4.3.2), learning from coworkers had negative effect while learning from friends and members of associations had positive effect over the dependent variable. Participation on Labor Union Strikes in Brazil (subsection 4.3.5) was predicted, at the SEM model, solely by learning from members of an association, regardless the other items on the Socialization Factor (actually, this sole item removed all other variables that entered the SEM model).

For this reason, a second set of Stepwise Regression was made, entering the Socialization Factor concurrently with its composing items. Changes observed were brought to the SEM models. Results presented in this section come from this "secondround" Stepwise Multiple Regression and Structural Equation Modeling (SEM).

The following subsections are organized according to the Political Participation factors and standalone items. Stepwise Multiple Regression results are presented in Appendix IV. Structural Models to explain each of these participation types are presented. Independent (exogenous) variables in the following SEM models were those that remained from Stepwise Multiple Regression. Concurrent models were built for each dependent variable (types of Political Participation). Criteria used to compare concurrent models were the improvement of prediction (given by the determination index, $\mathrm{R}^{2}$ ), Goodness-of-Fit and significance of covariances and regression weights. Models in this section are the ones that presented the best convergence of the aforementioned criteria. All covariances and regression weights presented for the 
following models are significant, considering $p<0.05$. Also, Goodness-of-Fit indices for all models were found adequate - for this reason, this issue will be shortly commented.

\subsubsection{Political Disillusion}

Political Disillusion negatively covariates with the perception of Quality of Representation (cov $=-0.25$ in Brazil; cov $=-0.22$ in Sweden). This negative covariance is also present on both countries, regarding the Party-Oriented View ( $\operatorname{cov}=-0.29$ in Brazil; cov $=-0.27$ in Sweden - Figures 4.13 and 4.14). Other independent variables were differently allocated to each country's models.

Education Level (assessed as demographic input) had significant negative effect (cov $=-0.20)$ on Political Disillusion in Brazil. Regarding the positive effect of Age $(\operatorname{cov}=0.25)$, it indicates that older Brazilians are more disillusioned than the younger ones. Perceptions over parties add relevant evidence. Party Rejection had positive effect $(\operatorname{cov}=0.08)$, while Party Membership $(\operatorname{cov}=-0.09)$ and Party Sympathy $(\operatorname{cov}=-$ 0.16) had negative effect on Political Disillusion in Brazil. These party perception items partially mediated the Stereotypes about parliamentarians' factors: Quality of Representation was mediated by all three items, while Party-Oriented View was mediated by Party Sympathy, as shown in Figure 4.13. The total of Political Disillusion's explained variance in Brazil was $\mathrm{R}^{2}=0.33$.

In Sweden, differently, two other Stereotypes factors entered the model, with positive effects on Political Disillusion: Personal Information $(\operatorname{cov}=0.19)$ and Corruption $(\operatorname{cov}=0.47)$. Party Membership partially mediated the relationship between Party-Oriented View and Political Disillusion, with also a negative effect on the later (Figure 4.14). The total of Political Disillusion's explained variance in Sweden was $\mathrm{R}^{2}=$ 0.46. Both Brazilian and Swedish models to explain Political Disillusion achieved acceptable fit (Table 30). 
Table 30. Goodness of Fit for prediction models on Political Disillusion.

\begin{tabular}{lccccccccccc}
\hline Scenario & $\boldsymbol{X}^{2}$ & d.f. & $\boldsymbol{X}^{2} /$ d.f. & RMSEA & SRMR & CFI & TLI & AGFI & $\begin{array}{c}\text { Achieved } \\
\text { Power } \\
(\mathbf{1} \boldsymbol{\beta})^{*}\end{array}$ & $\begin{array}{c}\text { Type I } \\
\text { error } \\
\text { alpha }\end{array}$ \\
\hline $\begin{array}{l}\text { Acceptance } \\
\text { Criteria }\end{array}$ & -- & -- & $\begin{array}{c}\text { between } \\
1 \text { and } 5\end{array}$ & $<0.07$ & $<0.08$ & $>0.92$ & $>0.92$ & $>0.90$ & $>0.80$ & fixed at \\
\hline Brazil & 388.79 & 112 & 3.47 & .050 & .065 & .94 & .93 & .94 & .99 & .01 \\
Sweden & 212.34 & 97 & 2.19 & .037 & .045 & .98 & .97 & .96 & .99 & .01 \\
\hline
\end{tabular}

* Post-Hoc Power Analysis calculated with software G-Power (version 3.1.9), considering Effect Size = 0.30.

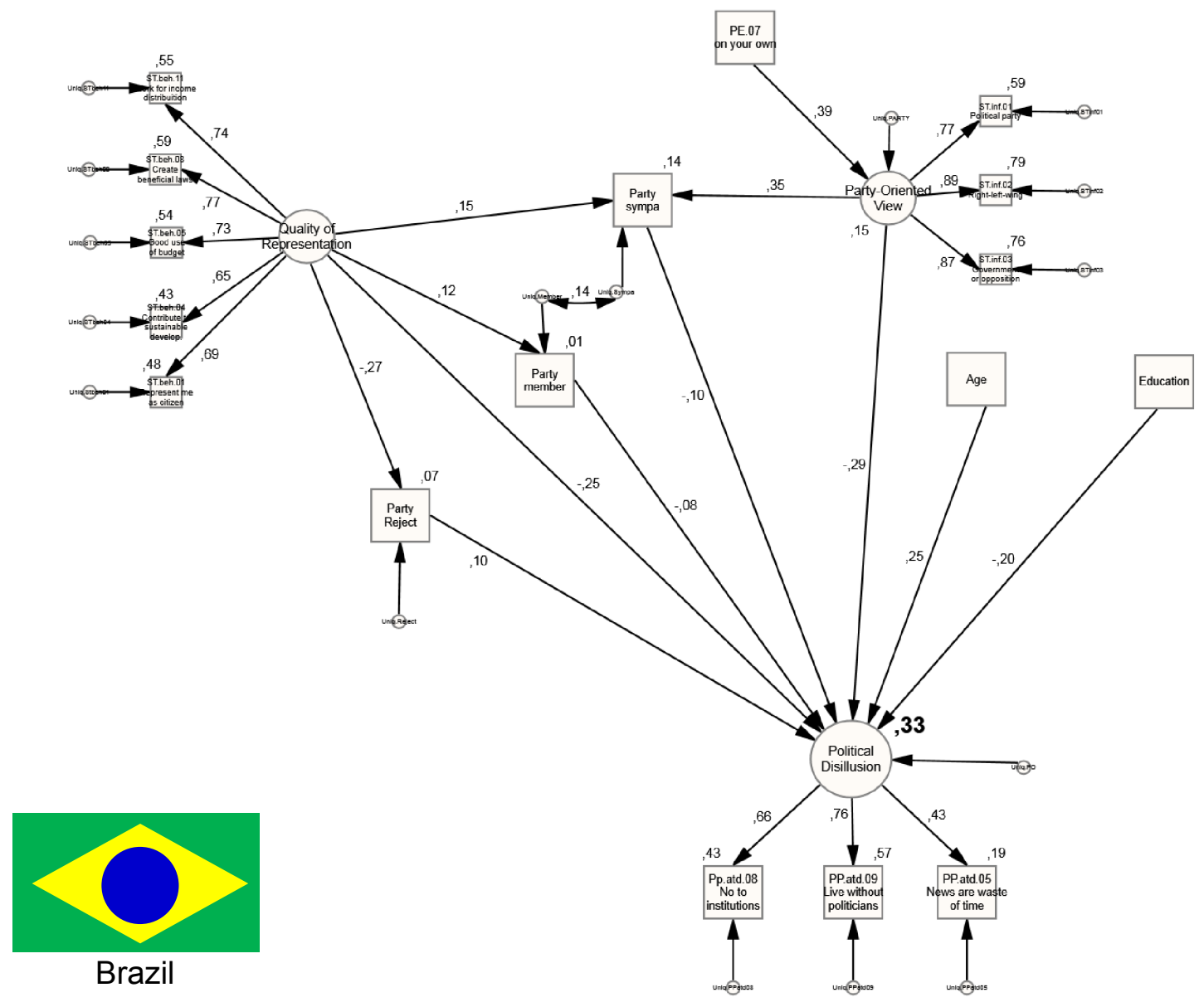

Figure 4.13. Explaining Political Disillusion in Brazil: Structural Equation Modeling results. 


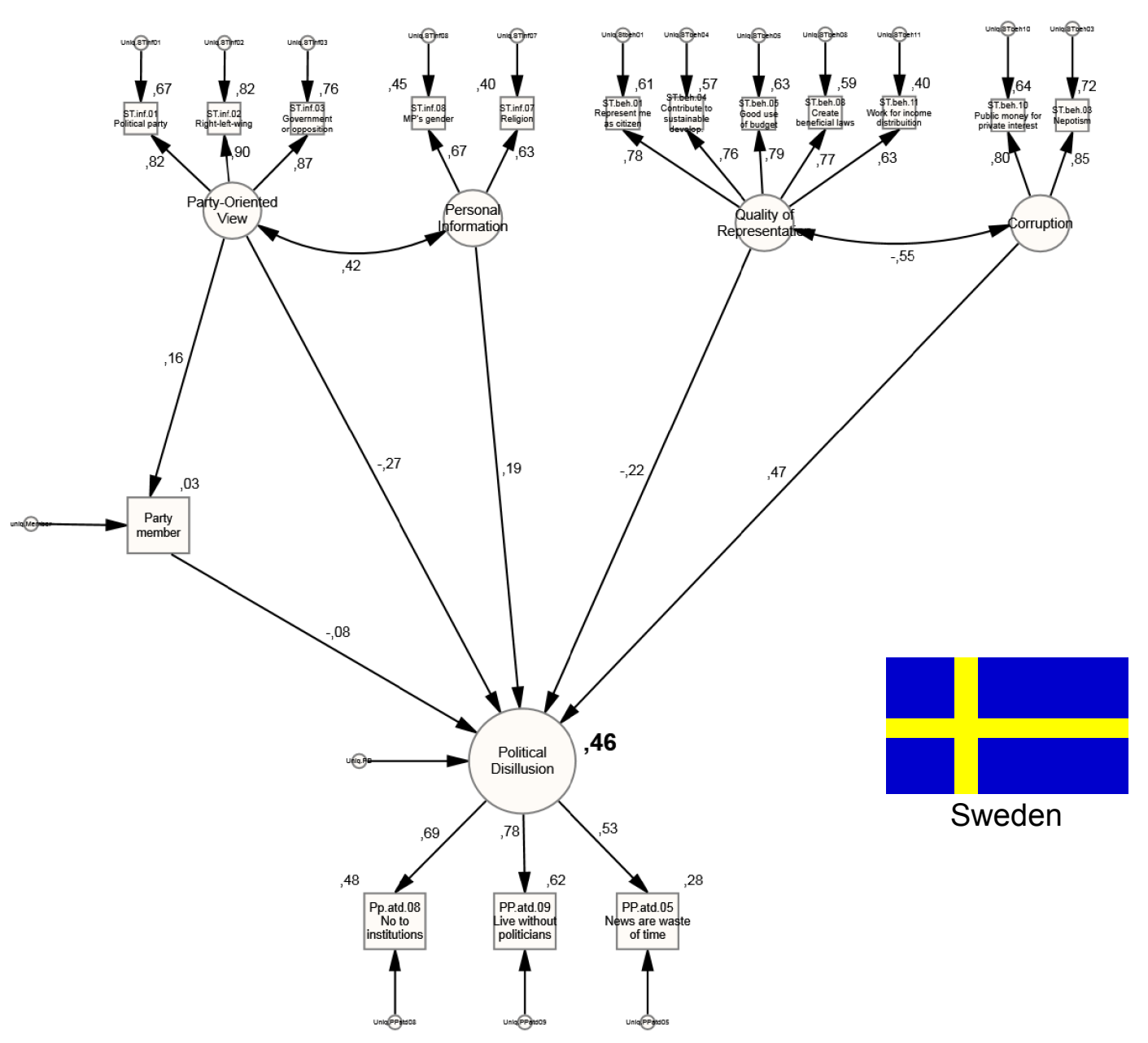

Figure 4.14. Explaining Political Disillusion in Sweden: Structural Equation Modeling results. 


\subsubsection{Pre-Political Engagement}

Behavioral Contagion played a core role on predicting Pre-Political Engagement, both in Brazil $(\operatorname{cov}=0.51)$ and Sweden $(\operatorname{cov}=0.46)$. There was a significant difference on this type of political action according to gender ${ }^{17}$. Women are more likely to Pre-Political Engagement than men ( $\operatorname{cov}=0.12$ in Brazil; $\operatorname{cov}=0.07$ in Sweden). On the other hand, men are more likely to try to convince others to engage political action (cov $=-0.30$ in Brazil; cov $=-0.16$ in Sweden). Learning about politics from members of an association had positive effect on Behavioral Contagion (cov = 0.42 in Brazil; cov $=0.43$ in Sweden). This is the common ground on both models (Figures 4.15 and 4.16). They had well-adjusted fit indices (Table 31).

In Brazil, Party Sympathy positively covariates with Behavioral Contagion (0.20) and attention to Personal Information (cov $=0.17$ ), but it had a negative effect on PrePolitical Engagement $(\operatorname{cov}=-0.12)$. Attention to Personal Information $(\operatorname{cov}=0.32)$ had positive effect on Behavioral Contagion, producing a mediated effect on the dependent variable. The Perception of good Quality of Representation had a direct negative effect $(\operatorname{cov}=-0.08)$. The total of explained variance for Pre-Political Engagement in Brazil was $R^{2}=0.27$ (Figure 4.15).

Whereas in Brazil, Quality of Representation (from Stereotypes about Parliamentarians) had negative impact on Pre-Political Engagement, in Sweden perceived Corruption played the same role $(\operatorname{cov}=-0.10)$. The total of explained variance for Pre-Political Engagement in Sweden was $R^{2}=0.23$ (Figure 4.16).

${ }^{17}$ Gender was codified as $1=$ men, and $2=$ women. Therefore, positive covariance indicates female prevalence, negative covariance indicates male prevalence. 


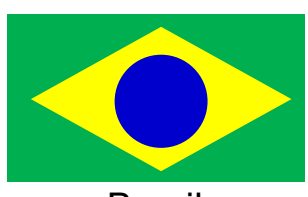

Brazil

(1)

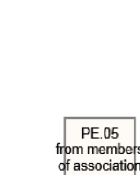

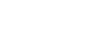
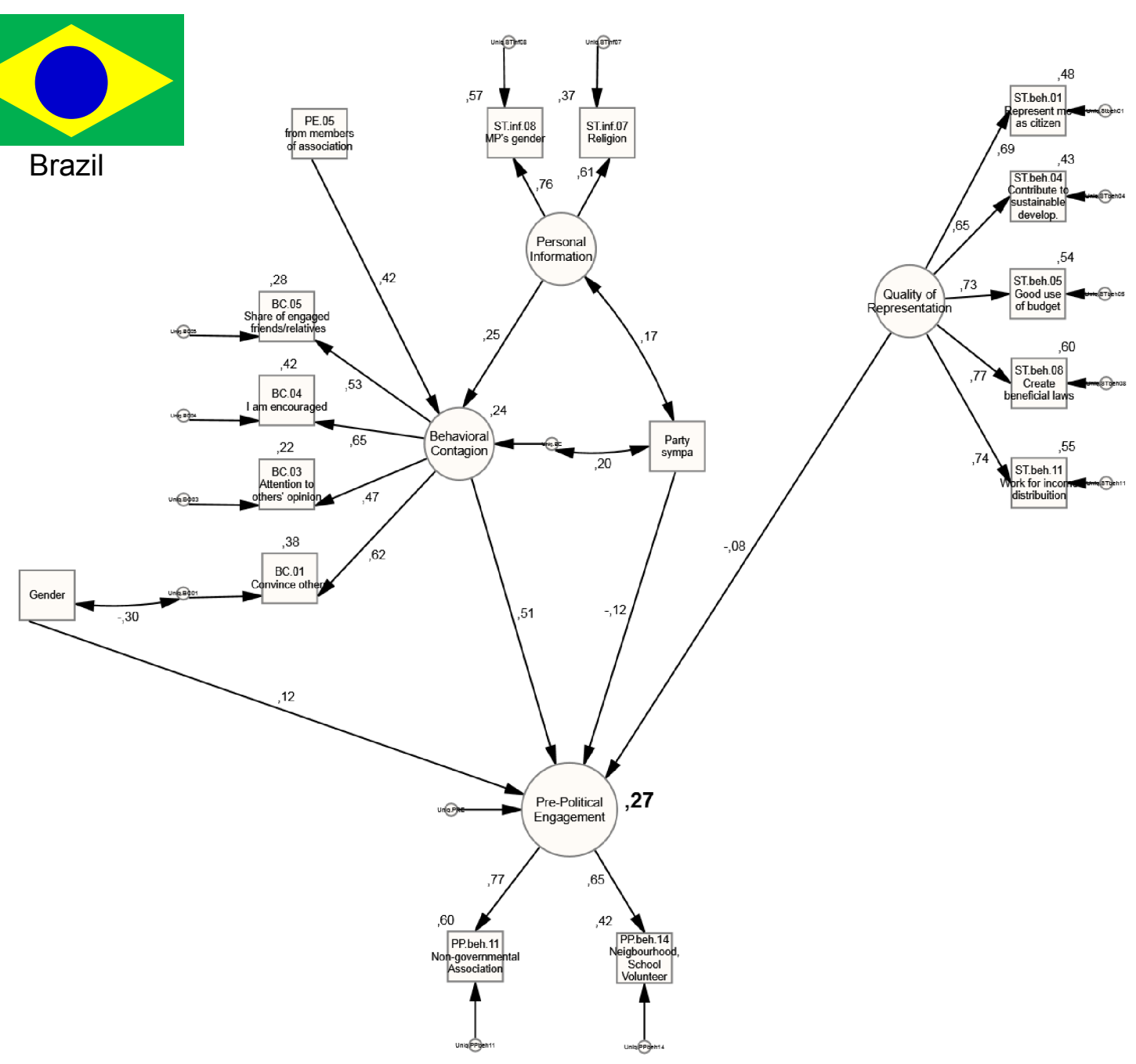

Figure 4.15. Explaining Pre-Political Engagement in Brazil: Structural Equation Modeling results. 


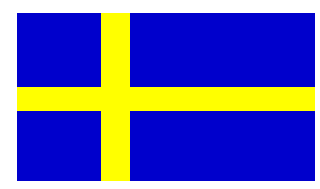

Sweden

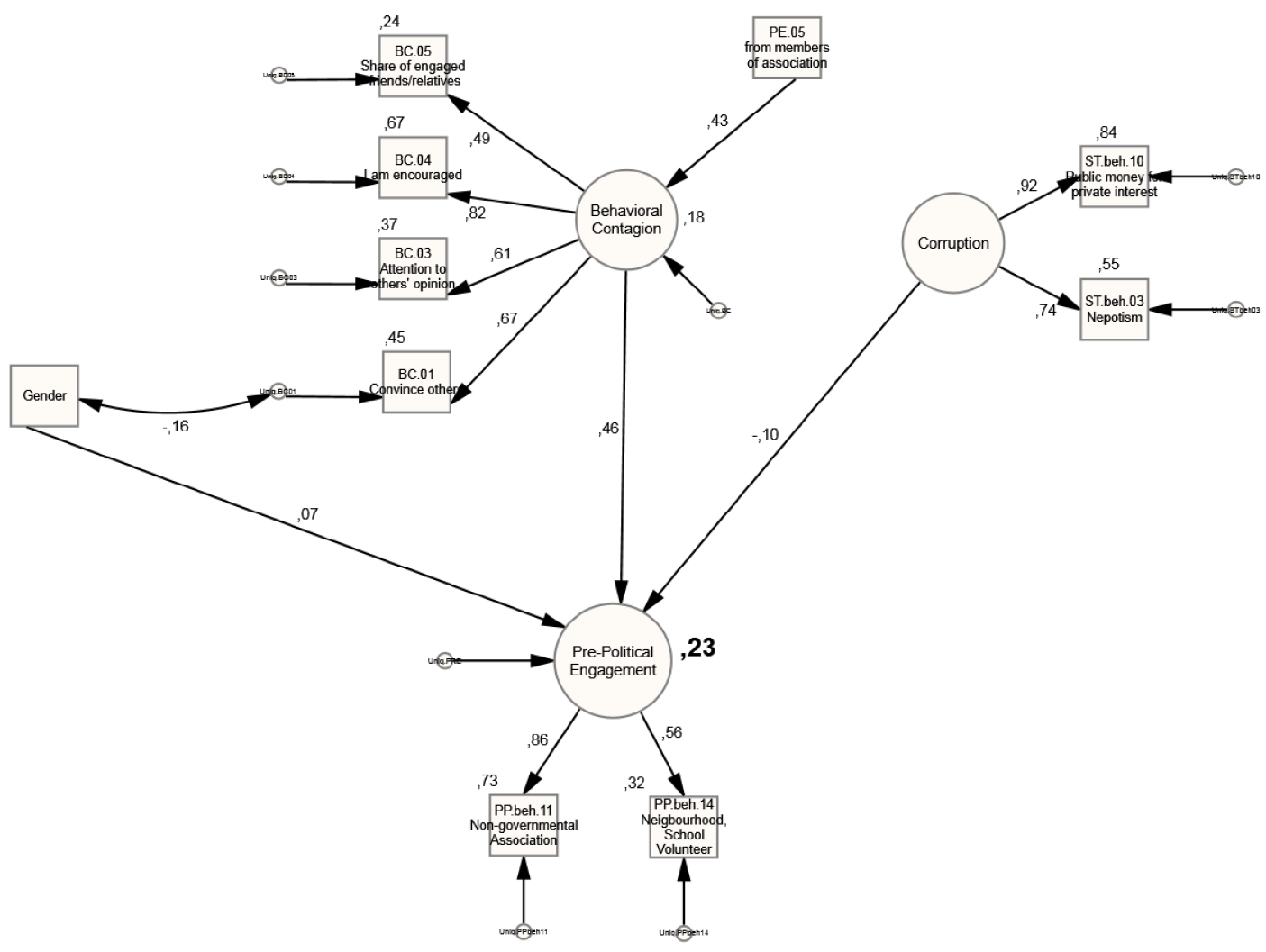

Figure 4.16. Explaining Pre-Political Engagement in Sweden: Structural Equation Modeling results.

Table 31. Goodness of Fit for prediction models on Pre-Political Engagement

\begin{tabular}{|c|c|c|c|c|c|c|c|c|c|c|}
\hline Scenario & $x^{2}$ & d.f. & $X^{2} /$ d.f. & RMSEA & SRMR & CFI & TLI & AGFI & $\begin{array}{c}\text { Achieved } \\
\text { Power } \\
(1-\beta)^{*}\end{array}$ & $\begin{array}{l}\text { Type I } \\
\text { error } \\
\text { alpha }\end{array}$ \\
\hline $\begin{array}{l}\text { Acceptance } \\
\text { Criteria }\end{array}$ & -- & -- & $\begin{array}{c}\text { between } \\
1 \text { and } 5\end{array}$ & $<0.07$ & $<0.08$ & $>0.92$ & $>0.92$ & $>0.90$ & $>0.80$ & $\begin{array}{c}\text { fixed at } \\
.01\end{array}$ \\
\hline Brazil & 334.82 & 98 & 3.42 & .050 & .070 & .93 & .92 & .94 & .99 & .01 \\
\hline Sweden & 96.51 & 32 & 3.02 & .048 & .035 & .97 & .95 & .96 & .99 & .01 \\
\hline
\end{tabular}

* Post-Hoc Power Analysis calculated with software G-Power (version 3.1.9), considering Effect Size $=0.30$. 


\subsubsection{Institutional Participation}

In both Brazil and Sweden, Institutional Participation (considering the secondorder factor, that comprises Attention and Action, as explained in Section 4.1.1) is predicted by the Critical Information (second-order factor from Stereotypes about Parliamentarians), mediated by Behavioral Contagion. In Sweden, however, three more variables had significant prediction power towards Institutional Participation. Party Membership had a positive effect (cov $=0.27$ ), partially mediating the effect of Behavioral Contagion (cov $=0.43$ ); hence, being a member of a party helped engaging into political participation in Sweden. On the other hand, the lower the perceived Quality of Representation, the greater the chances of engaging into institutional political action (cov $=-0.16)$. Learning politics alone helped participation, however mediated by Behavioral Contagion $(\operatorname{cov}=0.30)$. Both Brazilian and Swedish models achieved good fit (see Table 32).

In both countries (Figures 4.17 and 4.18), a relevant share of variance was explained by the independent variables that entered the model (Brazil: $R^{2}=0.83$; Sweden: $\left.R^{2}=0.80\right)$. Regarding the first-order factor on the dependent (endogenous) variable, relevant shares of variance were also explained for Attention (Brazil: $R^{2}=$ 0.87; Sweden: $\left.R^{2}=0.81\right)$ and Action (Brazil: $R^{2}=0.62 ;$ Sweden: $\left.R^{2}=0.66\right)$.

It is noteworthy that Party Membership, Quality of Representation and learning politics alone were important independent variables in Sweden, but they did not have a significant role in Brazil. This might indicate cultural differences, to be discussed on Chapter 5. Though some variables related to education (Education level, PE.01, PE.02, PE.04, PE.05) entered the Stepwise Multiple Regression models (Appendix IV, Tables IV.5 and IV.6), at the Structural Equation Modeling they were removed, as they seriously downturned fit and had no relevant contribution on Institutional Participation prediction. 
Table 32. Goodness of Fit for models on Institutional Participation (2nd order factor)

\begin{tabular}{|c|c|c|c|c|c|c|c|c|c|c|}
\hline Scenario & $x^{2}$ & d.f. & $X^{2} /$ d.f. & RMSEA & SRMR & CFI & TLI & AGFI & $\begin{array}{c}\text { Achieved } \\
\text { Power } \\
(1-\beta)^{*}\end{array}$ & $\begin{array}{l}\text { Type I } \\
\text { error } \\
\text { alpha }\end{array}$ \\
\hline $\begin{array}{l}\text { Acceptance } \\
\text { Criteria }\end{array}$ & -- & -- & $\begin{array}{l}\text { between } 1 \\
\text { and } 5\end{array}$ & $<0.07$ & $<0.08$ & $>0.92$ & $>0.92$ & $>0.90$ & $>0.80$ & $\begin{array}{c}\text { fixed at } \\
.01\end{array}$ \\
\hline Brazil & 746.77 & 182 & 4.10 & .056 & .047 & .93 & .91 & .91 & .94 & .01 \\
\hline Sweden & 569.56 & 165 & 3.45 & .053 & .048 & .93 & .92 & .92 & .91 & .01 \\
\hline
\end{tabular}

* Post-Hoc Power Analysis calculated with software G-Power (version 3.1.9), considering Effect Size = 0.30.

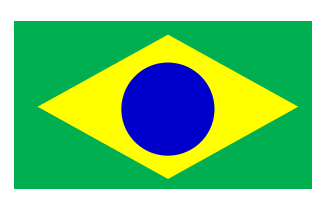

Brazil
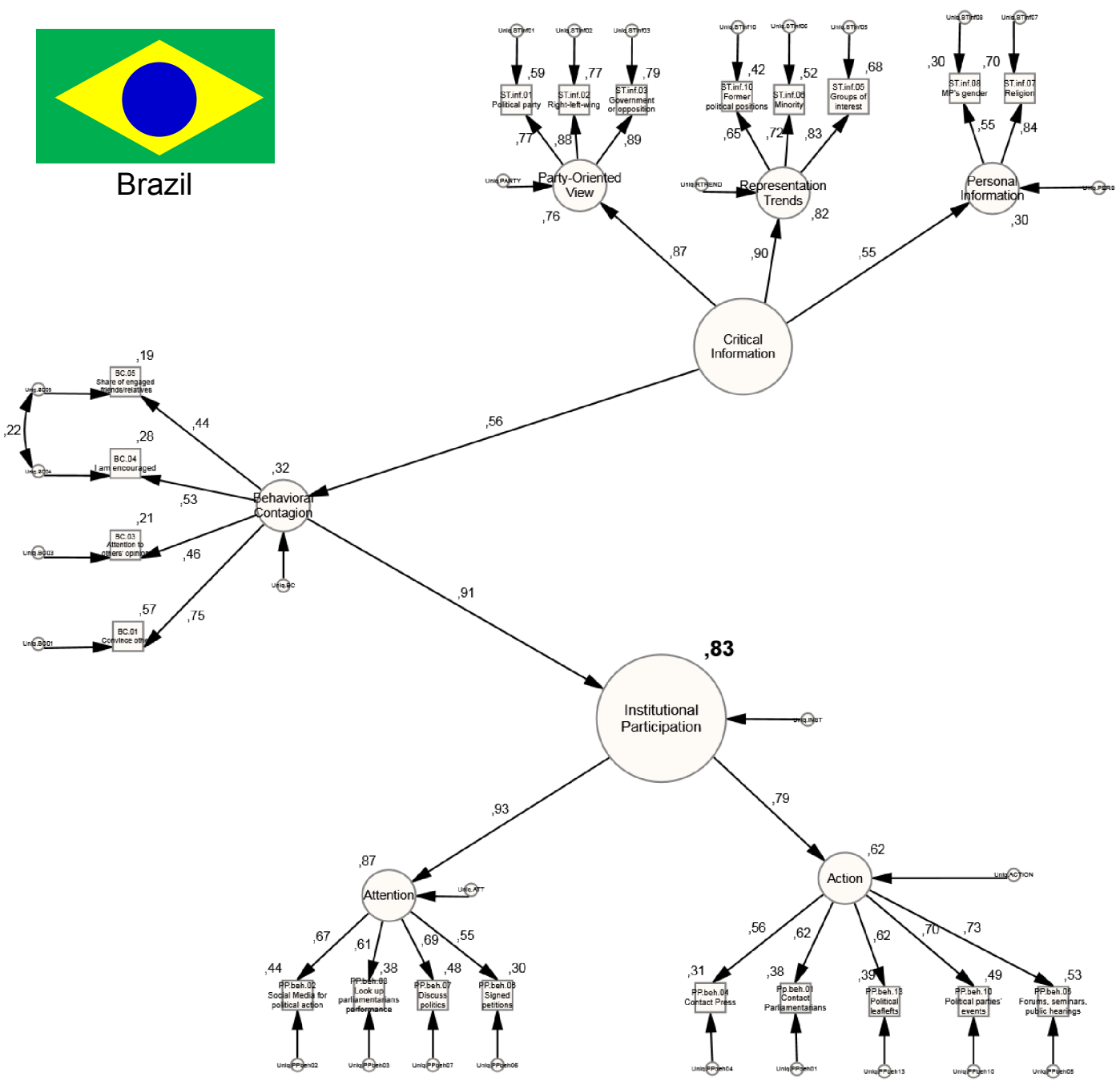

Figure 4.17. Explaining Institutional Participation in Brazil: Structural Equation Modeling results. 


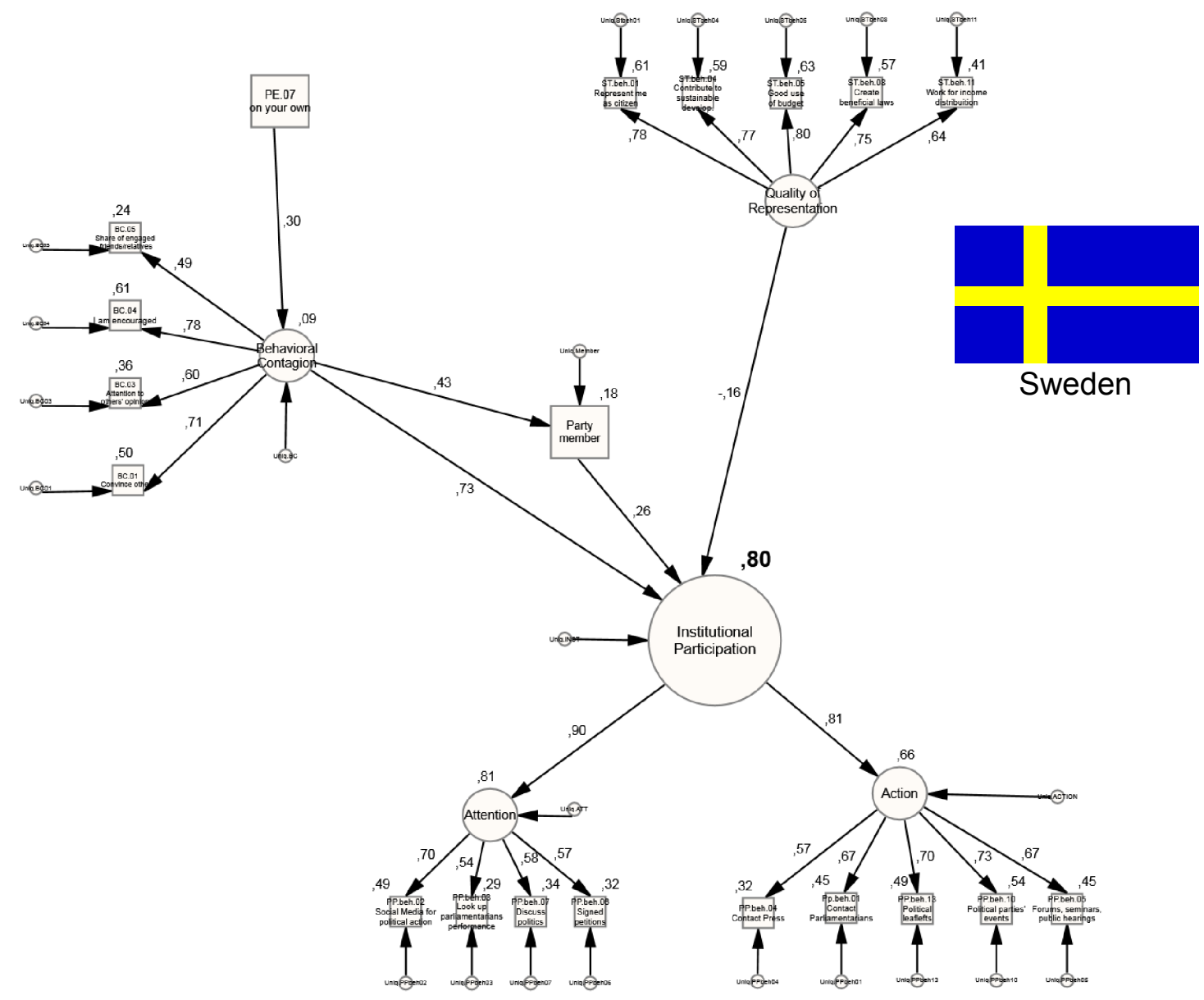

Figure 4.18. Explaining Institutional Participation in Sweden: Structural Equation Modeling results.

\subsubsection{Political Consumerism}

On Political Consumerism, the common ground between Brazil and Sweden is that Behavioral Contagion had direct positive effect (Brazil: $\operatorname{cov}=0.34$; Sweden: $\operatorname{cov}=$ 0.25 ) and that men are a little more likely to engage in this type of action (Brazil: cov = 0.12; Sweden: $\operatorname{cov}=0.10$ ). Other variables entered the model differently (Figures 4.19 and 4.20). 
In Brazil, Education had a positive direct effect on Political Consumerism (cov = 0.16), while Party-Oriented View had positive effect, mediated by Behavioral Contagion (respectively, cov $=0.48$, Behavioral Contagion's explained variance: $R^{2}=0.28$ ) Quality of Representation had a small negative effect (cov $=-0.08)$. Total of variance explained for Political Consumerism was $\mathrm{R}^{2}=0.16$ in Brazil.

In Sweden, Party-Oriented View (cov $=0.11)$ and perceiving parliamentarians Corruption $(\operatorname{cov}=-0.18)$ had direct impact on Political Consumerism. Regarding Political Orientation ${ }^{18}$, left-winged citizens were more likely to engage Political Consumerism. Total of variance explained for Political Consumerism in Sweden was $\mathrm{R}^{2}$ $=0.18$. All Goodness-of-Fit Indices showed model adequacy, for both countries (see Table 33).

Table 33. Goodness of Fit for models on Political Consumerism

\begin{tabular}{|c|c|c|c|c|c|c|c|c|c|c|}
\hline Scenario & $x^{2}$ & d.f. & $X^{2} /$ d.f. & RMSEA & SRMR & CFI & TLI & AGFI & $\begin{array}{c}\text { Achieved } \\
\text { Power } \\
(1-\beta)^{*}\end{array}$ & $\begin{array}{c}\text { Type I } \\
\text { error } \\
\text { alpha }\end{array}$ \\
\hline $\begin{array}{l}\text { Acceptance } \\
\text { Criteria }\end{array}$ & -- & -- & $\begin{array}{c}\text { between } \\
1 \text { and } 5\end{array}$ & $<0.07$ & $<0.08$ & $>0.92$ & $>0.92$ & $>0.90$ & $>0.80$ & $\begin{array}{l}\text { fixed at } \\
\quad .01\end{array}$ \\
\hline Brazil & 359.51 & 87 & 4.13 & .056 & .073 & .94 & .93 & .94 & .99 & .01 \\
\hline Sweden & 225.28 & 52 & 4.33 & .062 & .060 & .95 & .94 & .94 & .99 & .01 \\
\hline
\end{tabular}

${ }^{18}$ Assessed by the item 73 on the questionnaire (Appendix II) "In political matters, people talk of 'the left' and 'the right.' How would you place your views on this scale, generally speaking?" Participants answers were recoded to a range from zero (extreme left) to 10 (extreme right). Hence, negative covariance indicate left-wing prevalence, while positive covariance indicate right-wing prevalence. 


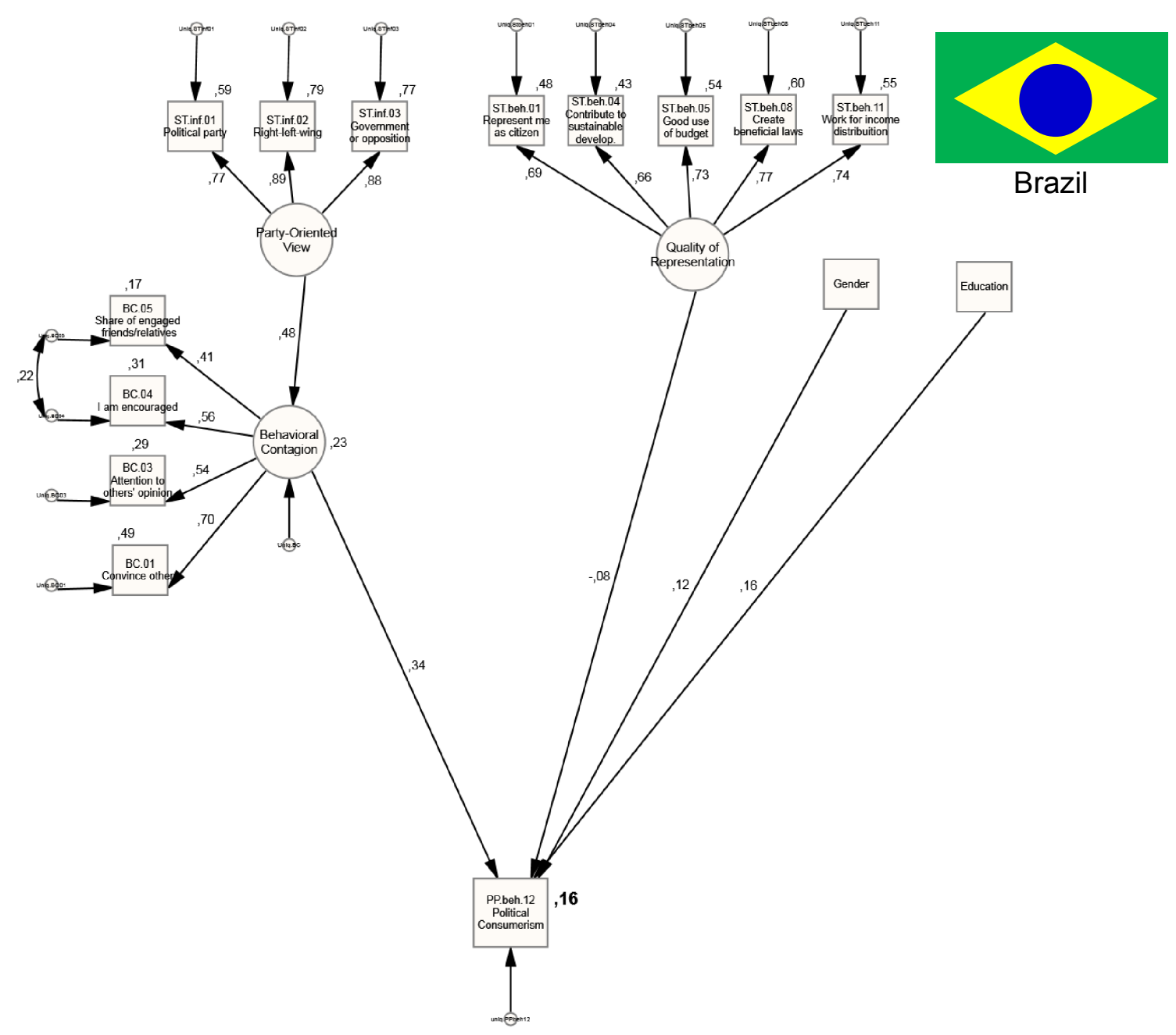

Figure 4.19. Explaining Political Consumerism in Brazil: Structural Equation Modeling results. 


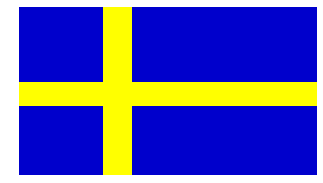

Sweden

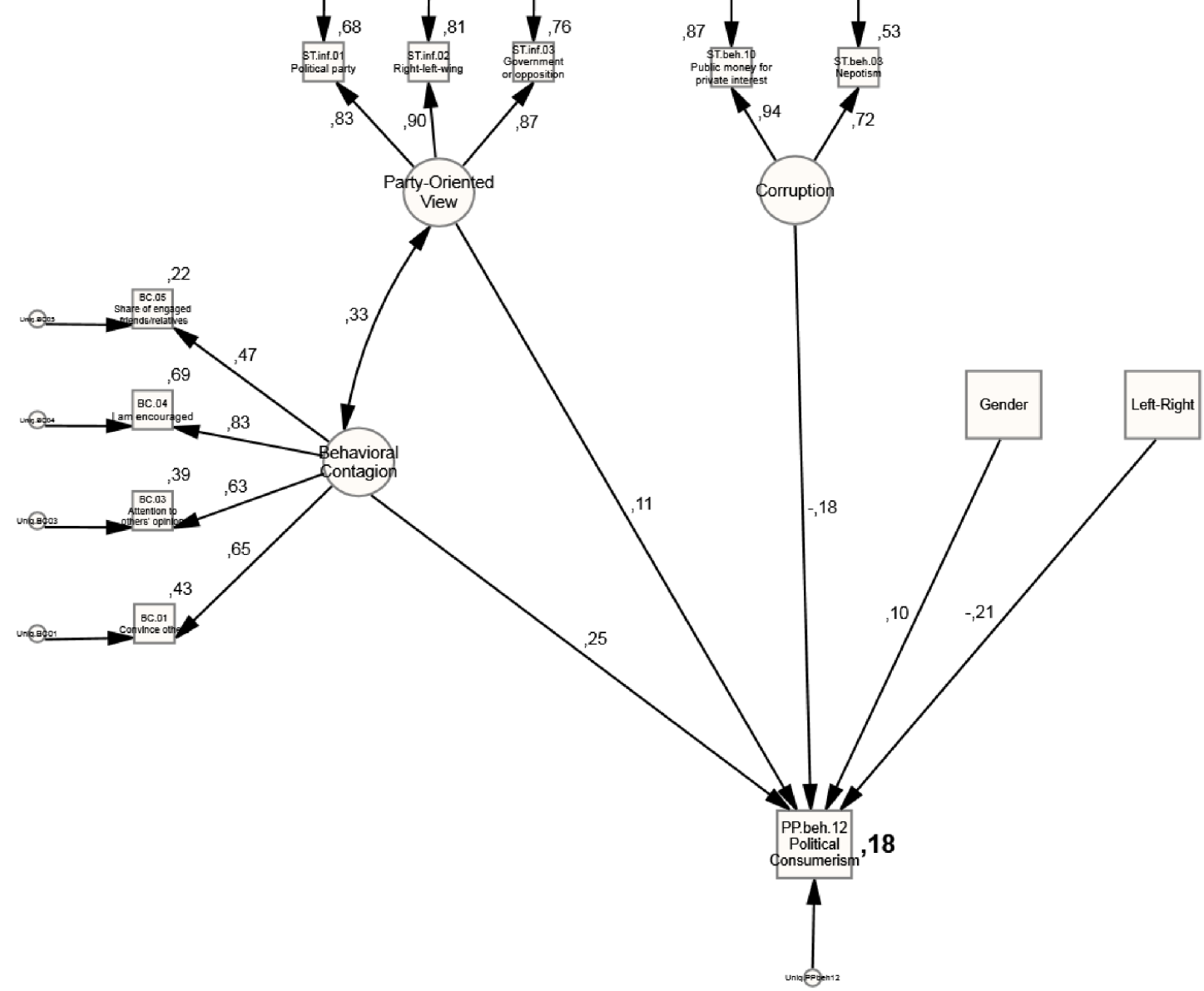

Figure 4.20. Explaining Political Consumerism in Sweden: Structural Equation Modeling results.

\subsubsection{Labor Union Strikes}

Questions in the present research had little prediction impact over participation on Labor Union Strikes (Brazil: $R^{2}=0.10$; Sweden $R^{2}=0.05-$ Figures 4.21 and 4.22). In Brazil, the item "learning from members of an association" solely accounted for all 
explained variance $(\operatorname{cov}=0.31)$. In Sweden, Behavioral Contagion $(\operatorname{cov}=0.13)$, attention to Personal Information (cov $=0.13)$ and the perception of parliamentarians' Corruption (cov $=0.09)$ had positive and direct impact. Calculation of Goodness of Fit does not apply to the Brazilian model, as it is just-identified (there is only one possible solution, as there are no degrees of freedom on the model); hence, it is considered "perfectly fit". The Swedish model was adequate, according to model fit indices presented in Table 34.

Table 34. Goodness of Fit for models on Participating in Labor Union Strikes

\begin{tabular}{|c|c|c|c|c|c|c|c|c|c|c|}
\hline Scenario & $x^{2}$ & d.f. & $x^{2} /$ d.f. & RMSEA & SRMR & CFI & TLI & AGFI & $\begin{array}{c}\text { Achieved } \\
\text { Power } \\
(1-\beta)^{*}\end{array}$ & $\begin{array}{c}\text { Type I } \\
\text { error } \\
\text { alpha }\end{array}$ \\
\hline $\begin{array}{l}\text { Acceptance } \\
\text { Criteria }\end{array}$ & -- & -- & $\begin{array}{c}\text { between } \\
1 \text { and } 5\end{array}$ & $<0.07$ & $<0.08$ & $>0.92$ & $>0.92$ & $>0.90$ & $>0.80$ & $\begin{array}{l}\text { fixed at } \\
\quad .01\end{array}$ \\
\hline Brazil & .00 & 0 & .00 & .318 & .000 & 1.00 & .00 & .00 & 1.00 & .01 \\
\hline Sweden & 41.00 & 24 & 1.71 & .028 & .027 & .99 & .98 & .98 & .99 & .01 \\
\hline
\end{tabular}

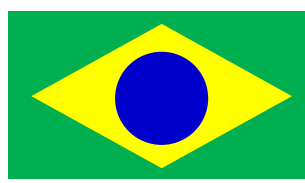

Brazil

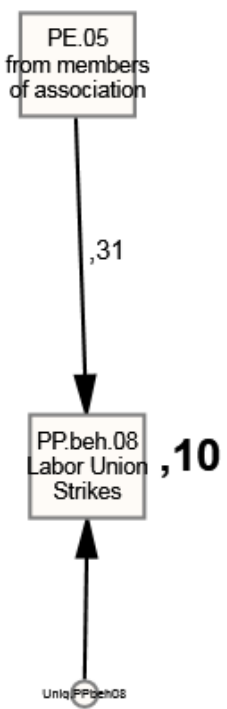

Figure 4.21. Explaining participation in Labor Union Strikes in Brazil: Structural Equation Modeling results. 


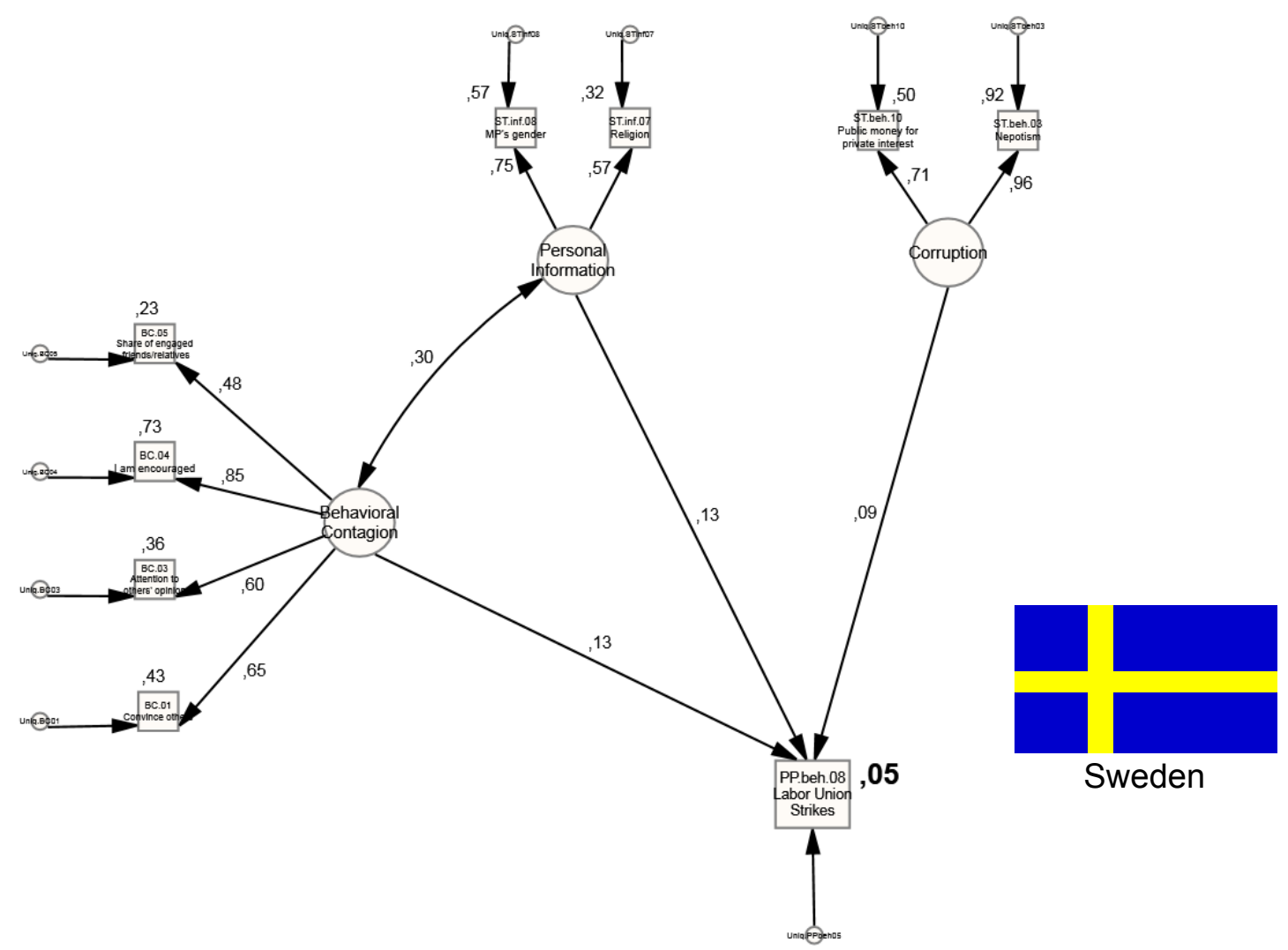

Figure 4.22. Explaining participation in Labor Union Strikes in Sweden: Structural Equation Modeling results.

\subsubsection{Street Demonstrations}

In Sweden, Behavioral Contagion $(\operatorname{cov}=0.40)$ had positive direct impact on participation in Street Demonstrations. Additionally, Quality of Representation (cov = -0.13) had a negative direct impact, i.e., the perception of the bad quality of parliamentarians' work helps to explain the engagement on Street Demonstrations - in Sweden, $\mathrm{R}^{2}=0.18$

In Brazil, the same effects were observed for Behavioral Contagion (cov $=0.38$ ) and Quality of Representation (cov $=-0.07$ ). However, other variables entered the model. Wealth (cov $=-0.09)$ and Age (cov $=-0.17)$ had negative direct effect, i.e., poorer and younger people are more likely to engage on street demonstrations, in 
Brazil. The total of variance explained for participation on Street Demonstrations in Brazil was $R^{2}=0.19$. Both Brazilian and Swedish models were well fit (Table 35; see models in Figures 4.23 and 4.24).

Table 35. Goodness of Fit for models on Participating in Street Demonstrations

\begin{tabular}{|c|c|c|c|c|c|c|c|c|c|c|}
\hline Scenario & $x^{2}$ & d.f. & $X^{2} /$ d.f. & RMSEA & SRMR & CFI & TLI & AGFI & $\begin{array}{c}\text { Achieved } \\
\text { Power } \\
(1-\beta)^{*}\end{array}$ & $\begin{array}{l}\text { Type I } \\
\text { error } \\
\text { alpha }\end{array}$ \\
\hline $\begin{array}{l}\text { Acceptance } \\
\text { Criteria }\end{array}$ & -- & -- & $\begin{array}{c}\text { between } \\
1 \text { and } 5\end{array}$ & $<0.07$ & $<0.08$ & $>0.92$ & $>0.92$ & $>0.90$ & $>0.80$ & $\begin{array}{c}\text { fixed at } \\
.01\end{array}$ \\
\hline Brazil & 13.27 & 49 & 2.66 & .041 & .054 & .97 & .96 & .97 & .99 & .01 \\
\hline Sweden & 99.74 & 34 & 2.93 & .047 & .038 & .98 & .97 & .97 & .99 & .01 \\
\hline
\end{tabular}

${ }^{*}$ Post-Hoc Power Analysis calculated with software G-Power (version 3.1.9), considering Effect Size = 0.30.

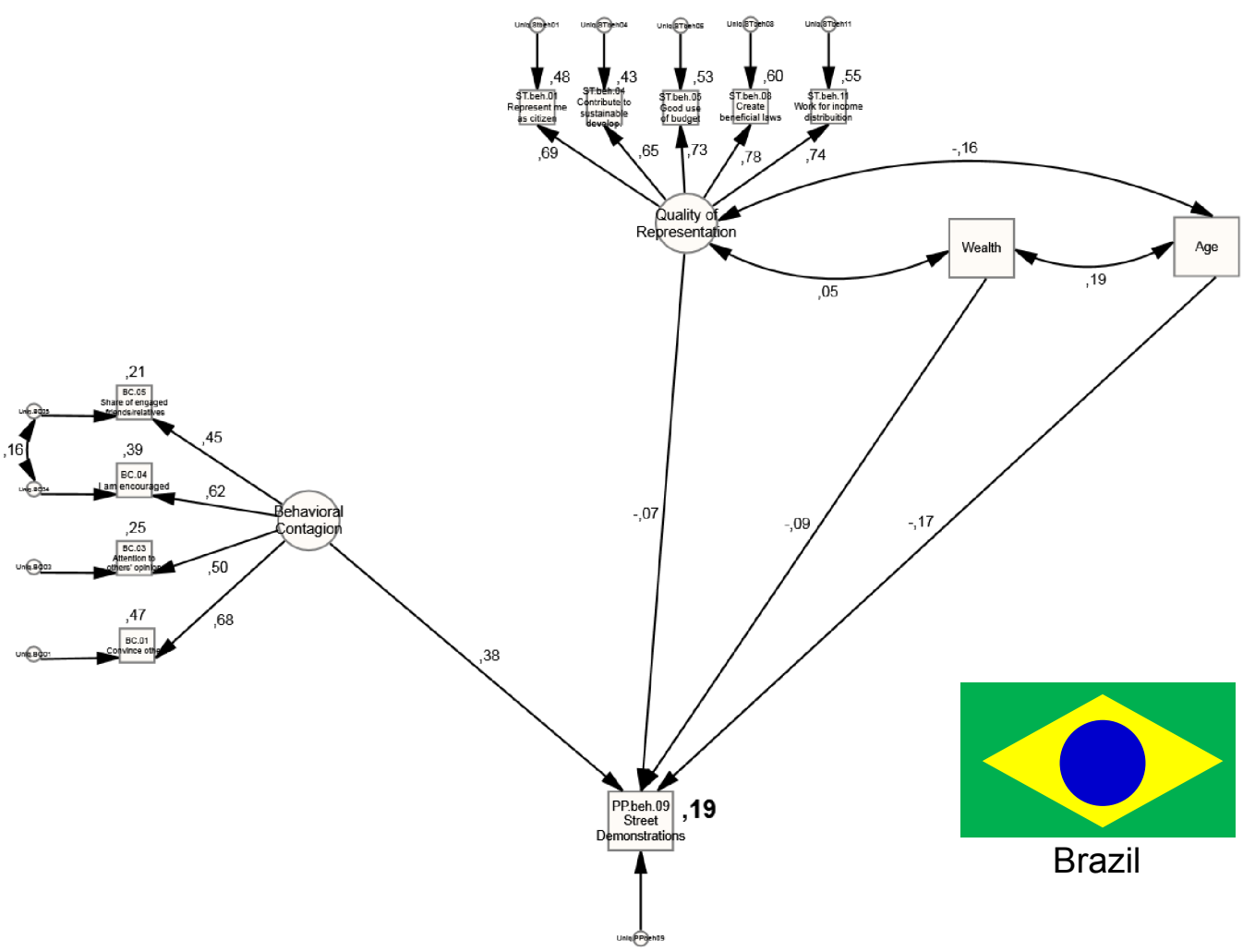

Figure 4.23. Explaining participation in Street Demonstrations in Brazil: Structural Equation Modeling results. 


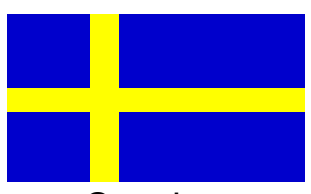

Sweden
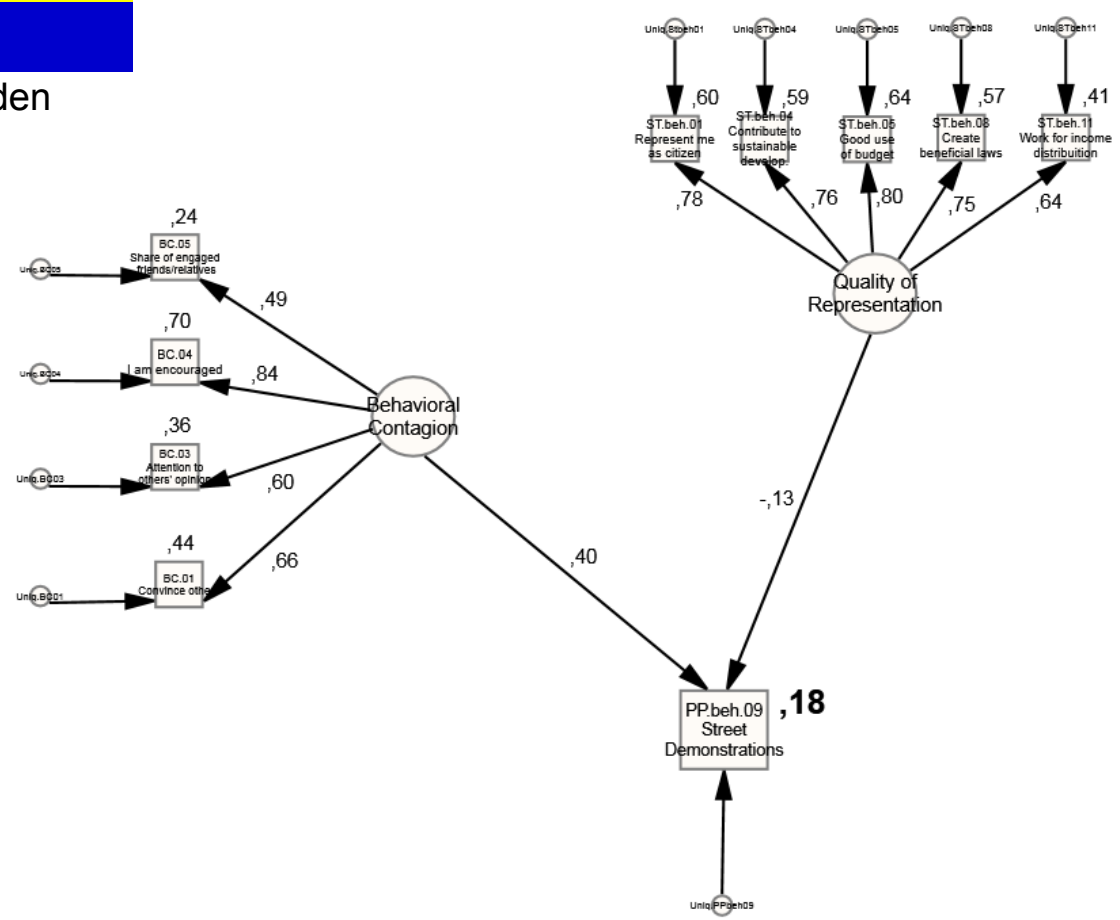

Figure 4.24. Explaining participation in Street Demonstrations in Sweden: Structural Equation Modeling results.

\subsubsection{Violence Legitimacy}

The perception that violence is a legitimate political action was explained, in Brazil, by Behavioral Contagion (cov $=0.23$ ), a negative perception of Quality of Representation (cov $=-0.15)$ and Age $(\operatorname{cov}=-0.21)$. Total of variance explained for Political Violence Legitimacy in Brazil was $\mathrm{R}^{2}=0.12$.

In Sweden, the perception of parliamentarians' Corruption had positive effect. Party-Oriented View had negative direct effect on Political Violence Legitimacy (cov = -0.14). Attention to parliamentarians' Personal Information had positive effect (cov = 
0.15). These two Critical Information factors were partially mediated by Behavioral Contagion (respectively, cov $=0.33$ and 0.31$)$. Behavioral Contagion $(\operatorname{cov}=0.20)$ had positive direct effect on Political Violence Legitimacy. Total of variance explained for Political Violence Legitimacy in Sweden was $R^{2}=0.09$. Goodness-of-Fit indices were adequate for both countries (Table 36; see models in Figures 4.25 and 4.26).

Table 36. Goodness of Fit for models on Political Violence Legitimacy

\begin{tabular}{|c|c|c|c|c|c|c|c|c|c|c|}
\hline Scenario & $x^{2}$ & d.f. & $X^{2} /$ d.f. & RMSEA & SRMR & CFI & TLI & AGFI & $\begin{array}{c}\text { Achieved } \\
\text { Power } \\
(1-\beta)^{*}\end{array}$ & $\begin{array}{l}\text { Type I } \\
\text { error } \\
\text { alpha }\end{array}$ \\
\hline $\begin{array}{l}\text { Acceptance } \\
\text { Criteria }\end{array}$ & -- & -- & $\begin{array}{c}\text { between } \\
1 \text { and } 5\end{array}$ & $<0.07$ & $<0.08$ & $>0.92$ & $>0.92$ & $>0.90$ & $>0.80$ & $\begin{array}{c}\text { fixed at } \\
\quad .01\end{array}$ \\
\hline Brazil & 134.53 & 42 & 3.20 & .047 & .066 & .96 & .95 & .96 & .99 & .01 \\
\hline Sweden & 97.67 & 48 & 2.04 & .034 & .037 & .99 & .98 & .97 & .99 & .01 \\
\hline
\end{tabular}

* Post-Hoc Power Analysis calculated with software G-Power (version 3.1.9), considering Effect Size = 0.30.

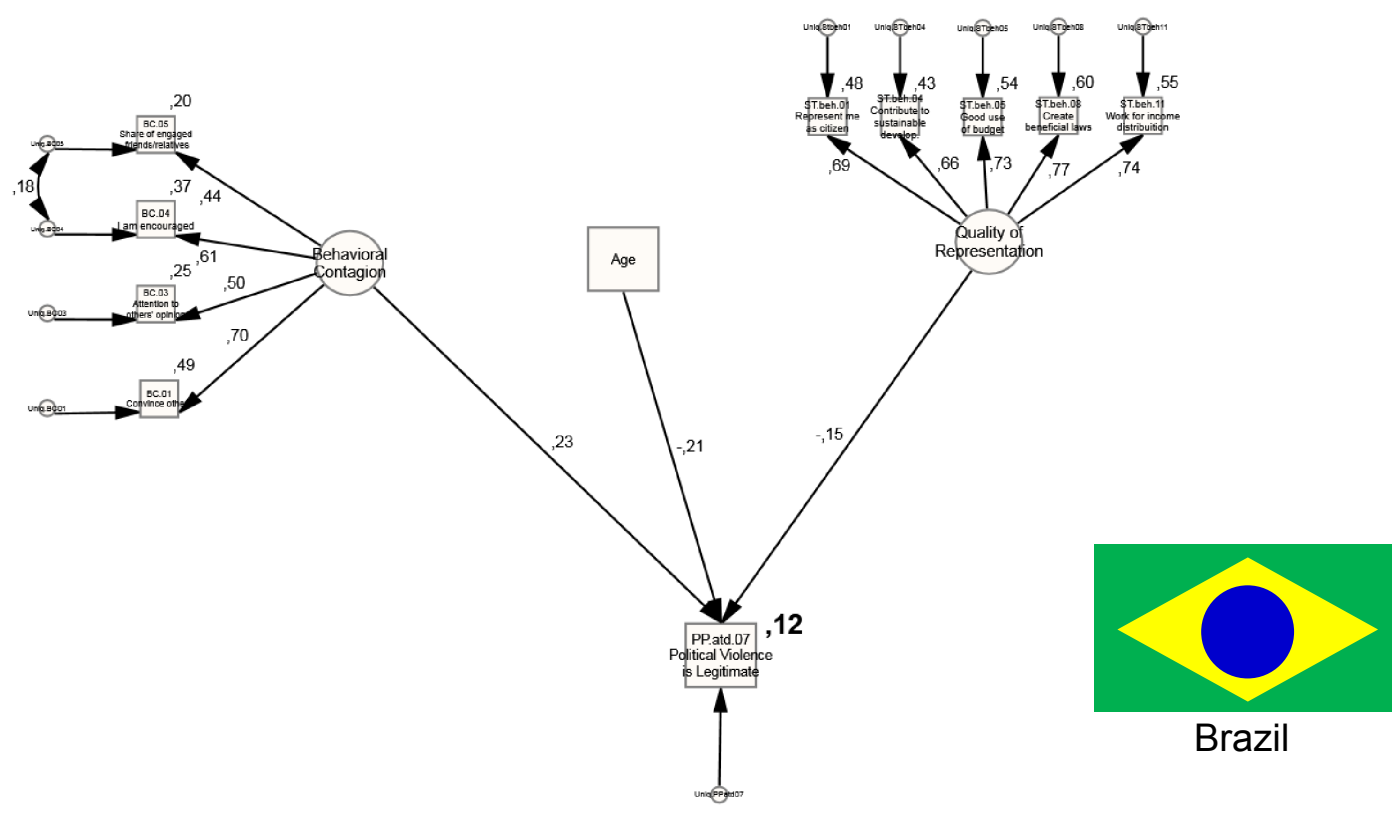

Figure 4.25. Explaining Political Violence Legitimacy in Brazil: Structural Equation Modeling results. 


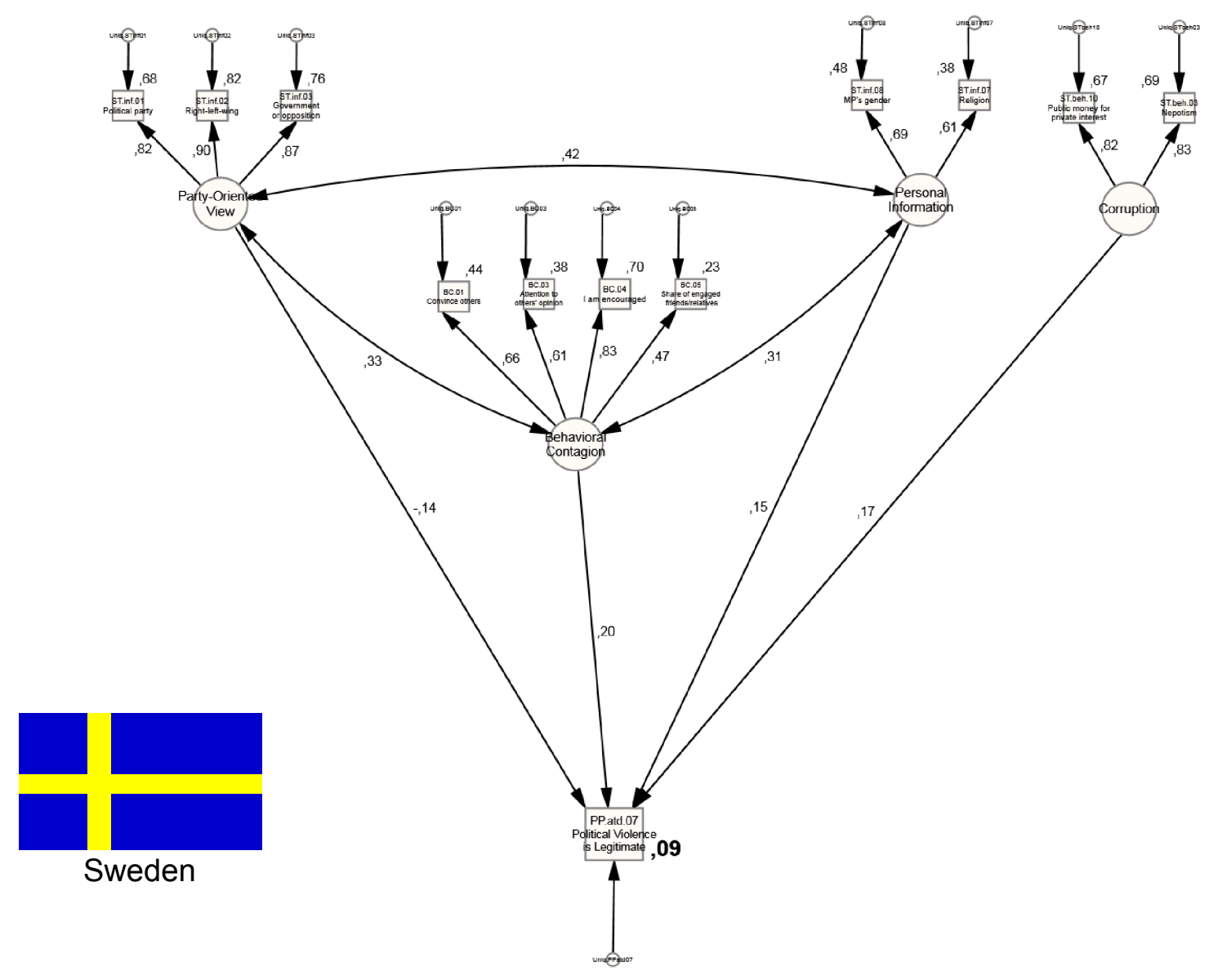

Figure 4.26. Explaining Political Violence Legitimacy in Sweden: Structural Equation Modeling results.

\subsubsection{Overview of SEM results}

As numerous models were presented in this section, Table 37 summarizes the Structural Equation Models for each type of Political Participation. 
Table 37. Summary of SEM models - predicting Political Participation factors and standalone items.

\begin{tabular}{|c|c|c|c|c|}
\hline $\begin{array}{c}\text { Dependent } \\
\text { (endogenous) } \\
\text { variable }\end{array}$ & Predicted by: & $\mathbf{R}^{2}$ & $\begin{array}{r}\text { Sweden } \\
\text { Predicted by: }\end{array}$ & $\mathbf{R}^{2}$ \\
\hline $\begin{array}{l}\text { Political } \\
\text { Disillusion }\end{array}$ & $\begin{array}{c}\text { Party-Oriented View (-) } \\
\text { Quality of Representation ( }) \\
\text { Party Membership (-) } \\
\text { Party Sympathy (-) } \\
\text { Party Rejection (+) } \\
\text { PE.07. "on your own" (med) } \\
\text { Age ( + ) } \\
\text { Education (- ) }\end{array}$ & .33 & $\begin{array}{c}\text { Party-Oriented View }(-) \\
\text { Quality of Representation }(-) \\
\text { Party Membership ( }- \text { ) } \\
\text { Personal Information }(+) \\
\text { Corruption }(+)\end{array}$ & .46 \\
\hline $\begin{array}{l}\text { Pre-Political } \\
\text { Engagement }\end{array}$ & $\begin{array}{c}\text { PE.05. from members of } \\
\text { association (med) } \\
\text { Behavioral Contagion }(+) \\
\text { Gender (women) } \\
\text { Personal Information (med) } \\
\text { Party Sympathy }(-) \\
\text { Quality of Representation }(-)\end{array}$ & .27 & $\begin{array}{l}\text { PE.05. from members of } \\
\text { association (med) } \\
\text { Behavioral Contagion }(+) \\
\text { Gender (women) } \\
\text { Corruption }(-)\end{array}$ & .23 \\
\hline $\begin{array}{l}\text { Institutional } \\
\text { Participation }\end{array}$ & $\begin{array}{l}\text { Behavioral Contagion }(+) \\
\text { Critical Information, } 2^{\text {nd }} \text { order } \\
\text { (med) }\end{array}$ & .83 & $\begin{array}{l}\text { Behavioral Contagion }(+) \\
\text { Quality of Representation }(-) \\
\text { PE.07. "on your own" (med) } \\
\text { Party Membership }(+)\end{array}$ & .80 \\
\hline $\begin{array}{c}\text { Political } \\
\text { Consumerism }\end{array}$ & $\begin{array}{l}\text { Behavioral Contagion (+ ) } \\
\text { Gender (women) } \\
\text { Party-Oriented View (med) } \\
\text { Quality of Representation ( }- \text { ) } \\
\text { Education }(+)\end{array}$ & .16 & $\begin{array}{c}\text { Behavioral Contagion }(+) \\
\text { Gender (women) } \\
\text { Party-Oriented View }(+) \\
\text { Corruption }(-) \\
\text { Left-Right, political orientation } \\
\text { (left) }\end{array}$ & .18 \\
\hline $\begin{array}{l}\text { Labor Union } \\
\quad \text { Strikes }\end{array}$ & $\begin{array}{l}\text { PE.05. from members of } \\
\text { association }(+)\end{array}$ & .10 & $\begin{array}{c}\text { Behavioral Contagion }(+) \\
\text { Personal Information }(+) \\
\text { Corruption }(+)\end{array}$ & .05 \\
\hline
\end{tabular}


Table 37. Summary of SEM models - predicting Political Participation factors and standalone items.

\begin{tabular}{|c|c|c|c|c|}
\hline & Brazil & & Sweden & \\
\hline $\begin{array}{l}\text { (endogenous) } \\
\text { variable }\end{array}$ & Predicted by: & $\mathbf{R}^{2}$ & Predicted by: & $\mathbf{R}^{2}$ \\
\hline $\begin{array}{c}\text { Street } \\
\text { Demonstrations }\end{array}$ & $\begin{array}{c}\text { Behavioral Contagion }(+) \\
\text { Quality of Representation }(-) \\
\text { Wealth }(-) \\
\text { Age }(-)\end{array}$ & .19 & $\begin{array}{c}\text { Behavioral Contagion ( + ) } \\
\text { Quality of Representation ( }- \text { ) }\end{array}$ & .18 \\
\hline Violence & $\begin{array}{c}\text { Behavioral Contagion (+) } \\
\text { Quality of Representation }(-) \\
\text { Age }(-)\end{array}$ & .12 & $\begin{array}{c}\text { Behavioral Contagion }(+) \\
\text { Party-Oriented View }(-) \\
\text { Personal Information }(+) \\
\text { Corruption }(+)\end{array}$ & .09 \\
\hline
\end{tabular}

Notes:

$(+)=$ Independent (exogenous) variable with positive effect on the dependent (endogenous) variable. $(-)=$ Independent (exogenous) variable with negative effect on the dependent (endogenous) variable. (med) $=$ Independent (exogenous) variable whose effect on the dependent (endogenous) variable is mediated by (an)other variable(s).

(women), (left) $=$ for gender and political orientation (Left-Right), the word between parentheses translate the positive or negative covariance into its real-world meaning. 


\section{Chapter 5: Discussion}

The items in the first draft of the questionnaire were based on previous literature, but the Delphic Panel participants had plenty of freedom to change them, since items should be suitable simultaneously for the Brazilian and Swedish contexts. Hence, after changes, the factor structure was unpredictable. Exploratory Factor Analysis was used to find non-predetermined factor structures and Confirmatory Factor Analysis was then employed to achieve comparability. Likewise, prediction models were freely tested with Stepwise Multiple Regression and improved with Structural Equation Modeling. Means for Brazilian and Swedish participants underwent t-tests for comparison.

This research results are discussed in the following four sections. First, general remarks on factor structures for the study of the selected phenomena; then, detailed examinations on CFA for each independent variable and their effect onto Political Participation; next, implications of this research findings to the Political Participation literature; finally, evidences of cultural differences retrieved from data.

\subsection{General Remarks on Factor Structure}

Exploratory Factor Analysis (EFA) presented differences between Brazil and Sweden. Those differences indicate cultural trends or context-specific issues. It is not a surprise, as these countries were chosen for their supposed contrasts (Bethell, 1985; Moisés \& Carneiro, 2008; Rothstein \& Uslaner, 2005; Schück, 2003; Scobbie, 2010; Scott, 1988; Wallin, 2014), and that the political scene is constantly changing. As explained on Section 2.6.4, Brazil and Sweden currently deal with very different political demands, and this might influence the citizens either to stay attentive or to 
engage on different types of action. Differences on factor structures do not seem to be a problem of measurement quality, but a reflection of real-world changes in course.

For illustration, if other countries were added to this study, one on a very stable moment and other close to a political revolution, it should be expected that factor structures would also be different. Why? Because when "monitorial citizens" get into action (a revolution could be a favorable moment), they mix "Attention" and "Action" behaviors, with implications on the factor structure. If citizens monitor without acting (supposedly on a very stable democracy), there might be a clearer separation between "Attention" and "Action" factors.

Brazil and Sweden are not living political system revolutions, nor serene stability. In both countries, people took the streets for different demands - bus fare reduction, freedom of speech and punishment to corrupt politicians in Brazil (Damasceno, 2013; Lima, 2013; Fernandes, 2013; Ramos, 2013; Ranthum, 2013); defense of immigrant rights in Sweden (Artiles \& Meardi, 2014; Hirvonen, 2013; Malmberg, Andersson, \& Östh, 2013), to name a few; recent elections were tense and intensely disputed, mobilizing voters around the political agenda of candidates, especially via social media discussions (BBC, 2014b; Castro, 2014; Christensen \& Kolling, 2014; Johnson \& Pollard, 2014; Larsson \& Kalsnes, 2014; Martín, 2014; Missau Ruviaro \& Missau Ruviaro, 2014). These events might have had different effects on the "mixing" of Attention and Action in the two countries, with reflections on EFA results. For example, in Sweden, participating in institutional meetings, contacting parliamentarians and contacting the written press were "mixed" with the Attention factor, while in Brazil attentive people were more likely to engage Political Consumerism.

The same reasoning is applied to the differences on Critical Information (from Stereotypes about Parliamentarians) factor structure on EFA results. Brazilians and Swedes employ distinct references to comprehend parliamentarians' differences. The 
parliamentarian's "Personal Information" factor (gathering gender and religion) was spontaneously found on EFA for Brazil, and it resisted the test of reducing the number of factors (see Section 4.1.2.1). It is understood that Brazilians either pay attention to Personal Information or to more "sophisticated" information, as Party-Oriented View and Representation Trends were strongly inter-correlated. Moreover, if the Personal Information factor was not found for the Swedish data, could it be specific of the Brazilian population? The answer to this question came with the Confirmatory Factor Analysis (CFA).

When Personal Information was inserted into the Swedish CFA model, Model Fit improved (comparing Model $\mathrm{A}$ and Model $\mathrm{C}$ on Table 12) - therefore, it was beneficial to keep it for Sweden, even if it was not present during EFA. Moreover, Personal Information had significant prediction power for Political Disillusion, Labor Union Strikes and Political Violence Legitimation in Sweden, an evidence of this factor's incremental validity.

Confirmatory Factor Analysis (CFA) allowed the finding of equivalent factor structures for all tested variables, by forcing items to stay on specific factors or to remain as standalone items. This forced positioning of items produced valid models otherwise Goodness-of-Fit would not reach acceptable parameters and equivalence tests would fail. Factor structure and metric equivalences allowed the comparison between the two countries.

As scales dealt very widely with the studied phenomena, bandwidth-fidelity trade-off became a relevant issue. Adding more items could help improving internal consistency (Cronbach's alpha and Jöreskog's Rho) and convergence (Rho ${ }_{v c}$ ); however, it would make the questionnaire much longer, reducing the interest of participants to respond (Boyle, 1991; Tremblay, 2001).

Parameters adopted for internal consistency (Cronbach's alpha and Jöreskog's Rho above 0.60 ) and convergence ( $\mathrm{Rho}_{\mathrm{vc}}$ between 0.30 and 0.70 ) may be considered 
low by the mainstream literature (Hair et al., 2009; Marôco, 2010; Pasquali, 2012). However, CFA models showed adequacy, as Goodness-of-Fit indices are regarded evidencing that factor structures were not distorted. When factors entered Structural Equation Models for predicting Political Participation, a relevant share of the dependent (endogenous) variable's variance was explained (given by $\mathrm{R}^{2}$, see Table 37 ). The good prediction potential is a previously mentioned advantage of "low consistency" factors (Boyle, 1991; Tremblay, 2001).

\subsection{Understanding Political Participation: the Contribution of each Independent (Exogenous)}

\section{Variable}

As each independent (exogenous) variable entered prediction SEM models, their contribution to explaining Political Participation is discussed. The following subsections approach theoretical implications of the relationships found in SEM models, considering differences between Brazil and Sweden.

\subsubsection{The effect of Stereotypes about Parliamentarians}

Though the items on Stereotypes about Parliamentarians were divided in two blocks, Critical Information and Behavior Prediction, there was no pre-conceived factor structure for them. Factor structures found with CFAs were compatible between the selected countries and allowed several comparisons, discussed below. 


\subsubsection{Critical Information}

The second-order factor for Critical Information about parliamentarians was composed by Party-Oriented View, Representation Trends and Personal Information first-order factors. The general Critical Information measure offers an evidence of participants' sensitivity to the variability of parliamentarians. It is inferred that, if a participant ignores one type of information, that is not relevant to him/her to tell the difference of one politician to another. Hence, stereotypes supposedly work as cues to understand which groups are present at the parliament.

Institutional Participation in Brazil (Figure 4.17 and Table 37) was the only context where the second-order factor for Critical Information played a significant role. Its effect was mediated by Behavioral Contagion, which will be discussed in detail on Section 5.2.4. Nonetheless, in Brazil, the citizen's capacity to tell the difference among parliamentarians has an important effect to mobilize participants into Institutional Participation. There is previous evidence that Brazilians cannot easily understand their country politics and do not usually know the difference among parties and among politicians (Henrique, 2010). In Sweden, none of the Critical Information factors helped predicting Institutional Participation (Figure 4.18). There is previous evidence that Swedes understand the difference among parties (Rothstein \& Uslaner, 2005). Why, then, is Critical Information important in Brazil, but not in Sweden?

In Brazil, those who understand politicians' differences have an "advantage" to participate, if compared to those who see no difference (Henrique, 2010; Moisés, 2008). In Sweden, since most citizens understand party-related differences, that knowledge does not represent an advantage of "the more informed" over "the less informed" citizens, on what concerns Institutional Participation. The absence of Critical Information factors on the prediction of Swede's Institutional Participation indicates that some Swedes get engaged, other do not, when they regard politician's differences. 
This is supported by the t-test results. Swedes, more often than Brazilians, pay attention to Party-related information. Brazilians, on the contrary, pay more attention to Representation Trends and Personal Information. This suggests that Brazilians, more than Swedes, need to rely on "additional information" about parliamentarians, since parties, government-opposition dichotomy, left and right wings do not provide enough information to tell parliamentary groups apart. Reliance on Representation Trends may actually indicate the need for less obvious, somewhat technical information, like the groups or minorities each parliamentarian represents and his/her former political positions (Carlin \& Love, 2013; Garzia, 2013; Koch, 2003). This evidences that Brazilians do not see parties' differences so clearly as the Swedes do (Kinzo, 2004; Sallum Júnior, Graeff \& Lima, 1990). In a different manner, the reliance on Personal Information as a relevant cue indicates a lack of capacity to understand the political arena (Henrique, 2010; Samuels, 1997; Shildo, 1990). Since Brazilians relied more on Personal Information than Swedes, this reinforces the difficulty to understand Brazilian politics with "traditional" information - parties, government-opposition dichotomy, or right and left wings.

The Personal Information factor also played a relevant role in Sweden. Political Disillusion and support to Political Violence increased in the same direction as attention to Personal Information, i.e., a positive covariance was found (Figures 4.14 and 4.26). Under this perspective, attention to Personal Information antagonizes with prodemocratic behaviors. These Swedes seem to ignore the mainstream politics (as Party-related information and Representation Trends seem to be secondary to them), and choose to "break the social contract", i.e., they engage into non-negotiating postures. This would explain, on the same way, why attention to Personal Information predicts participation on Labor Union Strikes - which intention is to force employers to negotiate. 
In Sweden, both gender and religion are currently related to breaking the social contract. Feminist activism makes its points through intensively contesting actions (Cowell-Meyers, 2014; Wikstrom, 2014). Religion, on its turn, is related to the immigration of Muslims - which is the underlying motivation of 2013 riots, when the killing of an immigrant triggered violent protests (The Local, 2013c, 2013d, 2013e and 2014). In both cases, the fact that Personal Information entered the prediction models is an evidence of its incremental validity for assessing political opinion in Sweden. Moreover, this finding was only made possible through the cross-country comparison, as on the first look "Personal Information" seemed to be a Brazilian-specific factor.

Differently from Sweden, Personal Information in Brazil was associated with Pre-Political Engagement (Figure 4.15), mediated by Behavioral Contagion. This might reflect the insertion of churches into the political scene and gender-equality activism. In Brazil, churches are actively connected to the mainstream politics, especially the Christian Evangelicals (as Protestants are usually referred to in Brazil - Kleba \& Wendausen, 2009; Montero, 2009; Oro, 2003). Likewise, feminist and gay-rights activism have gained importance on the recent years (Facchini, 2010). Often, these two themes are connected, as homosexual and feminist activism antagonize with Christian commonly spread beliefs (Natividade, 2010).

In both countries, Political Disillusion decreased as the citizen showed a PartyOriented View, i.e., a negative covariance was found (Figures 4.13 and 4.14). This highlights that understanding the party-related differences helps preventing citizens to fall into hopelessness towards political institutions. Similarly, it helps preventing Swedes from supporting Political Violence (Figure 4.26).

Party-Oriented View had positive effects onto Political Consumerism (Figures 4.19 and 4.20), both in Brazil (mediated by Behavioral Contagion) and in Sweden (directly). This reflects the growing importance of parties with an environmental agenda ("green" parties, such as Partido Verde in Brazil or Miljöpartiet in Sweden), in both 
countries, in opposition to "gray" parties, those friendly to big businesses (Breiting \& Wickenberg, 2010; Dolezal, 2010). In Sweden, it was found that left-wing participants are more likely to engage Political Consumerism, which actually reflects the trend of environmental-friendly parties, as they usually oppose big businesses (Green-Pedersen, 2012; Holmberg \& Hedberg, 2009). In Brazil, instead of the political orientation, the increase of Education Level positively predicted Political Consumerism. Therefore, use of consumption choices to pressure businesses seems to be related to the scientific knowledge provided by formal education.

It is remarkable that Critical Information factors had a relevant effect on some types of political participation, while it helped preventing Disillusion (in both countries) and violence (in Sweden), as there was a negative covariance with these. This highlights that the understanding of group differences is not necessarily attached to prejudice and discrimination (corroborating Jussim, McCauley \& Lee, 1995; Mackie, 1973; Ryan, 2003). Party-Oriented View and the general Critical Information factors had a pro-democratic effect - hence, the ability to differentiate politicians based on these criteria produced a positive attitude towards politicians. Personal Information, on the contrary, was associated with Disillusion and Violence, unveiling a negative attitude. Generally speaking, Critical Information factors were indeed ambivalent, as explained in Section 2.2.1. Moreover, they allow the identification of citizens' trends to pro-democratic or antidemocratic behaviors.

The capacity of predicting the dependent (endogenous) variables (Political Participation factors or standalone items) is an evidence of Incremental Validity for the Critical Information factors. Future studies may explore more questions under the perspective that the attention to Critical Information represents the understanding of differences among parliamentarians, parties, and groups they represent. The introduction of this variable contributed to the increase of explained variance on prediction models. 
Stereotypes about Parliamentarians, beyond Critical Information, also relates to how citizens try to predict the behaviors of their representatives. Therefore, the next section discusses the effect of Behavior Prediction onto Political Participation.

\subsubsection{Behavior Prediction}

Regarding citizens' expectations upon parliamentarians' behaviors in Brazil and Sweden, Quality of Representation was found to be better in Sweden, and Corruption was perceived as higher in Brazil. This finding actually supports previous studies on each country's political culture, as they indicate poor trust, high corruption and low perceived efficacy of political institutions in Brazil (Azevedo \& Chaia, 2008, Cunha, 2006; Moisés, 2008; Moisés \& Carneiro, 2008; Ribeiro, 2007) and high trust, low perceived corruption and good efficacy of Swedish political institutions (Rothstein \& Uslaner, 2005; Wallin, 2014). It is reasonable to infer that Swedes are more satisfied with their democratic institutions than Brazilians, which is also supported by the studies above.

With that in mind, Political Participation in Sweden was unexpectedly lower than Brazil, when means were compared. Brazilians were more engaged on Institutional Participation, also considering Attention and Action factors separately. Brazilians were also more active on Pre-Political Engagement, Labor Union Strikes and Street Demonstrations. Brazilians also showed greater Political Violence Legitimation and they were more disillusioned than Swedes.

This contrasts with the statements that Brazilians are apathetic and not interested on politics (Moisés \& Carneiro, 2008) and that Swedes are "post-modern" citizens that feel integrated to the political system and participate in political activities through trade unions and political parties more than other countries (Hooghe \& Dejaeghere, 2007). This brings back Teorell's (2006) question: "which degree of participation should be considered satisfactory?" 
Revisiting prediction SEM models (summarized on Table 37), it was found that Political Disillusion in Sweden increases as perception of Corruption Increases and perception of Quality of Representation lowers. The same effect was found for Quality of Representation in Brazil, but perceived Corruption did not help predicting Political Disillusion there. The absence of the Corruption factor on the model indicates that Brazilians can get Disillusioned or not, notwithstanding how corrupt politicians seem to be.

For both countries, bad Quality of Representation is connected to Disillusion. Nevertheless, when the Swedish Institutional Participation prediction model is revisited (Figure 4.18, or Table 37), it is found that citizens that perceive bad Quality of Representation are more likely to pay Attention and to get into Action (as the first-order factor names suggest). Consequently, it is true that dissatisfied citizens may get more interested on politics, in Sweden. It is suggested in previous research (Amnå \& Ekman, 2014) that people get into action when they distrust people in power. The same effect was observed on other types of Political Participation in Sweden, like participating on Labor Union Strikes (where higher perceived corruption increased engagement, Figure 4.22), on Street Demonstrations (where lower Quality of Representation increased engagement, Figure 4.24) and Political Violence Legitimation (increased by perceived Corruption, Figure 4.26). Outlooking the Swedish data, Corruption had positive effect on social-contract-breaking attitudes (Political Disillusion and Political Violence Legitimation) and negotiation-breaking (Labor Union Strikes). The common ground among these is that people lost their faith on reaching agreements via "mainstream politics".

Political Consumerism and Pre-Political Engagement underwent a reversed effect in Sweden: lower perceived Corruption increased engagement. The link between politicians' honesty (given by the reversed Corruption effect) and Political Consumerism is however difficult to explain. It challenges the argument of Stolle, 
Hooghe and Micheletti (2005), as they state that Political Consumerism may be accompanied by disappointment with the mainstream politics. Corruption items suggest that parliamentarians make use of public money for private interests (ST.beh.10) and practice nepotism (ST.beh.03). When reading them reversely, it is possible to understand that citizens have greater chances to engage Political Consumerism as they see parliamentarians making good use of public resources and avoiding nepotism. Conceivably, "honest parliamentarians" serve as a good example of respect for the law and inspire citizens to engage Political Consumerism. This type of political action requires "honesty" from companies, as they would be punished (boycotted) for exploring slave labor, harming the environment or other easy-profit-driven strategies. The same reasoning could be applied to Pre-Political Engagement, as communitarian activity requires members to be honest, so the mutual trust encourages collective action (corroborating Realo, Allik \& Greenfield, 2008).

In Brazil, differently, perceived Corruption and Quality of Representation did not have any effect on Institutional Participation (Figure 4.17) - in spite of that, a large share of variance was explained $\left(R^{2}=0.83\right)$ by Critical Information and Behavioral Contagion, as discussed. Revisiting the other Political Participation prediction models, it was observed that bad Quality of Representation mobilized people to take the streets (Figure 4.23) and to support political Violence (Figure 4.25). On the same direction, low Quality of Representation is related to Pre-Political Engagement and to Political Consumerism in Brazil. For these last two types of participation, the effect was the opposite from that one found in Sweden: when politicians are "not doing a good job", Pre-Political Engagement and Political Consumerism increased.

It is remarkable that, despite corruption being a very important issue on Brazilian politics (Bethell, 2008; Cinnanti, 2011; Henrique, 2013; Moisés, 1992), this factor did not enter any of the Brazilian prediction models. A careful interpretation must be held here. The absence of Corruption in the prediction models does not necessarily 
indicate that Brazilians are insensitive to it - especially considering that Brazilians took the streets on Marches Against Corruption (Colon \& Moura, 2011; Estadão.com.br, 2011; Lima, 2012) since 2011 and on June 2013 protests (Abreu \& Medeiros, 2013; BBC Brasil, 2013; Ranthum, 2013). It might be the case that some Brazilians react to Corruption by engaging political action, others do not - hence, statistics become trendless, and no significant covariance is found. It is possible that the same trendlessness happened to other types of Political Participation in Brazil, but present results are not enough to uphold a steady conclusion.

It is interesting to observe, though, that Quality of Representation played a significant role on predicting participation in Brazil. Distrust in political institutions is usually associated to low participation, but it is admitted that some degree of dissatisfaction is necessary to mobilize citizens (Cinnanti, 2011; Lavalle \& Vera, 2011).

Under another perspective, Corruption did not enter SEM models for Institutional Participation and Street Demonstrations in Sweden, too. Low Quality of Representation, instead, was a significant predictor. One possible interpretation is that corruption alone is not enough to explain citizens' dissatisfaction with politicians, but perceiving the low Quality of Representation may catalyze action, which adds evidences to Amnå and Ekman's (2014) findings.

At the end, these results left an open question: if Corruption is perceived to be lower in Sweden, what do Swedes "do right" and Brazilians "do wrong" when it comes to prevent it? Reexamining Teorell's (2006) question, the answer might not be "more participation is better", but probably how people participate is important. This must be assessed through non-quantitative techniques. Wallin (2014) explored this matter by interviewing politicians, judges and public servants in Sweden. Interviewees frequently stated that it is important that the people trust the system, and therefore they are rigorous on the use of public resources and on being transparent and accountable. Interviewed citizens said that they pay politicians' salaries, so they expect a good work 
to be done. This contrasts with Brazilians' reported hopelessness on fixing corruption, as they were resigned to the belief that corruption is an inevitable part of the political system (Henrique, 2013; Moisés \& Carneiro, 2008).

\subsubsection{Political Education}

\section{Exploratory Factor Analysis showed that Formal (and Home) Education} composes a distinct sphere of learning politics from "Socialization plus learning alone". However, the first factor was not consistent for the use on further analysis. "Socialization", in turn, could be considered a factor with good internal consistency for the adopted parameters (Jöreskog's Rho $=0.67$; Rho ${ }_{\mathrm{vc}}=0.41$ for Brazil; Jöreskog's Rho $=0.69 ;$ Rho $_{\mathrm{vc}}=0.43$ for Sweden). Surprisingly, despite its items had been positively intercorrelated, it was finally found that item PE.05 (“... from members of an association / trade union / party in which you are a member ") had direct effect onto engaging Labor Union Strikes in Brazil and indirect effect on Pre-Political Engagement in both countries, regardless the other items in that factor. This reinforces that the use of Structural Equation Modeling (SEM) was useful to prevent erroneous conclusions, as Modification Indices allow such in-depth, item-to-item verification, and that Goodness-of-Fit Indices do indicate the occurrence of problems in the model. This problem would hardly be found with the sole use of Multiple Regression.

At the end, no factors for Political Education were kept. As learning contexts seemed very distinct, the seven items for Political Education entered Stepwise Multiple Regression and SEM as standalones.

Comparison of means indicates that attaining elementary and secondary education levels have greater impact on the learning of politics in Sweden than in Brazil. When it comes to the contribution of University education, the opposite was 
observed: Brazilians, more than Swedes, say that the University contributed to their learning of politics.

This indicates a difference between educational curricula policies in Brazil and Sweden. In Sweden, elementary and secondary schools must approach political issues in their curricula (Børhaug, 2008). As education is developed as a "ladder", University education will not provide Swedes with the basics of political issues (they were provided in the previous steps). In comparison, Brazilian indoctrinating disciplines on the first and second grades (mentioned in Section 2.3.2) were not welcomed in times of democracy (Menezes \& Santos, 2002; Menin, 2002), and to present day they were not reinserted. Hence, Brazilians did not learn much about politics at school, and they may be critical about their own indoctrinating education - which may be explored on further studies. Anyway, University gains importance to Brazilians' political learning. Brazilian University students are usually involved in political action, such as June 2013 rallies and President Collor's impeachment (Bethell, 2008; Gohn, 2009; Ranthum, 2013); University professors and students fought military dictatorship (Durham, 1998). Politics is not formally inserted on Brazilian University education, but the greater importance Brazilians gave to this locus of learning might be effect of actual political action initiated at the Universities and the personal initiatives of some professors to regard politics as an inevitable part of education (Demo, 2005).

There was no significant difference on the importance citizens of both countries gave to the learning of politics from their families. On both countries, learning politics alone (item PE.07 “...on your own”) had greater importance, having Brazilians found it more important than Swedes.

The contribution of these contexts to explaining Political Participation was disappointingly low. As Table 37 is examined, the only Political Education selfevaluative items that entered the models are PE.05 (“... from members of an 
association / trade union / party in which you are a member") and PE.07 [“... on your own (reading books, newspapers, Internet, watching TV, radio, etc.)."].

Item PE.05 had its effect onto Pre-Political Engagement mediated by Behavioral Contagion. Pre-Political Engagement is essentially a composition of volunteering and community-oriented action, usually organized by non-governmental organizations (NGOs), churches, kids' schools, or neighbourhood associations. This actually means that people who learn about politics at these places share experiences, exert influence onto each other mutually (Behavioral Contagion), and drive their action to the same places (Realo, Allik \& Greenfield, 2008). In other words, item PE.05 is essentially attached to the membership to some community-driven organization, just as PrePolitical Engagement. The mutual influence (Behavioral Contagion) helps to turn "learning" into "action" (see Figures 4.15 and 4.16).

Item PE.05 was connected to participating in Labor Union Strikes, in Brazil however, in this case, it had a direct effect (Figure 4.21). Similarly, this strong direct link is explained by the fact that both independent and dependent variables mention "labor union". Therefore, learning about politics from other labor union members helped engaging this type of action. The absence of item PE.05 on the Swedish model for predicting Labor Union Strikes is thus surprising; however, it seems that in Sweden this type of participation is better explained by non-negotiation postures (as explained in Section 5.2.1.1) and by Behavioral Contagion.

Item PE.07 [“... on your own (reading books, newspapers, Internet, watching TV, radio, etc.)."] had mediated effect in the two models it participated. First, in Brazil, mediated by Party-Oriented View, it helped preventing Political Disillusion (Figure 4.13). It is clear that learning alone helped Brazilian citizens to understand the functioning of "mainstream politics", (as concepts of left-right wings, government versus opposition and party differences are understood) and this had a "prevention effect" onto Political Disillusion, since a negative covariance was found. 
In Sweden, learning alone was mediated by Behavioral Contagion when predicting Institutional Participation. This highlights that learning politics alone has a positive effect onto Behavioral Contagion (Figure 4.18), then with a positive effect onto Institutional Participation.

Other than items PE.05 and PE.07, the demographic item "Education" (last level of formal education achieved) entered two SEM models with significant effect, both for Brazil. The more educated Brazilians tend to be less Disillusioned (Figure 4.13), which represents an inversion on previous evidence. Henrique (2010) and Moisés and Carneiro (2008) had found that more educated Brazilians were the most dissatisfied with the functioning of democratic institutions. This reversion may have happened on recent years, and its explanation is challenging. As data collection took place four months prior to the elections, traditional media and social media were taken by intense political discussions (Castro, 2014; Christensen \& Kolling, 2014; Nidecker, 2014), which might have influenced the more educated Brazilians to renovate their hopes on the democratic process.

Education attainment is also present at the Political Consumerism prediction model. The more educated Brazilians were more likely engaged to Political Consumerism (Figure 4.19). This might be a reflection of a better understanding of sustainability and sociological implications, as provided by formal education (Farias et al., 2012; Milfont, 2010).

Generally speaking, Political Education had very little effect onto Political Participation. Item PE.05 was found important where the context of learning was also the context of participation (association, labor union, community). Item PE.07, the "learning alone" item, was important for predicting Political Disillusion in Brazil and Institutional Participation in Sweden. All other loci of political learning were excluded from SEM analyses - school, university, family, coworkers and friends. Education level predicted Political Disillusion and Political Consumerism in Brazil. 
Why did the loci of political learning have such little effect, especially those related to formal education (school and university)? As discussed on Section 2.3, there is previous evidence that Education does not significantly contribute to engaging political action (Kam \& Palmer, 2008; Persson, 2012). The present study does not allow to firmly state whether the almost absence of formal education in the prediction models represents its ineffectiveness to create politicized attitudes or if it is just a trendless statistic. At the second situation, there is the possibility that education has effect for some participants to engage political action, but not to others. Putting it simple, if in a class half of the students engage political action, but the other half does not, no trend comes out from statistics. Moreover, Parry (1999) asserts that different types of education may result from different types of understanding about what should be the role of schools: to question society or to help keeping the traditions. These different political views may lead to different engagement attitudes, producing trendless statistics.

Qualitative studies are necessary to evaluate the effect of different educational curricula and different socialization contexts on forming more participation-prone citizens. This goes beyond the scope of this study, as an in-depth analysis of school programs and open-ended interviews would be needed to understand the phenomena.

\subsubsection{Behavioral Contagion}

Behavioral Contagion became a one-dimensional variable intended to evaluate how much the participants followed someone else's influence or tried to influence others into Political Participation, according to the t-tests. It mixes behaviors of influencing others (item BC.01, "I usually try to convince friends to participate in political action"), following the influence of others (items BC.03, "I pay attention to the opinion of friends who are more politically active than I am"; BC.04 "I am encouraged by people 
close to me to participate in politics.") and the size of the participant's network [item BC.05, "How big a share of your friends/relatives usually take part in political activities (approximately)?"]. These items were intended to represent the influence phenomena described by Le Bon (2008) and the later literature in Section 2.3.2.

The item BC.02 ("I understand the politics of my country better than most of my friends") was intended to assess if the participant could have an important influence by his/her better knowledge about the country politics. However, this item was removed, as it did not make a reliable factor with the others. It can be understood by the removal of this item that knowledge does not significantly relate with influencing others or following influence. This actually finds support on Le Bon (2008), who asserts that the clairvoyance (i.e., intelligence) antagonizes the strong will, which is necessary to influence the crowd; the intelligent person is more likely to be doubtful and hesitant, while the person with strong, yet irrational conviction, exerts strong influence on the crowd.

As the items composing Behavioral Contagion represent both "influencing" and "being influenced", the one-factor structure indicates that what is really important on this matter is to be part of a politically active network. After all, if a participant says that he/she exerts influence on others and are influenced by others, he/she is probably one node of a "web of influence".

Gomes and Maheirie (2011) found evidences that mutual influence for political action is usually mixed to everyday activities, and that friends in Movimento Passe Livre (Zero Bus Fare Movement) serve as models of politically active people. While Le Bon describes the effect of that influence as an irrational "feeling of invincible power", Gomes and Maheirie consider that participants consciously feel happy for being part of the group and fighting for a common cause. Regarding Gomes and Maheirie's argument, the participation on a politically active group is a means of exerting influence onto others and being influenced by them. Therefore, the Behavioral Contagion factor 
indicates that the participant is part of a politically active network (as a formal institution or built on informal relationships), and that people on this network mutually influence each other. Moreover, Gomes and Maheirie's findings challenge Le Bon's statement that strong will comes from irrational conviction of lowly-clairvoyant persons. Further qualitative studies are needed to deepen the evidences on the effect of intelligence over network influence (social capital, if you will), since no more studies were found exploring this link.

In its final compound, Behavioral Contagion had a strong positive effect on Political Participation. In all models on Section 4.3 where this variable enters, it had the strongest direct covariance to the target type of Political Participation. It also had mediating effect on Political Education items (PE.05 and PE.07, as discussed on the previous Section) for both countries and on Critical Information factors (from Stereotypes about Parliamentarians) for Brazilians. As prediction models are regarded, it is evidenced that Behavioral Contagion provided the main contribution to the understanding of the selected Political Participation types. This highlights a strong Incremental Validity for this variable, even though it has a very simple factor structure.

Regarding prediction models for Pre-Political Engagement (Figures 4.15 and 4.16), Behavioral Contagion has a pivotal role, as it covaries with all other independent variables, except Quality of Representation (for Brazil) and Corruption (for Sweden). The learning of politics from members of an association, labor union or party is mediated by Behavioral Contagion, which emphasizes that the mutual influence is fundamental to change the learned knowledge into action. Moreover, concerning gender, in both countries women are more likely to engage this type of action (corroborating Ackelsberg, 2003; Burns, Schlozman \& Verba 2001; Micheletti, 2003), though men play a significant role on convincing others to engage. In Brazil, though Behavioral Contagion covaried positively with Party Sympathy, the lesser participants were sympathetic to parties, the more they engaged into community-oriented activities. 
Complementarily, attention to parliamentarians' Personal Information, mediated by Behavioral Contagion, resulted on likelihood to Pre-Political Engagement. Hence, Brazilians who avoid mainstream politics and integrate a network of influence may mobilize their communities, as they do not trust the capacity of politicians to solve their problems (Amnå and Ekman, 2014; Stolle, Hooghe \& Micheletti, 2005).

Behavioral Contagion was also pivotal for Institutional Participation. In Brazil, attention to parliamentarians' characteristics (Critical Information) seems to discriminate citizens who are prone to engage institution-oriented action. As this variable was mediated by Behavioral Contagion, it is understood that the network influence is needed to convert the knowledge about parliamentarians into action. In Sweden, citizens' dissatisfaction with Quality of Representation is already a direct Institutional Participation trigger. However, a greater effect is caused by Behavioral Contagion, as it helps converting the lone learning of politics (item PE.07) into action and, besides, offers explanation to the Party Membership, enhancing its effects onto participation. In other words, party membership may eventually occur to a person who already incorporates an influence network - perhaps as friends convince him/her to become a member, to improve chances of participating on specific events (Figure 4.18). In both Brazil and Sweden, Behavioral Contagion was important to convert beliefs into action (corroborating Cho \& Rudolph, 2008; Lake \& Huckfeldt, 1998; Le Bon, 2008 and Moscovici, 1985).

As discussed on Section 5.2.1.1, Party-Oriented View had positive influence onto Political Consumerism. In Brazil, it was mediated by Behavioral Contagion, but in Sweden there was a simple covariance connection between these two factors. As Green Parties (Partido Verde in Brazil, Miljöpartiet in Sweden) may set an environmental agenda and other left-wing parties may deal with fair trade issues, Behavioral Contagion may help convert the intention into effective politically-oriented 
consumption choices. After all, as a form of pressuring companies and governments, Political Consumerism (boycotts or buycotts) have to have wide adhesion.

Behavioral Contagion was a significant predictor of Labor Union Strikes engagement in Sweden (Figure 4.22), with a strong covariance with attention to parliamentarians' Personal Information. Behavioral Contagion might be related to touting colleagues into joining the strike, as massive participation is needed to make pressuring successful.

Differently from the aforementioned types of Political Participation, Behavioral Contagion predicted engagement into Street Demonstrations without mediation or covariation effects (Figures 4.23 and 4.24). This indicates that, for some people, social influence may function as the only reason to join Street Demonstrations. Negative Quality of Representation plays a secondary role in both countries, as well as age and wealth (which had negative effects) in Brazil.

Similarly, Behavioral Contagion had the strongest effect over Political Violence Legitimation in Brazil, separately from age and Quality of Representation (these two with negative effects). In Sweden, differently, Behavioral Contagion was related to both Party-Oriented View and Personal Information factors. Therefore, Behavioral Contagion is related to disappointment with the mainstream politics (as Party-Oriented View had negative effect onto Political Violence Legitimation) and the adoption of "nonnegotiation" postures (related to the Personal Information factor, as explained in Section 5.2.1.1).

Several studies mentioned on Section 2.4 (e.g. Djupe \& Grant, 2001; McClurg, 2003; McFarland \& Thomas, 2006) showed evidences of Behavioral Contagion effects. It is interesting that Cho and Rudolph (2008) had stated that social dissemination is relevant, regardless other measures such as social involvement, political engagement, interpersonal trust, education, income, age, race and gender. Accordingly, this study found Behavioral Contagion as the strongest predictor of Political Participation. 
The influence to join mainstream politics, suggested by this study's items on Behavioral Contagion, may be distanced from some specific contexts of political action. Future studies may add more items to this questionnaire, to explore additional forms of influencing others and being influenced. Moreover, if future studies investigate specific types of political action, items may receive specific wording in order to better predict each type of participation. For example, instead of BC01 be worded as "I usually try to convince friends to participate in political action", it could be rephrased on a study on Political Consumerism: "I usually try to convince friends to choose products under relevant ethical or environmental criteria". Nevertheless, presented findings support the strong effect of Behavioral Contagion onto Political Participation, making it worth to explore this variable and its implications.

As a matter of fact, Behavioral Contagion seemed to blur the boundaries between individual and collective political action (Carneiro, 2014; Lake \& Huckfeldt, 1998). If political actions do take place by the mobilization of collective interests, can we expect to find truly individual types of political action? When political action is oriented to influence the parliament, to pressure companies to adopt environmentprotecting practices or to forgo the exploration of slave labor, to negotiate wage raises with employers, etc., effectiveness come from collective action. Could voting be the paradigmatic action of individuals in isolation, or does the influence of his/her friends and relatives make voting a collective decision?

Survey-based research designs deal with the limit of using individuals' responses to infer collective processes (as criticized by Cho \& Rudolph, 2008). This problem is actually difficult to solve, as surveys are not friendly to collective answering - many disadvantages would appear, such as risking participants' privacy and having answers reflecting the most influent participant's opinion. However, this research results demonstrated that it is actually possible to ask people about influencing and being influenced on an individually responded questionnaire. Moreover, there is strong 
evidence of results validity; inferences made upon them bring relevant insights to how political action happens, and plenty of implications for future studies.

\subsubsection{Party Preferences and Demographic Characteristics}

The questionnaire included several items to assess the effect of demographic characteristics and party preferences on Political Participation. Those items entered the prediction models differently, according to the country and the type of participation under analysis.

Party preferences had a relevant effect on Political Disillusion for Brazilians. It can be depicted from Figure 4.13 that party-sympathizers and party members are less Disillusioned (cov $=-0.10$ and -0.08 , respectively). Those who reject parties are more likely to feel Disillusioned (cov $=0.10)$. Rejecting, being sympathetic or being a member of a party is related to the Quality of Representation - bad quality leads to rejection, good quality leads to sympathy or membership. In Sweden (Figure 4.14), only party membership had a significant effect on Disillusion, with negative orientation (cov $=-0.08$, just like Brazil). In Sweden it was not related to Quality of Representation, but actually to understanding the mainstream party politics - as party membership mediated to some extent the effect of Party-Oriented View factor.

Age had a relevant role only to some types of participation for the Brazilian participants. Older people are more likely to be disillusioned with politics (Figure 4.13) and youngsters are more likely to engage Street Demonstrations and to support Political Violence. These two are risky types of political actions, as in Brazil they face police repression, such as the recent episodes on June 2013 (Andrade, Affonso \& Bianchi, 2013; Damasceno, 2013; Gohn, 2014). The greater disappointment of older people might indicate that politicians did not respond adequately to the trust they were given in the past (Henrique, 2010; Moisés, 2005). 
Wealth, assessed via possession of goods, had negative impact on joining Street Demonstrations in Brazil. This indicates that poorer people were more likely to engage. The recent episodes of protesting were triggered by bus-fare raises and dissatisfaction with public services (Abreu \& Medeiros, 2013; Gohn, 2014; Vion-Dury, 2013), which are mostly used by the lower classes in Brazil (Vasconcelos, 2012).

In addition to the discussion on what predicts Political Participation, it is necessary to explore how each category may differ. The next Section discusses how the portrayal of Political Participation in the present study contributes to literature on this matter.

\subsection{The Different Types of Political Participation}

As explained in Section 1.1, the focus for the present study is the political participation regarding the bodies of the National Legislative Power. Thus, this study is leaned to give greater importance to Institutional Participation, and other types are approached for comparison purposes. The fact that Institutional Participation became the most complex dimension (Attention and Action gathered at a second-order factor) did not happen by chance.

Moreover, most independent (exogenous) variables aimed the mainstream politics, especially Stereotypes about Parliamentarians. Perhaps "stereotypes about businessmen" could better predict Political Consumerism or adhesion to Labor Union Strikes, but when this research was planned, greater importance was given to the members of parliaments. Items' wording for Behavioral Contagion were also trended to mainstream politics, as explained in Section 5.2.4. Political Education items were suitable to many types of political action; however, as most of the questionnaire dealt with mainstream politics, participants probably interpreted, by context, that items were referred to parliament-related politics. 
Probably for these reasons, the Institutional Participation factor had a greater amount of variance explained in prediction models for Brazil and Sweden $\left(R^{2}=0.83\right.$ and $R^{2}=0.80$, respectively). Since Political Disillusion items also referred to mainstream politics, it may be considered as an opposition to Institutional Participation. Political Disillusion was satisfactorily predicted by the independent variables that entered the models $\left(R^{2}=0.33\right.$ for Brazil, $R^{2}=0.46$ for Sweden). Other Political Participation types had lower extents of explained variance. Put in descending order: Pre-Political Engagement $\left(R^{2}=0.27\right.$ for Brazil, $R^{2}=0.23$ for Sweden), Street Demonstrations $\left(R^{2}=0.19\right.$ for Brazil, $R^{2}=0.18$ for Sweden), Political Consumerism $\left(R^{2}\right.$ $=0.16$ for Brazil, $R^{2}=0.18$ for Sweden); Political Violence Legitimation $\left(R^{2}=0.12\right.$ for Brazil, $R^{2}=0.09$ for Sweden); Labor Union Strikes $\left(R^{2}=0.10\right.$ for Brazil, $R^{2}=0.05$ for Sweden). This reinforces the argument that items' wording has to be closer to the type of participation under investigation. As participation in parliaments is the main interest for this study, independent variables were worded accordingly. It was useful to achieve a strong prediction of Institutional Participation, but other types of political action may demand different kinds of explanation.

Factor structure for Political Participation was consistent and equivalent between Brazil and Sweden. There are, however, opportunities for improvement. Adding items to each type of political participation could make factor structure better. Talò and Mannarini (2014), who also based their questionnaire on Ekman and Amnå's (2012) framework, used at least four items for each type of category investigated, achieving better factor consistency (Cronbach's alphas between 0.71 and 0.81 ). The trade-off between bandwidth and fidelity will still be an important issue, as this addition of items may reduce participants' interest to respond.

Additionally, the factor structure for Political Participation evidences that some types of political action may be different to the point that they do not form a continuum. Community-oriented action (named Pre-Political Participation herein) is different from 
Political Consumerism, as they did not join consistently the same factor. Labor Union

Strikes is different from Street Demonstrations, even though protesting could be a common ground between them. Present study's results do not allow to state that PrePolitical Engagement lies between Political Disillusion and Institutional Participation. Actually, the Institutional Participation factor sheltered Attention and Action behaviors according to a common target: the parliament / government issues. Differently from Ekman and Amnå's (2012) conception, Political Participation types might be distinguished according to the target in question: influencing the national parliament, improving community's quality of life (in the case of Pre-Political Engagement) changing companies' policies (in the case of Political Consumerism) or negotiating with employers (in case of Labor Union Strikes).

Considering this, it is suggested that Political Participation categories may be once again reframed. Ekman \& Amnå's (2012) categories are rearranged in Table 38. Political action categories are defined by the crossing of their targets (rows) with the continuum disengagement-attention-manifest participation (columns). As prior evidences and theoretical advances suggest (Anderson, 2010; Borba \& Ribeiro, 2010; Brussino, Rabbia \& Sorribas, 2008; Ekman \& Amnå, 2012; Stolle, Hooghe \& Micheletti, 2005; Talò \& Mannarini, 2014), citizens may engage in different types of political action, since they are not exclusive - though it might be rare to find one citizen involved on all or several types at the same moment. The number of political targets (rows) in undetermined, as new targets may appear in the future. Finally, as Behavioral Contagion seems to blur the boundary between individual and collective action, those rows were removed.

For each target, political action can be classified as Disengagement (active and passive), Attention and Manifest Participation (Non-Violent and Violent). It is suggested that disengagement sub-categories be renamed. The passive political attitude can be regarded as "Unconcerned", i.e., the citizen is careless for the political system. More 
relevantly, the active forms of disengagement are suggested to be named "Antagonistic", as these citizens might be not engaged on the mainstream political system, but they politicizedly engage alternative lifestyles. Antagonistic citizens are not careless about politics, but they strongly reject decisions in parliament and do something about it. It is the case of Hippies (which started by the rejection against war on Vietnam) and Anarchists (who reject the institutionalized state). 
Table 38. New categories for Political Participation

\begin{tabular}{|c|c|c|c|c|c|}
\hline \multirow[b]{2}{*}{ Target } & \multicolumn{2}{|c|}{ Disengagement } & \multirow[b]{2}{*}{ Attention } & \multicolumn{2}{|c|}{ Manifest Participation } \\
\hline & $\begin{array}{l}\text { Antagonistic } \\
\text { (Active forms) }\end{array}$ & $\begin{array}{l}\text { Unconcerned } \\
\text { (Passive forms) }\end{array}$ & & Non-Violent Action & Violent Action \\
\hline $\begin{array}{l}\text { Influencing the } \\
\text { Parliament }\end{array}$ & $\begin{array}{l}\text { Deliberate acts of non- } \\
\text { voting or blank voting } \\
\text { Deliberate antipolitical } \\
\text { lifestyles, e.g. hippies, } \\
\text { anarchists, or other groups } \\
\text { that support alternatives to } \\
\text { mainstream politics. } \\
\text { Disaffection for politics }\end{array}$ & $\begin{array}{l}\text { Non-voting } \\
\text { Avoid talking about politics } \\
\text { Perceiving politics as } \\
\text { uninteresting and } \\
\text { unimportant } \\
\text { Political passivity } \\
\text { "Non-reflected" non-political } \\
\text { lifestyles }\end{array}$ & $\begin{array}{l}\text { Taking interest in politics and } \\
\text { society } \\
\text { Perceiving politics as important } \\
\text { Reading newspapers and } \\
\text { watching TV when it comes to } \\
\text { political issues } \\
\text { Identifying with a certain ideology } \\
\text { and/or party } \\
\text { Discussing politics and societal } \\
\text { issues, with friends or on the } \\
\text { Internet }\end{array}$ & $\begin{array}{l}\text { Voting in elections and referenda } \\
\text { Contacting political representatives or civil } \\
\text { servants } \\
\text { Running for or holding public office } \\
\text { Donating money to political parties or } \\
\text { organizations } \\
\text { Signing petitions } \\
\text { Handing out political leaflets } \\
\text { Being a member of a political party } \\
\text { Attending party meetings } \\
\text { Civil disobedience } \\
\text { Writing to press } \\
\text { Demonstrating, protesting and other actions (e.g. } \\
\text { music festivals with a distinct political agenda) } \\
\text { Involvement in new social movements or forums }\end{array}$ & $\begin{array}{l}\text { Escracho - physically or morally } \\
\text { attacking politicians } \\
\text { Violent confrontations with } \\
\text { political opponents or the police }\end{array}$ \\
\hline $\begin{array}{l}\text { Changing } \\
\text { companies' } \\
\text { policies }\end{array}$ & $\begin{array}{l}\text { Defending companies' } \\
\text { environment-harming } \\
\text { policies and slave labor } \\
\text { exploration }\end{array}$ & $\begin{array}{l}\text { Buying products without } \\
\text { considering environmental or } \\
\text { slave-labor prevention criteria }\end{array}$ & $\begin{array}{l}\text { Monitoring technological advances } \\
\text { for sustainable development } \\
\text { Monitoring companies' } \\
\text { environment-harming policies } \\
\text { Monitoring accidents with } \\
\text { environmental impacts } \\
\text { Monitoring companies which } \\
\text { explore slave labor }\end{array}$ & $\begin{array}{l}\text { Buycotting, boycotting } \\
\text { Recycling }\end{array}$ & $\begin{array}{l}\text { Politically motivated attacks on } \\
\text { property } \\
\text { Rescuing animals from labs } \\
\text { Participating in violent } \\
\text { demonstrations or animal rights } \\
\text { actions }\end{array}$ \\
\hline
\end{tabular}


Table 38. New categories for Political Participation

\begin{tabular}{|c|c|c|c|c|c|}
\hline \multirow{2}{*}{ Target } & \multicolumn{2}{|c|}{ Disengagement } & \multirow{2}{*}{ Attention } & \multicolumn{2}{|c|}{ Manifest Participation } \\
\hline & $\begin{array}{l}\text { Antagonistic } \\
\text { (Active forms) }\end{array}$ & $\begin{array}{l}\text { Unconcerned } \\
\text { (Passive forms) }\end{array}$ & & Non-Violent Action & Violent Action \\
\hline $\begin{array}{c}\text { Negotiating } \\
\text { with Employers }\end{array}$ & $\begin{array}{l}\text { Convincing coworkers not } \\
\text { to be a member of Labor } \\
\text { Union }\end{array}$ & $\begin{array}{l}\text { Ignore Labor Union actions } \\
\text { and information }\end{array}$ & $\begin{array}{l}\text { Participating in Labor-Union } \\
\text { discussions on e-groups } \\
\text { Reading Labor Union newspapers } \\
\text { and informative leaflets }\end{array}$ & $\begin{array}{l}\text { Being a member of a Labor Union } \\
\text { Labor Union Strikes } \\
\text { Being a member of an accident-prevention } \\
\text { committee }\end{array}$ & $\begin{array}{l}\text { Séquestration de patron } \\
{\text { (bossnapping })^{19}-\text { Depriving the }}_{\text {employer of his/her freedom until }} \\
\text { he/she decides to negotiate. }\end{array}$ \\
\hline $\begin{array}{l}\text { Improving } \\
\text { Community's } \\
\text { Quality of Life }\end{array}$ & Damaging public assets & $\begin{array}{l}\text { Ignoring meetings organized } \\
\text { by community's members }\end{array}$ & $\begin{array}{l}\text { Observing community problems } \\
\text { and needs }\end{array}$ & $\begin{array}{l}\text { Belonging to a group with societal focus } \\
\text { Giving money to charity } \\
\text { Volunteering in social work, e.g. to support } \\
\text { women's shelter or to help homeless people } \\
\text { Charity work or faith-based community work } \\
\text { Activity within community based organizations }\end{array}$ & $\begin{array}{l}\text { Sabotaging or obstructing roads } \\
\text { and railways } \\
\text { Squatting buildings }\end{array}$ \\
\hline
\end{tabular}

\footnotetext{
${ }^{19}$ As discussed by Hayes (2012).
} 
Testing this suggested reframing would require the elaboration of a Political Participation inventory, i.e., a questionnaire with an extensive list of political behaviors, to verify the empirical factor structure. Moreover, cross-cultural research with the employment of CFAs proved to be useful to elaborate factor structures which are compatible to different contexts and to avoid the risk of creating a measure which is valid to only one country. Hence, it is recommended that future researches do country comparisons with this intent.

\subsection{Cultural Differences and Similarities}

Corruption was perceived as higher in Brazil, Quality of Representation better in Sweden, as results indicated. This difference was actually expected, as previous evidences indicated (Bethell, 1985; Moisés \& Carneiro, 2008; Rothstein \& Uslaner, 2005; Schück, 2003; Scobbie, 2010; Scott, 1988). However, a salient difference between Brazil and Sweden was the fact that Corruption did not influence any of the types of Political Participation in Brazil. But it did have predicting power for all tested types in Sweden, except Institutional Participation and Street Demonstrations.

On the contrary, Swedes did seem to pay more attention to the "mainstream politics" information, as their mean for Party-Oriented View was higher than in Brazil. However, the attention to Critical Information had significant impact to Institutional Participation in Brazil, not in Sweden. At last, Personal Information, a factor spontaneously found in Brazil, was relevant to predict Political Disillusion, Labor Union Strikes and Political Violence Legitimation in Sweden, while it could only predict PrePolitical Engagement in Brazil.

From the two paragraphs above, it may be deduced that, when it comes to Stereotypes about Parliamentarians, what is relevant to one country has greater effect on the other. It is not like these countries trade variables' effects as they trade 
manufactured goods, though. Stereotypes about Parliamentarians may be more nearly related to the political culture than other independent variables assessed. Stereotypes, just as other cultural artifacts, are systems of shared beliefs (Geertz, 1973; Jussim, McCauley \& Lee, 1995; Mackie, 1973; Ryan, 2003; Sacchi, Carnaghi, Castellini \& Colombo, 2013; Smith et al., 2013). What is commonsense to one country (such as Brazilian corruption) loses its power to differentiate citizens' attitudes and behaviors. However, in Brazil, where people more difficultly understand parliamentarians' differences (Henrique, 2010; Kinzo, 2004; Moisés \& Carneiro, 2008; Sallum Júnior, Graeff \& Lima, 1990), the Critical Information was relevant to tell the difference between Brazilians who engage Institutional Participation and those who do not.

Revisiting the theoretical model on Section 2.7, Figure 2.3, it is possible to conclude that mediating effects of Stereotypes about Parliamentarians and Behavioral Contagion existed on the prediction models, but they operated differently in each country.

For Brazilians, Critical Information factors were mediated by Behavioral Contagion in predicting Political Participation, whenever these two variables entered the model together. In Sweden, when Critical Information factors were present at the SEM models, they had direct effect on Political Participation behaviors. Then, to Brazilians, it is not enough to know the parliamentarians' differences, but citizens have to be part of a politically active network to convert knowledge into action. Hence, in Brazil, Behavioral Contagion could mediate not only Political Education (as discussed on Section 5.3.3), but also the Critical Information set in Stereotypes about Parliamentarians.

Political Education standalone items, when present in SEM models, were mediated either by Stereotypes or by Behavioral Contagion, as shown at Figure 2.3. The only exception was the adhesion to Labor Union Strikes in Brazil, where a direct effect was observed. All other variables were removed from that model, so this item did 
not have to compete for prediction power. As explained, there was a close connection between being a member of a Labor Union and learning politics from the other members.

Contrasting with Realo, Allik and Greenfield (2008, see Figure 1.1), participation in Brazil was more frequent than in Sweden - except on Political Consumerism, where difference was not significant. This difference might be an effect of recent developments in both countries' political context, as explained in Section 2.6.3, especially considering that Realo, Allik and Greenfield's (2008) based their research on metadata from studies published in 2004

For both countries, Quality of Representation and Corruption (the two behavior prediction factors in Stereotypes about Parliamentarians) had direct effects on several Political Participation types. As citizens seemed to be mobilized by dissatisfaction with politicians, low Quality of Representation encouraged political action, while low Corruption discouraged. A reverse effect was observed on Political Consumerism in Sweden, where the lower perceived Corruption encouraged action. Curiously, these factors did not predict Institutional Participation in Brazil.

These results evidence that Brazilians and Swedes indeed relay on different mindsets to understand their political arena. Cultural differences may explain what becomes commonsense to one country or another. Swedes' Horizontal Individualism (Singelis et al., 1995 and Triandis \& Gelfand, 1998) is probably the ground for their low tolerance on corruption - i.e., parliamentarians are expected to respect laws as citizens do, as egalitarianism and solidarity are a core values (under Hofstede's 1980 concepts). Brazilians' Vertical Collectivism is related to their tolerance to social hierarchy, and it is understood that parliamentarians break rules when loyalty to their nuclear groups is more important. Moreover, in Brazil, voters may feel that they are part of groups to which some politicians represent leaders - then, breaking the rules in the benefit of "my group" is tolerable, while other groups' corruption is condemnable. 
Moreover, Brazilians' great Power Distance (Hofstede, 1980) may be associated to their acceptance of politicians' (supposed) higher status and paralyzing distrust in institutions' capacity to fight corruption - as institutions lay outside Brazilians' radius of trust (Realo, Allik \& Greenfield, 2008).

This might explain why Critical Information and Behavioral Contagion were the only variables that predicted Institutional Participation, while in Sweden Quality or Representation and Party membership gained importance, together with Behavioral Contagion and learning about politics alone. Quality of Representation, in the Swedish model, indicates that Swedes pay attention to parliamentarians' behaviors, reacting to "bad quality politicians" in the institutional field. Brazilians, otherwise, primarily care about which group is represented by the parliamentarian - therefore their greater attention to Critical Information. For this reason common prediction models were not essayed; the main contribution of the seemly "incompatible" SEM models was to identify how Brazilian and Swedish mindsets differ. 


\section{Chapter 6: Conclusions and Future Directions}

As phenomena in present study were approached with a newly conceived questionnaire, there was a risk of exploring non-relevant variables or that the explored variables were context-specific (i.e., that they existed only in one country). Therefore, comparing countries with very different political traditions is useful to check if the studied topics are relevant phenomena and if they are present in more than one context. For these reasons, the finding of equivalent factor structures is a relevant indication that yes, the studied matters were present on both countries (so they are not context-specific). The relevance of the chosen independent variables was given by their prediction potential, with good shares of variance explained - especially to Institutional Participation, the main category of interest herein.

The main contribution of this research was to add empirical evidence to the theoretical approach on Political Participation, by exploring its factor structure with the comparison of two contrasting countries. Moreover, it provided evidence that the concept of Stereotypes can be used to describe parliamentarians, with relevant usefulness to predict participation. It was also found that Behavioral Contagion played a pivotal role on predicting participation, to the point that it is questionable whether strictly individual political action exists.

Since items in the Behavioral Contagion represent influence on other people and being influenced, it is evidenced that being part of a politically active network is basilar to political action engagement. Regarding previous studies, networks can be either formally constituted (Anderson, 2010) or ephemerally grouped, like those made upon internet summons (Brussino, Rabbia \& Sorribas, 2008; Hooghe \& Dejaeghere, 2007; Inglehart \& Catterberg, 2002). Anyway, the examples of engaged friends and relatives work as an encouragement circle, admittedly necessary to face the risks of political action - which might have been exaggeratedly interpreted by Le Bon (2008) as the 
"feeling of invincible power". Political Education, in turn, had disappointingly low prediction capacity over political participation, which left open questions for practitioners and qualitative studies (see Section 5.2.3). These phenomena were not context-dependent (they are reasonably similar in Brazil and Sweden), and deserve better attention on future studies, in more countries, to make it possible to state whether they are or not Etic phenomena. The finding of Etic variables could be further used to establish comparisons among several countries. This research did a first step in that direction.

\subsection{Limitations and Solutions}

Researches are made with limited resources. It was not different with this one. The use of internet helped reducing costs to administer the survey, but it entailed limits for the selection of participants. The elaboration of a cross-cultural questionnaire on opposite sides of the Atlantic Ocean imposed restrictions for qualitative approaches such as focus groups; the Delphic Panel was made as an alternative. Social desirability issues were faced on the elaboration of the questionnaire. At last, the intention of widely compassing the assessed variables carries the cost of lowering factors analyses internal consistency.

The present study's main limitation is related to the data collection on the internet. Only participants who have access to the internet were reached, and it is also necessary to be able to use the computer and to understand the survey questions without assistance. It is not possible to control the effect of participants' self-selection, i.e., the participant is actually going to participate or not - this may depend on his/her own interest on the study theme. Furthermore, the resulting samples are not accurate representations of the Brazilian and the Swedish populations, as some they are leaned to under-represent the lower educated cohorts; therefore, results in this dissertation 
shed light on some psychological phenomena, but further studies, with representative samples, are required to describe how the Brazilian and Swedish populations behave.

As this survey is focused on the individual level, the interpretation of the cultural content sharing and collectively organized actions are restricted (according to the criticism of Cho \& Rudolph, 2008; McFarland \& Thomas, 2006; and Smith et al., 2013). Solving this problem would require additional studies, with different methodologies. The solution for this problem would be to identify and contact groups that usually organize political actions (such as the study of Gomes \& Maheirie, 2011) primarily through the use of qualitative techniques - such as interviews or ethnography - to observe how they operate. This greatly surpasses the resources available for the study - and it explains the choice for data collection through the internet, despite the limitations described herein.

Likewise, the option to conduct a Delphic Panel for the construction of the questionnaire is a means of dealing with resource limits for conducting qualitative inroads in the countries selected for the study. The Delphic Panel can be done via Internet, reducing travel costs for directly contacting people who are immersed in the culture of the selected countries.

Delphic Panel allowed the elaboration of a questionnaire considering Brazilian and Swedish culture simultaneously. This mitigated the risk of building imposed-etic questions, as it may happen when a questionnaire is written in one country and translated to others. Moreover, the decentralized back-translation procedure introduced the participation of translation judges and revisers, resulting on a very careful translation.

It is actually difficult to identify the reasons for response bias, especially on cross-cultural studies (Caprara et al., 2000; Smith et al., 2013). It could either be a result of acquiescence, cultural differences or actual construct manifestation differences (Byrne \& Campbell, 1999). Moreover, Brazil is a presidential republic, 
Sweden is a parliamentary monarchy, but it is really difficult to accurately assert to what degree this difference impacts their attitudes and behaviors. In the present study, important score differences were found between Brazilians and Swedes, as reported on Section 4.3, indicating that yes, actual construct differences may have influenced the way these two groups responded to the items. It is also plausible that cultural idiosyncrasies may have influenced participants' responses, since Brazilians and Swedes actually regard differently to their politicians and engage differently to political actions.

It is to be considered a positive quality of Political Participation scale that it asks for previous behavior, which is the closest proxy to the future behavior on a survey (Ouellette \& Wood, 1998). In contrast, social desirability (Hair et al., 2009; Pasquali, 2010; Viswanathan, 2005) was a critical concern, which led to the creation of political attitude items. Asking about delicate behaviors (like "how many times have you engaged into political violence?") could result on participants' avoidance to answer this and other questions. Also, it would be hard to ask about negative behavior occurrences (like "how many times have you avoided discussions on politics?"). Therefore, nonparticipation items represent attitudes towards politics (most of them with negative trend). Positively-trended items were inserted to avoid acquiescence or extreme responding biases (Pasquali, 2010, Viswanathan, 2005).

\subsection{Research Agenda}

The choice of two very contrasting countries was useful to submit the investigated variables to a strong test of resistance: Factor Structure Equivalence and Metric Equivalence demonstrated that the variables are not Emic phenomena to Brazil or Sweden. However, it is still early to state that factor structures found in this study are "universal", meaning that they would be found the same way in various different 
countries (i.e., Etic phenomena). Future studies in other countries may replicate this investigation, again submitting participants' answers to Exploratory Factor Analyses, so factor structures are freely estimated, and to Confirmatory Factor Analyses, so crosscountry compatible factor structures are fetched. This procedure would make these variables useful to culture unpacking (such as Hofstede, 1980; Inglehart \& Welzel, 2010; Schwartz, 1994) on the political field.

Since Quality of Representation played a relevant role to the prediction of some types of Political Participation in Brazil, this factor should get better attention on future studies, applied to larger and better representative samples. In turn, trendlessness of Corruption in Brazil might be investigated under qualitative techniques, since its explanation is challenging under the light of previous researches that indicated the crucial role of this issue in Brazilian politics (Azevedo \& Chaia, 2008; Cunha, 2006; Henrique, 2010; Moisés \& Carneiro, 2008; Ribeiro, 2007). Corruption did not enter SEM models for Institutional Participation and Street Demonstrations in Sweden, too. This leaves open questions about how corruption is controlled, in the "micro" level, in both countries. How do people actually react to corruption? Are there groups that react and groups that do not react to corruption? What are the differences among them? How do they operate?

\subsection{Implications for Democracy}

On the practical realm, strategies for encouraging Political Participation must consider the stimulation of network influences, with the understanding that Behavioral Contagion may serve to improve engagement. For example, the invitation of citizens to watch a public hearing on a nation-wide interesting policy may benefit from incentivizing different interest groups to mobilize their networks into political discussions about the issue on debate. 
Comprehending the mechanics of Stereotypes about Parliamentarians might be useful to encourage engagement. First, because the use of Critical Information factors to assess the understanding of parliamentarians' differences was a valuable strategy. In Brazil, the understanding of parliamentarians' differences, catalyzed by Behavioral Contagion, strongly predicted Institutional Participation. In both countries, Critical Information factors had relevant influence on engaging different types of political action. Therefore, providing people with clear and trustworthy information about parliamentarians may actually contribute to multiply the monitorial citizens and promptitude to act when necessary.

Second, dissatisfaction with Quality of Representation entices several types of political action, in both countries. In Sweden, Corruption makes people lose faith on mainstream politics. This poses the challenge of using that dissatisfaction as a push to political action, without steering into antidemocratic postures. Moreover, if satisfaction with the system is ever reached, how to keep citizens interested in politics?

The effect of Political Education on participation was up to a little extent, but there is a large field yet to explore on it. Parry's (1999) discussion about if students should be encouraged to question society or to keep traditions is still valid - after all, even "democratic traditions" may be questioned. However, under the light of this study's results, additional practical questions may be explored: how could Political Education curricula provide students with adequate tools for the understanding of parliamentarians' differences? How Behavioral Contagion can be explored on educational terms, so that students learn to organize collective action? This study demonstrated that these elements are important to make citizens more politicallyprone, and it is valuable to use this knowledge to foster conscious actions. 


\section{References}

Aarts, H., Gollwitzer, P., \& Hassin, R. R. (2004). Goal contagion: perceiving is for pursuing. Journal of Personality and Social Psychology, 87, 23-27.

Abreu, D. \& Medeiros, E. (2013, June 21). Da redução da passagem ao fim do voto secreto: são muitas as reivindicações. Correio Braziliense. Retrieved from http://www.correiobraziliense.com.br/app/noticia/politica/2013/06/21/ interna_politica,372639/da-reducao-da-passagem-ao-fim-do-voto-secreto-saomuitas-as-reivindicacoes.shtml

Ackelsberg, M. A. (2003). Broadening the Study of Women's Participation. In: S. Carroll (ed.). Women and American Politics. Oxford: Oxford University Press.

Ajzen, I. \& Fishbein, M. (2005). The influence of attitudes on behavior. In D. Albarracin, B. T. Johnson \& M. P. Zanna (Eds.), The handbook of attitudes (pp. 173-222). New York: Taylor \& Francis

Alencar, M. E. (2015, January 1). Com novo governo, Dilma tenta se blindar contra impactos negativos da Lava Jato. RFI. Retrieved from: http://www.portugues.rfi.fr/ brasil/20150101-com-novo-governo-dilma-tenta-se-blindar-contra-impactosnegativos-da-lava-jato

Allison, P. D. (2003). Missing data techniques for structural equation modeling. Journal of abnormal psychology, 112(4), 545.

Allport, G. W. (1935). Attitudes. Em C. Murchison (Org.), The handbook of social psychology (pp. 798 - 844). Massachusetts: Clark University Press.

Allport, G. W. (1954). The nature of prejudice. Massachussets: Addison-Wesley.

Almond, G. \& Verba, S. (1963). The civic culture. Princeton: Princeton University. 
Almond, G. A., \& Verba, S. (1980). The civic culture revisited: An analytic study. Boston: Little Brown.

Altman, D., \& Pérez-Liñán, A. (2002). Assessing the quality of democracy Freedom, competitiveness and participation in eighteen Latin American countries. Democratization, 9(2), 85-100.

Amnå, E., \& Ekman, J. (2014). Standby citizens diverse faces of political passivity. European Political Science Review, 6(02), 261-281.

Amnå, E., Ekström, M., Kerr, M., \& Stattin, H. (2009). Political socialization and human agency: The development of civic engagement from adolescence to adulthood. Statsvetenskaplig tidskrift, 111(1), 27-40.

Anderson, M. R. (2010). Community psychology, political efficacy, and trust. Political Psychology, 31(1), 59-84.

Andrade, H., Affonso, J. \& Bianchi, P. (2013, June 20). Manifestantes entram em confronto com policiais no Rio e pelo menos 62 ficam feridos. UOL Notícias. Retrieved from: http://noticias.uol.com.br/cotidiano/ultimas-noticias/ 2013/06/20/em-frente-a-prefeitura-do-rio-manifestantes-entram-em-confrontocom-policiais.htm

Arceneaux, K. (2008). Can partisan cues diminish democratic accountability? Political Behavior, 30, 139-160.

Artiles, A. M., \& Meardi, G. (2014). Public opinion, immigration and welfare in the context of uncertainty. Transfer: European Review of Labour and Research, 20(1), 53-68.

Azevedo, F. A., \& Chaia, V. L. M. (2008). O Senado nos editoriais dos jornais paulistas (2003 - 2004). Opinião Publica, 14(1), 173-204. Retrieved from: 
http://www.scielo.br/ scielo.php?script=sci_arttext\&pid=S0104-62762008000100 007\&lng=en\&nrm=iso

Bagozzi, R. P., \& Yi, Y. (1988). On the evaluation of structural equation model, Journal of the Academy of Marketing Science, 16(1), 74-94.

Baier, A. (1986). Trust and Antitrust. Ethics, 96(2), 231-260.

Balzaretti, A., Silva, A. P., Rech, G., \& Da Sois, T. (2014). Coligação Unidos Pelo Brasil: Uma Terceira Via à Brasileira. Cultura Científica, 1(2).

Baquero, M. (2001). Cultura política participativa e desconsolidação democrática: reflexões sobre o Brasil contemporâneo. São Paulo em Perspectiva, 15(4), 98104.

Barcellos, J. (2014, July 10). Fatores que influenciarão as eleições 2014. Sul21. Retrieved from: http://www.sul21.com.br/jornal/fatores-que-influenciarao-aseleicoes-2014/

Bargh, J. A., Gollwitzer, P. M., LeeChai, A., Barndollar, K., \& Trötschel, R. (2001). The automated will: nonconscious activation and pursuit of behavioral goals. Journal of Personality and Social Psychology, 81, 1014-1027.

Barman, R. J (1999). Citizen Emperor: Pedro II and the Making of Brazil, 1825-1891. Stanford: Stanford University Press.

Barnes, M. (2003). Languages and ethnic groups. In: K. Helle (Ed.). The Cambridge History of Scandinavia Volume 1: Prehistory to 1520. Cambridge: Cambridge University. 
BBC Brasil (2013, June 20). Mesmo com a redução das tarifas, atos são mantidos em $\mathrm{SP}$ e Rio. BBC Brasil. Retrieved from http://www.bbc.co.uk/portuguese/ noticias/130619_protestos_quarta.shtml

BBC (2014a, September 15). Profile: Far-right Sweden Democrats. BBC. Retrieved from http://www.bbc.com/news/world-europe-29202793

BBC (2014b, September 15). Sweden election: Social Democrats rule out far-right pact. BBC. Retrieved from: http://www.bbc.com/news/ world-europe-29195683

Bellin, E. (2012). Reconsidering the robustness of authoritarianism in the Middle East: Lessons from the Arab Spring. Comparative Politics, 44(2), 127-149.

Benevides, M. V. D. M. (1996). Educação para a democracia. Lua Nova: Revista de cultura e política, 38, 223-237.

Bentes, A. (2014, October 26). Dilma derrota Aécio na eleição mais disputada dos últimos 25 anos. El País. Retrieved from: http://brasil.elpais.com/brasil/2014/ 10/26/ politica/1414362936_748118.html

Berger, B. (2009). Political Theory, Political Science, and the End of Civic Engagement. Perspectives on Politics, 7(2), 335-350.

Bergman, M. (2011). Best in Class: Public Finances in Sweden during the Financial Crisis. Panoeconomicus, 58(4), 431-453.

Bergsten, C. F. (2013, August 29). The Swedish model for economic recovery. The Washington Post. Retrieved from http://www.washingtonpost.com/opinions/ obama-should-take-lessons-from-sweden-to-g-20/2013/08/29/2a48a5fa-10c011e3-bdf6-e4fc677d94a1_story.html 
Berinsky, A. J., \& Lenz, G. S. (2011). Education and political participation: Exploring the causal link. Political Behavior, 33(3), 357-373.

Bertoncelo, E. R. E. (2009). "Eu quero votar para presidente": uma análise sobre a campanha das diretas. Lua Nova, 76, 169-196.

Betancourt, H., \& Lopez, S. R. (1993). The study of culture, ethnicity, and race in American psychology. American Psychologist, 48(6), 629-637.

Bethell, L. (1985). The Cambridge History of Latin America, Volume III: from Independence to c.1870. Cambridge: Cambridge University Press.

Bethell L. (2008). The Cambridge History of Latin America, Volume IX: Brazil since 1930. Cambridge: Cambridge University Press.

Bianchi, P. (2013, Octorber 4). Prefeitura ignora protesto de professores no Rio. Terra Notícias. Retrieved from http://noticias.terra.com.br/educacao/prefeitura-ignoraprotesto-de-professores-no-rio,ac0f1ad527581410VgnVCM10000098 cceb0aRCRD.html

Blanc-Noel, N. (2013). Resolving the dilemma between equality and liberty: the Swedish political system. Eastern Journal of European Studies, 4(1), 25-40.

Boehnke, K., Arnaut, C., Bremer, T., Chinyemba, R., Kiewitt, Y., Koudadjey, A. K., Mwangase, R. \& Neubert, L. (2014). Toward Emically Informed Cross-Cultural Comparisons: A Suggestion. Journal of Cross-Cultural Psychology, 45(10), $1655-1670$.

Bohmer, S., \& Briggs, J. L. (1991). Teaching privileged students about gender, race, and class oppression. Teaching Sociology, 19(2), 154-163. 
Bollen, K. A. (1980). Issues in the comparative measurement of political democracy. American Sociological Review, 370-390.

Bollen, K. A. (1989). Structural equations with latent variables. New York: John Wiley.

Bollen, K. A. (1990). Political democracy: conceptual and measurement traps. Studies in Comparative International Development, 25(1), 7-24.

Bollen, K. A. (1998). Structural equation models. New York: John Wiley \& Sons

Bono, J. E., \& llies, R. (2006). Charisma, positive emotions and mood contagion. The Leadership Quarterly, 17(4), 317-334.

Borba, J. \& Ribeiro, E. A. (2010). Participação convencional e não convencional na América Latina. Revista Latinoamericana de Opinión Pública, 1(0), Retrieved from http://www.waporlatinoamerica.org/index.cfm?fuseaction=main.home \&seccion $=513 \#$

Borba, J. (2005). Cultura política, ideologia e comportamento eleitoral: alguns apontamentos teóricos sobre o caso brasileiro. Opinião Pública, 11(1), 147-168.

Borchert, J. (2003). Professional Politicians: Towards a Comparative Perspective. In: J. Borchert, J. Zeiss (eds.). The political class in advanced democracies: a comparative handbook ( pp. 1-25). Oxford: Oxford University.

Borges Filho, N. (2010). Ética e Política. Seqüência: Estudos Jurídicos e Políticos, 14(26), 28-32.

Børhaug, K. (2008). Educating voters: political education in Norwegian upper - secondary schools. Journal of Curriculum Studies, 40(5), 579-600. 
Boyle, G. J. (1991). Does item homogeneity indicate internal consistency or item redundancy in psychometric scales. Personality and individual differences, 12(3), 291-294.

Breiting, S., \& Wickenberg, P. (2010). The progressive development of environmental education in Sweden and Denmark. Environmental Education Research, 16(1), 9-37.

Bresser-Pereira, L. C. (2011). Transição, consolidação democrática e revolução capitalista. Dados, 54(2), 223-258.

Brewer, M. B. \& Brown, R. J. (1998). Intergroup Relations. In D. Gilbert, S. Fiske, G. Lindzey (Eds.). The handbook of social psychology (Vol. 2, 4th ed., pp. 554-594). Boston: McGraw-Hill.

Brigham, J. C. (1971). Ethnic stereotypes. Psychological Bulletin, 76, 15-38.

Briley, D. A., Morris, M. W., \& Simonson, I. (2000). Reasons as carriers of culture: Dynamic vs. dispositional models of cultural influence on decision making. Journal of Consumer Research, 27(2), 157-178.

Brislin, R. W. (1970). Back-Translation for Cross-Cultural Research. Journal of CrossCultural Psychology, 1(3), 185-216.

Brooks, K. W. (1979). Delphi technique: Expanding applications. North Central Association Quarterly, 54(3), 377-385.

Brown, T. (2006). Confirmatory Factor Analysis for applied research. New York: Guilford Press.

Browne, M. W. \& Cudeck, R. (1989). Single sample cross-validation indices for covariance structures. Multivariate Behavioral Research, 24, 445-455. 
Brussino, S., Rabbia, H. \& Sorribas, P. (2008). Una Propuesta de Categorización de la Participación Política de Jóvenes Cordobeses. Psicologia Política, 8 (16), 285304.

Brussino, S., Rabbia, H. H., \& Sorribas, P. (2009). Perfiles sociocognitivos de la participación política de los jóvenes. Interamerican Journal of Psychology, 43(2), 279-287.

Burns, N., Schlozman, K., \& Verba, S. (2001). The private roots of public action: gender, equality, and political participation. Cambridge, MA: Harvard University Press.

Byrne, B. M., \& Campbell, T. L. (1999). Cross-cultural comparisons and the presumption of equivalent measurement and theoretical structure A look beneath the surface. Journal of Cross-Cultural Psychology, 30(5), 555-574.

Byrne, B. M., Shavelson, R. J., \& Muthén, B. (1989). Testing for the equivalence of factor covariance and mean structures: The issue of partial measurement invariance. Psychological Bulletin,105, 456-466.

Cacioppo, J. T., \& Hawkley, L. C. (2009). Perceived social isolation and cognition. Trends in cognitive sciences, 13(10), 447-454.

Calmfors, L. (2012). Sweden: From macroeconomic failure to macroeconomic success. CESifo working paper: Fiscal Policy, Macroeconomics and Growth, No. 3790. Retrieved from www.econstor.eu/bitstream/10419/57944/1/71558359X.pdf

Câmara dos Deputados (2012, September 28). Abertura do processo de impeachment de Collor completa 20 anos. Câmara Notícias. Retrieved from http://www2.camara.leg.br/camaranoticias/noticias/POLITICA/427000- 
ABERTURA-DO-PROCESSO-DE-IMPEACHMENT-DE-COLLOR-COMPLETA20-ANOS.html

Camargo, A., Hippolito, L., D'Araújo, M. C. S. \& Flaskman, D. R. (1986). Artes da Política: Diálogo Com Amaral Peixoto. Rio de Janeiro: Nova Fronteira. Disponível em: http://bibliotecadigital.fgv.br/dspace/handle/10438/6756

Campilongo, C. F. (1994). O Judiciário e a democracia no Brasil. Revista USP, 21, 116-125.

Canel-Çınarbaş, D., Cui, Y., \& Lauridsen, E. (2011). Cross-Cultural Validation of the Beck Depression Inventory-II Across US and Turkish Samples. Measurement and Evaluation in Counseling and Development, 44(2), 77-91.

Canfora, L. (2006). Como entrou e como finalmente saiu de cena a democracia grega. Estudos Avançados, 20(58), 167-188.

Capistrano, D. J., \& Castro, H. C. D. O. (2010). O Papel do Estado e Cultura Política na Argentina e no Brasil. Opinião Pública, 16(2), 338-365.

Caprara, G. V., Barbaranelli, C., Bermúdez, J., Maslach, C., \& Ruch, W. (2000). Multivariate Methods for the Comparison of Factor Structures in Cross-Cultural Research An Illustration with the Big Five Questionnaire. Journal of CrossCultural Psychology, 31(4), 437-464.

Caprara, G. V., Barbaranelli, C., Bermúdez, J., Maslach, C., \& Ruch, W. (2000). Multivariate Methods for the Comparison of Factor Structures in Cross-Cultural Research An Illustration with the Big Five Questionnaire. Journal of CrossCultural Psychology, 31(4), 437-464. 
Caprara, G. V., Vecchione, M., Capanna, C., \& Mebane, M. (2009). Perceived political self-efficacy: Theory, assessment, and applications. European Journal of Social Psychology, 39(6), 1002-1020.

Carlin, R. E., \& Love, G. J. (2013). The Politics of Interpersonal Trust and Reciprocity: An Experimental Approach. Political Behavior, 35(1), 43-63.

Carneiro, T. L. \& Torres, C. V. (2012). Imagem do Congresso Nacional e Autoeficácia política. Resumenes de las Ponencias - 1 Congreso Iberoamericano de Psicología Política, Lima: Associação Iberoamericana de Psicologia Política.

Carneiro, T. L. (2014). Da "Imobilidade" à Ação: Por que os Brasileiros Saíram às Ruas em Junho de 2013? O Contágio Comportamental como Parte da Explicação. ELegis, 14, 26-45.

Carreirão, Y. S. (2002). Identificação ideológica e voto para presidente. Opinião Pública, 8(1), 54-79

Carta Capital (2013, June 13). "Não é direito de expressão, é vandalismo", afirma Alckmin. Carta Capital. Retrieved from http://www.cartacapital.com.br/ sociedade/nao-vamos-deixar-que-se-confunda-baderna-com-direito-a-livremanifestacao-afirma-alckmin-6239.html

Castro, L. R. (2010). Juventude e socialização política: atualizando o debate. Psicologia: Teoria e Pesquisa, 25(4), 479-487.

Castro, M. (2014, October 23). Eleitor compra briga nas redes sociais. Exame.com. Retrieved from: http://exame.abril.com.br/rede-de-blogs/midias-sociais/2014/ 10/23/eleitor-compra-briga-nas-redes-sociais/

Cattell, R. B. (1973). Personality and mood by questionnaire. Oxford: Jossey-Bass. 
Cattell, R. B. (1982). The psychometry of objective motivation measurement: A response to the critique of Cooper and Kline. British Journal of Educational Psychology, 52(2), 234-241.

Catterberg, G., \& Moreno, A. (2006). The individual bases of political trust: Trends in new and established democracies. International Journal of Public Opinion Research, 18(1), 31-48.

Chagas, P. V. (2013, December 31). Cinco pactos foram a resposta do governo federal aos protestos de junho. Agência Brasil. Retrieved from http://memoria.ebc.com.br/agenciabrasil/noticia/2013-12-31/cinco-pactos-foramresposta-do-governo-federal-aos-protestos-de-junho

Chauhan, Y. (2013). Sweden: Government and Society. In Encyclopædia Britannica. Retrieved from http://www.britannica.com/EBchecked/topic/576478/Sweden /259780/Labour-and-taxation\#toc30537

Chen, G. M., \& Chung, J. (1994). The impact of Confucianism on organizational communication. Communication Quarterly, 42(2), 93-105.

Cheung, G. W., \& Rensvold, R. B. (1999). Testing factorial invariance across groups: A reconceptualization and proposed new method.Journal of Management, 25, 127.

Cho, W. K. T., \& Rudolph, T. J. (2008). Emanating political participation: untangling the spatial structure behind participation. British Journal of Political Science, 38(2), 273.

Christensen, S. F. \& Kolling, M. (2014, October 29). Brazil's presidential elections: what now? Council on Hemispheric Affairs. Refrieved from http://www.coha.org/ brazils-presidential-elections-what-now/ 
Chung, H., \& Thewissen, S. (2011). Falling back on old habits? A comparison of the social and unemployment crisis reactive policy strategies in Germany, the UK and Sweden. Social Policy \& Administration, 45(4), 354-370.

Cialdini, R. B., \& Trost, M. R. (1998). Social influence: Social norms, conformity, and compliance. In: D. T. Gilbert, S. T. Fiske, and G. Lindzey (Eds.), The handbook of social psychology (4th ed., Vol. 2, pp. 151-192). Boston: McGraw-Hill

Cinnanti, C. J. J. (2011). A (des)confiança do cidadão no Poder Legislativo e a qualidade da democracia no Brasil. E-Legis, 6(6), 84-95.

Cittadino, G. (2004). Poder Judiciário, ativismo judiciário e democracia. Alceu, 5(9), 105-113.

Cohen, J. (1990). Things I have learned (so far). American psychologist, 45(12), 13041312.

Cohen, J. (1992). A power primer. Psychological Bulletin, 112, 155-159.

Colling, L. (2007). Personagens homossexuais nas telenovelas da Rede Globo: criminosos, afetados e heterossexualizados. Revista Gênero, 8(1), 207-222.

Colon, L. \& Moura, R. M. (2011, September 7). Marcha contra Corrupção reúne 25 mil em Brasília. Estadão.com.br. Retrieved from http://www.estadao.com.br/ noticias/nacional,marcha-contra-corrupcao-reune-25-mil-embrasilia,769550,0.htm

Consolim, M. C. (2008). Posfácio. In: G. Le Bon (2008). Psicologia das multidões (M. S. Cunha, Trad.). São Paulo: Martins Fontes (Originally published in 1895). 
Costa, C. (2014, November 4). \#SalaSocial: Insatisfeitos com eleições pedem ajuda a militares e aos EUA. BBC Brasil. Retrieved from: http://www.bbc.co.uk/ portuguese/noticias/2014/11/141103_salasocial_intervencao_militar_cc

Cowell-Meyers, K. (2014, June 20). Sweden's Feminist Initiative has lessons for social movements elsewhere. The Washington Post. Retrieved from: http://www.washingtonpost.com/blogs/monkey-cage/wp/2014/06/20/swedensfeminist-initiative-has-lessons-for-social-movements-elsewhere/

Cronbach, L. J. (1990). Essentials of Psychological Testing, $5^{\text {th }}$. ed. New York: Harper Collins.

Cronbach, L. J., \& Gleser, G. C. (1965). The bandwidth-fidelity dilemma. Psychological Tests and personnel directions, 97-107.

Cuddy, A. J., Fiske, S. T., Kwan, V. S., Glick, P., Demoulin, S., Leyens, J. P., Bond, M. H., Croizet, J. C., Ellemers, N., Sleebos, E., Htun T. T., Kim, H. J., Maio, G., Perry, J., Petkova, K., Todorov, V., Rodriguez-Bailón, R., Morales, E., Moya, M., Palacios, M., Smith, V., Perez, R., Vala, J., \& Ziegler, R. (2009). Stereotype content model across cultures: Towards universal similarities and some differences. British Journal of Social Psychology, 48(1), 1-33.

Cunha, R. (2006). Mídia reforça imagem negativa do parlamento. Ciência e Cultura, 58 (2), 8-10. Retrieved from: http://cienciaecultura.bvs.br/scielo.php?script= sci_arttext\&pid=S0009-67252006000200004\&lng=en\&nrm=iso

Custer, R. L., Scarcella, J. A., \& Stewart, B. R. (1999). The modified Delphi technique: A rotational modification. Journal of Vocational and Technical Education, 15(2), $1-10$. 
Cyphert, F. R., \& Gant, W. L. (1971). The Delphi Technique: A Case Study. Phi Delta Kappan, 52(5), 272-273.

Dahl, R. (1956). A preface to democratic theory. Chicago: University of Chicago Press.

Dalton, R. J. (2004). Democratic Challenges, Democratic Choices: The Erosion of Political Support in Advanced Industrial Democracies. Oxford: Oxford University Press.

Dalton, R. J. (2008). Citizenship norms and the expansion of political participation. Political studies, 56(1), 76-98.

Dalton, R. J., \& Anderson, C. J. (Eds.). (2011). Citizens, context, and choice: How context shapes citizens' electoral choices. Oxford: Oxford University Press.

Damasceno, M. (2013, June 14). Imprensa estrangeira destaca truculência da polícia brasileira em protestos. Deutsche Welle. Retrieved from http://www.dw.de/imprensa-estrangeira-destaca-truculência-da-polícia-brasileiraem-protestos/a-16883228

Davidsson, J. B., \& Marx, P. (2013). Losing the Issue, Losing the Vote: Issue Competition and the Reform of Unemployment Insurance in Germany and Sweden. Political Studies, 61(3), 505-522.

Davies, I. (1999). What has happened in the teaching of politics in schools in England in the last three decades, and why? Oxford Review of Education, 25(1-2), 125140.

Dee, T. S. (2004). Are there civic returns to education?. Journal of Public Economics, 88(9), 1697-1720. 
Delli Carpini, M. X. \& Keeter, S. (1996). What Americans Know About Politics And Why It Matters. New Haven: Yale University Press.

Demo, P. (2005). Saber Pensar. Revista da ABENO, 5(1), 75-79.

Deutsche Welle (2013, May 24). Sweden sends reinforcements to capital after fifth night of rioting. Deutsche Welle. Retrieved from : http://www.dw.de/swedensends-reinforcements-to-capital-after-fifth-night-of-rioting/a-16835451

Diamond, L. J. (1996). Is the third wave over?. Journal of democracy, 7(3), 20-37.

Diário do Nordeste (2011, October 13). Marcha reúne 20 mil no DF. Diário do Nordeste. Retrieved from http://diariodonordeste.globo.com/materia.asp? codigo $=1055341$

Dickson, D. \& Senero, J. (2014, December 27). Swedish centre-left do eight-year deal with opposition to avert snap election. Reuters. Retrieved from: http://www.reuters.com/article/2014/12/27/us-sweden-politics-pollidUSKBN0K505120141227

Diener, E. (1980). Deindividuation: The absence of self- awareness and self regulation in group members. In P. B. Paulus (Org.), Psychology of group influence (pp.209-242). Hillsdale: Erlbaum.

Dik, G., \& Aarts, H. (2007). Behavioral cues to others' motivation and goal pursuits: The perception of effort facilitates goal inference and contagion. Journal of Experimental Social Psychology, 43(5), 727-737.

Djupe, P. A., \& Grant, J. T. (2001). Religious institutions and political participation in America. Journal for the Scientific Study of Religion, 40(2), 303-314. 
Dolezal, M. (2010). Exploring the stabilization of a political force: The social and attitudinal basis of green parties in the age of globalization. West European Politics, 33(3), 534-552.

Downs, A. (1957). An economic theory of democracy. New York: Harper \& Row.

Druckman, J. N. (2001). The implications of framing effects for citizen competence. Political Behavior, 23(3), 225-256.

Drury, J. \& Reicher, S. (1999). The intergroup dynamics of collective empowerment: Substantiating the social identity model of crowd behavior. Group Processes \& Intergroup Relations, 2, 381-402.

Duarte, A. L. C., Nunes, M. L. T., \& Kristensen, C. H. (2008). Esquemas desadaptativos: revisão sistemática qualitativa. Revista brasileira de terapias cognitivas, 4(1). Retrieved from http://pepsic.bvsalud.org/scielo.php?script= sci_arttext\&pid=S1808-56872008000100004\&Ing=pt\&tlng=es.

Dudley, R. L., \& Gitelson, A. R. (2002). Political literacy, civic education, and civic engagement: A return to political socialization? Applied Developmental Science, 6(4), $175-182$.

Durham, E. (1998). O ensino superior na América Latina: tradições e tendências. Revista Novos Estudos, 51, 91-105.

Duriguetto, M. L., de Souza, A. R., \& Nogueira, K. (2009). Sociedade civil e movimentos sociais: debate teórico e ação prático-política. Katalysis, 12(1) 1321.

Duverger, M. (1980). Os partidos políticos (2a ed.). Brasília: Universidade de Brasília. 
Eagly A, Chaiken S. (1998). Attitude structure and function. In D. Gilbert, S. Fiske, G. Lindzey (Eds.). The handbook of social psychology (Vol. 1, 4th ed., pp. 269-322). Boston: McGraw-Hill.

Eger, M. A. (2010). Even in Sweden: the effect of immigration on support for welfare state spending. European Sociological Review, 26(2), 203-217.

Ekman, J., \& Amnå, E. (2012). Political participation and civic engagement: Towards a new typology. Human Affairs, 22(3), 283-300.

Elkins, Z. (2000). Quem iria votar? Conhecendo as conseqüências do voto obrigatório no Brasil. Opinião Pública, 6(1), 109-136.

Embaixada Americana (2008). Eleições para o Congresso. Retrieved from http://www.embaixada-americana.org.br/HTML/electionsinbrief/congress.htm

Emler, N., \& Frazer, E. (1999). Politics: the education effect. Oxford Review of Education, 25(1-2), 251-273.

Enander, H. (2013). The liberal reform period. In Encyclopædia Britannica. Retrieved from http://www.britannica.com/EBchecked/topic/576478/Sweden/29875/Theliberal-reform-period

Estadão.com.br (2011, December 16). Retrospectiva 2011: Marcha contra a corrupção mostra força das mídias sociais. Estadão.com.br. Retrieved from http://www.estadao.com.br/noticias/nacional, retrospectiva-2011-marcha-contraa-corrupcao-mostra-forca-das-midias-sociais,811952,0.htm

Estadão.com.br (2013, June 20). Protestos reúnem mais de 1 milhão nas ruas pelo País; grupo invade e depreda o Itamaraty; em Ribeirão, um morre atropelado. Estadão.com.br. Retrieved from http://blogs.estadao.com.br/estadao-urgente/ protestos-ocorrem-em-75-cidades-e-terao-seguranca-reforcada/ 
Eysenck, M. W. \& Keane, M. T. (1994). Psicologia cognitiva: Um manual introdutório. Porto Alegre: Artes Médicas.

Facchini, R. (2010). Movimento homossexual no Brasil: recompondo um histórico. Cadernos AEL, 10(18/19). Retrieved from: http://www.ael.ifch.unicamp.br/ publicacoes_ael/index.php/cadernos_ael/article/viewFile/73/75

Farias, L. A., Moreira, R. S., Rocha, A. C. A., Oliveira, A. C. H., Cunha, A. V., di Traglia, B. B., Ayllón, R. M., Schwartz, B. C., Romero, F., \& Graça, T. (2012). Contribuições do ensino das Ciências Naturais e de Química para a promoção do consumo responsável-grupo Quimicando com a ciência. Revista Ciência em Extensão, 8(3), 219-227.

Farid, A. (2014). Student Online Readiness Assessment Tools: A Systematic Review Approach. Electronic Journal of e-Learning, 12(4) 375-382.

Favero, D. \& Diniz, F. (2013, June 20). RS: protesto em Porto Alegre acaba em saques e confrontos; 20 são presos. Terra Notícias. Retrieved from http://noticias.terra.com.br/brasil/cidades/rs-protesto-em-porto-alegre-acaba-emsaques-e-confrontos-20-sao-presos,d88095c85046f310VgnVCM1 0000098cceb0aRCRD.html

Fehr, E., \& Fischbacher, U. (2004). Social norms and human cooperation. Trends in cognitive sciences, 8(4), 185-190.

Fernandes, P. (2013, June 9). Manifestações - o que você não viu na TV. O Casarão. Retrieved from http://jornalocasarao.com/2013/07/09/manifestacoes-o-que-vocenao-viu-na-tv/

Festinger, L. (1975). Teoria da dissonância cognitiva. Rio de Janeiro: Zahar. 
Festinger, L., Pepitone, A., \& Newcomb, T. M. (1952). Some consequences of deindividuation in a group. Journal of Abnormal and Social Psychology, 47, 382389.

Finkel, S. E., \& Smith, A. E. (2011). Civic education, political discussion, and the social transmission of democratic knowledge and values in a new democracy: Kenya 2002. American Journal of Political Science, 55(2), 417-435.

Fishbein, M. \& Ajzen, I. (1975). Belief, Attitude, Intention, and Behavior: An Introduction to Theory and Research. Massachusetts: Addison-Wesley.

Fiske, S. T. (1998). Stereotyping, Prejudice and Discrimination. In D. Gilbert, S. Fiske, G. Lindzey (Eds.). The handbook of social psychology (Vol. 2, 4th ed., pp. 357411). Boston: McGraw-Hill.

Fiske, A. P., Kitayama, S., Markus. H. R., \& Nisbett, R. E. (1998). The cultural matrix of social psychology. In D. T. Gilbert, S. T. Fiske, \& G. Linzey (Eds.). Handbook of social psychology (4th ed., pp. 915-981). Boston: McGraw-Hill.

Fleischer, D. V. (2004). Political reform: the missing link. In: M. A. Font, A. P. Spanakos, C. Bordin (Eds.). Reforming Brazil. Maryland: Lexington Books.

Folha de S. Paulo (2013a, June 20). Manifestações levam 1 milhão de pessoas às ruas em todo país. Folha de São Paulo. Retrieved from http://www1.folha.uol.com.br/cotidiano/2013/06/1298755-manifestacoes-levam1-milhao-de-pessoas-as-ruas-em-todo-pais.shtml

Fornell, C., \& Larcker, D. F. (1981), Evaluating structural equation models with unobservable variables and measurement error. Journal of Marketing Research, 18(1), 39-50. 
Franke, R. H., Hofstede, G., \& Bond, M. H. (1991). Cultural roots of economic performance: A research note. Strategic management journal, 12(S1), 165-173.

Frazer, E. (1999). Introduction: the idea of political education. Oxford Review of Education, 25(1-2), 5-22.

Frazer, E. (2000). Citizenship education: anti-political culture and political education in Britain. Political studies, 48(1), 88-103.

Freedman, J. L., \& Perlick, D. (1979). Crowding, contagion, and laughter. Journal of Experimental Social Psychology, 15(3), 295-303.

Freire, P. (2001). Política e Educação: ensaios (5a ed.). São Paulo: Cortez.

Freud, S. (1921) Psicologia das Massas e a Análise do Eu. Em: S. Freud. Obras Completas de Sigmund Freud (Vol. 15, Paulo César de Sousa, Trad.). São Paulo: Companhia das Letras.

Friede, R. (2006). Curso de ciência política e teoria geral do Estado: teoria constitucional e relações internacionais (3a ed.). Rio de Janeiro: Forense Universitária.

Fuks, M., Perissinoto, R. M. \& Ribeiro, E. A. (2003). Cultura política e desigualdade: o caso dos conselhos municipais de Curitiba. Revista de Sociologia e Política, 21, $125-145$.

Fuks, M., \& Perissinotto, R. M. (2006). Recursos, decisão e poder: conselhos gestores de políticas públicas de Curitiba. Revista Brasileira de Ciências Sociais, 21(60), $67-81$. 
G1 (2013a, June 20). Protestos pelo país têm 1,25 milhão de pessoas, um morto e confrontos. G1. Retrieved from http://g1.globo.com/brasil/noticia/2013/06/ protestos-pelo-pais-tem-125-milhao-de-pessoas-um-morto-e-confrontos.html

G1 (2014, July 7). Datafolha mostra Dilma com 38\%, Aécio com $20 \%$ e Campos com 9\%. G1. Retrieved from: http://g1.globo.com/politica/eleicoes/2014/noticia/ 2014/07/pesquisa-datafolha-mostra-dilma-com-38-aecio-20-e-campos-9.html

Galston, W. A. (2001). Political knowledge, political engagement, and civic education. Annual review of political science, 4(1), 217-234.

Gamarnikow, E. (2013). Educação, (in)justiça social e direitos humanos: combatendo desigualdades na globalização turbocapitalista. Revista Brasileira de Educação, 18(52), 189-243.

Garzia, D. (2013). Changing Parties, Changing Partisans: The Personalization of Partisan Attachments in Western Europe. Political Psychology, 34(1), 67-89.

Geertz, C. (1973). The Impact of the Concept of Culture on the Concept of Man. In: C. Geertz. The interpretation of cultures: Selected essays. New York: Basic books. Retrieved from http://academic.regis.edu/rlumpp/PDF\%20files/ Geertz\%20_\%20 Impact\%20of\%20Culture.pdf.

Geertz, C. (1993). Religion as a Cultural System. In: C. Geertz. The interpretation of cultures: Selected essays. Waukegan: Fontana Press. Retrieved from http://isites.harvard.edu/fs/docs/icb.topic152604.files/ Week_4/Geertz_Religon_as_a_Cultural_System_.pdf

Gelfand, M. J., Erez, M., \& Aycan, Z. (2007). Cross-cultural organizational behavior. Annual Review of Psychology, 58, 479-514. 
Gini, C. (1921). Measurement of inequality of incomes. The Economic Journal, 31(121), 124-126.

Gohn, M. D. G. M. (2009). Lutas e movimentos pela educação no Brasil a partir de 1970. Eccos Revista Científica, 11(1), 23-38.

Gohn, M. G. (2014). A sociedade brasileira em movimento: vozes das ruas e seus ecos políticos e sociais. Caderno $\mathrm{CRH}, 27(71), 431-441$.

Golebiowska, E. A. (2003). When to tell?: Disclosure of concealable group membership, stereotypes, and political evaluation. Political Behavior, 25(4), 313337.

Gomes, L. (2007). 1808. Rio de Janeiro: Globo Livros.

Gomes, L. (2010). 1822. Rio de Janeiro: Globo Livros.

Gomes, L. (2013). 1889. Rio de Janeiro: Globo Livros.

Gomes, M. D. A., \& Maheirie, K. (2011). Passe Livre Já: participação política e constituição do sujeito. Revista Psicologia Política, 11(22), 359-375.

Gondim, E. \& Rodrigues, O. M. (2010). John Rawls: a educação política. Universitas Humanística, 69, 211-224.

Green-Pedersen, C. (2012). A giant fast asleep Party incentives and the politicisation of European integration. Political Studies, 60(1), 115-130.

Grimberg, C. (1935). A history of Sweden (C. W. Foss, Trad.). Rock Island, Illinois: Augustana Book Concern. Retrieved from https://archive.org/details/ historyofsweden006730mbp

Groves, T. (2011). Looking up to Paulo Freire: education and political culture during the Spanish transition to democracy. Paedagogica Historica, 47(5), 701-717. 
Guimarães, C. (2013, June 24). Protesto em Goiânia termina em confronto com a polícia. Folha de S. Paulo. Retrieved from: http://www1.folha.uol.com.br/ cotidiano/2013/06/1300762-protesto-em-goiania-termina-em-confronto-com-apolicia.shtml

Gustavson, C. G. (1986). The small giant: Sweden enters the industrial era. Athens, $\mathrm{OH}$ : Ohio University Press.

Hair, J. F., Black, W. C., Babin, B. J., Anderson, R. E. \& Tatham, R. L. (2009). Análise multivariada de dados (A. S. Sant'Anna e A. Chaves Neto, Trads.). Porto Alegre: Bookman.

Hall, E. T. (1966). The hidden dimension. Garden City: Anchor Books.

Hall, E. T. (1998). The power of hidden differences. In M. J. Bennett (Ed.). Basic concepts of intercultural communication: Selected readings (pp. 53-67). Yarmouth: Intercultural Press.

Hansson, K., Cars, G., Ekenberg, L., \& Danielson, M. (2013). The importance of recognition for equal representation in participatory processes: Lessons from Husby. Footprint, 13, 81-98.

Harrigan, N., Achananuparp, P., \& Lim, E. P. (2012). Influentials, novelty, and social contagion: The viral power of average friends, close communities, and old news. Social Networks, 34(4), 470-480.

Harris, M. (1976). History and significance of the emic/etic distinction. Annual review of anthropology, 5, 329-350.

Hartley, E. L. (1946). Problems in prejudice. New York: King's Crown. 
Haslam, S. A., Turner, J. C., Oakes, P. J., McGarty, C., \& Reynolds, K. J. (1997). The group as a basis for emergent stereotype consensus. European review of social psychology, 8(1), 203-239.

Hattie, J. (1985). Methodology review: assessing unidimensionality of tests and Itenls. Applied Psychological Measurement, 9(2), 139-164.

Hayduk, L. A. (1987). Structural equation modeling with LISREL: Essentials and advances. Baltimore, MD: The Johns Hopkins University Press.

Hayes, G. (2012). Bossnapping: situating repertoires of industrial action in national and global contexts. Modern \& Contemporary France, 20(2), 185-201.

Hayton, J. C., Allen, D. G., \& Scarpello, V. (2004). Factor retention decisions in exploratory factor analysis: A tutorial on parallel analysis. Organizational research methods, 7(2), 191-205.

Heller, M. (1995). Language choice, social institutions, and symbolic domination. Language in Society, 24(03), 373-405.

Henderson, J., \& Chatfield, S. (2011). Who matches Propensity scores and bias in the causal effects of education on participation. Journal of Politics, 73(3), 646-658.

Henrique, A. L. (2010). Cidadãos crentes, críticos e ocultos: assimetrias da confiança no Congresso Nacional. Anais do $7^{\circ}$ Encontro da Associação Brasileira de Ciência Política, Recife - PE.

Henrique, A. L. (2013). O que pensa quem "bate à porta" de uma Casa que só "apanha"?: Percepções e orientações dos visitantes sobre o Congresso Nacional. Opinião Pública, 19(2), 346-379. 
Hibbing, J. R., \& Patterson, S. C. (1994). Public trust in the new parliaments of Central and Eastern Europe. Political studies, 42(4), 570-592.

Highton, B. (2009). Revisiting the relationship between educational attainment and political sophistication. The Journal of Politics, 71(04), 1564-1576.

Hirvonen, K. (2013). Sweden: when hate becomes the norm. Race \& Class, 55(1), 7886.

Hofstad, H. (2013). Planning Models in Sweden and Norway: Nuancing the Picture. Scandinavian Political Studies, 36(3), 270-292.

Hofstede, G. (1980). Culture's consequences: Comparing values, behaviors, institutions and organizations across nations. Beverly Hills: Sage.

Hofstede, G. (1983). The cultural relativity of organizational practices and theories. International Business Studies, 14, 75-89.

Hofstede, G. (1984a). Cultural dimensions in management and planning. Asia Pacific Journal of Management, 1(2), 81-99.

Hofstede, G. (1984b). The cultural relativity of the quality of life concept. Academy of Management Review, 9, 389-398.

Hofstede, G. (1991). Cultures and organizations: Software of the mind. Maidenhead, UK: McGraw-Hill.

Hofstede, G. (1993). Cultural constrain in management theories. Academy of Management Executive, 7, 81-94.

Hofstede, G. \& Bond, M. (1988). The Confucius connection: from cultural roots to economic growth. Organizational Dynamics, 16, 5-21. 
Hogan, J., \& Roberts, B. W. (1996). Issues and non-issues in the fidelity-bandwidth trade-off. Journal of Organizational Behavior, 17(6), 627-637.

Holmberg, S., \& Hedberg, P. (2009). Party Influence on Nuclear Power Opinion in Sweden. In Department of Political Science, University of Gothenburg. Conference on Nuclear Power Attitudes in Western Europe. Mannheim April (pp. 24-25).

Hooghe, M., \& Dassonneville, R. (2011). The effects of civic education on political knowledge. A two year panel survey among Belgian adolescents. Educational Assessment, Evaluation and Accountability, 23(4), 321-339.

Hooghe, M., \& Dejaeghere, Y. (2007). Does the 'monitorial citizen' exist? An empirical investigation into the occurrence of postmodern forms of citizenship in the Nordic countries. Scandinavian Political Studies, 30(2), 249-271.

Hoppe, H. H. (2001). Democracy-The God That Failed: The Economics and Politics of Monarchy, Democracy and Natural Order. New Jersey: Transaction Publishers.

Horn, J. L. (1965). A rationale and test for the number of factors in factor analysis. Psychometrika, 32, 179-185.

Hsu, C. C., \& Sandford, B. A. (2007). The Delphi technique: making sense of consensus. Practical Assessment, Research \& Evaluation, 12(10), 1-8.

Hu, L., \& Bentler, P. M. (1999). Cutoff criteria for fit indices in covariance structure analysis: Conventional criteria versus new alternatives. Structural Equation Modeling, 6, 1-55

Huckfeldt, R. e Sprague, J. (1995). Citizens, Politics, and Social Communication: Information and Influence in an Election Campaign. Cambridge: Cambridge University Press. 
Hui, C. H., \& Triandis, H. C. (1983). Multistrategy Approach to Cross-Cultural Research The Case of Locus of Control. Journal of cross-cultural psychology, 14(1), 65-83

Huntington, S. P. (1991). Democracy's third wave. Journal of democracy, 2(2), 12-34.

Inglehart, R. (1988). The renaissance of political culture. American Political Science Review, 82(4), 1203-1230.

Inglehart, R., \& Catterberg, G. (2002). Trends in political action: The developmental trend and the post-honeymoon decline. International Journal of Comparative Sociology, 43(3-5), 300-316.

Inglehart, R., \& Welzel, C. (2010). Changing mass priorities: The link between modernization and democracy. Perspectives on Politics, 8(2), 551-567.

Instituto Humanitas Unisinos (2013, June 5). As manifestações de rua e a resposta do governo. Instituto Humanitas Unisinos. Retrieved from http://www.ihu.unisinos.br/noticias/521684-as-manifestacoes-de-rua-e-aresposta-do-governo

Jackman, R. W., \& Miller, R. A. (1996). A renaissance of political culture? American Journal of Political Science, 40(3), 632-659.

James, V. Z. (1986). Manual de Psicología Social. Barcelona: Paidós.

Jennings, M. K., Stoker, L., \& Bowers, J. (2009). Politics across generations: Family transmission reexamined. The Journal of Politics, 71(03), 782-799.

Jesus, J. G. de. (2013). Psicologia das massas: contexto e desafios brasileiros. Psicologia \& Sociedade, 25(3), 493-503. 
Johnson, J. P., \& Lenartowicz, T. (1999). Culture, freedom and economic growth: do cultural values explain economic growth?. Journal of World Business, 33(4), 332356.

Johnson, S. \& Pollard, N. (2014, September 10). Trouble in paradise? Sweden risks deadlock in tight election race. Reuters. Retrieved from: http://www.reuters.com/ article/2014/09/10/us-sweden-election-risk-idUSKBNOH50RF20140910

Jones J. M. G., Sanderson C .F. B. \& Black N. A. (1992) What will happen to the quality of care with fewer junior doctors? A Delphi study of consultant physicians' views. Journal of the Royal College of Physicians London 26, 36-40.

Jones, M. B., \& Jones, D. R. (1995). Preferred pathways of behavioral contagion. Journal of psychiatric research, 29(3), 193-209.

Jöreskog, K. G. (1971). Simultaneous factor analysis in several populations. Psychometrika, 36, 409-426.

Jorge, V. L. (2003). A cobertura do congresso nacional pelos jornais brasileiros, 19851990. Revista Estudos Históricos, 1(31), 64-82.

Jost, J. T., \& Banaji, M. R. (1994). The role of stereotyping in system-justification and the production of false consciousness. British Journal of Social Psychology, 33(1), 1-27.

Jussim, L. J., McCauley, C. R., \& Lee, Y. T. (1995). Why study stereotype accuracy and inaccuracy? In Y. T. Lee, L. J. Jussim \& C. R. McCauley (Eds.). Stereotype accuracy: Toward appreciating group differences (pp. 3-27). Washington, DC: American Psychological Association. 
Kaase, M. \& Marsh, A. (1979). Political Action. A Theoretical Perspective. In: S. Barnes \& M. Kaase (Eds.). Political Action: Mass Participation in Five Western Democracies. London: Sage.

Kam, C. D. (2007). Implicit attitudes, explicit choices: When subliminal priming predicts candidate preference. Political Behavior, 29(3), 343-367.

Kam, C. D., \& Palmer, C. L. (2008). Reconsidering the effects of education on political participation. The Journal of Politics, 70(03), 612-631.

Kam, C. D., \& Palmer, C. L. (2011). Rejoinder: Reinvestigating the causal relationship between higher education and political participation. Journal of Politics, 73(3), 659-663.

Katz, D. \& Braly, K. (1933). Racial stereotypes of one hundred college students. Journal of Abnormal and Social Psychology, 28, 280-290.

Keesing, R. M. (1974). Theories of culture. Annual review of anthropology, 3, 73-97.

Kinder, D. R. \& Sears, D. O. (1985). Public opinion and political action. In: G. Lindsey, E. Aronson (eds.). The Handbook of Social Psychology, Vol. II, $3^{\text {rd }}$ ed. New York: Random House, pp. 659-741.

Kinzo, M. A. G. (2001). A democratização brasileira: um balanço do processo político desde a transição. São Paulo em Perspectiva, 15(4), 3-12.

Kinzo, M. A. G. (2004). Partidos, eleições e democracia no Brasil pós-1985. Revista Brasileira de Ciências Sociais, 19(54), 23-41.

Kleba, M. E., \& Wendausen, A. (2009). Empoderamento: processo de fortalecimento dos sujeitos nos espaços de participação social e democratização política. Saúde e Sociedade, 18(4), 733-743. 
Kline, P. (1979). Psychometrics and psychology. London: Academic Press.

Kluckhohn, C. (1951). Values and value orientation in the theory of action. In T. Parsons, E. A. Shils, (eds.), Toward a General Theory of Action (pp. 388-433). New York: Harper.

Koch, J. W. (2003). Being certain versus being right: Citizen certainty and accuracy of house candidates' ideological orientations. Political Behavior, 25(3), 221-246.

Krassa, M. A. (1988). Social groups, selective perception, and behavioral contagion in public opinion. Social Networks, 10(2), 109-136.

Kroeber, A. L., \& Kluckhohn, C. (1952). Culture: A Critical Review of Concepts and Definitions. Papers of the Peabody Museum, vol. 47, no. 1. Cambridge: Peabody Museum.

Kuklinski, J. H., \& Hurley, N. L. (1994). On hearing and interpreting political messages: A cautionary tale of citizen cue-taking. Journal of Politics, 56(3), 729-751.

Kuschnir, K. \& Carneiro, L. P. (1999). As dimensões subjetivas da política: cultura política e antropologia da política. Revista Estudos Históricos, 13(24), 227-250.

Kuymulu, M. B. (2013). Reclaiming the right to the city: Reflections on the urban uprisings in Turkey. City, 17(3), 274-278.

Lake, R. L. D., \& Huckfeldt, R. (1998). Social capital, social networks, and political participation. Political Psychology, 19(3), 567-584.

Lane, R. (1992) Political culture: residual category or general theory? Comparative Political Studies, 25(3), 362-387.

LaPiere, R. T. (1934). Attitudes versus actions. Social Forces, 13, 230-237. 
Laraia, R. B. (1997). Cultura: um conceito antropológico (11a. ed.). Rio de Janeiro: Zahar.

Larsson, A. O., \& Kalsnes, B. (2014). 'Of course we are on Facebook': Use and nonuse of social media among Swedish and Norwegian politicians. European Journal of Communication. Retrieved from: http://ejc.sagepub.com/content/early /2014/05/14/0267323114531383.abstract

Lau, R. R., \& Redlawsk, D. P. (2001). Advantages and disadvantages of cognitive heuristics in political decision making. American Journal of Political Science, 45(4), 951-971.

Lavalle, A., \& Vera, E. I. (2011). A trama da crítica democrática da participação à Representação e à Accountability. Lua Nova, 84, 353-364.

Le Bon, G. (2008). Psicologia das multidões (M. S. Cunha, Trad.). São Paulo: Martins Fontes (Obra original publicada em 1895).

Leal, A. (2013, June 21). Quase 2 milhões de brasileiros participaram de manifestações em 438 cidades. Agência Brasil. Retrieved from http://memoria.ebc.com.br/agenciabrasil/noticia/2013-06-21/quase-2-milhoes-debrasileiros-participaram-de-manifestacoes-em-438-cidades

Leighley, J. E. (1995). Attitudes, opportunities and incentives: A field essay on political participation. Political Research Quarterly, 181-209.

Lima, B. (2014, October 27). Reeleita, Dilma mantém maioria no Congresso no $2^{\circ}$ mandato. R7. Retrieved from: http://noticias.r7.com/eleicoes-2014/reeleita-dilmamantem-maioria-no-congresso-no-2-mandato-27102014

Lima, L. \& Frota, M. (2014, October 6). Derrota de Marina Silva reacende movimento para criação da Rede Sustentabilidade. Último Segundo. Retrived from: 
http://ultimosegundo.ig.com.br/politica/2014-10-06/derrota-de-marina-silvareacende-movimento-para-criacao-da-rede-sustentabilidade.html

Lima, M. R. S., \& Santos, F. (2001). O Congresso e a política de comércio exterior. Lua Nova, (52), 121-149.

Lima, V. A. (2013, June 25). As manifestações de junho e a mídia. Observatório de Imprensa. Retrieved from http://www.observatoriodaimprensa.com.br/news/ view/_ed752_as_manifestacoes_de_junho_e_a_midia

Lima, W. (2012, September 7). Marcha contra a corrupção reúne 7 mil manifestantes em $\quad$ Brasília. Ultimo Segundo. $\quad$ Retrieved from http://ultimosegundo.ig.com.br/politica/2012-09-07/marcha-contra-a-corrupcao$\underline{\text { reune-7-mil-manifestantes-em-brasilia.html }}$

Limongi, F. \& Guarnieri, F. (2014). A base e os partidos: As eleições presidenciais no Brasil pós-redemocratização. Novos estudos, 99, 05-24.

Lindkvist, T. (2003). Kings and provinces in Sweden. In: K. Helle (Ed.). The Cambridge History of Scandinavia Volume 1: Prehistory to 1520. Cambridge: Cambridge University.

Lindvall, J., \& Rothstein, B. (2006). Sweden: The fall of the strong state. Scandinavian Political Studies, 29(1), 47-63.

Linstone H. \& Turoff M. (eds.) (1975). The Delphi Method: Techniques and Applications. Massachusetts: Addison-Wesley.

Linz, J. J., \& Stepan, A. (1999). A transição e consolidação da democracia: a experiência do Sul da Europa e da América do Sul. São Paulo: Paz e Terra. 
Lipset, S. M. (1993). Reflections on Capitalism, Socialism \& Democracy. Journal of Democracy, 4(2), 43-55.

López, J. F. (2011, August 11). Income Distribution and the Occupy Wall Street Movement. The Huffington Post. Retrieved from: http://www.huffingtonpost.com/ jose-fernando-lopez/cbo-munitions-to-occupy-w_b_1080729.html

Lorentzen, T., Angelin, A., Dahl, E., Kauppinen, T., Moisio, P., \& Salonen, T. (2014). Unemployment and economic security for young adults in Finland, Norway and Sweden: From unemployment protection to poverty relief. International Journal of Social Welfare, 23(1), 41-51.

Lupia, A. \& McCubbins, M. (2000). The institutional foundations of political competence: how citizens learn what they need to know. In: Lupia, A., McCubbins, M., Popkin, S. (Eds.) Elements of reason: cognition, choice, and the bounds of rationality. Cambridge, Cambridge University Press.

Luskin, R. C., Fishkin, J. S., \& Jowell, R. (2002). Considered opinions: Deliberative polling in Britain. British Journal of Political Science, 32(3), 455-487.

Lyons, A., \& Kashima, Y. (2003). How are stereotypes maintained through communication? The influence of stereotype sharedness. Journal of personality and social psychology, 85(6), 989-1005.

Macedo, D. G. D., \& Baccega, M. A. (2012). Afinal, o que é gênero em comunicação? O consumo da programação midiática televisiva. Comunicação \& Informação, 13(1), 58-68.

Macedo, F. (2013, June 25). O povo tem o direito de ir à rua, diz chefe do MP de SP. Estadão.com.br. Retrieved from http://www.estadao.com.br/noticias/ nacional,opovo-tem-o-direito-de-ir-a-rua-diz-chefe-do-mp-de-sp,1046705,0.htm 
Macedo, J. R. (1995). Um outro olhar para a Antiguidade: a contribuição de Moses Finley. Anos 90, 3(3).

Mackie, M. (1973). Arriving at "truth" by definition: the case of stereotype inaccuracy. Social Problems, 20, 431-447.

Malmberg, B., Andersson, E., \& Östh, J. (2013). Segregation and Urban Unrest in Sweden. Urban Geography, 34(7), 1031-1046.

Marôco, J. (2010). Análise de equações estruturais: fundamentos teóricos, software e aplicações. Pero Pinheiro: Report Number.

Martín, M. (2014, October 2). A batalha eleitoral do Brasil se deflagra nas redes. El País. Retrieved from: http://brasil.elpais.com/brasil/2014/10/02/politica/1412206 023_560998.html

Martín-Baró, I. (1996). O papel do Psicólogo. Estudos de psicologia, 2(1), 7-27.

Martins, A. (2012, April 21). Marcha Contra a Corrupção vai hoje às ruas de mais de 40 cidades pedir julgamento do mensalão. UOL Notícias. Retrieved from http://noticias.uol.com.br/cotidiano/ultimas-noticias/2012/04/21/marcha-dacorrupcao-quer-tornar-corrupcao-crime-hediondo-e-pede-julgamento-domensalao.htm

Matland, R. E. (2005). Enhancing women's political participation: legislative recruitment and electoral systems. J. Ballington and A. Karam (Eds.). Women in parliament: Beyond numbers (Chap. 3, pp. 93-111). Stockholm: International Institute for Democracy and Electoral Assistance (IDEA).

Matland, R. E. \& Studlar, D. T. (1996). The contagion of women candidates in singlemember district and proportional representation electoral systems: Canada and Norway. The journal of politics, 58(03), 707-733. 
Mayer, A. K. (2011). Does education increase political participation? Journal of Politics, 73(3), 633-45.

Mayr, S., Erdfelder, E., Buchner, A., \& Faul, F. (2007). A short tutorial of GPower. Tutorials in Quantitative Methods for Psychology, 3(2), 51-59.

McClurg, S. D. (2003). Social networks and political participation: The role of social interaction in explaining political participation. Political Research Quarterly, 56(4), 449-464.

McDonald, R. P. (1981). The dimensionality of tests and items. British Journal of Mathematical and Statistical Psychology, 34(1), 100-117.

McDougall, W. (1927). The group mind. Cambridge: Cambridge University Press. Disponível em: https://archive.org/details/groupmind032676mbp.

McFarland, D. A., \& Thomas, R. J. (2006). Bowling young: How youth voluntary associations influence adult political participation. American sociological review, 71(3), 401-425.

McGuire, G. R. (1987). Pathological Subconscious And Irrational Determinism In The Social Psychology Of The Crowd: The Legacy Of Gustave Le Bon. Advances Psychology, 40, 201-217. Retrieved from http://www.sciencedirect.com/ science/article/pii/S0166411508600746

Menezes, E. T. \& Santos, T. H. (2002). OSPB (Organização Social e Política Brasileira). In E. T. Menezes, T. H. Santos. Dicionário Interativo da Educação Brasileira. São Paulo: Midiamix. Retrieved from http://www.educabrasil.com.br/ eb/dic/dicionario.asp?id=365

Menin, M. S. D. S. (2002). Valores na Escola. Educação e Pesquisa, 28(1), 91-100. 
Merkel, W. (2004). Embedded and defective democracies. Democratization, 11(5), 3358.

Michaud, K. E., Carlisle, J. E., \& Smith, E. R. (2009). The relationship between cultural values and political ideology, and the role of political knowledge. Political Psychology, 30(1), 27-42.

Micheletti, M. (2003). Why More Women? Issues of Gender and Political Consumerism. In: M. Micheletti, A. Follesdal and D. Stolle (eds.). Politics, Products, and Markets: Exploring Political Consumerism Past and Present. New Brunswick, NJ: Transaction Press.

Miguel, L. F. (2001). Meios de comunicação de massa e política no Brasil. Diálogos latinoamericanos, 3, 43-70.

Miguel, L. F. (2002). A Democracia Domesticada: Bases Antidemocráticas do Pensamento Democrático Contemporâneo. Dados, 45(3), 483-511.

Miguel, L. F. (2003). Capital político e carreira eleitoral: algumas variáveis na eleição para o Congresso brasileiro. Revista de Sociologia Política, 20, 115-134.

Milbrath, L. W. (1965). Political Participation. Chicago: RandMcNally.

Milbrath, L. W. \& Goel, M. L. (1977). Political Participation (2nd ed). Boston: Rand McNally.

Milfont, T. (2010). Global warming, climate change and human psychology. In: V. Corral Verdugo, C. H. Garcia-Cadena, Martha Frias-Armenta (Eds.). Psychological approaches on sustainability: current trends on theory, research and applications. New York: Nova Science Publishers, pp. 19-42. 
Mishler, W., \& Rose, R. (2005). What are the political consequences of trust? A test of cultural and institutional theories in Russia. Comparative Political Studies, 38(9), 1050-1078.

Missau Ruviaro, E., \& Missau Ruviaro, H. (2014). Os Reflexos da Rede na Democracia Representativa: uma análise da eleição presidencial brasileira de 2014 sob a ótica de aplicativos sociais. Revista Democracia Digital e Governo Eletrônico, (11), 163-186.

Mitchell, W. C. (1984). Schumpeter and public choice, Part I: Precursor to public choice?. Public Choice, 42(1), 73-88.

Mocca, E. (2005). O futuro incerto dos partidos políticos argentinos. Estudos Avançados, 19(55), 49-63

Moisés, J. A. (1992). Democratização e cultura política de massas no Brasil. Lua Nova: Revista de Cultura e Política, 26, 05-51.

Moisés, J. A. (2005). A Desconfiança nas Instituições Democráticas. Opinião Pública, 11(1), 33-63.

Moisés, J. A. (2008). Cultura política, instituições e democracia: lições da experiência brasileira. Revista Brasileira de Ciências Sociais, 23(66), 11-43.

Moisés, J. Á. (2010). Os significados da democracia segundo os brasileiros. Opinião Pública, 16(2), 269-309.

Moisés, J. Á., \& Carneiro, G. P. (2008). Democracia, desconfiança política e insatisfação com o regime: o caso do Brasil. Opinião Pública, 14(1), 1-42.

Montero, P. (2009). Secularização e espaço público: a reinvenção do pluralismo religioso no Brasil. Etnográfica, 13(1), 07-16. 
Montes, M. L., \& Meyer, M. (1984). Festa na política. Lua Nova: Revista de Cultura e Política, 1(3), 85-89.

Moraes, G. (2013, June 11). Manifestações de junho e a resposta do Poder Público: 1 milhão de brasileiros surpreendem as autoridades - Bloco 1. Câmara Notícias. Retrieved from http://www2.camara.leg.br/camaranoticias/radio/materias/ reportagem-especial/446979-manifestacoes-de-junho-e-a-resposta-do-poderpublico-1-milhao-de-brasileiros-surpreendem-as-autoridades-bloco-1.html

Moscovici, S. (1985). L'âge des foules: un traité historique de psychologie des masses. Bruxelles: Les Éditions Complexe. Retrieved from http://classiques.uqac.ca/ contemporains/moscovici_serge/age_des_foules/age_des_foules.pdf

Murdock, G. P. (1932). The science of culture. American Anthropologist, 34(2), 200215.

Natividade, M. (2010). Uma homossexualidade santificada?: Etnografia de uma comunidade inclusiva pentecostal. Religião \& Sociedade, 30(2), 90-121.

Neher, C. (2014, October 27). Novo Congresso exige mudanças na forma de governar de Dilma. Deutsche Welle. Retrieved from: http://www.dw.de/novo-congressoexige-mudan\%C3\%A7as-na-forma-de-governar-de-dilma/a-18024393

Neiva, E. R. \& Mauro, T. G. (2011). Atitudes e mudanças de atitudes. In C. V. Torres, \& E. R. Neiva, (Orgs.). Psicologia Social: principais temas e vertentes (Cap. 8, pp. 171-203). Porto Alegre: Artmed.

Nicol, C. J. (1995). The social transmission of information and behaviour. Applied Animal Behaviour Science, 44(2), 79-98.

Nicolau, J. \& Schmitt, R. (1995). Sistema eleitoral e sistema partidário. Lua Nova, Revista de Cultura e Política, (36), 127-147. 
Nidecker, F. (2014, February 7). Presidenciáveis 'acordam' para poder das redes sociais. BBC Brasil. Retrieved from: http://www.bbc.co.uk/portuguese/ noticias/2014/02/140205_campanha_redes_fl

Niemi, R. G., \& Hepburn, M. A. (1995). The rebirth of political socialization. Perspectives On Political Science, 24(1), 7-16.

Norris, P. (1999). Critical Citizens: Global Support for Democratic Government. Oxford: Oxford University Press.

Norris, P., Walgrave, S., \& Van Aelst, P. (2005). Who demonstrates? Antistate rebels, conventional participants, or everyone?. Comparative politics, 37(2) 189-205.

Nye, R. A. (1973). Two paths to a psychology of social action Gustave Lebon and Georges Sorel. The Journal of Modern History, 45(3) 411-438.

Okoli, C., \& Pawlowski, S. D. (2004). The Delphi method as a research tool an example, design considerations and applications. Information \& Management, 42(1), 15-29.

Olatunji, B. O., Moretz, M. W., McKay, D., Bjorklund, F., de Jong, P. J., Haidt, J., Hursti, T. J., Imada, S., Koller, S., Mancini, F. Page, A. C. \& Schienle, A. (2009). Confirming the three-factor structure of the Disgust Scale-Revised in eight countries. Journal of cross-cultural psychology, 40(2), 234-255.

Olatunji, B. O., Moretz, M. W., McKay, D., Bjorklund, F., de Jong, P. J., Haidt, J., Hursti, T. J., Imada, S., Koller, S., Mancini, F., Page, A. C. \& Schienle, A. (2009). Confirming the three-factor structure of the Disgust Scale-Revised in eight countries. Journal of cross-cultural psychology, 40(2), 234-255. 
Oliveira, L. B., \& Guzzo, R. S. L. (2013, Setember). A vida e a obra de Ignácio MartínBaró: o paradigma da libertação. Anais do Encontro de Iniciação Científica PUCCampinas, Campinas, São Paulo, 18.

Oliveira, N. D. (2008). Democracia e educação Kant, Dewey, Habermas. Filosofazer, 17(33), 19-29.

Olsen, J. M. (2014, December 3). Swedish Prime Ministers to Call for Early Elections. The Huffington Post. Retrieved from: http://www.huffingtonpost.com/ 2014/12/03/sweden-early-elections_n_6263742.html

Organization for Economic Co-operation and Development (2013). PISA 2012 Results: What Students Know and Can Do - Student Performance in Mathematics, Reading and Science (Volume I). OECD Publishing. Retrieved from http://dx.doi.org/10.1787/9789264201118-en.

Oro, A. P. (2003). Organização eclesial e eficácia política o caso da Igreja Universal do Reino de Deus. Civitas - Revista de Ciências Sociais, 3(1), 97-109.

Orrman, E. (2003). The condition of the rural population. In: K. Helle (Ed.). The Cambridge History of Scandinavia Volume 1: Prehistory to 1520. Cambridge: Cambridge University.

Ottati, V. \& Lee, Y. T. (1995) Accuracy: a neglected component of stereotype research. In Y. T. Lee, L. J. Jussim \& C. R. McCauley (Eds.). Stereotype accuracy: Toward appreciating group differences (pp. 29-59). Washington, DC: American Psychological Association.

Ouellette, J. A., \& Wood, W. (1998). Habit and intention in everyday life: the multiple processes by which past behavior predicts future behavior. Psychological Bulletin, 124(1), 54-74. 
Oyserman, D., \& Sorensen, N. (2009). Understanding cultural syndrome effects on what and how we think: A situated cognition model. In C.-Y. Chiu, R. Wyer, \& Y.Y. Hong (Eds.), Problems and solutions in cross-cultural theory, research and application (pp. 25-52). New York: Psychology Press.

Oyserman, D., Sorensen, N., Reber, R., \& Chen, S. X. (2009). Connecting and separating mind-sets: culture as situated cognition. Journal of personality and social psychology, 97(2), 217-235.

Paes, C. \& Antunes, S. (2013, June 23). Confronto entre policiais e ativistas marca protesto com 70 mil em BH. G1. Retrieved from http://g1.globo.com/minasgerais/noticia/2013/06/confronto-entre-policiais-e-ativistas-marca-protesto-com70-mil-em-bh.html

Palha, C. R. L. (2011). Televisão e política: o mito Tancredo Neves entre a morte, o legado e a redenção. Revista Brasileira de História, 31(62), 217-234.

Parry, G. (1999). Constructive and reconstructive political education. Oxford Review of Education, 25(1-2), 23-38.

Pasquali, L. (2010). Testes referentes a construto: teoria e modelo de construção. Em: L. Pasquali. Instrumentação psicológica: fundamentos e práticas (Cap. 8, pp. 165-198). Porto Alegre: Artmed.

Pasquali, L. (2012). Análise Fatorial para Pesquisadores. Brasília: LabPAM.

Patterson, S. C. (1968). The political cultures of the American states. The Journal of Politics, 30(1), 187-209.

Paxton, P. (1999). Is social capital declining in the United States? A multiple indicator assessment 1. American Journal of sociology, 105(1), 88-127. 
Pereira, C., \& Mueller, B. (2000). Uma teoria da preponderância do poder Executivo O sistema de comissões no Legislativo brasileiro. Revista Brasileira de Ciências Sociais, 15(43), 45-67.

Persson, M. (2012). Does Type of education affect Political Participation? results From a Panel survey of swedish adolescents. Scandinavian Political Studies, 35(3), $198-221$.

Pietryka, M. T., \& Boydstun, A. E. (2012). Going Maverick: How Candidates Can Use Agenda-Setting to Influence Citizen Motivations and Offset Unpopular Issue Positions. Political Behavior, 34(4), 737-763.

Pires, B. (2013, June 13). Em uma semana, quatro protestos contra aumento da tarifa em São Paulo. Estadão.com.br. Retrieved from http://www.estadao.com.br/ especiais/em-uma-semana-quatro-protestos-contra-aumento-da-tarifa-em-saopaulo,203763.htm

Pollard, N. \& Johnson, S. (2014, September 14). Sweden heads for minority left government, far right surges. Reuters. Retrieved from: http://www.reuters.com/article/2014/09/14/us-sweden-electionidUSKBNOH80SA20140914

Powell, C. (2003). The Delphi technique: myths and realities. Journal of advanced nursing, 41(4), 376-382.

Pring, R. (1999). Political education: relevance of the humanities. Oxford Review of Education, 25(1-2), 71-87.

Putnam, R. D., Leonardi, R. \& Nanetti, R. (1993). Making Democracy Work: Civic Traditions in Modern Italy. Princeton: Princeton University. 
Putnam, R. D. (1995). Bowling alone: America's declining social capital. Journal of democracy, 6(1), 65-78.

Putnam, R. D. (1996) Comunidade e democracia: a experiência da Itália moderna, Rio de Janeiro: Fundação Getúlio Vargas.

Putnam, R. D., Leonardi, R., Nanetti, R. Y., \& Pavoncello, F. (1983). Explaining institutional success: The case of Italian regional government. The American Political Science Review, 55-74.

Rahn, W. M. (1993). The Role of Partisan Stereotypes in Information Processing about Political Candidates. American Journal of Political Science, 37(2), 472-496

Ramos, N. (2013, June 20) A imprensa, outro alvo dos manifestantes no Brasil. AFP. Retrieved from http://br.noticias.yahoo.com/imprensa-outro-alvo-dosmanifestantes-brasil-205948389.html

Ranthum, R. (2013, June 16). Um ensaio sobre o mês de junho de 2013. Observatório da Imprensa. Retrieved from http://www.observatoriodaimprensa.com.br/ news/view/_ed755_um_ensaio_sobre_o_mes_de_junho_de_2013

Rawls, J. (2000). O Liberalismo Político. São Paulo: Ática.

Realo, A., Allik, J., \& Greenfield, B. (2008). Radius of trust Social capital in relation to familism and institutional collectivism. Journal of Cross-Cultural Psychology, 39(4), 447-462.

Reicher, S. (2008). The psychology of crowd dynamics. In M. A. Hogg \& R. S. Tindale (Orgs.), Blackwell handbook of social psychology: Group processes (pp. 182208). Oxford: Blackwell. 
Reimann, M., \& Zimbardo, P. G. (2011). The dark side of social encounters: Prospects for a neuroscience of human evil. Journal of Neuroscience, Psychology, and Economics, 4(3), 174.

Rennó, L. R. (2001). Confiança interpessoal e comportamento político: microfundamentos da teoria do capital social na América Latina. Opinião pública, 7(1), 33-59.

Resende, J. M., \& Dionísio, B. M. (2005). Escola pública como «arena» política: contexto e ambivalências da socialização política escolar. Análise Social, $X L(176), 661-680$.

Ribeiro, E. A. (2007). Cultura política, instituições e experiência democrática no Brasil. Sociologia e Política, 28, 205-219.

Ribeiro, M. T. R. (2001). Antes Tarde do que nunca: Gabriel Tarde e a emergência das ciências sociais. Revista de Antropologia, 44(1), 325-330.

Ricci, P. (2003). The content of Brazilian legislative output: national laws or pork barrel politics?. Dados, 46(4), 699-734.

Richard, I. (2014, December 31). Morte de Eduardo Campos fez da corrida presidencial a mais acirrada desde 1989. Agência Brasil. Retrieved from: http://agenciabrasil.ebc.com.br/politica/noticia/2014-12/morte-de-eduardocampos-fez-da-corrida-presidencial-mais-acirrada-desde

Richter, M. N. (1956). The conceptual mechanism of stereotyping. American Sociological Review, 568-571.

Rizério, L. (2015, January 29). Entre desconfiança com Levy, manifestações e Petrobras, Dilma enfrenta "dias de cão". InfoMoney. Retrieved from: 
http://www.infomoney.com.br/mercados/politica/noticia/3833992/entredesconfianca-com-levy-manifestacoes-petrobras-dilma-enfrenta-dias-cao

Rosa, G. L. (2012). Globollywood." Caminho das Índias" entre estereótipos, castas e code-mixing. Lingue e Linguaggi, 7, 59-68.

Rosanvallon, P. (2008). Counter-Democracy: Politics in an Age of Distrust. Cambridge: Cambridge University Press.

Rossier, J., Dahourou, D., \& McCrae, R. R. (2005). Structural and mean-level analyses of the five-factor model and locus of control further evidence from Africa. Journal of Cross-Cultural Psychology, 36(2), 227-246.

Rothstein, B., \& Uslaner, E. M. (2005). All for all: Equality, corruption, and social trust. World politics, 58(01), 41-72.

Rottenbacher, J. M., Espinosa, A., \& Magallanes, J. M. (2011). Analisando o preconceito: bases ideológicas do racismo, do sexismo e da homofobia em uma amostra de habitantes da cidade de Lima-Peru. Revista Psicologia Política, 11(22), 225-246.

Ryan, C. S. (2003). Stereotype accuracy. European review of social psychology, 13(1), $75-109$.

Ryan, C. S. \& Bogart, L. M. (2001). Longitudinal changes in the accuracy of new group members' in-group and out-group stereotypes. Journal of Experimental Social Psychology, 37(2), 118-133.

Ryle, G. (1951). The concept of mind. London: Hutchinson House. (Obra original publicada em 1949). 
Sabucedo, J. M. (1984). Psicología y participación política. Boletín de Psicología, 5, 61-77.

Sacchi, S., Carnaghi, A., Castellini, F., \& Colombo, M. (2013). Group merger between political parties: The role of the ingroup projection process. Political psychology, 34(1), 91-105.

Sáez, M. A. \& Freidenberg, F. (2002). Partidos políticos na América Latina. Opinião Pública (Campinas), 8(2), 137-157.

Sallum Júnior, B., \& Casarões, G. S. P. (2011). O impeachment do presidente Collor: a literatura e o processo. Lua Nova, 82, 163-200.

Sallum Júnior, B., Graeff, E. P. \& Lima, E. G. (1990). Eleições presidenciais e crise do sistema partidário. Lua Nova, 20, 69-87.

Samuels, D. (1997). Determinantes do voto partidário em sistemas eleitorais centrados no candidato: evidências sobre o Brasil. Dados, 40(3). Retrieved from http://www.scielo.br/scielo.php?pid=S0011-52581997000300008\&script=sci_ arttext

Samuels, D., \& Zucco, C. (2013). The Power of Partisanship in Brazil: Evidence from Survey Experiments. American Journal of Political Science, 58(1), 212-225.

Sandoval, S. A. (1997). O comportamento político como campo interdisciplinar de conhecimento: a reaproximação da sociologia e da psicologia social. In: L. Camino; L. Lhulhier \& S. Sandoval (Orgs.). Estudos sobre comportamento político, (pp. 13-24). Florianópolis: Letras Contemporâneas.

Schafer, J. L., \& Graham, J. W. (2002). Missing data: Our view of the state of the art. Psychological Methods, 7, 147-177. 
Schierup, C. U., Ålund, A., \& Kings, L. (2014). Reading the Stockholm riots-a moment for social justice?. Race \& Class, 55(3), 1-21.

Schlösser, A. (2013, September). Práxis de transformacão: diálogo entre Paulo Freire, Ignácio Martín-Baró e Jon Sobrino. Em Anais do 11 Congresso Nacional de Educação. Curitiba: Educere. Retrieved from http://educere.bruc.com.br/ ANAIS2013/pdf/7835_4337.pdf

Schneider, M. C. \& Bos, A. L. (2011). An exploration of the content of stereotypes of black politicians. Political Psychology, 32(2), 205-233.

Schück, H. (2003). Sweden under the dynasty of the Folkungs In: K. Helle (Ed.). The Cambridge History of Scandinavia Volume 1: Prehistory to 1520. Cambridge: Cambridge University.

Schudson (1998). The Good Citizen: A History of American Public Life. New York: Free Press.

Schumpeter, J. (1942). Capitalism, socialism and democracy. London: Allen \& Unwin.

Schwartz, S. H. (1992). Universals in the content and structure of values: Theoretical advances and empirical tests in 20 countries. In: M. P, Zanna (Ed.) Advances in experimental social psychology, (Vol. 25, pp. 1-65). San Diego: Academic Press.

Schwartz, S. H. (1994). Beyond individualism/collectivism: New cultural dimensions of values. In U. Kim, H. C. Triandis, C. Kagitçibasi, S. C. Choi \& G. Yoon (Eds.), Individualism and Collectivism: Theory application and methods (pp. 85-122). Newbury Park, CA: Sage.

Schwartz, S. H. (2011). Studying values: personal adventure, future directions. Journal of Cross-Cultural Psychology, 42(2), 307-319. 
Scobbie, I. (2010). The A to Z of Sweden. London: Rowman \& Littlefield.

Scott, F. D. (1988). Sweden: The Nation's History. Carbondale, IL: Southern Illinois University.

Scott-Long, J. (1983). Confirmatory factor analysis (a preface to Lisrel). Thousand Oaks, CA: Sage.

Secco, L. (2013, June 8). Manifestantes serão enjaulados no discurso da Grande Imprensa? Viomundo. Retrieved from http://www.viomundo.com.br/politica/ lincoln-secco-virada-politica.html

Seligson, M. (2002). The Renaissance of Political Culture or the Renaissance of the Ecological Fallacy? Comparative Politics, 34(3), 273-292.

Shachar, R., \& Nalebuff, B. (1999). Follow the leader: Theory and evidence on political participation. American Economic Review, 525-547.

Shildo, G. (1990). The brazilian elecions of 1989. Electoral Studies, 9(3), 251-256.

Silva, I. R.; Goyeneche, P. L. \& Silva, T. D. (2009, May). Família e pactos sociais - dos contratualistas ao Welfare Mix. Anais do 1 Simpósio sobre a Família. Tubarão, SC: Unisul.

Silva, R. P. M. D. (1998). Teoria da justiça de John Rawls. Revista CEJ, 2(6), 103-118. Retrieved from http://www2.cjf.jus.br/ojs2/index.php/ revcej/article/view/156/244.

Silveira, S. J. C. (2013). Uma síntese da inflação no Brasil entre 1979 e 1994. Estudos do CEPE, 37, 132-147.

Simon, B., Loewy, M., Sturmer, S., Weber, U., Freytag, P., Habig, C., Kampmeier, C., \& Spahlinger, P. (1998). Collective identification and social movement participation. Journal of Personality and Social Psychology, 74(3), 646-658. 
Singelis, T. M., Triandis, H. C., Bhawuk, D. P., \& Gelfand, M. J. (1995). Horizontal and vertical dimensions of individualism and collectivism: $A$ theoretical and measurement refinement. Cross-cultural research, 29(3), 240-275.

Smelser, N. J. (1965). Theory of collective behavior. New York: The Free Press. Retrieved from https://archive.org/details/theoryofcollecti00smel

Smith, P. B., \& Bond, M. H. (1999). Social psychology across cultures: Analysis and perspectives. Needham Heights: Prentice Hall.

Smith, P. B., Dugan, S., \& Trompenaars, F. (1996). National culture and the values of organizational employees a dimensional analysis across 43 nations. Journal of cross-cultural psychology, 27(2), 231-264.

Smith, P. B., Fischer, R., Vignoles, V. L. \& Bond, M. H. (2013). Understanding social psychology across cultures: Living and working in a changing world. London: Sage.

Smith, P. B., Huang, H. J., Harb, C., \& Torres, C. (2012). How Distinctive Are Indigenous Ways of Achieving Influence? A Comparative Study of Guanxi, Wasta, Jeitinho, and "Pulling Strings". Journal of Cross-Cultural Psychology, 43(1), 135-150.

Smith, P. B., Wasti, S. A., Grigoryan, L., Achoui, M., Bedford, O., Budhwar, P., Lebedeva, N., Leong, C. H. \& Torres, C. (2014). Are Guanxi-Type SupervisorSubordinate Relationships Culture-General? An Eight-Nation Test of Measurement Invariance. Journal of Cross-Cultural Psychology, 45(6) 921-938.

Soares, A. M., Farhangmehr, M., \& Shoham, A. (2007). Hofstede's dimensions of culture in international marketing studies. Journal of business research, $60(3)$, 277-284. 
Sondheimer, R. M. \& Green, D. P. (2010). Using experiments to estimate the effects of education on voter turnout. American Journal of Political Science, 54(1), 174189.

Spencer, M. S., Fitch, D., Grogan-Kaylor, A., \& Mcbeath, B. (2005). The equivalence of the Behavior Problem Index across US ethnic groups. Journal of Cross-Cultural Psychology, 36(5), 573-589.

Spigariol, A., Shiomoda, C., Felizatte, R. \& Bonici, S. (2013, June 21). Especial protestos pelo Brasil: por trás da notícia. JPress. Retrieved from http://jpress.jornalismojunior.com.br/2013/06/especial-protestos-brasil/

Stewart J., O’Halloran C., Harrigan P., Spencer J.A. \& Barton J.R. (1999) Identifying appropriate tasks for the pre-registration year. British Medical Journal, 319(7204), 224-229.

Stolle, D., Hooghe, M. \& Micheletti, M. (2005). Politics in the supermarket: political consumerism as a form of political participation. International Political Science Review, 26(3), 245-269.

Svallfors, S. (2011). A bedrock of support? Trends in welfare state attitudes in Sweden, 1981-2010. Social Policy \& Administration, 45(7), 806-825.

Sveriges Riksdag (2012). The history of the Riksdag. Retrieved from http://www.riksdagen.se/en/How-the-Riksdag-works/Democracy/The-history-ofthe-Riksdag/

Talò, C., \& Mannarini, T. (2014). Measuring Participation: Development and Validation the Participatory Behaviors Scale. Social Indicators Research (online only), 1-18. Retrieved from: http://link.springer.com/article/10.1007/s11205-014-0761-0

Taine, H. (1885). Les origines de la France contemporaine. Paris: Hachette. 
Tajfel, H. \& Turner, J. C. (1979). An integrative theory of intergroup conflict. In S. Worchel \& W. G. Austin (Orgs.), The social psychology of intergroup relations (pp. 33-47). Chicago: Nelson-Hall.

Tavares, J. A. G. (1994). Sistemas eleitorais nas democracias contemporâneas: teoria, instituições, estratégia. Rio de Janeiro: Relume-Dumará.

Teixeira, A. (1936). Educação para a democracia. Livraria J. Olympio.

Tella, T. (2010). Comparação entre os sistemas políticos da Argentina, do Brasil e do Chile: raízes históricas. Revista Brasileira de Ciências Sociais, 25(72), 9-20.

Teorell, J. (2006). Political participation and three theories of democracy: A research inventory and agenda. European Journal of Political Research, 45(5), 787-810.

Terra Notícias (2013, June 18). Globo e Veja viram alvo de manifestantes em novo ato $\begin{array}{lllll}\text { em } & \text { SP. } & \text { Terra } & \text { Notícias. } & \text { Retrieved from }\end{array}$ http://noticias.terra.com.br/brasil/cidades/globo-e-veja-viram-alvo-demanifestantes-em-novo-ato-em-sp,2ec2fe174395f310VgnVCM3000009 acceb0aRCRD.html

The Economist (2013a, January 31). Nothern Lights. The Economist. Retrieved from : http://www.economist.com/news/special-report/21570840-nordic-countries-arereinventing-their-model-capitalism-saysadrian?zid=309\&ah=80dcf288b8561b012f603b9fd9577f0e

The Economist (2013b, March 14). A big crush on Sweden. The Economist. Retrieved from http://www.economist.com/news/britain/21573536-british-politicians-wantlearn-sweden-they-are-missing-its-biggest-lessonbig?zid $=309 \& a h=80 d c f 288 b 8561$ b012f603b9fd9577f0e 
The Economist (2013c, June 29). The march of protest. The Economist. Retrieved from http://www.economist.com/news/leaders/21580143-wave-anger-sweeping-citiesworld-politicians-beware-marchprotest?zid=309\&ah=80dcf288b8561b012f603b9fd9577f0e

The Economist (2013d, August 17). Reinfeldt Redux. The Economist. Retrieved from http://www.economist.com/news/europe/21583659-despite-swedens-successesfredrik-reinfeldt-could-lose-next-election-reinfeldtredux?zid=309\&ah=80dcf288b8561b012f603b9fd9577f0e

The Huffington Post (2013, May 28) Sweden Riots: Stockholm 'Back To Normal,' Say Police. The Huffington Post. Retrieved from http://www.huffingtonpost.com/ 2013/05/28/sweden-riots-stockholm-back-to-normal_n_3344543.html

The Local (2013a, May 14). Stockholm man shot dead by police. The Local (Swedish Edition). Retrieved fromhttp://www.thelocal.se/20130514/47872

The Local (2013b, May 28). Stockholm cop probed over pre-riot killing. The Local (Swedish Edition). Retrieved from: http://www.thelocal.se/20130528/48196

The Local (2013c, December 16). Video - Swedish Nazis attack families at demo. The Local (Swedish Edition). Retrieved from http://www.thelocal.se/20131216/ threehurt-in-stockholm-anti-nazi-demo

The Local (2013d, December 17). Why Swedes are rallying in their thousands against neo-Nazis. The Local (Swedish Edition). Retrieved from http://www.thelocal.se/20131217/new-anti-nazi-demo-planned-for-weekendracism-karrtorp-sweden-nazism 
The Local (2013e, 22 de dezembro). Anti-racism rally attracts thousands in Stockholm.

The Local (Swedish Edition). Disponível em: http://www.thelocal.se/20131222/ thousands-gather-to-rally-against-racism

The Local (2014, August 29). How immigration became a key election issue. The Local (Swedish Edition). Retrieved from: http://www.thelocal.se/20140829/ $\underline{\text { reinfeldtrefugee-focus-puts-immigration }}$

Theiss-Morse, E., \& Hibbing, J. R. (2005). Citizenship and civic engagement. Annual Review of Political Science, 8, 227-249.

Thomas, D. C. (2008). Cross-Cultural Management: Essential Concepts (2nd. ed.). Thousand Oaks: Sage.

Thompson, B. (2005). Exploratory and Confirmatory Factor Analysis: Understanding concepts and applications. Washington, DC: American Psychological Association.

Tilton, T. A. (1974). The social origins of liberal democracy: The Swedish case. The American Political Science Review, 68(2), 561-571.

Torres, C. V., \& Neves, L. M. G. D. S. (2013). Research topics in Social Psychology in Brazil. Estudos de Psicologia (Natal), 18(1), 05-12.

Tremblay, P. F. (2001). Research in second language learning motivation: psychometric and research design considerations. In Z. Dörnyei \& R. Schmidt (Eds.), Motivation and second language acquisition (Technical Report \#23, pp. 239-255). Honolulu: University of Hawaii, Second Language Teaching and Curriculum Center. 
Triandis, H. C., \& Gelfand, M. J. (1998). Converging measurement of horizontal and vertical individualism and collectivism. Journal of Personality and Social Psychology, 74(1), 118-128.

Tribunal Superior Eleitoral (2013). Eleições no Brasil: uma história de 500 anos. Brasília: Tribunal Superior Eleitoral.

Trotter, W. (1921). Instincts of the Herd in Peace and War. London: Adelphi Terrace. Retrieved from https://archive.org/details/instinctsofherdi00trot.

Turner, J. C., Brown, R. J., \& Tajfel, H. (1979). Social comparison and group interest in ingroup favouritism. European Journal of Social Psychology, 9(2), 187-204.

Tylor, E. B. (1920). Primitive culture: researches into the development of mythology, philosophy, religion, art, and custom (6th ed., edição original publicada em 1871). London: John Murray. Retrieved from https://openlibrary.org/books/ OL6946625M/Primitive_culture.

Uchoa, P. (2013, June 26). O que o movimento 'Occupy' tem a ver com os protestos no Brasil? BBC Brasil. Retrieved from: http://www.bbc.co.uk/portuguese/ noticias/2013/06/130625_impacto_occupy_gm

United Nations Development Program (2013). Human Development Report 2013 - the rise of the south: human progress in a diverse world. New York: United Nations Development Program. Retrieved from http://hdr.undp.org/en/content/humandevelopment-report-2013

UOL (2014, October 26). Aécio Neves deve liderar oposição a Dilma no Congresso. UOL. Retrieved from: http://eleicoes.uol.com.br/2014/noticias/2014/10/26/aecioneves-deve-liderar-oposicao-a-dilma-no-congresso.htm 
UOL Notícias (2013, June 20). Em dia de maior mobilização, protestos levam mais de 1 milhão de pessoas às ruas no Brasil. UOL Notícias. Retrieved from http://noticias.uol.com.br/cotidiano/ultimas-noticias/2013/06/20/em-dia-de-maiormobilizacao-protestos-levam-centenas-de-milhares-as-ruas-no-brasil.htm

Van der Hulst, M. (2000). The parliamentary mandate: a global comparative study. Genebra: Inter-Parliamentary Union. Retrieved from http://www.ipu.org/PDF/ publications/mandate_e.pdf

Van Der Meer, T. (2010). In what we trust? A multi-level study into trust in parliament as an evaluation of state characteristics. International review of administrative sciences, 76(3), 517-536.

Van Deth, J. W. (1986). A note on measuring political participation in comparative research. Quality and Quantity, 20(2-3), 261-272.

Van Deth, J. W. (2001, April). Studying political participation: towards a theory of everything? In Joint Sessions of Workshops. Grenoble, France: European Consortium for Political Research. Retrieved from: http://www.researchgate.net/publication/258239977_Studying_Political_Participa tion_Towards_a_Theory_of_Everything/file/3deec5278acbb80331.pdf

Van Stekelenburg, J., \& Klandermans, B. (2013). The social psychology of protest. Current Sociology, 61(5-6), 886-905.

Vasconcelos, E. A. (2012, June 1). O transporte urbano no Brasil. Le Monde Diplomatique. Retrieved from: http://www.diplomatique.org.br/artigo.php?id=1181

Vasilopoulos, N. L., Cucina, J. M., \& Hunter, A. E. (2007). Personality and training proficiency Issues of bandwidth-fidelity and curvilinearity. Journal of Occupational and Organizational Psychology, 80(1), 109-131. 
Verba, S., \& Nie, N. H. (1972): Participation in America: Political Democracy and Social Equality. New York: Harper \& Row.

Verba, S. Nie, N. H. \& Kim, J. O. (1978). Participation and Political Equality: A SevenNation Comparison. Cambridge: Cambridge University Press.

Verba, S., Schlozman, K. L., \& Brady, H. E. (1995). Voice and equality: Civic voluntarism in American politics. Harvard: Harvard University Press.

Vion-Dury, P. (2013, June 14). Corruption, mauvaise gestion: São Paulo s'enflamme. Le nouvel Observateur. Retrieved from http://rue89.nouvelobs.com/ 2013/06/14/face-a-corruption-mauvaise-gestion-les-rues-sao-paulosenflamment-243313

Viswanathan, M. (2005). Measurement error and research design. London: Sage.

Wachelke, J. F. R., \& Hammes, I. C. (2009). Representações sociais sobre política segundo posicionamento político na campanha eleitoral de 2006. Psicologia em Estudo, 14(3), 519-528.

Wallin, C. (2014). Um país sem excelências e mordomias. São Paulo: Geração.

White, L. A. (1959). The Concept of Culture. American Anthropologist, 61(2), 227-251.

Wikstrom, C. (2014, August 19). Sweden feminists roar into political arena. Al Jazeera. Retrieved from: http://www.aljazeera.com/indepth/features/2014/08/swedenfeminists-roar-into-political-arena-2014816132534429519.html

Wolf, E. J., Harrington, K. M., Clark, S. L., \& Miller, M. W. (2013). Sample size requirements for structural equation models an evaluation of power, bias, and solution propriety. Educational and Psychological Measurement, 73(6), 913-934.

Wright, S. (1998). The politicization of 'culture'. Anthropology today, 14(1), 7-15. 
Wyatt, R. O., Katz, E., \& Kim, J. (2000). Bridging the spheres: Political and personal conversation in public and private spaces. Journal of communication, 50(1), 7192.

Yeh, R. S., \& Lawrence, J. J. (1995). Individualism and Confucian dynamism: a note on Hofstede's cultural root to economic growth. Journal of international business studies, 26(3) 655-669.

Zimmermann, E. A. (1992). Racial ideas and social reform: Argentina, 1890-1916. Hispanic American Historical Review, 72(1), 23-46.

Zimmerman, M. A., \& Zahniser, J. H. (1991). Refinements of sphere-specific measures of perceived control: Development of a sociopolitical control scale. Journal of Community Psychology, 19(2), 189-204. 
Appendices 


\section{Appendix I}

Short description of Delphic Panel's participants' experience.

Table I.1. Experts who participated at the Delphic Panel

\begin{tabular}{|c|c|c|c|c|}
\hline Sweden & 1 & Anders Linnhag & Riksdagen & $\begin{array}{l}\text { Anders Linnhag is an economist with an M.A. from } \\
\text { University of California at Santa Barbara. He has held } \\
\text { various government positions and is currently working } \\
\text { at the Research Service at the Swedish Parliament } \\
\text { (Riksdagens Utredningstjänst - RUT). He has a deep } \\
\text { interest in the Brazilian society, especially the } \\
\text { economy. }\end{array}$ \\
\hline Sweden & 2 & Henric Barkman & Karlstad Municipality & $\begin{array}{l}\text { Henric Barkman is a PhD Candidate on Political } \\
\text { Science at Stockholm University. His research } \\
\text { concerns encompasse methodology on social } \\
\text { sciences, sustainable consumption, emerging forms of } \\
\text { participation, such as lifestyle politics and culture } \\
\text { jamming. }\end{array}$ \\
\hline
\end{tabular}


Table I.1. Experts who participated at the Delphic Panel

\begin{tabular}{|c|c|c|c|c|}
\hline Country & $\#$ & Name & Instituition & Short Résumé \\
\hline Sweden & 3 & Karin Hansson & Stockholm University & $\begin{array}{l}\text { Karin Hansson has developed several studies on } \\
\text { public decision making and electronic participation } \\
\text { participation) on political issues. She is currently a } \\
\text { PhD student at Stockholm University. }\end{array}$ \\
\hline Sweden & 4 & Magnus Boström & Örebro University & $\begin{array}{l}\text { Magnus Boström is Sociology Professor at Örebro } \\
\text { University. His research concerns politics in relation } \\
\text { transnational environmental and sustainability issue } \\
\text { Boström is also studying how various factors shape } \\
\text { green consumerism and organized activism. }\end{array}$ \\
\hline Sweden & 5 & Michele Micheletti & Stockholm University & $\begin{array}{l}\text { Michele Micheleti is Political Science Professor at } \\
\text { Stockholm University and currently the President of } \\
\text { the Swedish Political Science Association. Her } \\
\text { research regards collective action, multicultural } \\
\text { democracy, political consumerism sustainable } \\
\text { citizenship and other issues. }\end{array}$ \\
\hline
\end{tabular}


Table I.1. Experts who participated at the Delphic Panel

\begin{tabular}{|c|c|c|c|c|}
\hline Country & $\#$ & Name & Instituition & Short Résumé \\
\hline Sweden & 6 & Nils Gustafsson & Lund University & $\begin{array}{l}\text { Nils Gustafsson is PhD in Political Science. His } \\
\text { dissertation, "Leetocracy. Social network sites, } \\
\text { political participation and inequality", dealt with how } \\
\text { the use of social media (social network sites, blogs, } \\
\text { microblogging services, etc.) changed political } \\
\text { participation in Sweden. }\end{array}$ \\
\hline Sweden & 7 & Sofia Josefine Palm & Stockholm Municipality & $\begin{array}{l}\text { Sofia Palm is bachelor in Political Science and } \\
\text { Sociology. She developed a study on the } 2013 \text { riots in } \\
\text { Stockholm, at Uppsala University. }\end{array}$ \\
\hline Sweden & 8 & Sven Oskarsson & Uppsala University & $\begin{array}{l}\text { Sven Oskarsson is PhD in Political Science. His } \\
\text { research interests concerns political behavior in } \\
\text { Sweden, political tolerance in India, Pakistan and } \\
\text { Uganda and the relationship between education and } \\
\text { political participation, tracing the results of school } \\
\text { reforms. }\end{array}$ \\
\hline
\end{tabular}


Table I.1. Experts who participated at the Delphic Panel

\begin{tabular}{|c|c|c|c|c|}
\hline Country & \# & Name & Instituition & Short Résumé \\
\hline Sweden & 9 & Viktor Dahl & Örebro University & $\begin{array}{l}\text { Viktor Dahl is PhD in Political Science from Örebro } \\
\text { University. His research interest concerns the political } \\
\text { socialization and unconventional political behavior. His } \\
\text { dissertation was about young people's positive } \\
\text { attitudes toward and involvement in illegal political } \\
\text { activity. }\end{array}$ \\
\hline Brazil & 1 & Ana Lúcia Henrique & $\begin{array}{c}\text { Brazilian Chamber of } \\
\text { Deputies }\end{array}$ & $\begin{array}{l}\text { Ana Lúcia Henrique is a PhD student at the Federal } \\
\text { University of Goiás (UFG) and a Brazilian visiting } \\
\text { scholar at the University of Pittsburgh (USA). She has } \\
\text { an MA in Political Science and Sociology (IUPERJ, } \\
\text { 2009), BA degrees in Journalism (UFRJ, 1985) and } \\
\text { Public Relations (IESB, 2007), as well as an MBA in } \\
\text { Marketing Management (CEAG-FGV-SP, 1992). }\end{array}$ \\
\hline
\end{tabular}


Table I.1. Experts who participated at the Delphic Panel

\begin{tabular}{|c|c|c|c|c|}
\hline Country & \# & Name & Instituition & Short Résumé \\
\hline Brazil & 3 & Cristiano Ferri Soares de Faria & $\begin{array}{c}\text { Brazilian Chamber of } \\
\text { Deputies }\end{array}$ & $\begin{array}{l}\text { Cristiano Faria is PhD in Sociology and Political } \\
\text { Science from Rio de Janeiro State University (UERJ } \\
\text { and Associate Researcher to Ash Center for } \\
\text { Democratic Governance and Innovation, at Harvard } \\
\text { University. He is the mastermind and manager behir } \\
\text { e-Democracia, the Brazilian Chamber of Deputies' } \\
\text { social media for political participation. }\end{array}$ \\
\hline Brazil & 4 & Igor Ribas Brandão & University of Brasília & $\begin{array}{l}\text { Igor Brandão is a PhD Student on Political Science } \\
\text { University of Brasília and a visiting researcher at } \\
\text { California Univesity. His research regards } \\
\text { accountability, institutional development and public } \\
\text { policies. }\end{array}$ \\
\hline Brazil & 5 & João Luiz Pereira Marciano & $\begin{array}{c}\text { Brazilian Chamber of } \\
\text { Deputies }\end{array}$ & $\begin{array}{l}\text { João Luiz Marciano is PhD in Information Sciences } \\
\text { from University of Brasília. He is a professor at the } \\
\text { Brazilian Chamber of Deputies' Legislative Master } \\
\text { Program. He coordinates research programs on } \\
\text { education, traditional media and politics. }\end{array}$ \\
\hline
\end{tabular}


Table I.1. Experts who participated at the Delphic Panel

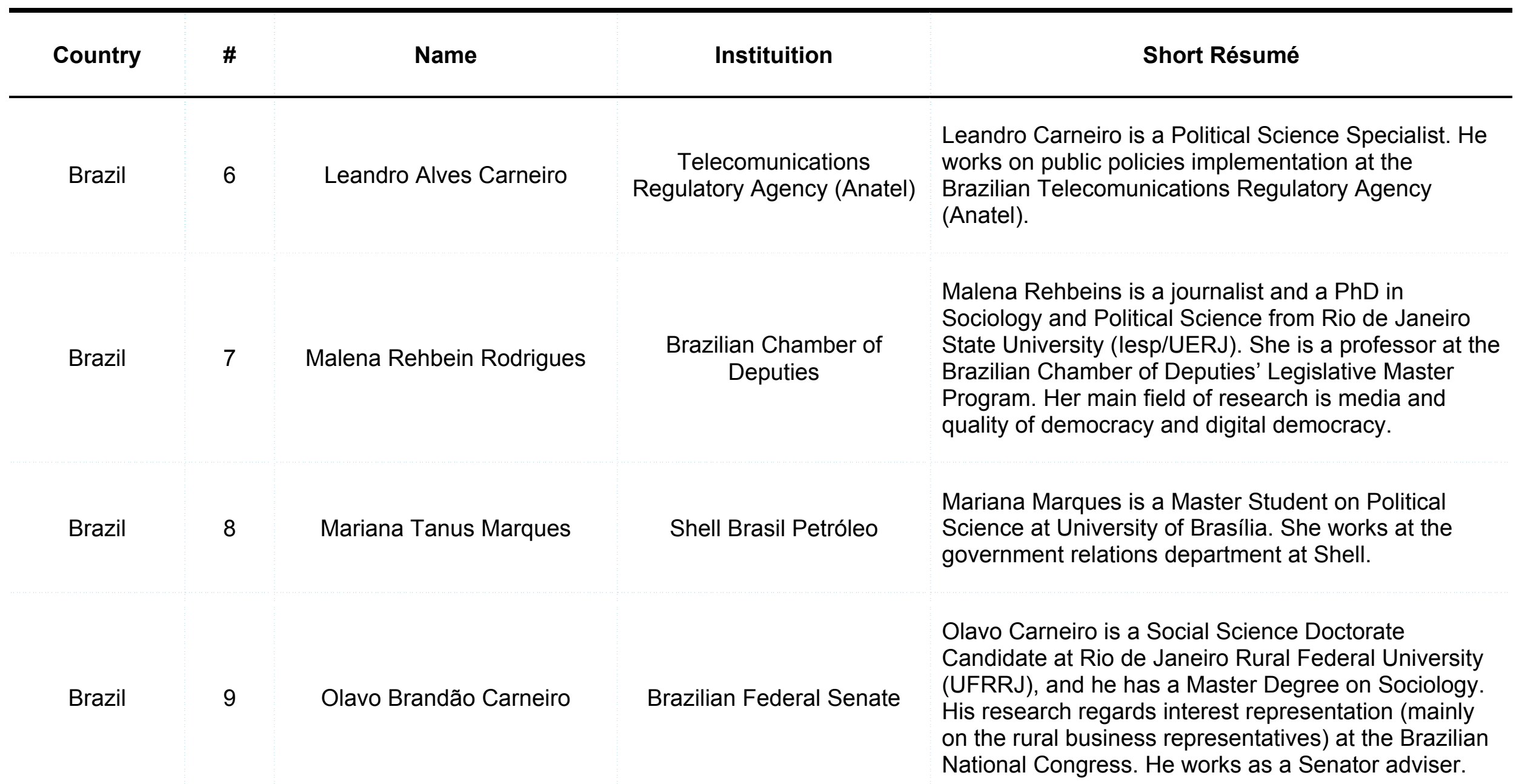


Table I.1. Experts who participated at the Delphic Panel

\begin{tabular}{|c|c|c|c|c|}
\hline Brazil & 10 & Pedro Lucas de Moura Palotti & $\begin{array}{l}\text { National School for Public } \\
\text { Administration (ENAP) }\end{array}$ & $\begin{array}{l}\text { Pedro Palotti is a Political Science PhD student at } \\
\text { University of Brasilia. He works as a Public Policies } \\
\text { Specialist at the National School for Public } \\
\text { Administration. }\end{array}$ \\
\hline Brazil & 12 & Thiago Moreira da Silva & University of Brasília & $\begin{array}{l}\text { Thiago Silva is a Political Science PhD student at } \\
\text { University of Brasilia. His research regards political } \\
\text { behavior, voting and representation. }\end{array}$ \\
\hline
\end{tabular}




\section{Appendix II}

Delphic Panel final questionnaire version, in English, Portuguese and Swedish

This is the questionnaire version achieved at the end of Delphic Panel. This was the raw material for back-translation. Original (English) and Translated (Portuguese / Swedish) versions are presented. Variable codes for SPSS and AMOS were inserted after data collection, so the reader can keep track of variables' origins. 


\section{Home screen - Informed Consent}

Thanks for your participation in this survey! It is a transnational study of people's views on politics in their countries. The study is part of the PhD project of Thiago Carneiro, a student of Social Psychology at the University of Brasilia, Brazil, in partnership with Södertörn University.

By participating in this survey, you agree that your responses are used for statistical analysis, together with the other participants' ones. As a result of this study, we calculate averages, percentages and other indicators on the general opinion of the participants.

You will not tell us your name and we will not use your answers to try to guess who you are. Your privacy will be preserved. Just want to know the general opinion of citizens on your country's politics.

All resulting reports will be made available in scientific publications and are intended to describe the expectations of society in relation to political institutions.

At any time, you can refuse to participate. If you do not reach the end of the questionnaire, we will consider that you no longer want to participate and therefore none of your answers will be used.

If you have questions about this research, please contact the responsible researcher at e-mail: <mail address> .

If you are interested in receiving the results of the study, let us know by writing to the email address above.

By participating in this research, you will be contributing to the advancement of science in understanding the politics of his country. Please do not leave any item unanswered!

In order to have access to the research questions, please check the box below:

\section{[ ] I have read and agree to the above terms}




\section{What is your opinion about the members of the [Swedish Parliament/Brazilian National Congress]?}

\begin{tabular}{|c|c|c|c|c|c|c|c|c|c|c|c|c|c|c|}
\hline \multicolumn{15}{|c|}{ Stereotypes: Behavior prediction } \\
\hline \multirow{2}{*}{$\begin{array}{l}\# \\
1 \\
1\end{array}$} & \multirow{2}{*}{$\begin{array}{l}\text { Variable code } \\
\text { in SPSS and } \\
\text { AMOS } \\
\text { ST.beh. } 01\end{array}$} & \multirow{2}{*}{$\begin{array}{l}\text { In your opinion, what do the } \\
\text { parliamentarians really do? } \\
\text { Tell us how big a share of them do } \\
\text { the following: } \\
\text { They represent my interests as a citizen }\end{array}$} & \multicolumn{4}{|c|}{$\begin{array}{l}\text { None of them } \\
\nabla\end{array}$} & \multicolumn{3}{|c|}{ Some of them } & \multicolumn{4}{|c|}{ All of them } & \multirow{2}{*}{$\begin{array}{r}\begin{array}{r}\text { I don' } \\
\text { know }\end{array} \\
\text { IDK }\end{array}$} \\
\hline & & & $0 \%$ & $10 \%$ & $20 \%$ & $30 \%$ & $40 \%$ & $50 \%$ & $60 \%$ & $70 \%$ & $80 \%$ & $90 \%$ & $100 \%$ & \\
\hline 2 & ST.beh.02 & $\begin{array}{l}\text { They favor companies over the } \\
\text { interests of citizens }\end{array}$ & $0 \%$ & $10 \%$ & $20 \%$ & $30 \%$ & $40 \%$ & $50 \%$ & $60 \%$ & $70 \%$ & $80 \%$ & $90 \%$ & $100 \%$ & IDK \\
\hline 3 & ST.beh.03 & $\begin{array}{l}\text { They help their own friends and family } \\
\text { to achieve important positions (they } \\
\text { practice nepotism) }\end{array}$ & $0 \%$ & $10 \%$ & $20 \%$ & $30 \%$ & $40 \%$ & $50 \%$ & $60 \%$ & $70 \%$ & $80 \%$ & $90 \%$ & $100 \%$ & IDK \\
\hline 4 & ST.beh.04 & $\begin{array}{l}\text { They contribute for the sustainable } \\
\text { development }\end{array}$ & $0 \%$ & $10 \%$ & $20 \%$ & $30 \%$ & $40 \%$ & $50 \%$ & $60 \%$ & $70 \%$ & $80 \%$ & $90 \%$ & $100 \%$ & IDK \\
\hline 5 & ST.beh.05 & $\begin{array}{l}\text { They make good use of budget to } \\
\text { improve services (schools, hospitals, } \\
\text { police) for the people }\end{array}$ & $0 \%$ & $10 \%$ & $20 \%$ & $30 \%$ & $40 \%$ & $50 \%$ & $60 \%$ & $70 \%$ & $80 \%$ & $90 \%$ & $100 \%$ & IDK \\
\hline 6 & ST.beh.06 & $\begin{array}{l}\text { They accomplish the promises they } \\
\text { make while in electoral campaign }\end{array}$ & $0 \%$ & $10 \%$ & $20 \%$ & $30 \%$ & $40 \%$ & $50 \%$ & $60 \%$ & $70 \%$ & $80 \%$ & $90 \%$ & $100 \%$ & IDK \\
\hline 7 & ST.beh.07 & $\begin{array}{l}\text { They behave coherently to their parties' } \\
\text { declared ideology }\end{array}$ & $0 \%$ & $10 \%$ & $20 \%$ & $30 \%$ & $40 \%$ & $50 \%$ & $60 \%$ & $70 \%$ & $80 \%$ & $90 \%$ & $100 \%$ & IDK \\
\hline 8 & ST.beh.08 & $\begin{array}{l}\text { They create laws beneficial to the } \\
\text { country (They adopt laws beneficial to } \\
\text { the country) }\end{array}$ & $0 \%$ & $10 \%$ & $20 \%$ & $30 \%$ & $40 \%$ & $50 \%$ & $60 \%$ & $70 \%$ & $80 \%$ & $90 \%$ & $100 \%$ & IDK \\
\hline 9 & ST.beh.09 & $\begin{array}{l}\text { They do a good job on representing [my } \\
\text { country]'s position on international } \\
\text { matters. }\end{array}$ & $0 \%$ & $10 \%$ & $20 \%$ & $30 \%$ & $40 \%$ & $50 \%$ & $60 \%$ & $70 \%$ & $80 \%$ & $90 \%$ & $100 \%$ & IDK \\
\hline 10 & ST.beh.10 & $\begin{array}{l}\text { They use public money for their private } \\
\text { interests }\end{array}$ & $0 \%$ & $10 \%$ & $20 \%$ & $30 \%$ & $40 \%$ & $50 \%$ & $60 \%$ & $70 \%$ & $80 \%$ & $90 \%$ & $100 \%$ & IDK \\
\hline
\end{tabular}




\section{Stereotypes: Behavior prediction}

\begin{tabular}{|c|c|c|c|c|c|c|c|c|c|c|c|c|c|c|}
\hline \multirow{2}{*}{$\begin{array}{l}\# \\
11\end{array}$} & \multirow{2}{*}{$\begin{array}{l}\text { Variable code } \\
\text { in SPSS and } \\
\text { AMOS } \\
\text { ST.beh.11 }\end{array}$} & \multirow{2}{*}{$\begin{array}{l}\text { In your opinion, what do the } \\
\text { parliamentarians really do? } \\
\text { Tell us how big a share of them do } \\
\text { the following: } \\
\text { They work for a fairer income } \\
\text { distribuition among [Brazilians/Swedes] }\end{array}$} & \multicolumn{4}{|c|}{$\begin{array}{l}\text { None of them } \\
\nabla\end{array}$} & \multicolumn{3}{|c|}{ Some of them } & \multicolumn{4}{|c|}{ All of them } & \multirow{2}{*}{$\begin{array}{c}\begin{array}{c}\text { I don't } \\
\text { know }\end{array} \\
\text { IDK }\end{array}$} \\
\hline & & & $0 \%$ & $10 \%$ & $20 \%$ & $30 \%$ & $40 \%$ & $50 \%$ & $60 \%$ & $70 \%$ & $80 \%$ & $90 \%$ & $100 \%$ & \\
\hline 12 & ST.beh.12 & $\begin{array}{l}\text { They represent their constituents' } \\
\text { interests }\end{array}$ & $0 \%$ & $10 \%$ & $20 \%$ & $30 \%$ & $40 \%$ & $50 \%$ & $60 \%$ & $70 \%$ & $80 \%$ & $90 \%$ & $100 \%$ & IDK \\
\hline & Open01. Is ther & re anything else you want to add to this & list? & What d & lo you & think tl & hat pa & rliameı & ntarian & ns usu & ally do & ? [Free & text an & swer] \\
\hline
\end{tabular}

$$
==/ /==
$$




\section{Political Participation - Non participation atitudes}

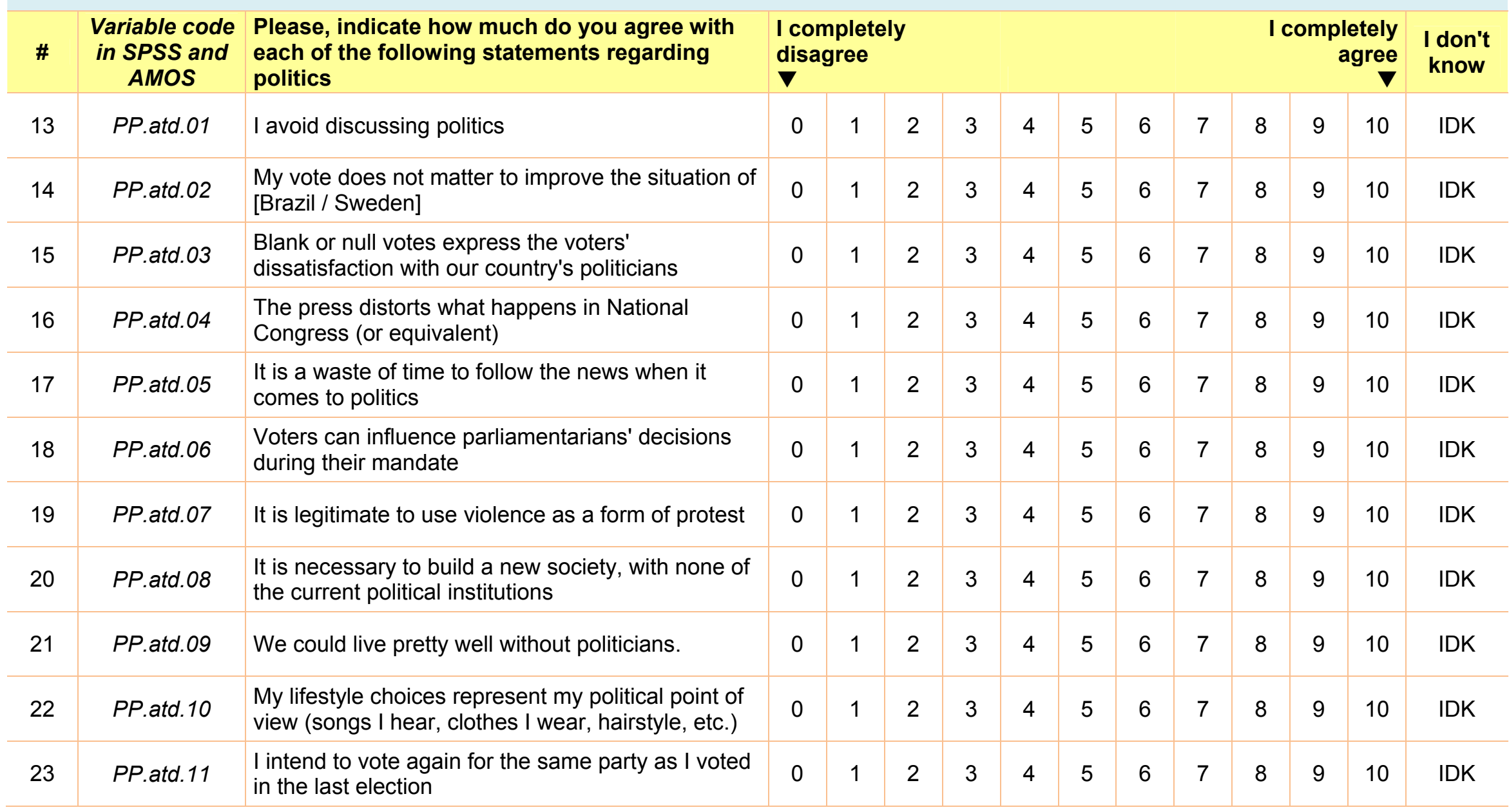




\section{Political Participation - Non participation atitudes}

\begin{tabular}{|c|c|c|c|c|c|c|c|c|c|c|c|c|c|c|}
\hline \multirow{2}{*}{$\begin{array}{l}\# \\
24\end{array}$} & \multirow{2}{*}{$\begin{array}{l}\text { Variable code } \\
\text { in SPSS and } \\
\text { AMOS } \\
\text { PP.atd.12 }\end{array}$} & \multirow{2}{*}{$\begin{array}{l}\text { Please, indicate how much do you agree with } \\
\text { each of the following statements regarding } \\
\text { politics } \\
\text { NGOs and companies always have better } \\
\text { performance than the government to serve to } \\
\text { citizens' interests }\end{array}$} & \multicolumn{8}{|c|}{$\begin{array}{l}\text { I completely } \\
\text { disagree } \\
\nabla\end{array}$} & \multicolumn{3}{|c|}{$\begin{array}{r}\text { I completely } \\
\text { agree } \\
\nabla\end{array}$} & \multirow{2}{*}{$\begin{array}{c}\begin{array}{c}\text { I don' } \\
\text { know }\end{array} \\
\text { IDK }\end{array}$} \\
\hline & & & 0 & 1 & 2 & 3 & 4 & 5 & 6 & 7 & 8 & 9 & 10 & \\
\hline & Open02. What a & are your impressions on national politics? [Free & ext ar & 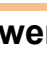 & & & & & & & & & & \\
\hline
\end{tabular}

$$
==/ /==
$$




\section{Political Participation - Past behavior}

\begin{tabular}{|c|c|c|c|c|c|c|c|c|c|}
\hline \multirow{2}{*}{$\begin{array}{l}\# \\
25\end{array}$} & \multirow{2}{*}{$\begin{array}{l}\text { Variable code } \\
\text { in SPSS and } \\
\text { AMOS } \\
\text { PP.beh.01 }\end{array}$} & \multirow{2}{*}{$\begin{array}{l}\text { How often have you done each of the following since } 2010 \text { (last } \\
\text { election campaign for the national parliament)? } \\
\text { I have contacted parliamentarians directly (by meeting, telephone or } \\
\text { through the Internet) }\end{array}$} & \multicolumn{6}{|c|}{ How many times? } & \multirow{2}{*}{$\begin{array}{l}\text { I don't } \\
\text { know } \\
\text { IDK }\end{array}$} \\
\hline & & & 0 & 1 & 2 & 3 & 4 & 5 or more & \\
\hline 26 & PP.beh.02 & $\begin{array}{l}\text { I have used social networks on Internet (Facebook, Twitter, Youtube, } \\
\text { others) to engage into political action }\end{array}$ & 0 & 1 & 2 & 3 & 4 & 5 or more & IDK \\
\hline 27 & PP.beh.03 & I looked up for information about the performance of parliamentarians & 0 & 1 & 2 & 3 & 4 & 5 or more & IDK \\
\hline 28 & PP.beh.04 & $\begin{array}{l}\text { I contacted the written press, radio or TV station to communicate } \\
\text { something politically important }\end{array}$ & 0 & 1 & 2 & 3 & 4 & 5 or more & IDK \\
\hline 29 & PP.beh.05 & $\begin{array}{l}\text { I have participated in institutional meetings (forums, seminars, public } \\
\text { hearings) about political issues. }\end{array}$ & 0 & 1 & 2 & 3 & 4 & 5 or more & IDK \\
\hline 30 & PP.beh.06 & I signed petitions on public issues & 0 & 1 & 2 & 3 & 4 & 5 or more & IDK \\
\hline 31 & PP.beh.07 & I took part in discussions about political issues & 0 & 1 & 2 & 3 & 4 & 5 or more & IDK \\
\hline 32 & PP.beh.08 & I took part in strikes organized by labor unions & 0 & 1 & 2 & 3 & 4 & 5 or more & IDK \\
\hline 33 & PP.beh.09 & I have participated in street demonstrations & 0 & 1 & 2 & 3 & 4 & 5 or more & IDK \\
\hline 34 & PP.beh.10 & I have participated in events organized by political parties & 0 & 1 & 2 & 3 & 4 & 5 or more & IDK \\
\hline 35 & PP.beh.11 & $\begin{array}{l}\text { I have helped an association not linked to parties or government (labor } \\
\text { union, social minority organization, church, NGO etc.) }\end{array}$ & 0 & 1 & 2 & 3 & 4 & 5 or more & IDK \\
\hline
\end{tabular}




\section{Political Participation - Past behavior}

\begin{tabular}{|c|c|c|c|c|c|c|c|c|c|}
\hline \multirow{2}{*}{$\begin{array}{l}\# \\
36\end{array}$} & \multirow{2}{*}{$\begin{array}{l}\text { Variable code } \\
\text { in SPSS and } \\
\text { AMOS } \\
\text { PP.beh.12 }\end{array}$} & \multirow{2}{*}{$\begin{array}{l}\text { How often have you done each of the following since } 2010 \text { (last } \\
\text { election campaign for the national parliament)? } \\
\text { I have chosen or refused products for political, ethical or environmental } \\
\text { protection reasons }\end{array}$} & \multicolumn{6}{|c|}{ How many times? } & \multirow{2}{*}{$\begin{array}{l}\text { I don't } \\
\text { know } \\
\text { IDK }\end{array}$} \\
\hline & & & 0 & 1 & 2 & 3 & 4 & 5 or more & \\
\hline 37 & PP.beh.13 & I have handed out political leaflets & 0 & 1 & 2 & 3 & 4 & 5 or more & IDK \\
\hline 38 & PP.beh.14 & $\begin{array}{l}\text { I have worked as a volunteer (for my kids' school / church / } \\
\text { neighbourhood / other) }\end{array}$ & 0 & 1 & 2 & 3 & 4 & 5 or more & IDK \\
\hline & Open03. Are yo & ou engaged in any other kind of political action? [Free text answer] & & & & & & & \\
\hline
\end{tabular}

$$
==/ /==
$$




\section{Party engagement}

\begin{tabular}{c|c|c|l}
\hline$\#$ & $\begin{array}{c}\text { Variable code in } \\
\text { SPSS and AMOS }\end{array}$ & Question & Answer \\
\hline 39 & PartyMember & Are you a member of a political party? & Yes / No \\
\hline 40 & PartySympa & $\begin{array}{l}\text { If not, do you sympathize with any political } \\
\text { party ? }\end{array}$ & Yes / No \\
\hline 41 & SweParty / BraParty & If yes (to any of the two above), which party ? & (Free text answer - optional answer) \\
\hline 42 & PartyReject & Do you reject any political party? & No / Yes, one party / Yes, some parties / Yes, all parties \\
\hline 43 & Worked4Party & $\begin{array}{l}\text { In the last election, have you worked for the } \\
\text { campaign of a candidate or a party? }\end{array}$ & Yes / No \\
\hline & & &
\end{tabular}




\section{Behavioral Contagion}

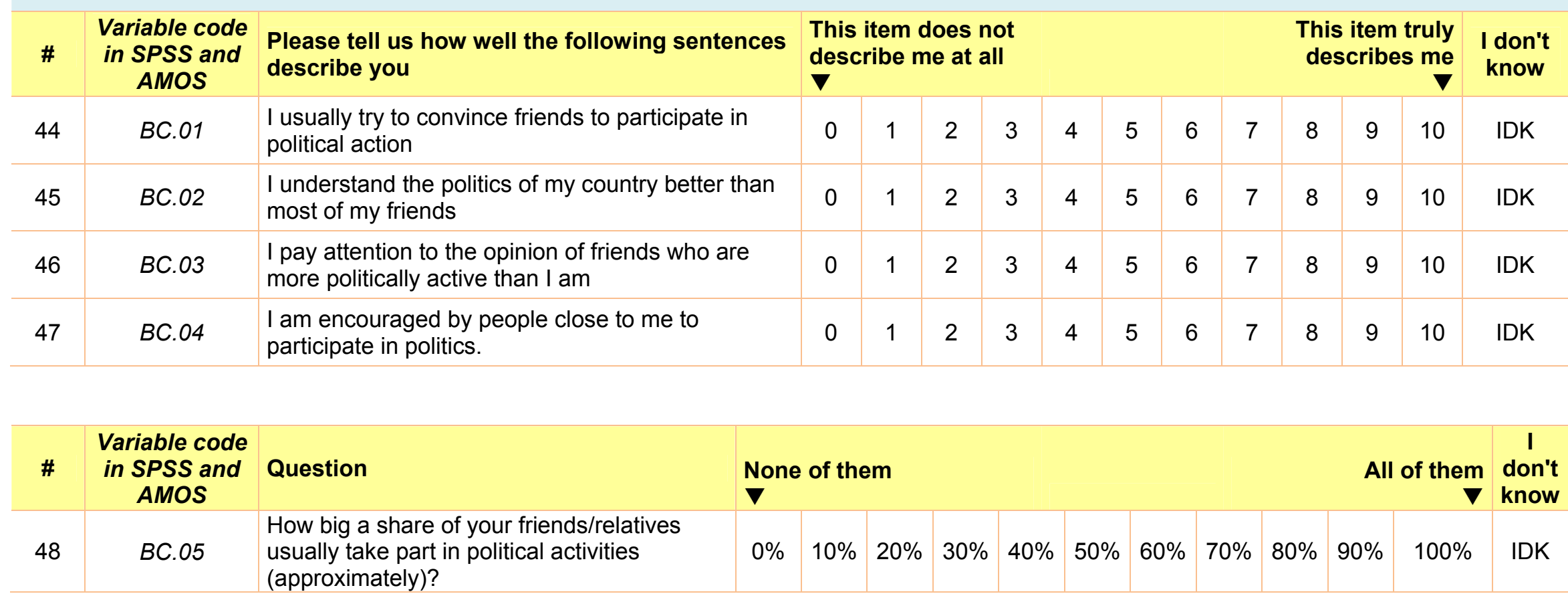

$=ニ / /=ニ$ 


\section{Political Education / Political Socialization}

\begin{tabular}{|c|c|c|c|c|c|c|c|c|c|c|c|c|c|c|}
\hline \multirow{2}{*}{$\begin{array}{l}\# \\
49\end{array}$} & \multirow{2}{*}{$\begin{array}{l}\text { Variable code } \\
\text { in SPSS and } \\
\text { AMOS } \\
\text { PE.01 }\end{array}$} & \multirow{2}{*}{$\begin{array}{l}\text { We learn about politics in many ways on our } \\
\text { life, with different people in different places. } \\
\text { So, tell us how much have you learned about } \\
\text { politics ... } \\
\text {... at school (primary school - 1st grade, or high } \\
\text { school - 2nd grade) }\end{array}$} & \multicolumn{8}{|c|}{$\begin{array}{l}\text { I have learned } \\
\text { nothing } \\
\nabla\end{array}$} & \multicolumn{3}{|c|}{$\begin{array}{r}\text { I have } \\
\text { learned a lot }\end{array}$} & \multirow{2}{*}{$\begin{array}{c}\begin{array}{c}\text { I don't } \\
\text { know }\end{array} \\
\text { IDK }\end{array}$} \\
\hline & & & 0 & 1 & 2 & 3 & 4 & 5 & 6 & 7 & 8 & 9 & 10 & \\
\hline 50 & PE.02 & $\begin{array}{l}\text {... at the University (or other institution of Higher } \\
\text { Education - 3rd grade) }\end{array}$ & 0 & 1 & 2 & 3 & 4 & 5 & 6 & 7 & 8 & 9 & 10 & IDK \\
\hline 51 & PE.03 & ... from your family & 0 & 1 & 2 & 3 & 4 & 5 & 6 & 7 & 8 & 9 & 10 & IDK \\
\hline 52 & PE.04 & ... from coworkers & 0 & 1 & 2 & 3 & 4 & 5 & 6 & 7 & 8 & 9 & 10 & IDK \\
\hline 53 & PE.05 & $\begin{array}{l}\text {... from members of an association / trade union / } \\
\text { party in which you are a member }\end{array}$ & 0 & 1 & 2 & 3 & 4 & 5 & 6 & 7 & 8 & 9 & 10 & IDK \\
\hline 54 & PE.06 & ... from friends & 0 & 1 & 2 & 3 & 4 & 5 & 6 & 7 & 8 & 9 & 10 & IDK \\
\hline 55 & PE.07 & $\begin{array}{l}\text {... on your own (reading books, newspapers, } \\
\text { Internet, watching TV, radio, etc). }\end{array}$ & 0 & 1 & 2 & 3 & 4 & 5 & 6 & 7 & 8 & 9 & 10 & IDK \\
\hline & \multicolumn{14}{|c|}{ Open04. Where else or from whom have you learned about politics? [Free text answer] } \\
\hline
\end{tabular}




\section{Stereotypes - Critical information about parliamentarians}

\begin{tabular}{|c|c|c|c|c|c|c|c|c|c|c|c|c|c|c|}
\hline \# & $\begin{array}{l}\text { Variable code } \\
\text { in SPSS and } \\
\text { AMOS }\end{array}$ & $\begin{array}{l}\text { How often do you care about this information } \\
\text { about parliamentarians who discuss matters of } \\
\text { your interest? }\end{array}$ & $\mathrm{Nev}$ & & & & & & & & & \multicolumn{2}{|c|}{ Always } & $\begin{array}{l}\text { I don't } \\
\text { know }\end{array}$ \\
\hline 56 & ST.inf.01 & His/her political party & 0 & 1 & 2 & 3 & 4 & 5 & 6 & 7 & 8 & 9 & 10 & IDK \\
\hline 57 & ST.inf.02 & If he/she is left-winged or right-winged & 0 & 1 & 2 & 3 & 4 & 5 & 6 & 7 & 8 & 9 & 10 & IDK \\
\hline 58 & ST.inf.03 & $\begin{array}{l}\text { If he/she represents the governing party(ies), the } \\
\text { opposition or a neutral position }\end{array}$ & 0 & 1 & 2 & 3 & 4 & 5 & 6 & 7 & 8 & 9 & 10 & IDK \\
\hline 59 & ST.inf.04 & $\begin{array}{l}\text { His/her area of expertise (ex.: environment, foreign } \\
\text { affairs, economic development, human rights etc.) }\end{array}$ & 0 & 1 & 2 & 3 & 4 & 5 & 6 & 7 & 8 & 9 & 10 & IDK \\
\hline 60 & ST.inf.05 & $\begin{array}{l}\text { The groups of interest in which he/she takes part } \\
\text { (labor unions, entrepreneurs associations, } \\
\text { environmental protection institutions, farmers } \\
\text { associations etc) }\end{array}$ & 0 & 1 & 2 & 3 & 4 & 5 & 6 & 7 & 8 & 9 & 10 & IDK \\
\hline 61 & ST.inf.06 & $\begin{array}{l}\text { If he/she represents some minority (ex.: } \\
\text { indians/native people, immigrants, gays/LGBT, } \\
\text { disabled people etc.). }\end{array}$ & 0 & 1 & 2 & 3 & 4 & 5 & 6 & 7 & 8 & 9 & 10 & IDK \\
\hline 62 & ST.inf.07 & His/her religion & 0 & 1 & 2 & 3 & 4 & 5 & 6 & 7 & 8 & 9 & 10 & IDK \\
\hline 63 & ST.inf.08 & The parliamentarian's gender (male/female) & 0 & 1 & 2 & 3 & 4 & 5 & 6 & 7 & 8 & 9 & 10 & IDK \\
\hline 64 & ST.inf.09 & If he/she has been involved in scandals & 0 & 1 & 2 & 3 & 4 & 5 & 6 & 7 & 8 & 9 & 10 & IDK \\
\hline
\end{tabular}




\section{Stereotypes - Critical information about parliamentarians}

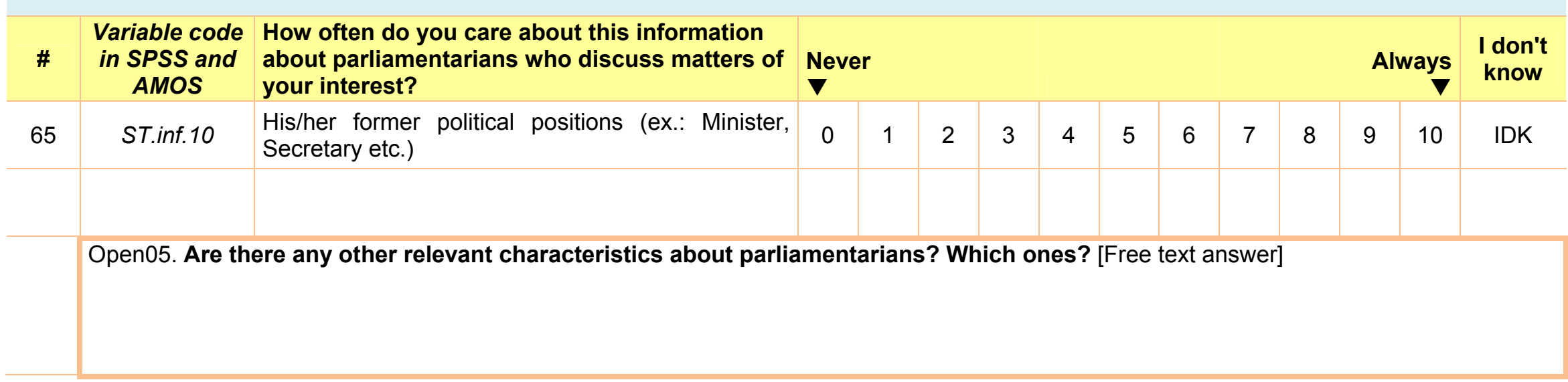

$$
==/ /==
$$




\begin{tabular}{|c|c|c|c|}
\hline \# & $\begin{array}{l}\text { Variable code in } \\
\text { SPSS and AMOS }\end{array}$ & Question & Answer \\
\hline 66 & Gender & Gender & [ ] Male / [ ] Female \\
\hline 67 & Age & Age & I am __ years old \\
\hline 68 & Education & Education: & $\begin{array}{l}\text { [ ] Incomplete elementary school } \\
\text { [ ] Complete elementary school } \\
\text { [ ] Incomplete high school } \\
\text { [ ] Complete high school } \\
\text { [ ] Incomplete university education } \\
\text { [ ] Complete university education } \\
\text { [ ] Post-graduated speciallist } \\
\text { [ ] Complete Master Degree } \\
\text { [ ] Complete PhD }\end{array}$ \\
\hline 69 & City & Where do you live? & [Please type the name of your city] \\
\hline 70 & Occupation & What is your (main) job? & [Free text answer] \\
\hline 71 & RelateToParliament & $\begin{array}{l}\text { Is your profession directly related to the } \\
\text { parliamentarian activity? }\end{array}$ & [ ]Yes/[ ] No \\
\hline
\end{tabular}


Demographic information

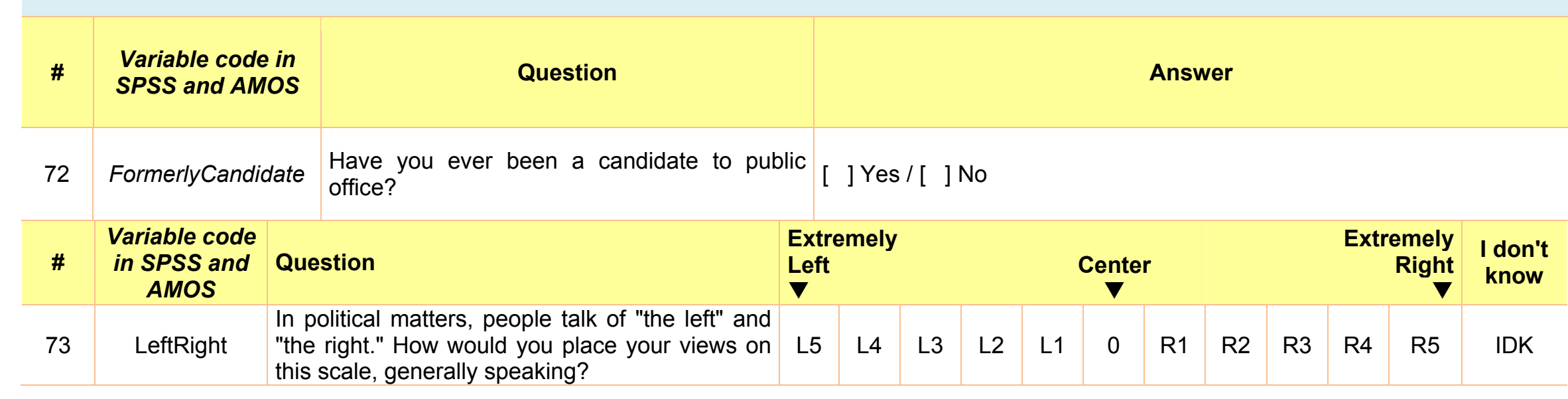

\begin{tabular}{|c|c|l|l|}
\hline \# & $\begin{array}{c}\text { Variable code in } \\
\text { SPSS and AMOS }\end{array}$ & $\begin{array}{l}\text { Please tell us, do you have any of the things } \\
\text { below? }\end{array}$ & Answer \\
\hline 74 & I own one or more... & \\
\hline & lownComputer & Computer with access to the internet & [ ] Yes / [ ] No \\
\hline lownPhone & Cell phone or a tablet with access to the internet & [ ] Yes / [ ] No \\
\hline lownTV & Modern TV set (plasma, LCD or LED) & [ ] Yes / [ ] No \\
\hline lownCar & Car & [ ] Yes / [ ] No \\
\hline lownApart & Appartment of my own & [ ] Yes / [ ] No \\
\hline
\end{tabular}




\begin{tabular}{|c|c|l|l|}
\hline \# & $\begin{array}{c}\text { Variable code in } \\
\text { SPSS and AMOS }\end{array}$ & $\begin{array}{l}\text { Please tell us, do you have any of the things } \\
\text { below? }\end{array}$ & Answer \\
\hline lownHouse & House of my own & [ ] Yes / [ ] No \\
\hline lownOffice & Business office / store / workshop & [ ] Yes / [ ] No \\
\hline lownStocks & Shares of stock exchange & [ ] ] Yes / [ ] No \\
\hline lownBoat & Boat (for leisure only) & [ ] Yes / [ ] No \\
\hline lownComp50 & Company with more than 50 employees & [ ] Yes / [ ] No \\
\hline
\end{tabular}




\section{Tela inicial - Consentimento Informado}

Agradecemos sua participação nessa pesquisa! Trata-se de um estudo transnacional da opinião das pessoas sobre a política em seus países. O estudo faz parte do projeto de doutorado de Thiago Carneiro, aluno de Psicologia Social na Universidade de Brasília, Brasil, em parceria com Södertörns Högskola, Suécia.

Ao participar dessa pesquisa, você concorda que suas respostas sejam usadas para análise estatística, junto com a dos outros participantes. Como resultado desse estudo, calcularemos os médias, percentuais e outros indicadores sobre a opinião geral dos participantes.

Você não nos dirá seu nome e não usaremos suas respostas para tentar adivinhar quem é você. Sua privacidade será preservada. Apenas queremos saber a opinião geral dos cidadãos sobre a política de seu país.

Todos os relatórios resultantes serão disponibilizados em publicações científicas e pretendem descrever as expectativas da sociedade em relação às instituições políticas.

A qualquer momento, você pode se recusar a participar. Se você não chegar ao fim do questionário, consideraremos que não deseja mais participar e, portanto, nenhuma de suas respostas será utilizada.

Caso tenha dúvidas sobre essa pesquisa, entre em contato com o pesquisador responsável no e-mail: <endereço de e-mail>

Se você tiver interesse em receber os resultados do estudo, informe-nos pelo e-mail acima.

Ao participar dessa pesquisa, você estará contribuindo para o progresso da ciência no entendimento da política de seu país. Por favor, não deixe item algum sem resposta!

Para poder prosseguir à pesquisa, marque:

\section{[ ] Eu li e concordo com os termos acima}




\section{Qual a sua opinião sobre os membros do Congresso Nacional (Senadores e Deputados Federais)?}

\begin{tabular}{|c|c|c|c|c|c|c|c|c|c|c|c|c|c|c|}
\hline \multirow{2}{*}{$\begin{array}{l}\# \\
1\end{array}$} & \multirow{2}{*}{$\begin{array}{c}\text { Variable code } \\
\text { in SPSS and } \\
\text { AMOS } \\
\text { ST.beh.01 }\end{array}$} & \multirow{2}{*}{$\begin{array}{l}\text { Em sua opinião, o que os(as) } \\
\text { parlamentares realmente fazem? } \\
\text { Diga aproximadamente quantos } \\
\text { deles(as) fazem o seguinte: } \\
\text { Representam meus interesses como } \\
\text { cidadão }\end{array}$} & \multicolumn{4}{|c|}{ Nenhum deles } & \multicolumn{3}{|c|}{ Alguns deles } & \multicolumn{4}{|c|}{ Todos eles } & \multirow{2}{*}{$\begin{array}{c}\text { Não Sei } \\
\text { NS }\end{array}$} \\
\hline & & & $0 \%$ & $10 \%$ & $20 \%$ & $30 \%$ & $40 \%$ & $50 \%$ & $60 \%$ & $70 \%$ & $80 \%$ & $90 \%$ & $100 \%$ & \\
\hline 2 & ST.beh.02 & $\begin{array}{l}\text { Favorecem as empresas em detrimento } \\
\text { dos interesses dos cidadãos }\end{array}$ & $0 \%$ & $10 \%$ & $20 \%$ & $30 \%$ & $40 \%$ & $50 \%$ & $60 \%$ & $70 \%$ & $80 \%$ & $90 \%$ & $100 \%$ & NS \\
\hline 3 & ST.beh.03 & $\begin{array}{l}\text { Ajudam seus amigos e familiares a } \\
\text { alcançarem importantes cargos } \\
\text { (praticam nepotismo) }\end{array}$ & $0 \%$ & $10 \%$ & $20 \%$ & $30 \%$ & $40 \%$ & $50 \%$ & $60 \%$ & $70 \%$ & $80 \%$ & $90 \%$ & $100 \%$ & NS \\
\hline 4 & ST.beh.04 & $\begin{array}{l}\text { Contribuem para o desenvolvimento } \\
\text { sustentável }\end{array}$ & $0 \%$ & $10 \%$ & $20 \%$ & $30 \%$ & $40 \%$ & $50 \%$ & $60 \%$ & $70 \%$ & $80 \%$ & $90 \%$ & $100 \%$ & NS \\
\hline 5 & ST.beh.05 & $\begin{array}{l}\text { Fazem bom uso do orçamento para } \\
\text { melhorar os serviços (escolas, } \\
\text { hospitais, polícia) para as pessoas }\end{array}$ & $0 \%$ & $10 \%$ & $20 \%$ & $30 \%$ & $40 \%$ & $50 \%$ & $60 \%$ & $70 \%$ & $80 \%$ & $90 \%$ & $100 \%$ & NS \\
\hline 6 & ST.beh.06 & $\begin{array}{l}\text { Cumprem com as promessas que } \\
\text { fazem durante a campanha eleitoral }\end{array}$ & $0 \%$ & $10 \%$ & $20 \%$ & $30 \%$ & $40 \%$ & $50 \%$ & $60 \%$ & $70 \%$ & $80 \%$ & $90 \%$ & $100 \%$ & NS \\
\hline 7 & ST.beh.07 & $\begin{array}{l}\text { Agem de forma coerente com a } \\
\text { ideologia declarada de seus partidos }\end{array}$ & $0 \%$ & $10 \%$ & $20 \%$ & $30 \%$ & $40 \%$ & $50 \%$ & $60 \%$ & $70 \%$ & $80 \%$ & $90 \%$ & $100 \%$ & NS \\
\hline 8 & ST.beh.08 & Criam leis benéficas para o país & $0 \%$ & $10 \%$ & $20 \%$ & $30 \%$ & $40 \%$ & $50 \%$ & $60 \%$ & $70 \%$ & $80 \%$ & $90 \%$ & $100 \%$ & NS \\
\hline 9 & ST.beh.09 & $\begin{array}{l}\text { Fazem bom trabalho representando a } \\
\text { posição do Brasil em questões } \\
\text { internacionais. }\end{array}$ & $0 \%$ & $10 \%$ & $20 \%$ & $30 \%$ & $40 \%$ & $50 \%$ & $60 \%$ & $70 \%$ & $80 \%$ & $90 \%$ & $100 \%$ & NS \\
\hline 10 & ST.beh.10 & $\begin{array}{l}\text { Usam o dinheiro público para seus } \\
\text { interesses particulares }\end{array}$ & $0 \%$ & $10 \%$ & $20 \%$ & $30 \%$ & $40 \%$ & $50 \%$ & $60 \%$ & $70 \%$ & $80 \%$ & $90 \%$ & $100 \%$ & NS \\
\hline
\end{tabular}




\section{Estereótipos - Previsão de comportamento}

\begin{tabular}{|c|c|c|c|c|c|c|c|c|c|c|c|c|c|c|}
\hline \multirow{2}{*}{$\begin{array}{l}\# \\
11\end{array}$} & \multirow{2}{*}{$\begin{array}{l}\text { Variable code } \\
\text { in SPSS and } \\
\text { AMOS } \\
\text { ST.beh. } 11\end{array}$} & \multirow{2}{*}{$\begin{array}{l}\text { Em sua opinião, o que os(as) } \\
\text { parlamentares realmente fazem? } \\
\text { Diga aproximadamente quantos } \\
\text { deles(as) fazem o seguinte: } \\
\text { Trabalham por uma distribuição de } \\
\text { renda mais justa entre os brasileiros }\end{array}$} & \multicolumn{4}{|c|}{$\begin{array}{l}\text { Nenhum deles } \\
\nabla\end{array}$} & \multicolumn{3}{|c|}{ Alguns deles } & \multicolumn{4}{|c|}{ Todos eles } & \multirow{2}{*}{$\begin{array}{c}\text { Não Sei } \\
\text { NS }\end{array}$} \\
\hline & & & $0 \%$ & $10 \%$ & $20 \%$ & $30 \%$ & $40 \%$ & $50 \%$ & $60 \%$ & $70 \%$ & $80 \%$ & $90 \%$ & $100 \%$ & \\
\hline 12 & ST.beh.12 & $\begin{array}{l}\text { Representam o interesse de seu } \\
\text { eleitorado }\end{array}$ & $0 \%$ & $10 \%$ & $20 \%$ & $30 \%$ & $40 \%$ & $50 \%$ & $60 \%$ & $70 \%$ & $80 \%$ & $90 \%$ & $100 \%$ & NS \\
\hline & $\begin{array}{l}\text { Open01. Você g } \\
\text { [Resposta de te> }\end{array}$ & $\begin{array}{l}\text { gostaria de acrescentar algo a essa } \\
\text { xto livre] }\end{array}$ & $a ? 0 \mathrm{q}$ & ue vo & êe ache & & os parl & aments & & eralme & nte faz & zem? & & \\
\hline
\end{tabular}

$$
==/ /==
$$




\section{Participação Política - Atitudes de não-participação}

\begin{tabular}{|c|c|c|c|c|c|c|c|c|c|c|c|c|c|c|}
\hline \multirow{2}{*}{$\begin{array}{l}\# \\
13\end{array}$} & \multirow{2}{*}{$\begin{array}{l}\text { Variable code } \\
\text { in SPSS and } \\
\text { AMOS } \\
\text { PP.atd.01 }\end{array}$} & \multirow{2}{*}{$\begin{array}{l}\text { Por favor, informe o quanto você concorda } \\
\text { com as seguintes afirmações sobre política }\end{array}$} & \multicolumn{8}{|c|}{$\begin{array}{l}\text { Discordo } \\
\text { totalmente } \\
\nabla\end{array}$} & \multicolumn{3}{|c|}{$\begin{array}{r}\text { Concordo } \\
\text { totalmente } \\
\nabla\end{array}$} & \multirow{2}{*}{$\begin{array}{c}\text { Não Sei } \\
\text { NS }\end{array}$} \\
\hline & & & 0 & 1 & 2 & 3 & 4 & 5 & 6 & 7 & 8 & 9 & 10 & \\
\hline 14 & PP.atd.02 & $\begin{array}{l}\text { Meu voto não tem importância para melhorar a } \\
\text { situação do Brasil }\end{array}$ & 0 & 1 & 2 & 3 & 4 & 5 & 6 & 7 & 8 & 9 & 10 & NS \\
\hline 15 & PP.atd.03 & $\begin{array}{l}\text { Os votos em branco ou nulos expressam a } \\
\text { insatisfação dos eleitores com os políticos do } \\
\text { nosso país }\end{array}$ & 0 & 1 & 2 & 3 & 4 & 5 & 6 & 7 & 8 & 9 & 10 & NS \\
\hline 16 & PP.atd.04 & $\begin{array}{l}\text { A imprensa distorce o que acontece no Congresso } \\
\text { Nacional }\end{array}$ & 0 & 1 & 2 & 3 & 4 & 5 & 6 & 7 & 8 & 9 & 10 & NS \\
\hline 17 & PP.atd.05 & $\begin{array}{l}\text { É perda de tempo acompanhar o noticiário sobre } \\
\text { política }\end{array}$ & 0 & 1 & 2 & 3 & 4 & 5 & 6 & 7 & 8 & 9 & 10 & NS \\
\hline 18 & PP.atd.06 & $\begin{array}{l}\text { Os eleitores podem influenciar as decisões dos } \\
\text { parlamentares durante seus mandatos }\end{array}$ & 0 & 1 & 2 & 3 & 4 & 5 & 6 & 7 & 8 & 9 & 10 & NS \\
\hline 19 & PP.atd.07 & $\begin{array}{l}\text { É legítimo usar a violência como uma forma de } \\
\text { protesto }\end{array}$ & 0 & 1 & 2 & 3 & 4 & 5 & 6 & 7 & 8 & 9 & 10 & NS \\
\hline 20 & PP.atd.08 & $\begin{array}{l}\text { É necessário construir uma nova sociedade, sem } \\
\text { nenhuma das instituições políticas existentes }\end{array}$ & 0 & 1 & 2 & 3 & 4 & 5 & 6 & 7 & 8 & 9 & 10 & NS \\
\hline 21 & PP.atd.09 & Poderíamos viver muito bem sem os políticos. & 0 & 1 & 2 & 3 & 4 & 5 & 6 & 7 & 8 & 9 & 10 & NS \\
\hline 22 & PP.atd.10 & $\begin{array}{l}\text { Minhas escolhas de estilo de vida representam } \\
\text { meu ponto de vista política (as músicas que ouço, } \\
\text { as roupas que visto, meu corte de cabelo, etc.) }\end{array}$ & 0 & 1 & 2 & 3 & 4 & 5 & 6 & 7 & 8 & 9 & 10 & NS \\
\hline 23 & PP.atd.11 & $\begin{array}{l}\text { Pretendo votar novamente no mesmo partido que } \\
\text { votei nas últimas eleições }\end{array}$ & 0 & 1 & 2 & 3 & 4 & 5 & 6 & 7 & 8 & 9 & 10 & NS \\
\hline
\end{tabular}




\section{Participação Política - Atitudes de não-participação}

Variable code

in SPSS and

AMOS

24
Por favor, informe o quanto você concorda com as seguintes afirmações sobre política

As ONGs e empresas privadas sempre funcionam

melhor do que o governo para atender aos interesses dos cidadãos

\section{Discordo}

totalmente

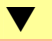

Concordo

totalmente Não Sei

\author{
0
}

0

4

$2 \quad 3$

\begin{tabular}{|l|l|l|}
\hline 5 & 6 & 7 \\
\hline
\end{tabular}

Open02. Qual a sua impressão sobre a política nacional? [Resposta de texto livre] 


\section{Participação Política - Comportamento Passado}

\begin{tabular}{|c|c|c|c|c|c|c|c|c|c|}
\hline \multirow{2}{*}{$\begin{array}{l}\# \\
25\end{array}$} & \multirow{2}{*}{$\begin{array}{l}\text { Variable code } \\
\text { in SPSS and } \\
\text { AMOS } \\
\text { PP.beh.01 }\end{array}$} & \multirow{2}{*}{$\begin{array}{l}\text { Quantas vezes você fez o que está na lista abaixo desde } 2010 \text { (a } \\
\text { última campanha eleitoral para o Senado e Câmara Federal)? } \\
\text { Entrei em contato diretamente com os parlamentares (em reuniões, por } \\
\text { telefone ou pela Internet) }\end{array}$} & \multicolumn{6}{|c|}{ Quantas vezes? } & \multirow{2}{*}{$\begin{array}{c}\text { Não Sei } \\
\text { NS }\end{array}$} \\
\hline & & & 0 & 1 & 2 & 3 & 4 & 5 ou mais & \\
\hline 26 & PP.beh.02 & $\begin{array}{l}\text { Usei as redes sociais na Internet (Facebook, Twitter, Youtube, outras) } \\
\text { para me envolver na ação política }\end{array}$ & 0 & 1 & 2 & 3 & 4 & 5 ou mais & NS \\
\hline 27 & PP.beh.03 & Busquei informações sobre o desempenho dos parlamentares & 0 & 1 & 2 & 3 & 4 & 5 ou mais & NS \\
\hline 28 & PP.beh.04 & $\begin{array}{l}\text { Entrei em contato com a imprensa escrita, rádio ou televisão para } \\
\text { divulgar algo de relevância política }\end{array}$ & 0 & 1 & 2 & 3 & 4 & 5 ou mais & NS \\
\hline 29 & PP.beh.05 & $\begin{array}{l}\text { Participei de reuniões institucionais (fóruns, seminários, audiências } \\
\text { públicas) sobre questões políticas. }\end{array}$ & 0 & 1 & 2 & 3 & 4 & 5 ou mais & NS \\
\hline 30 & PP.beh.06 & Assinei petições sobre questões públicas & 0 & 1 & 2 & 3 & 4 & 5 ou mais & NS \\
\hline 31 & PP.beh.07 & Participei de discussões sobre questões políticas & 0 & 1 & 2 & 3 & 4 & 5 ou mais & NS \\
\hline 32 & PP.beh.08 & Participei de greves organizadas pelos sindicatos laborais & 0 & 1 & 2 & 3 & 4 & 5 ou mais & NS \\
\hline 33 & PP.beh.09 & Participei de manifestações nas ruas & 0 & 1 & 2 & 3 & 4 & 5 ou mais & NS \\
\hline 34 & PP.beh.10 & Participei de eventos organizados por partidos políticos & 0 & 1 & 2 & 3 & 4 & 5 ou mais & NS \\
\hline 35 & PP.beh.11 & $\begin{array}{l}\text { Ajudei uma associação não vinculada aos partidos ou ao governo } \\
\text { (sindicato laboral, organização social de minorias, igreja, ONG, etc.) }\end{array}$ & 0 & 1 & 2 & 3 & 4 & 5 ou mais & NS \\
\hline
\end{tabular}




\section{Participação Política - Comportamento Passado}

\begin{tabular}{|c|c|c|c|c|c|c|c|c|c|}
\hline \multirow{2}{*}{$\begin{array}{l}\# \\
36\end{array}$} & \multirow{2}{*}{$\begin{array}{l}\text { Variable code } \\
\text { in SPSS and } \\
\text { AMOS } \\
\text { PP.beh.12 }\end{array}$} & \multirow{2}{*}{$\begin{array}{l}\text { Quantas vezes você fez o que está na lista abaixo desde } 2010 \text { (a } \\
\text { última campanha eleitoral para o Senado e Câmara Federal)? } \\
\text { Escolhi ou recusei produtos por motivos políticos, éticos ou de proteção } \\
\text { ambiental }\end{array}$} & \multicolumn{6}{|c|}{ Quantas vezes? } & \multirow{2}{*}{\begin{tabular}{|c|} 
Não Se \\
NS
\end{tabular}} \\
\hline & & & 0 & 1 & 2 & 3 & 4 & 5 ou mais & \\
\hline 37 & PP.beh.13 & Distribuí panfletos políticos & 0 & 1 & 2 & 3 & 4 & 5 ou mais & NS \\
\hline 38 & PP.beh.14 & $\begin{array}{l}\text { Trabalhei como voluntário (para a escola de meus filhos / igreja / } \\
\text { vizinhança / outros) }\end{array}$ & 0 & 1 & 2 & 3 & 4 & 5 ou mais & NS \\
\hline & \multicolumn{9}{|c|}{ Open03. Você se envolveu em algum outro tipo de ação política? [Resposta de texto livre] } \\
\hline
\end{tabular}

$$
==/ /==
$$




\section{Engajamento com Partidos}

\begin{tabular}{c|c|c|c}
\hline$\#$ & $\begin{array}{l}\text { Variable code in } \\
\text { SPSS and AMOS }\end{array}$ & Questão & Resposta \\
\hline 39 & PartyMember & Você é membro de algum partido político? & Sim / Não \\
\hline 40 & PartySympa & $\begin{array}{l}\text { Em caso negativo, você simpatiza com algum } \\
\text { partido político? }\end{array}$ & Sim / Não \\
\hline 41 & BraParty & $\begin{array}{l}\text { "Se você é membro E/OU simpatiza com } \\
\text { algum partido: qual é esse partido? }\end{array}$ & (Resposta de texto livre - resposta opcional) \\
\hline 42 & PartyReject & Você rejeita algum partido político? & Não / Sim, um partido / Sim, alguns partidos / Sim, todos os partidos \\
\hline 43 & Worked4Party & $\begin{array}{l}\text { Nas últimas eleições, você trabalhou para a } \\
\text { campanha de um candidato ou partido? }\end{array}$ & Sim / Não \\
\hline & & &
\end{tabular}




\section{Contágio comportamental}

\begin{tabular}{|c|c|c|c|c|c|c|c|c|c|c|c|c|c|c|}
\hline \multirow{2}{*}{$\begin{array}{l}\# \\
44\end{array}$} & \multirow{2}{*}{$\begin{array}{l}\text { Variable code } \\
\text { in SPSS and } \\
\text { AMOS } \\
\text { BC. } 01\end{array}$} & \multirow{2}{*}{$\begin{array}{l}\text { Diga até que ponto as frases abaixo te } \\
\text { descrevem }\end{array}$} & \multicolumn{11}{|c|}{$\begin{array}{l}\text { Este item } \\
\text { definitivamente não } \\
\text { me descreve } \\
\nabla\end{array}$} & \multirow{2}{*}{$\begin{array}{c}\text { Não Sei } \\
\text { NS }\end{array}$} \\
\hline & & & 0 & 1 & 2 & 3 & 4 & 5 & 6 & 7 & 8 & 9 & 10 & \\
\hline 45 & BC.02 & $\begin{array}{l}\text { Entendo a política de meu país melhor do que a } \\
\text { maioria dos meus amigos }\end{array}$ & 0 & 1 & 2 & 3 & 4 & 5 & 6 & 7 & 8 & 9 & 10 & NS \\
\hline 46 & BC.03 & $\begin{array}{l}\text { Presto atenção à opinião de amigos que são mais } \\
\text { ativos politicamente do que eu }\end{array}$ & 0 & 1 & 2 & 3 & 4 & 5 & 6 & 7 & 8 & 9 & 10 & NS \\
\hline 47 & BC. 04 & $\begin{array}{l}\text { As pessoas próximas a mim me encorajam a } \\
\text { participar da política }\end{array}$ & 0 & 1 & 2 & 3 & 4 & 5 & 6 & 7 & 8 & 9 & 10 & NS \\
\hline$\#$ & $\begin{array}{l}\text { Variable code } \\
\text { in SPSS and } \\
\text { AMOS }\end{array}$ & Questão & \multicolumn{8}{|c|}{$\begin{array}{l}\text { Nenhum deles } \\
\nabla\end{array}$} & \multicolumn{3}{|c|}{ Todos eles } & Não Sei \\
\hline 48 & BC. 05 & $\begin{array}{l}\text { Quantos de seus amigos/parentes costumam } \\
\text { participar de atividades políticas } \\
\text { (aproximadamente)? }\end{array}$ & $0 \%$ & $\begin{array}{l}10 \\
\%\end{array}$ & $\begin{array}{l}20 \\
\%\end{array}$ & $\begin{array}{l}30 \\
\%\end{array}$ & $\begin{array}{l}40 \\
\%\end{array}$ & $\begin{array}{l}50 \\
\%\end{array}$ & $\begin{array}{l}60 \\
\%\end{array}$ & $\begin{array}{l}70 \\
\%\end{array}$ & $\begin{array}{l}80 \\
\%\end{array}$ & $\begin{array}{l}90 \\
\%\end{array}$ & $\begin{array}{c}100 \\
\%\end{array}$ & NS \\
\hline
\end{tabular}

$=ニ / /=$ 
Educação Política / Socialização Política

\begin{tabular}{|c|c|c|c|c|c|c|c|c|c|c|c|c|c|c|}
\hline \multirow{2}{*}{$\begin{array}{l}\# \\
49\end{array}$} & \multirow{2}{*}{$\begin{array}{c}\text { Variable code } \\
\text { in SPSS and } \\
\text { AMOS } \\
\text { PE.01 }\end{array}$} & \multirow{2}{*}{$\begin{array}{l}\text { Aprendemos sobre política de muitas formas } \\
\text { em nossa vida, com diferentes pessoas e em } \\
\text { diferentes lugares. } \\
\text { Então, diga o quanto você aprendeu sobre } \\
\text { política... } \\
\ldots \text {... na escola (escola primária }-1^{\circ} \text { grau, ou ensino } \\
\text { médio }-2^{\circ} \text { grau) }\end{array}$} & \multicolumn{9}{|c|}{$\begin{array}{l}\text { Não aprendi } \\
\text { nada } \\
\nabla\end{array}$} & \multicolumn{2}{|c|}{$\begin{array}{r}\text { Aprendi } \\
\text { muito } \\
\nabla\end{array}$} & \multirow{2}{*}{\begin{tabular}{|c|} 
Não Se \\
NS \\
\end{tabular}} \\
\hline & & & 0 & 1 & 2 & 3 & 4 & 5 & 6 & 7 & 8 & 9 & 10 & \\
\hline 50 & PE.02 & $\begin{array}{l}\text {... na Universidade (ou outra instituição de Ensino } \\
\text { Superior }-3^{\circ} \text { grau) }\end{array}$ & 0 & 1 & 2 & 3 & 4 & 5 & 6 & 7 & 8 & 9 & 10 & NS \\
\hline 51 & PE.03 & ... com sua família & 0 & 1 & 2 & 3 & 4 & 5 & 6 & 7 & 8 & 9 & 10 & NS \\
\hline 52 & PE.04 & ... com colegas de trabalho & 0 & 1 & 2 & 3 & 4 & 5 & 6 & 7 & 8 & 9 & 10 & NS \\
\hline 53 & PE.05 & $\begin{array}{l}\text {... com membros de uma associação / sindicato / } \\
\text { partido ao qual você é afiliado }\end{array}$ & 0 & 1 & 2 & 3 & 4 & 5 & 6 & 7 & 8 & 9 & 10 & NS \\
\hline 54 & PE.06 & ... com amigos & 0 & 1 & 2 & 3 & 4 & 5 & 6 & 7 & 8 & 9 & 10 & NS \\
\hline 55 & PE.07 & $\begin{array}{l}\text {... por conta própria (lendo livros, jornais, Internet, } \\
\text { assistindo TV, ouvindo rádio, etc.) }\end{array}$ & 0 & 1 & 2 & 3 & 4 & 5 & 6 & 7 & 8 & 9 & 10 & NS \\
\hline & Open04. Onde r & mais ou com quem mais você aprendeu sobre pc & lítica? & {$[\operatorname{Res}$} & osta & de te & o liv & & & & & & & \\
\hline
\end{tabular}




\section{Estereótipos - Informações críticas sobre os parlamentares}

\begin{tabular}{|c|c|c|c|c|c|c|c|c|c|c|c|c|c|c|}
\hline \multirow{2}{*}{ \# } & \multirow{2}{*}{$\begin{array}{l}\text { Variable code } \\
\text { in SPSS and } \\
\text { AMOS } \\
\text { ST.inf.01 }\end{array}$} & \multirow{2}{*}{$\begin{array}{l}\text { Com que frequência você se importa com } \\
\text { essas informações sobre os parlamentares que } \\
\text { discutem assuntos de seu interesse? } \\
\text { O partido político dele/dela }\end{array}$} & \multicolumn{9}{|c|}{ Nunca } & \multicolumn{2}{|c|}{ Sempre } & \multirow{2}{*}{$\begin{array}{c}\text { Não Sei } \\
\text { NS }\end{array}$} \\
\hline & & & 0 & 1 & 2 & 3 & 4 & 5 & 6 & 7 & 8 & 9 & 10 & \\
\hline 57 & ST.inf.02 & $\begin{array}{l}\text { Se ele/ela tem posicionamento de esquerda ou de } \\
\text { direita }\end{array}$ & 0 & 1 & 2 & 3 & 4 & 5 & 6 & 7 & 8 & 9 & 10 & NS \\
\hline 58 & ST.inf.03 & $\begin{array}{l}\text { Se ele/ela representa o(s) partido(s) } \\
\text { governante(s), a oposição ou uma posição neutra }\end{array}$ & 0 & 1 & 2 & 3 & 4 & 5 & 6 & 7 & 8 & 9 & 10 & NS \\
\hline 59 & ST.inf.04 & $\begin{array}{l}\text { A área de especialização dele/dela (por exemplo: } \\
\text { meio ambiente, relações exteriores, } \\
\text { desenvolvimento econômico, direitos humanos, } \\
\text { etc.) }\end{array}$ & 0 & 1 & 2 & 3 & 4 & 5 & 6 & 7 & 8 & 9 & 10 & NS \\
\hline 60 & ST.inf.05 & $\begin{array}{l}\text { Os grupos de interesse dos quais ele/ela participa } \\
\text { (sindicatos laborais, associações de classe, } \\
\text { instituições de proteção ambiental, associações de } \\
\text { agricultores, etc.) }\end{array}$ & 0 & 1 & 2 & 3 & 4 & 5 & 6 & 7 & 8 & 9 & 10 & NS \\
\hline 61 & ST.inf.06 & $\begin{array}{l}\text { Se ele/ela representa alguma minoria (por } \\
\text { exemplo, povos indígenas, imigrantes, gays/LGBT, } \\
\text { pessoas portadoras de necessidades especiais, } \\
\text { etc.) }\end{array}$ & 0 & 1 & 2 & 3 & 4 & 5 & 6 & 7 & 8 & 9 & 10 & NS \\
\hline 62 & ST.inf.07 & A religião dele/dela & 0 & 1 & 2 & 3 & 4 & 5 & 6 & 7 & 8 & 9 & 10 & NS \\
\hline 63 & ST.inf.08 & O gênero do(a) parlamentar (se é homem/mulher) & 0 & 1 & 2 & 3 & 4 & 5 & 6 & 7 & 8 & 9 & 10 & NS \\
\hline 64 & ST.inf.09 & Se ele/ela se envolveu em algum escândalo & 0 & 1 & 2 & 3 & 4 & 5 & 6 & 7 & 8 & 9 & 10 & NS \\
\hline
\end{tabular}




\section{Estereótipos - Informações críticas sobre os parlamentares}

Variable code Com que frequência você se importa com

in SPSS and essas informações sobre os parlamentares que Nunca

AMOS

discutem assuntos de seu interesse?

Sempre Não Sei

\section{discutem assuntos de seu interesse?}

Os cargos políticos anteriormente ocupados por

65

ST.inf. 10

elela (por exemplo, Ministro(a), Secretário(a),

$\nabla$

$\nabla$ etc.)

Open05. Há alguma outra característica relevante sobre os parlamentares? Quais? [Resposta de texto livre] 


\section{Informações Demográficas}

\begin{tabular}{|c|c|c|c|}
\hline$\#$ & $\begin{array}{l}\text { Variable code in } \\
\text { SPSS and AMOS }\end{array}$ & Questão & Resposta \\
\hline 66 & Gender & Gênero & [ ] Homem / [ ] Mulher \\
\hline 67 & Age & Idade & Tenho ___ anos \\
\hline 68 & Education & Meu nível educacional é: & $\begin{array}{l}\text { [ ] Ensino fundamental (1o grau) incompleto } \\
\text { [ ] Ensino fundamental (1o grau) completo } \\
\text { [ ] Ensino médio (2o grau) incompleto } \\
\text { [ ] Ensino médio (2o grau) completo } \\
\text { [ ] Ensino Superior incompleto } \\
\text { [ ] Ensino Superior completo } \\
\text { [ ] Especialização em nível de pós-graduação } \\
\text { [ ] Mestrado completo } \\
\text { [ ] Doutorado (PhD) complete }\end{array}$ \\
\hline 69 & City & Onde você mora? & Informe o nome de sua cidade. \\
\hline 70 & Occupation & Qual a sua (principal) ocupação / profissão? & (Resposta de texto livre) \\
\hline 71 & RelateToParliament & $\begin{array}{l}\text { A sua profissão está diretamente relacionada } \\
\text { com a atividade parlamentar? Leve em } \\
\text { consideração a atividade parlamentar do } \\
\text { Congresso Nacional (Câmara dos Deputados } \\
\text { e Senado Federal), da Assembléia Estadual, } \\
\text { da Câmara Municipal e/ou da Câmara }\end{array}$ & [ ] Sim [ ] Não \\
\hline
\end{tabular}


Informações Demográficas

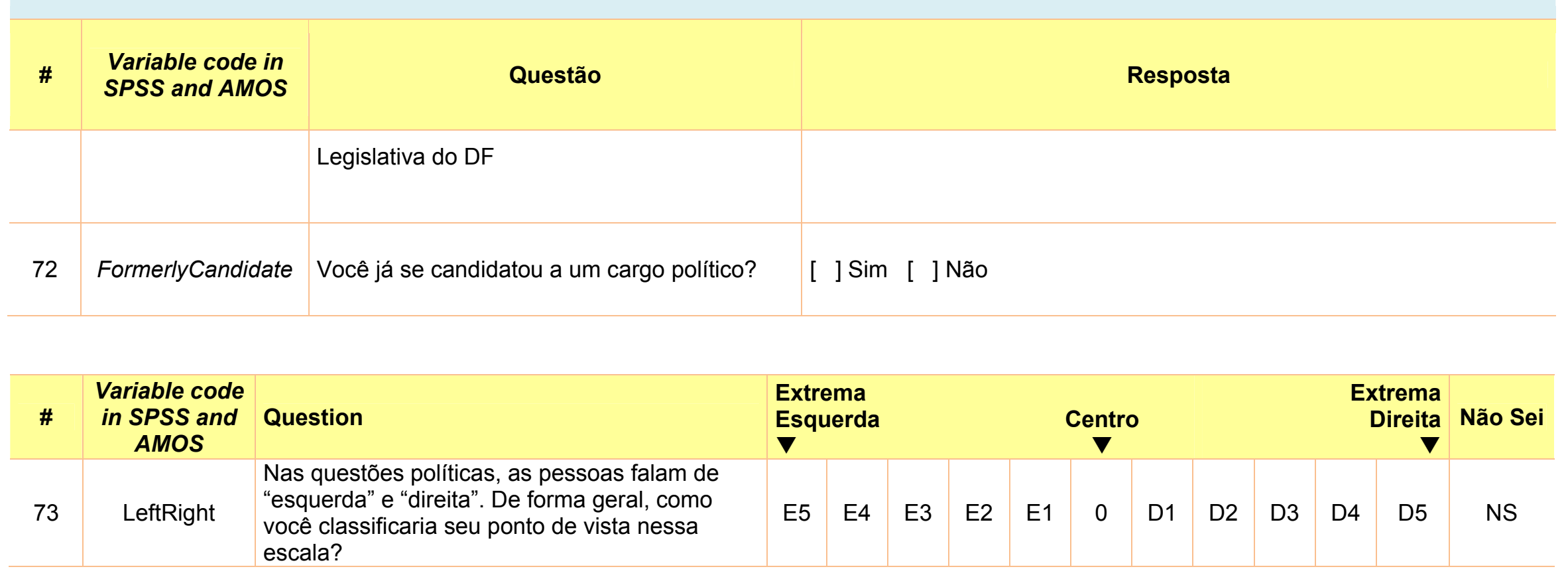




\begin{tabular}{|c|c|c|c|}
\hline$\#$ & $\begin{array}{l}\text { Variable code in } \\
\text { SPSS and AMOS }\end{array}$ & $\begin{array}{l}\text { Diga-nos se você possui algum dos itens } \\
\text { abaixo... }\end{array}$ & Resposta \\
\hline \multirow[t]{11}{*}{74} & & Eu tenho um ou mais... & \\
\hline & lownComputer & Computador com acesso à Internet & [ ] Sim [ ] Não \\
\hline & lownPhone & Telefone celular ou tablet com accesso à Internet & [ ] Sim [ ] Não \\
\hline & lownTV & Televisão Moderna (plasma, LCD ou LED) & [ ] Sim [ ] Não \\
\hline & lownCar & Carro & [ ] Sim [ ] Não \\
\hline & lownApart & Apartamento próprio & [ ] Sim [ ] Não \\
\hline & lownHouse & Casa própria & [ ] Sim [ ] Não \\
\hline & lownOffice & Escritório / Loja / Oficina & [ ] Sim [ ] Não \\
\hline & lownStocks & Ações da Bolsa de Valores & [ ] Sim [ ] Não \\
\hline & lownBoat & Barco (apenas para lazer) & [ ] Sim [ ] Não \\
\hline & lownComp50 & Empresa com mais de 50 funcionários & [ ] Sim [ ] Não \\
\hline
\end{tabular}




\section{Hemsida - Informerat samtycke}

Vi tackar för ditt deltagande i denna undersökning! Undersökningen avser en tvärkulturell studie om människors intryck av politiken i sina respektive länder. Studien bedrivs som en del i en doktorsavhandling av Thiago Carneiro, doktorand $\mathrm{i}$ socialpsykologi på Universitet i Brasília i Brasilien, i samarbete med Södertörns högskola.

Genom att delta i denna undersökning godkänner du att dina svar används för statistisk analys, tillsammans med andra deltagare. Med bakgrund i denna undersökning kommer vi att beräkna genomsnittsvärden, procentsatser och andra indikatorer om deltagarnas allmänna uppfattning.

Du behöver inte uppge ditt namn och dina svar kommer inte att användas för att ta reda på vem du är. Din personliga integritet kommer att respekteras. Vi vill helt enkelt veta din uppfattning om politiken i ditt land.

Samtliga rapporter kommer att tillgängliggöras i vetenskapliga publikationer, i syfte att beskriva samhällets förväntningar på sina politiska institutioner.

Du har rätt att sluta delta när du vill. Om du inte slutför enkäten, antas du inte längre vilja delta. Dina svar kommer följaktligen inte att beaktas.

Skulle du ha några frågor angående undersökningen, hänvisar vi till vår forskningsledare: <e-postadress>

Om du skulle vara intresserad av att erhålla resultaten från undersökning, meddela oss.

Genom din medverkan i denna forskning, bidrar du till ökad insikt i förståelsen av ditt lands politik. Var vänlig och besvara alla frågor!

För att fortsätta till undersökningen, kryssa i:

\section{[ ] Jag har läst och accepterar dessa villkor}




\section{Vad är din åsikt om Sveriges riksdagsledamöter?}

\begin{tabular}{|c|c|c|c|c|c|c|c|c|c|c|c|c|c|c|}
\hline \multirow{2}{*}{$\begin{array}{l}\# \\
1 \\
1\end{array}$} & \multirow{2}{*}{$\begin{array}{c}\text { Variable code } \\
\text { in SPSS and } \\
\text { AMOS } \\
\text { ST.beh.01 }\end{array}$} & \multirow{2}{*}{$\begin{array}{l}\text { Enligt din åsikt, vad gör } \\
\text { riksdagsledamöter egentligen? } \\
\text { Uppge vilken andel av dem som gör } \\
\text { följande: } \\
\text { De företräder mina medborgerliga } \\
\text { intressen }\end{array}$} & \multicolumn{4}{|l|}{ Inga } & \multicolumn{3}{|c|}{$\begin{array}{l}\text { Hälften av dem } \\
\nabla\end{array}$} & \multicolumn{4}{|r|}{ Alla } & \multirow{2}{*}{$\begin{array}{c}\text { Vet ej } \\
\text { VE }\end{array}$} \\
\hline & & & $0 \%$ & $10 \%$ & $20 \%$ & $30 \%$ & $40 \%$ & $50 \%$ & $60 \%$ & $70 \%$ & $80 \%$ & $90 \%$ & $100 \%$ & \\
\hline 2 & ST.beh.02 & $\begin{array}{l}\text { De gynnar företag framför } \\
\text { medborgarnas intressen }\end{array}$ & $0 \%$ & $10 \%$ & $20 \%$ & $30 \%$ & $40 \%$ & $50 \%$ & $60 \%$ & $70 \%$ & $80 \%$ & $90 \%$ & $100 \%$ & VE \\
\hline 3 & ST.beh.03 & $\begin{array}{l}\text { De hjälper sina egna vänner och } \\
\text { familjer så att de kan fă höga positioner } \\
\text { i samhället (de praktiserar nepotism) }\end{array}$ & $0 \%$ & $10 \%$ & $20 \%$ & $30 \%$ & $40 \%$ & $50 \%$ & $60 \%$ & $70 \%$ & $80 \%$ & $90 \%$ & $100 \%$ & VE \\
\hline 4 & ST.beh.04 & De bidrar till en hållbar utveckling & $0 \%$ & $10 \%$ & $20 \%$ & $30 \%$ & $40 \%$ & $50 \%$ & $60 \%$ & $70 \%$ & $80 \%$ & $90 \%$ & $100 \%$ & VE \\
\hline 5 & ST.beh.05 & $\begin{array}{l}\text { De använder offentliga medel effektivt } \\
\text { för att förbättra den offentliga servicen } \\
\text { (skolor, sjukvărd, polis) för folket }\end{array}$ & $0 \%$ & $10 \%$ & $20 \%$ & $30 \%$ & $40 \%$ & $50 \%$ & $60 \%$ & $70 \%$ & $80 \%$ & $90 \%$ & $100 \%$ & VE \\
\hline 6 & ST.beh.06 & De uppfyller sina vallöften & $0 \%$ & $10 \%$ & $20 \%$ & $30 \%$ & $40 \%$ & $50 \%$ & $60 \%$ & $70 \%$ & $80 \%$ & $90 \%$ & $100 \%$ & VE \\
\hline 7 & ST.beh.07 & $\begin{array}{l}\text { De agerar i enlighet med sina partiers } \\
\text { ideologier }\end{array}$ & $0 \%$ & $10 \%$ & $20 \%$ & $30 \%$ & $40 \%$ & $50 \%$ & $60 \%$ & $70 \%$ & $80 \%$ & $90 \%$ & $100 \%$ & VE \\
\hline 8 & ST.beh.08 & De stiftar lagar som främjar landet & $0 \%$ & $10 \%$ & $20 \%$ & $30 \%$ & $40 \%$ & $50 \%$ & $60 \%$ & $70 \%$ & $80 \%$ & $90 \%$ & $100 \%$ & VE \\
\hline 9 & ST.beh.09 & $\begin{array}{l}\text { De företräder Sveriges ståndpunkter i } \\
\text { internationella frågor på ett bra sätt }\end{array}$ & $0 \%$ & $10 \%$ & $20 \%$ & $30 \%$ & $40 \%$ & $50 \%$ & $60 \%$ & $70 \%$ & $80 \%$ & $90 \%$ & $100 \%$ & VE \\
\hline 10 & ST.beh.10 & $\begin{array}{l}\text { De använder offentliga medel för sina } \\
\text { privata intressen }\end{array}$ & $0 \%$ & $10 \%$ & $20 \%$ & $30 \%$ & $40 \%$ & $50 \%$ & $60 \%$ & $70 \%$ & $80 \%$ & $90 \%$ & $100 \%$ & VE \\
\hline
\end{tabular}




\section{Stereotyper - Beteendeprediktion}

\begin{tabular}{|c|c|c|c|c|c|c|c|c|c|c|c|c|c|c|}
\hline \multirow{2}{*}{$\begin{array}{l}\# \\
11\end{array}$} & \multirow{2}{*}{$\begin{array}{c}\text { Variable code } \\
\text { in SPSS and } \\
\text { AMOS } \\
\text { ST.beh.11 }\end{array}$} & \multirow{2}{*}{$\begin{array}{l}\text { Enligt din åsikt, vad gör } \\
\text { riksdagsledamöter egentligen? } \\
\text { Uppge vilken andel av dem som gör } \\
\text { följande: } \\
\text { De arbetar för en jämnare } \\
\text { inkomstfördelning bland svenskar. }\end{array}$} & \multicolumn{7}{|c|}{$\begin{array}{l}\text { Hälften av dem } \\
\qquad \nabla\end{array}$} & \multicolumn{4}{|r|}{$\stackrel{\text { Alla }}{\nabla}$} & \multirow{2}{*}{$\begin{array}{c}\text { Vet ej } \\
\text { VE }\end{array}$} \\
\hline & & & $0 \%$ & $10 \%$ & $20 \%$ & $30 \%$ & $40 \%$ & $50 \%$ & $60 \%$ & $70 \%$ & $80 \%$ & $90 \%$ & $100 \%$ & \\
\hline 12 & ST.beh.12 & $\begin{array}{l}\text { De representerar sina väljares } \\
\text { intressen }\end{array}$ & $0 \%$ & $10 \%$ & $20 \%$ & $30 \%$ & $40 \%$ & $50 \%$ & $60 \%$ & $70 \%$ & $80 \%$ & $90 \%$ & $100 \%$ & VE \\
\hline & $\begin{array}{l}\text { Open01. Finns } \\
\text { [Frivilligt svar] }\end{array}$ & det något mer du önskar tillägga till d & nna lis & ta på v & lad rik & sdags! & ledamć & öterna & vanlig & tvis gö & & & & \\
\hline
\end{tabular}

$$
==/ /==
$$


Politiskt deltagande - Icke-deltagande attityder

\begin{tabular}{|c|c|c|c|c|c|c|c|c|c|c|c|c|c|c|}
\hline \multirow{2}{*}{$\begin{array}{l}\# \\
13\end{array}$} & \multirow{2}{*}{$\begin{array}{l}\text { Variable code } \\
\text { in SPSS and } \\
\text { AMOS } \\
\text { PP.atd. } 01\end{array}$} & \multirow{2}{*}{$\begin{array}{l}\text { Var god ange i vilken grad du håller med om } \\
\text { följande uttalanden om politik } \\
\text { Jag undviker att diskutera politik }\end{array}$} & \multicolumn{8}{|c|}{$\begin{array}{l}\text { Håller absolut } \\
\text { inte med } \\
\nabla\end{array}$} & \multicolumn{3}{|c|}{$\begin{array}{r}\text { Håller } \\
\text { absolut med }\end{array}$} & \multirow{2}{*}{$\begin{array}{l}\text { Vet ej } \\
\text { VE }\end{array}$} \\
\hline & & & 0 & 1 & 2 & 3 & 4 & 5 & 6 & 7 & 8 & 9 & 10 & \\
\hline 14 & PP.atd.02 & $\begin{array}{l}\text { Min röst har ingen betydelse för att förbättra } \\
\text { situationen i Sverige }\end{array}$ & 0 & 1 & 2 & 3 & 4 & 5 & 6 & 7 & 8 & 9 & 10 & VE \\
\hline 15 & PP.atd.03 & $\begin{array}{l}\text { Blanka och ogiltiga röster uttrycker väljarnas } \\
\text { missnöje med vărt lands politiker }\end{array}$ & 0 & 1 & 2 & 3 & 4 & 5 & 6 & 7 & 8 & 9 & 10 & VE \\
\hline 16 & PP.atd.04 & Pressen förvanskar det som händer i Riksdagen & 0 & 1 & 2 & 3 & 4 & 5 & 6 & 7 & 8 & 9 & 10 & VE \\
\hline 17 & PP.atd.05 & Det är slöseri med tid att följa nyheterna om politik & 0 & 1 & 2 & 3 & 4 & 5 & 6 & 7 & 8 & 9 & 10 & VE \\
\hline 18 & PP.atd.06 & $\begin{array}{l}\text { Väljarna kan påverka riksdagsledamöternas beslut } \\
\text { under deras mandatperiod }\end{array}$ & 0 & 1 & 2 & 3 & 4 & 5 & 6 & 7 & 8 & 9 & 10 & VE \\
\hline 19 & PP.atd.07 & $\begin{array}{l}\text { Det är legitimt att använda våld som en form av } \\
\text { protest }\end{array}$ & 0 & 1 & 2 & 3 & 4 & 5 & 6 & 7 & 8 & 9 & 10 & VE \\
\hline 20 & PP.atd.08 & $\begin{array}{l}\text { Det är nödvändigt att bygga ett nytt samhälle, utan } \\
\text { några av de befintliga politiska institutionerna }\end{array}$ & 0 & 1 & 2 & 3 & 4 & 5 & 6 & 7 & 8 & 9 & 10 & VE \\
\hline 21 & PP.atd.09 & Vi skulle klara oss lika bra utan politiker & 0 & 1 & 2 & 3 & 4 & 5 & 6 & 7 & 8 & 9 & 10 & VE \\
\hline 22 & PP.atd.10 & $\begin{array}{l}\text { Mina beslut i livsstilsfrågor visar mina politiska } \\
\text { åsikter (musik jag lyssnar på, kläder jag bär, frisyr } \\
\text { etc.) }\end{array}$ & 0 & 1 & 2 & 3 & 4 & 5 & 6 & 7 & 8 & 9 & 10 & VE \\
\hline 23 & PP.atd.11 & $\begin{array}{l}\text { Jag avser att rösta igen på samma parti som jag } \\
\text { röstade på i senaste valet }\end{array}$ & 0 & 1 & 2 & 3 & 4 & 5 & 6 & 7 & 8 & 9 & 10 & VE \\
\hline
\end{tabular}




\section{Politiskt deltagande - Icke-deltagande attityder}

Variable code

in SPSS and

AMOS

24
Var god ange i vilken grad du håller med om följande uttalanden om politik

NGO:er och företag uppnår alltid bättre resultat än

regeringen när det handlar om att tillgodose medborgarnas intressen
Håller absolut

inte med

Håller

absolut med Vet ej
0

12

3

4

5

Open02. Vad är dina intryck av svensk politik? [Frivilligt svar]

$==/ /==$ 


\section{Politiskt deltagande - Tidigare beteende}

\begin{tabular}{|c|c|c|c|c|c|c|c|c|c|}
\hline \multirow{2}{*}{$\begin{array}{l}\# \\
25\end{array}$} & \multirow{2}{*}{$\begin{array}{l}\text { Variable code } \\
\text { in SPSS and } \\
\text { AMOS } \\
\text { PP.beh.01 }\end{array}$} & \multirow{2}{*}{$\begin{array}{l}\text { Hur många har gånger du gjort följande, av det som framgår } \\
\text { nedan, sedan } 2010 \text { (då senaste valet till Riksdagen ägde rum)? } \\
\begin{array}{l}\text { Jag har kontaktat riksdagsledamöter direkt (genom möten, telefon eller } \\
\text { internet) }\end{array}\end{array}$} & \multicolumn{6}{|c|}{ Hur många gånger har du gjort detta? } & \multirow{2}{*}{$\begin{array}{c}\text { Vet ej } \\
\text { VE }\end{array}$} \\
\hline & & & 0 & 1 & 2 & 3 & 4 & 5 eller flera & \\
\hline 26 & PP.beh.02 & $\begin{array}{l}\text { Jag har använt sociala medier (Facebook, Twitter, Youtube etc.) för att } \\
\text { delta i politiska aktiviteter }\end{array}$ & 0 & 1 & 2 & 3 & 4 & 5 eller flera & VE \\
\hline 27 & PP.beh.03 & Jag har sökt efter information om vad riksdagsledamöter har uträttat & 0 & 1 & 2 & 3 & 4 & 5 eller flera & VE \\
\hline 28 & PP.beh.04 & $\begin{array}{l}\text { Jag har kontaktat tidningar, radio eller TV för att kommunicera något } \\
\text { politiskt viktigt }\end{array}$ & 0 & 1 & 2 & 3 & 4 & 5 eller flera & VE \\
\hline 29 & PP.beh.05 & $\begin{array}{l}\text { Jag har deltagit i konferenser, seminarier, föredrag eller offentliga } \\
\text { utskottsförhör om politiska frågor. }\end{array}$ & 0 & 1 & 2 & 3 & 4 & 5 eller flera & VE \\
\hline 30 & PP.beh.06 & Jag har skrivit på namninsamlingar om politiska frågor & 0 & 1 & 2 & 3 & 4 & 5 eller flera & VE \\
\hline 31 & PP.beh.07 & Jag har deltagit i diskussioner om politiska frågor & 0 & 1 & 2 & 3 & 4 & 5 eller flera & VE \\
\hline 32 & PP.beh.08 & Jag har deltagit i strejker som organiserats av fackföreningar & 0 & 1 & 2 & 3 & 4 & 5 eller flera & VE \\
\hline 33 & PP.beh.09 & Jag har deltagit i gatudemonstrationer & 0 & 1 & 2 & 3 & 4 & 5 eller flera & VE \\
\hline 34 & PP.beh.10 & Jag har deltagit i evenemang organiserade av politiska partier & 0 & 1 & 2 & 3 & 4 & 5 eller flera & VE \\
\hline 35 & PP.beh.11 & $\begin{array}{l}\text { Jag har hjälpt någon organisation utan anknytning till partier eller } \\
\text { regeringen (fackförening, social minoritetsorgansation, kyrka, NGO etc) }\end{array}$ & 0 & 1 & 2 & 3 & 4 & 5 eller flera & VE \\
\hline
\end{tabular}




\section{Politiskt deltagande - Tidigare beteende}

Variable code

in SPSS and Hur många har gånger du gjort följande, av det som framgår AMOS nedan, sedan 2010 (då senaste valet till Riksdagen ägde rum)?

Hur många gånger har du gjort detta?

Vet ej

Jag har valt eller undvikit produkter av politiska eller etiska orsaker eller av miljöskäl.

36 PP.beh.12

PP.beh.13 Jag har delat ut politiska informationsblad.

38 PP.beh.14 Jag har arbetat som volontär (för mina barns

skola/kyrkan/grannskapet/andra sammanhang)

\begin{tabular}{l|l|l|l|l|l|l}
0 & 1 & 2 & 3 & 4 & 5 eller flera & VE
\end{tabular}

0

\begin{tabular}{|l|l|}
1 & 2 \\
\hline 1 & 2 \\
\hline
\end{tabular}

Open03. Är du engagerad i någon annan slags politisk aktivitet? [Frivilligt svar]

$$
==/ /==
$$




\section{Partiengagemang}

\begin{tabular}{c|c|c|c|}
\hline$\#$ & $\begin{array}{c}\text { Variable code in } \\
\text { SPSS and AMOS }\end{array}$ & \multicolumn{1}{|c|}{ Fråga } & \\
\hline 39 & PartyMember & Är du medlem i ett politiskt parti? & [ ] Ja / [ ] Nej \\
\hline 40 & PartySympa & $\begin{array}{l}\text { Om inte, sympatiserar du med något politiskt } \\
\text { parti? }\end{array}$ & [ ] Ja / [ ] Nej \\
\hline 41 & SweParty / BraParty & $\begin{array}{l}\text { Om du är medlem i och/eller sympatiserar } \\
\text { med något parti: vilket? }\end{array}$ & [Fritext svar - frivilligt svar] \\
\hline 42 & PartyReject & Förkastar du något parti? & $\begin{array}{l}\text { Nej, jag förkastar inget / Ja, förkastar ett parti / Ja, förkastar några } \\
\text { partier / Ja, jag förkastar samtliga partier }\end{array}$ \\
\hline 43 & Worked4Party & $\begin{array}{l}\text { Arbetade du i kampanjen för någon kandidat } \\
\text { eller parti i det senaste valet? }\end{array}$ & [ ] Ja / [ ] Nej \\
\hline & & & $=$
\end{tabular}




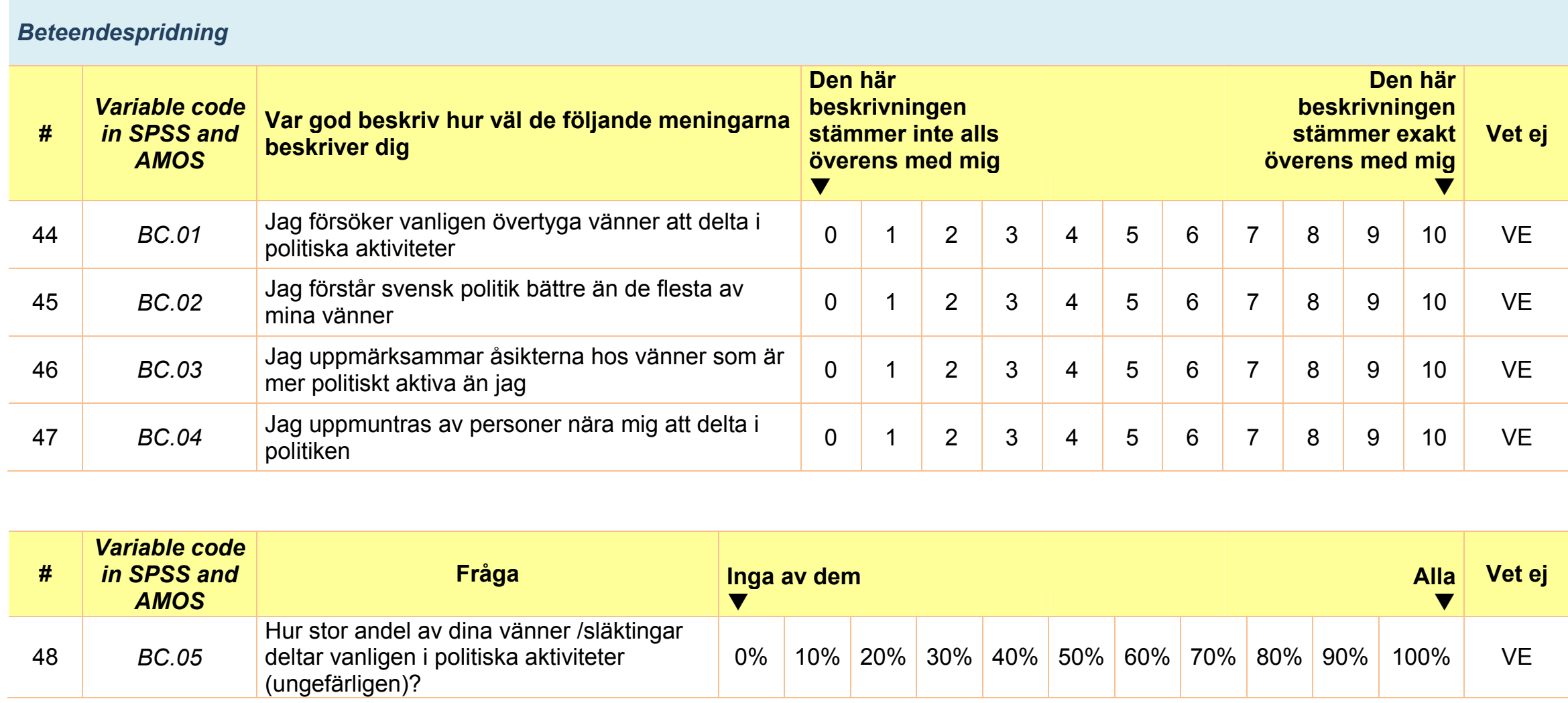

$$
==/ /==
$$


Politisk Utbildning / politisk socialisation

\begin{tabular}{|c|c|c|c|c|c|c|c|c|c|c|c|c|c|c|}
\hline \multirow{2}{*}{$\begin{array}{l}\# \\
49\end{array}$} & \multirow{2}{*}{$\begin{array}{l}\text { Variable code } \\
\text { in SPSS and } \\
\text { AMOS } \\
\text { PE.01 }\end{array}$} & \multirow{2}{*}{$\begin{array}{l}\text { Vi lär oss om politik på många sätt under vårt } \\
\text { liv, av många olika personer på olika platser. } \\
\text { Var god ange hur du har lärt dig om politik.... } \\
\text {... i grundskolan eller på gymnasiet }\end{array}$} & \multicolumn{7}{|c|}{$\begin{array}{l}\text { Jag har inte lärt mig } \\
\text { något } \\
\nabla\end{array}$} & \multicolumn{4}{|c|}{$\begin{array}{r}\text { Jag har lärt mig en } \\
\text { hel del }\end{array}$} & \multirow{2}{*}{$\begin{array}{c}\text { Vet e } \\
\text { VE }\end{array}$} \\
\hline & & & 0 & 1 & 2 & 3 & 4 & 5 & 6 & 7 & 8 & 9 & 10 & \\
\hline 50 & PE.02 & ... på universitetet eller annan högre utbildning & 0 & 1 & 2 & 3 & 4 & 5 & 6 & 7 & 8 & 9 & 10 & VE \\
\hline 51 & PE.03 & ... av din familj & 0 & 1 & 2 & 3 & 4 & 5 & 6 & 7 & 8 & 9 & 10 & VE \\
\hline 52 & PE.04 & ... av arbetskollegor & 0 & 1 & 2 & 3 & 4 & 5 & 6 & 7 & 8 & 9 & 10 & VE \\
\hline 53 & PE.05 & $\begin{array}{l}\text {... av medlemmar i förening/fackförening/parti där } \\
\text { du är medlem }\end{array}$ & 0 & 1 & 2 & 3 & 4 & 5 & 6 & 7 & 8 & 9 & 10 & VE \\
\hline 54 & PE.06 & ... av vänner & 0 & 1 & 2 & 3 & 4 & 5 & 6 & 7 & 8 & 9 & 10 & VE \\
\hline 55 & PE.07 & $\begin{array}{l}\text {... på egen hand (genom böcker, tidningar, } \\
\text { internet, TV, radio etc.) }\end{array}$ & 0 & 1 & 2 & 3 & 4 & 5 & 6 & 7 & 8 & 9 & 10 & VE \\
\hline & Open04. Var an & nnars eller från vem/vilka har du lärt dig om polit & $:[1]$ & & & & & & & & & & & \\
\hline
\end{tabular}

$$
==/ /==
$$


Stereotyper - Viktig information om riksdagsledamöter

\begin{tabular}{|c|c|c|c|c|c|c|c|c|c|c|c|c|c|c|}
\hline \multirow{2}{*}{$\begin{array}{c}\# \\
56\end{array}$} & \multirow{2}{*}{$\begin{array}{l}\text { Variable code } \\
\text { in SPSS and } \\
\text { AMOS } \\
\text { ST.inf.01 }\end{array}$} & \multirow{2}{*}{$\begin{array}{l}\text { Hur ofta bryr du dig om följande information } \\
\text { om riksdagsledamöter som diskuterar frågor } \\
\text { som är av intresse för dig? }\end{array}$} & \multicolumn{9}{|c|}{ Aldrig } & \multicolumn{2}{|c|}{$\stackrel{\text { Alltid }}{\nabla}$} & \multirow{2}{*}{$\begin{array}{c}\text { Vet ej } \\
\text { VE }\end{array}$} \\
\hline & & & 0 & 1 & 2 & 3 & 4 & 5 & 6 & 7 & 8 & 9 & 10 & \\
\hline 57 & ST.inf.02 & $\begin{array}{l}\text { Om han/hon ligger till vänster eller höger på den } \\
\text { politiska skalan }\end{array}$ & 0 & 1 & 2 & 3 & 4 & 5 & 6 & 7 & 8 & 9 & 10 & VE \\
\hline 58 & ST.inf.03 & $\begin{array}{l}\text { Om han/hon tillhör några av regeringspartiena, } \\
\text { oppositionen eller är neutral }\end{array}$ & 0 & 1 & 2 & 3 & 4 & 5 & 6 & 7 & 8 & 9 & 10 & VE \\
\hline 59 & ST.inf.04 & $\begin{array}{l}\text { Hans/hennes särskilda kunskapsområde (t.ex. } \\
\text { miljö, utrikespolitik, ekonomisk utveckling, } \\
\text { mänskliga rättigheter etc.) }\end{array}$ & 0 & 1 & 2 & 3 & 4 & 5 & 6 & 7 & 8 & 9 & 10 & VE \\
\hline 60 & ST.inf.05 & $\begin{array}{l}\text { Intressegrupper som han/hon är engagerad i } \\
\text { (fackföreningar, företagarorgansationer, } \\
\text { miljöorganisationer, jordbrukarorganisationer etc) }\end{array}$ & 0 & 1 & 2 & 3 & 4 & 5 & 6 & 7 & 8 & 9 & 10 & VE \\
\hline 61 & ST.inf.06 & $\begin{array}{l}\text { Om han/hon representerar någon minoritet (t.ex. } \\
\text { ursprungsbefolkning, invandrare, } \\
\text { homosexuella/HBT, funktionshindrade etc) }\end{array}$ & 0 & 1 & 2 & 3 & 4 & 5 & 6 & 7 & 8 & 9 & 10 & VE \\
\hline 62 & ST.inf.07 & Hans/hennes religion & 0 & 1 & 2 & 3 & 4 & 5 & 6 & 7 & 8 & 9 & 10 & VE \\
\hline 63 & ST.inf.08 & Riksdagsledamotens kön (man/kvinna) & 0 & 1 & 2 & 3 & 4 & 5 & 6 & 7 & 8 & 9 & 10 & VE \\
\hline 64 & ST.inf.09 & Om han/hon har varit inblandad i skandaler & 0 & 1 & 2 & 3 & 4 & 5 & 6 & 7 & 8 & 9 & 10 & VE \\
\hline
\end{tabular}


Stereotyper - Viktig information om riksdagsledamöter

\begin{tabular}{|c|c|c|c|c|c|c|c|c|c|c|c|c|c|c|}
\hline \multirow{2}{*}{$\begin{array}{c}\# \\
65\end{array}$} & \multirow{2}{*}{$\begin{array}{l}\text { Variable code } \\
\text { in SPSS and } \\
\text { AMOS } \\
\text { ST.inf. } 10\end{array}$} & \multirow{2}{*}{ 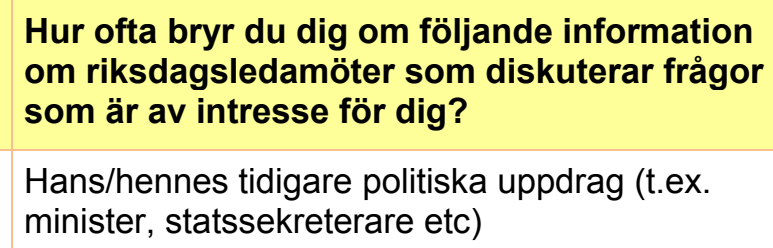 } & \multicolumn{9}{|c|}{ Aldrig } & \multicolumn{2}{|c|}{$\stackrel{\text { Alltid }}{\nabla}$} & \multirow{2}{*}{$\begin{array}{c}\text { Vet e } \\
\text { VE }\end{array}$} \\
\hline & & & 0 & 1 & 2 & 3 & 4 & 5 & 6 & 7 & 8 & 9 & 10 & \\
\hline & Open05. Finns & det några andra relevanta egenskaper hos riks & igsled & nöte & ? Vil & a? ( $\mathrm{F}$ & rivillig & svar) & & & & & & \\
\hline
\end{tabular}

$==/ /==$ 


\begin{tabular}{|c|c|c|c|}
\hline$\#$ & $\begin{array}{l}\text { Variable code in } \\
\text { SPSS and AMOS }\end{array}$ & Fråga & Svar \\
\hline 66 & Gender & Kön & [ ] Man / [ ] Kvinna \\
\hline 67 & Age & Ålder & Jag är ___ år gammal \\
\hline 68 & Education & Utbildning & 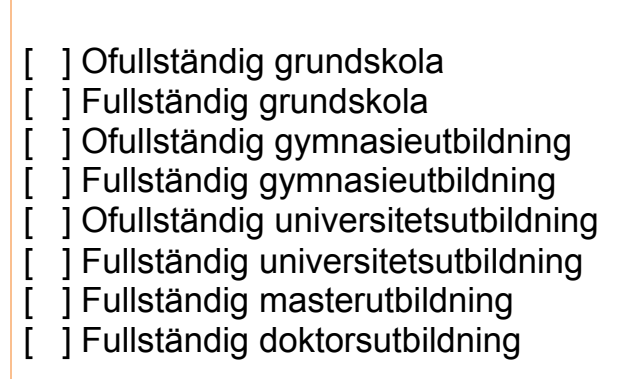 \\
\hline 69 & City & Var bor du & Var god ange staden där du bor \\
\hline 70 & Occupation & Vad är ditt (huvudsakliga) arbete? & (Fritext svar) \\
\hline 71 & RelateToParliament & $\begin{array}{l}\text { Är ditt yrke direkt relaterat till Riksdagens } \\
\text { verksamhet? }\end{array}$ & [ ] Ja/[ ] Nej \\
\hline
\end{tabular}


Demografisk information

\begin{tabular}{|c|c|c|c|c|c|c|c|c|c|c|c|c|c|c|c|}
\hline \# & \multicolumn{2}{|c|}{$\begin{array}{l}\text { Variable code in } \\
\text { SPSS and AMOS }\end{array}$} & Fråga & & \multicolumn{11}{|c|}{ Svar } \\
\hline 72 & \multicolumn{2}{|c|}{ FormerlyCandidate } & $\begin{array}{l}\text { Har du någonsin kandidaterat till ett politiskt } \\
\text { ämbete? }\end{array}$ & \multicolumn{12}{|c|}{ [ ] Ja/[ ] Nej } \\
\hline \# & $\begin{array}{c}\text { Variable code } \\
\text { in SPSS and } \\
\text { AMOS }\end{array}$ & & Fråga & \multicolumn{4}{|c|}{$\begin{array}{l}\text { yttersta } \\
\text { vänstern } \\
\nabla\end{array}$} & \multicolumn{5}{|c|}{$\stackrel{\text { Mitten }}{\nabla}$} & \multicolumn{2}{|c|}{$\begin{array}{r}\text { yttersta } \\
\text { högern } \\
\nabla\end{array}$} & Vej ej \\
\hline 73 & LeftRight & $\begin{array}{l}\text { Nar } \\
\text { "vän } \\
\text { egna }\end{array}$ & $\begin{array}{l}\text { det galler politık să talar man ofta om } \\
\text { ster" och "höger". Var skulle du placera dina } \\
\text { a åsikter på denna skala, generellt sett? }\end{array}$ & V5 & V4 & V3 & V2 & V1 & 0 & $\mathrm{H} 1$ & $\mathrm{H} 2$ & $\mathrm{H} 3$ & $\mathrm{H} 4$ & $\mathrm{H} 5$ & VE \\
\hline
\end{tabular}




\begin{tabular}{|c|c|c|c|}
\hline \# & $\begin{array}{l}\text { Variable code in } \\
\text { SPSS and AMOS }\end{array}$ & $\begin{array}{l}\text { Kan du ange om du äger någon av sakerna } \\
\text { nedan? }\end{array}$ & Svar \\
\hline \multirow[t]{11}{*}{74} & & Jag äger en eller fler... & \\
\hline & lownComputer & Dator med möjlig anslutning till internet & [ ] Ja/[ ] Nej \\
\hline & lownPhone & $\begin{array}{l}\text { Mobiltelefon eller surfplatta med möjlig anslutning till } \\
\text { internet }\end{array}$ & [ ] Ja / [ ] Nej \\
\hline & lownTV & Modern TV (plasma, LCD eller LED) & [ ] Ja / [ ] Nej \\
\hline & lownCar & Bil & [ ] Ja/[ ] Nej \\
\hline & lownApart & Egen lägenhet & [ ] Ja/[ ] Nej \\
\hline & lownHouse & Eget hus & [ ] Ja/[ ] Nej \\
\hline & lownOffice & Kontor/butik/verkstad eller liknande & [ ] Ja/[ ] Nej \\
\hline & lownStocks & Aktier & [ ] Ja/[ ] Nej \\
\hline & lownBoat & Båt (endast för fritidsändamål) & [ ] Ja / [ ] Nej \\
\hline & lownComp50 & Företag med fler än 50 anställda & [ ] Ja/[ ] Nej \\
\hline
\end{tabular}




\section{Appendix III}

Table III.1. Acceptance and interpretation parameters for Exploratory Factor Analysis (EFA) in this study.

\begin{tabular}{|c|c|c|c|}
\hline Index name & Criteria & Notes & $\begin{array}{c}\text { Theoretical } \\
\text { Reference }\end{array}$ \\
\hline KMO & $>0.70$ & $\begin{array}{l}\text { Kaiser-Meyer-Olkin (KMO) test estimates the } \\
\text { "factorability" of the covariance matrix. The } \\
\text { more items share covariance, the closer KMO } \\
\text { will get to } 1 \text {, indicating that it will be easier to } \\
\text { extract factors. KMO over } 0.70 \text { is considered } \\
\text { to be "regular"; over } 0.80 \text {, "good" and over } \\
0.90 \text {, "excellent". }\end{array}$ & Pasquali (2012) \\
\hline Eigenvalues & $\begin{array}{l}\text { Given by } \\
\text { Parallel } \\
\text { Analysis }\end{array}$ & $\begin{array}{l}\text { Eigenvalues greater than } 1 \text { is a lower bound } \\
\text { criterion for the first Factor Extraction. Parallel } \\
\text { Analysis estimated the actual necessary } \\
\text { Eigenvalues to accept the Factor Structure as } \\
\text { empirically relevant. }\end{array}$ & $\begin{array}{l}\text { Horn (1965). } \\
\text { Pasquali (2012) } \\
\text { Thompson (2005) }\end{array}$ \\
\hline $\begin{array}{l}\text { Factor } \\
\text { Loadings } \\
\text { (or Factor } \\
\text { Structure } \\
\text { Coefficients) }\end{array}$ & $>0.30$ & $\begin{array}{l}\text { Factor loadings indicate the correlation } \\
\text { between the item and the factor. Loadings } \\
\text { above } 0.30 \text { are considered acceptable. } \\
\text { However, Loadings above } 0.25 \text { were } \\
\text { accepted if the item contributed for the } \\
\text { improvement of Cronbach's alpha and was } \\
\text { considered highly relevant under the } \\
\text { theoretical perspective. }\end{array}$ & $\begin{array}{l}\text { Hair et al. (2009) } \\
\text { Pasquali (2012) }\end{array}$ \\
\hline $\begin{array}{l}\text { Cronbach's } \\
\text { alpha }\end{array}$ & $>0.60$ & $\begin{array}{l}\text { On exploratory research it is acceptable to } \\
\text { keep factors with Cronbach's alpha over } 0.60 \text {. } \\
\text { This was the criterion employed here, } \\
\text { considering that factors' consistency would } \\
\text { be further tested on CFA. }\end{array}$ & $\begin{array}{l}\text { Boyle (1991) } \\
\text { Trenblay (2001) }\end{array}$ \\
\hline
\end{tabular}




\section{Appendix IV}

Table IV.1. Acceptance and interpretation parameters for Confirmatory Factor Analysis (CFA) and Structural Equation Modeling $(\mathrm{SEM})^{20}$ in this study.

\begin{tabular}{|c|c|c|c|}
\hline Index name & Criteria & Notes & $\begin{array}{l}\text { Theoretical } \\
\text { Reference }\end{array}$ \\
\hline $\begin{array}{l}\text { Chi-square I } \\
\text { degrees of } \\
\text { freedom ratio }\end{array}$ & $\begin{array}{l}X^{2} / \text { d.f. } \\
\text { between } 1 \\
\text { and } 5\end{array}$ & $\begin{array}{l}\text { Indicates "over-adjusted" or "under-adjusted" models. } \\
\text { It also assesses the model parsimony. }\end{array}$ & Hair et al. (2009) \\
\hline \multirow{3}{*}{$\begin{array}{l}\text { Root Mean Square } \\
\text { Error of } \\
\text { Approximation } \\
\text { (RMSEA) }\end{array}$} & \multirow{3}{*}{$<0.70$} & \multirow{3}{*}{$\begin{array}{l}\text { RMSEA evaluates how well the model fits to the } \\
\text { population based on non-centralized } X^{2} \text {. It punishes } \\
\text { the less parsimonious model, i.e., the one with more } \\
\text { free parameters. RMSEA under } 0.8 \text { indicates } \\
\text { reasonable fit; under } 0.5 \text { indicates good fit. }\end{array}$} & Brown (2006) \\
\hline & & & $\begin{array}{l}\text { Browne \& Cudeck } \\
\text { (1989) }\end{array}$ \\
\hline & & & $\begin{array}{l}\text { Byrne \& Campbell } \\
\text { (1999) }\end{array}$ \\
\hline \multirow{2}{*}{$\begin{array}{l}\text { Standardized } \\
\text { Root Mean Square } \\
\text { Residual } \\
\text { (SRMR) }\end{array}$} & \multirow{2}{*}{$<0.80$} & \multirow{2}{*}{$\begin{array}{l}\text { SRMR is the average discrepancy between the } \\
\text { observed correlation matrix and the matrix predicted } \\
\text { by the model. }\end{array}$} & Brown (2006) \\
\hline & & & Hu \& Bentler (1999). \\
\hline \multirow{2}{*}{$\begin{array}{l}\text { Comparative Fit } \\
\text { Index } \\
\text { (CFI) }\end{array}$} & \multirow[b]{2}{*}{$>0.92$} & \multirow{2}{*}{$\begin{array}{l}\text { CFI evaluates the fit of a model in relation to a more } \\
\text { restricted, nested baseline model ("null" or } \\
\text { "independence" models). CFI under } 0.95 \text { can be } \\
\text { accepted if other indices indicate good fit. }\end{array}$} & Brown (2006) \\
\hline & & & $\begin{array}{l}\text { Byrne \& Campbell } \\
\text { (1999) }\end{array}$ \\
\hline \multirow{2}{*}{$\begin{array}{l}\text { Tucker-Lewis } \\
\text { Index } \\
\text { (TLI) }\end{array}$} & \multirow{2}{*}{$>0.92$} & \multirow{2}{*}{$\begin{array}{l}\text { TLI punishes the introduction of free parameters that } \\
\text { do not contribute to the model fit. }\end{array}$} & Brown, T. (2006) \\
\hline & & & Hu \& Bentler (1999) \\
\hline \multirow{2}{*}{$\begin{array}{l}\text { Adjusted } \\
\text { Goodness-of-Fit } \\
\text { Index } \\
\text { (AGFI) }\end{array}$} & \multirow{2}{*}{$>0.90$} & \multirow{2}{*}{$\begin{array}{l}\text { Goodness-of-Fit index, less sensible to the sample } \\
\text { size than other indicators. AGFI tends to be } \\
\text { conservative, i.e., it may eventually reject good } \\
\text { models. }\end{array}$} & Hair et al. (2009) \\
\hline & & & Bagozzi \& Yi (1988) \\
\hline \multirow{5}{*}{ Jöreskog's rho } & \multirow{5}{*}{$>0.6$} & \multirow{5}{*}{$\begin{array}{l}\text { Jöreskog's Rho }(\rho) \text { calculates the shared variance } \\
\text { between items associated with the same factor. This } \\
\text { represents the internal factor consistency, indicating } \\
\text { how much of the latent factor is assessed by its items. }\end{array}$} & Jöreskog (1971) \\
\hline & & & Marôco (2010) \\
\hline & & & $\begin{array}{l}\text { Fornell e Larcker } \\
\text { (1981) }\end{array}$ \\
\hline & & & Bagozzi \& Yi (1988) \\
\hline & & & Farid (2014) \\
\hline $\begin{array}{l}\text { Standardized } \\
\text { Residual } \\
\text { Covariances }\end{array}$ & $<4$ & $\begin{array}{l}\text { Standardized Residual Covariances refers to the } \\
\text { difference between observed covariance and adjusted } \\
\text { covariance. Residuals over } 4 \text { indicate potentially } \\
\text { unacceptable errors, and changes in model are } \\
\text { recommended to improve Goodness-of-Fit. }\end{array}$ & Hair et al. (2005) \\
\hline
\end{tabular}

$20 \mathrm{CFI}, \mathrm{TLI}, \mathrm{SRMR}$ and RMSEA parameters were primarily based on Hair et al's (2009) recommendations (p. 573), as they take into consideration the sample size and number of observed variables (questionnaire items). These authors emphasize that their guidelines are not to be taken as absolute rules. 


\section{Appendix V}

Tables for Stepwise Multiple Regression, entering Political Participation factors and standalone items as dependent (endogenous) variables.

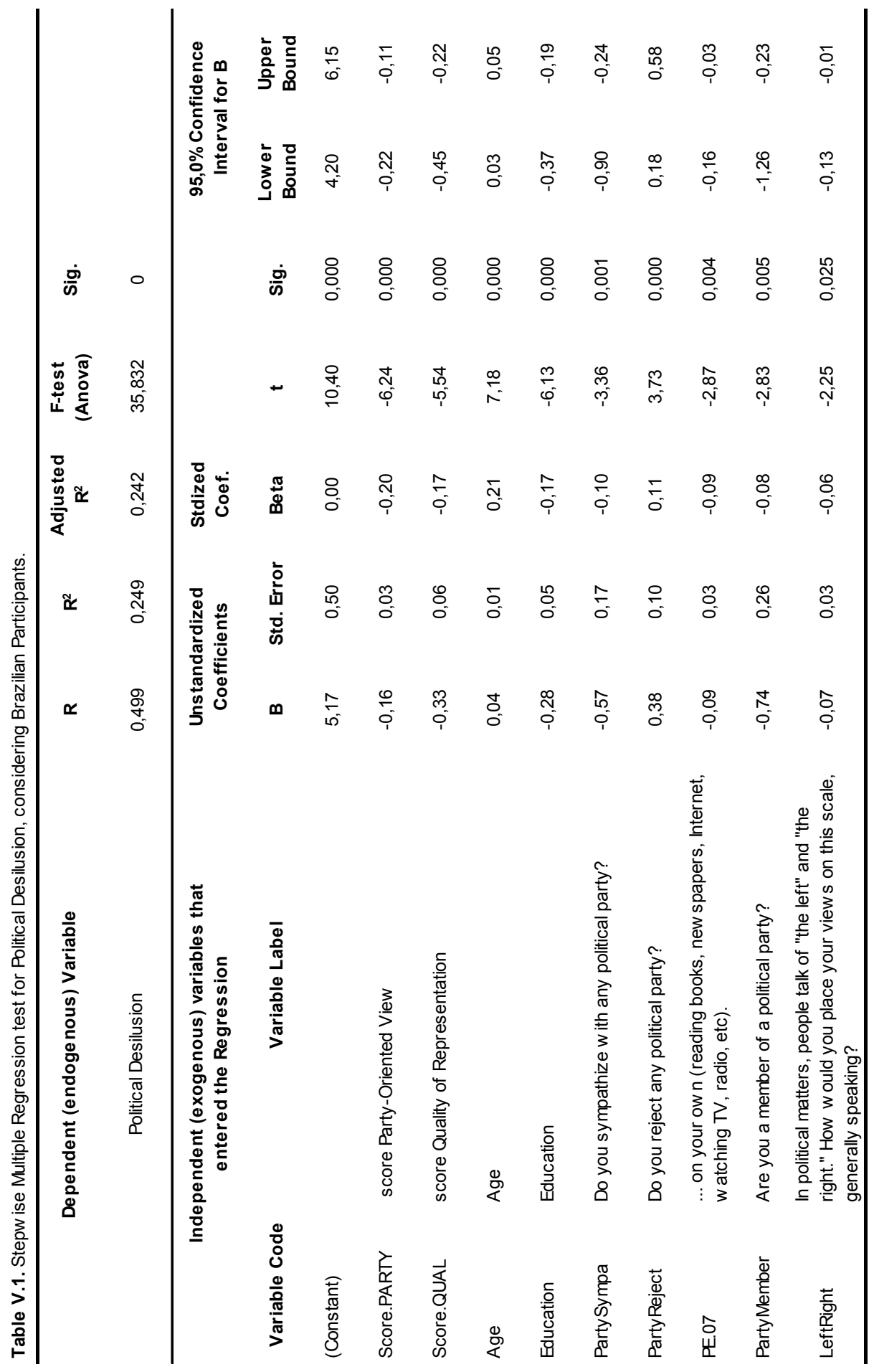




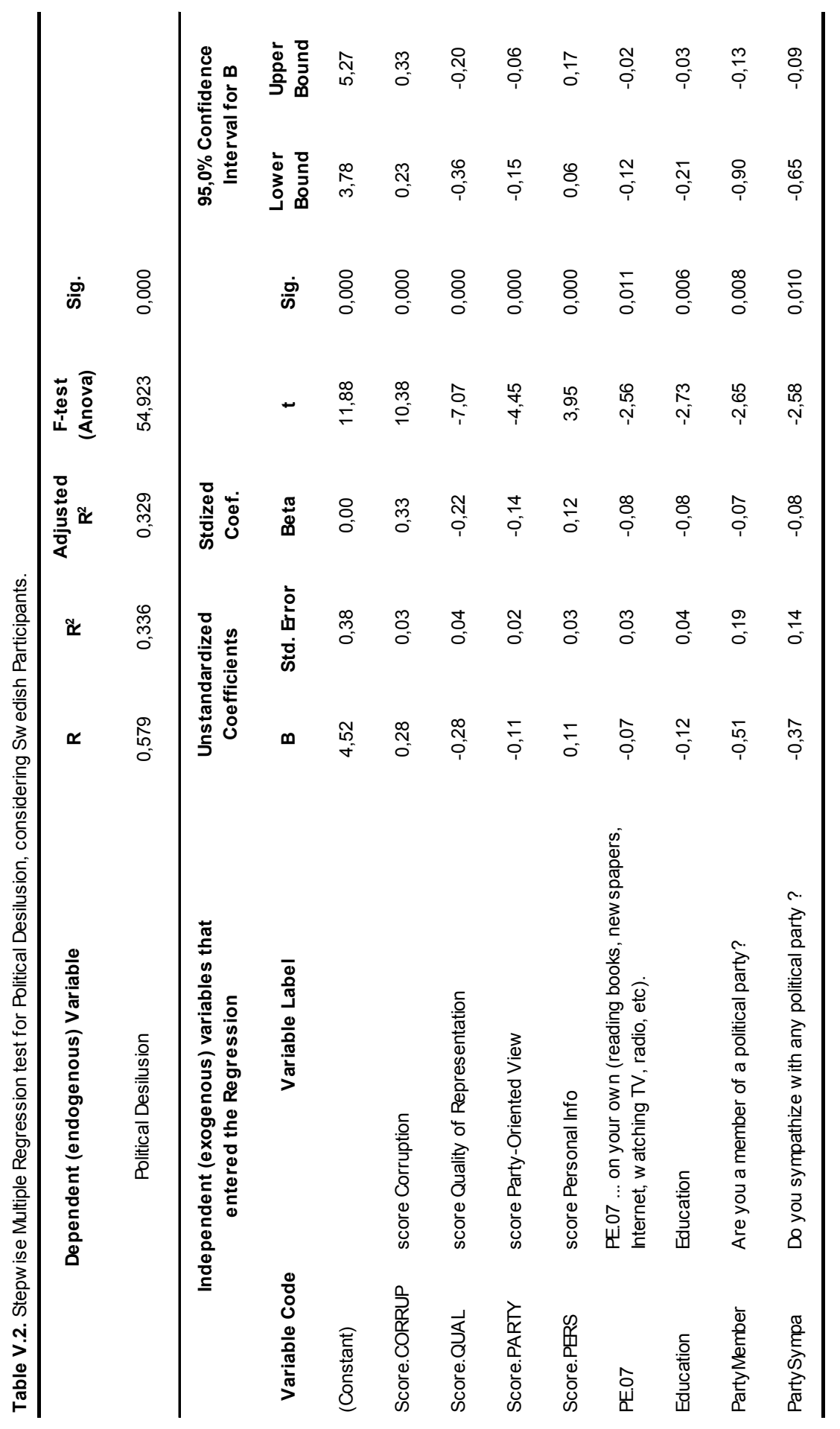




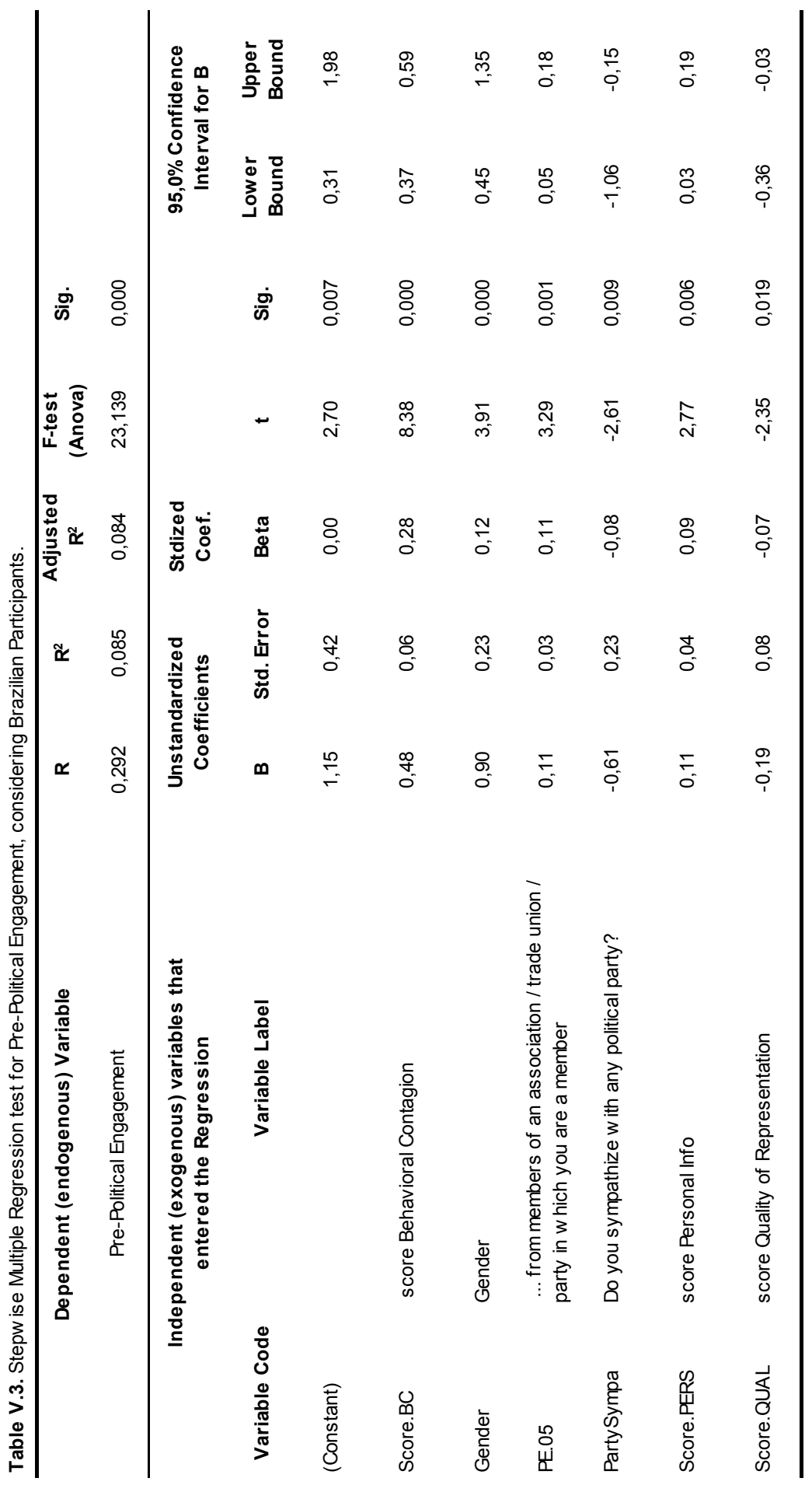




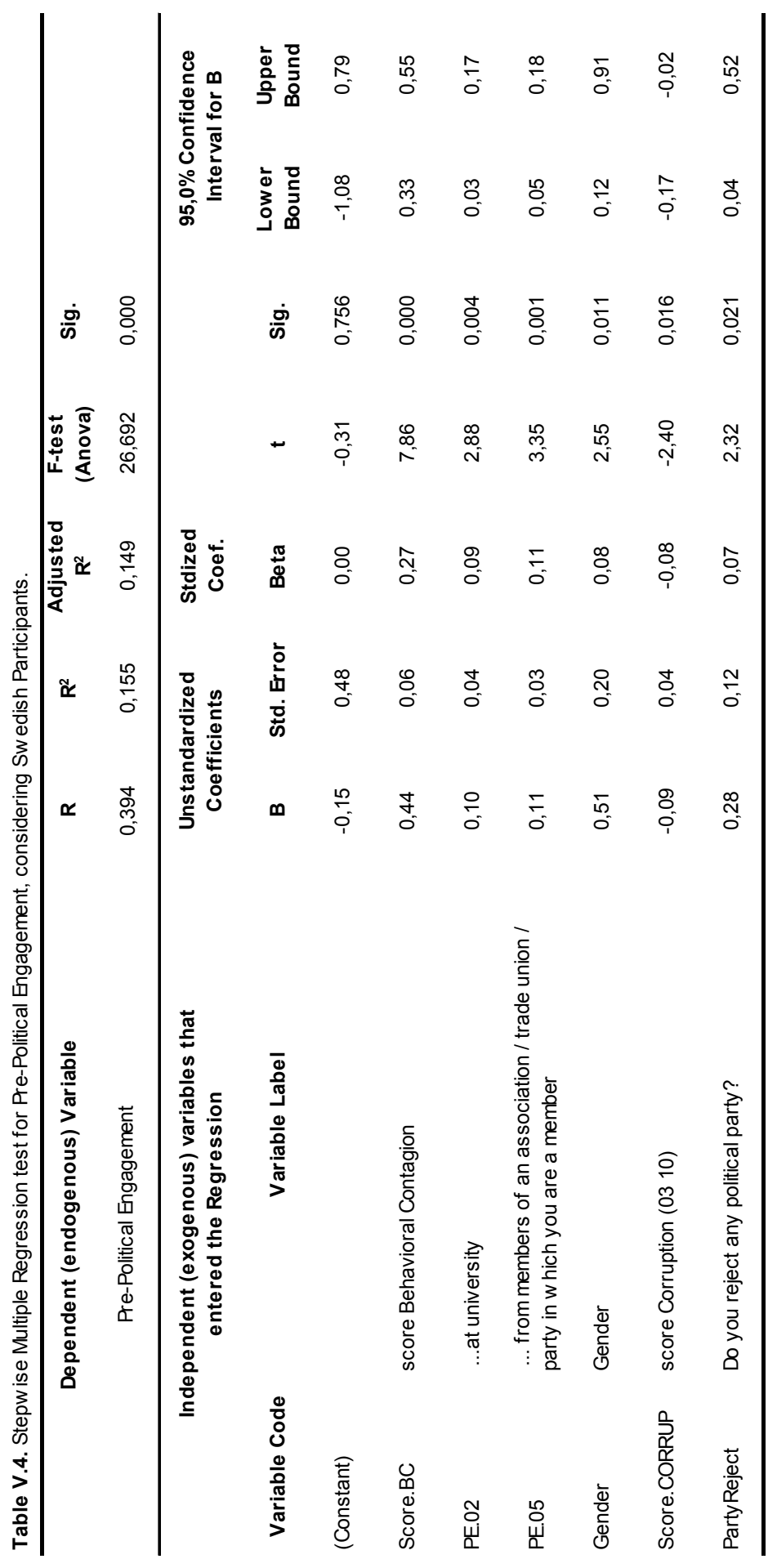




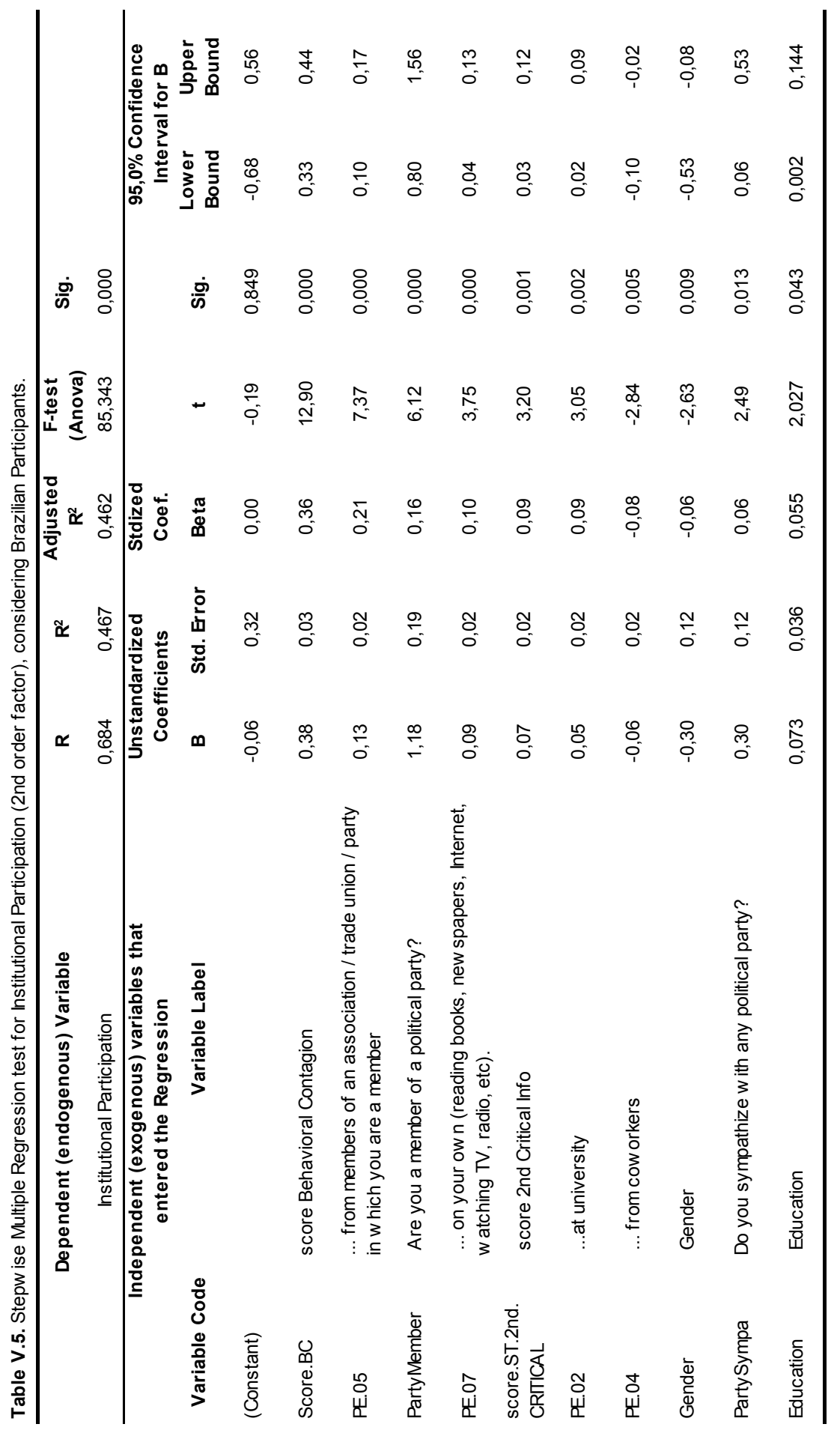




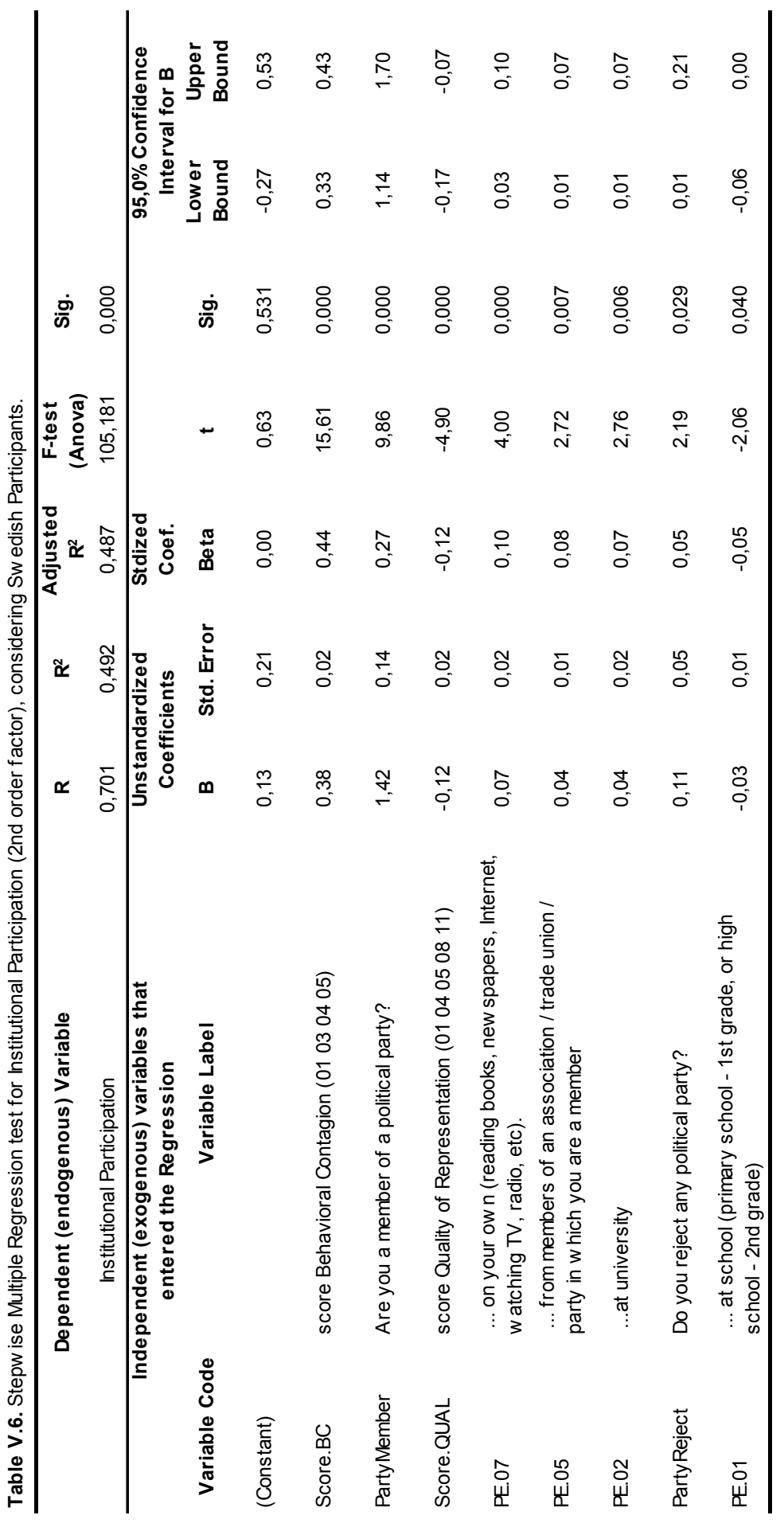




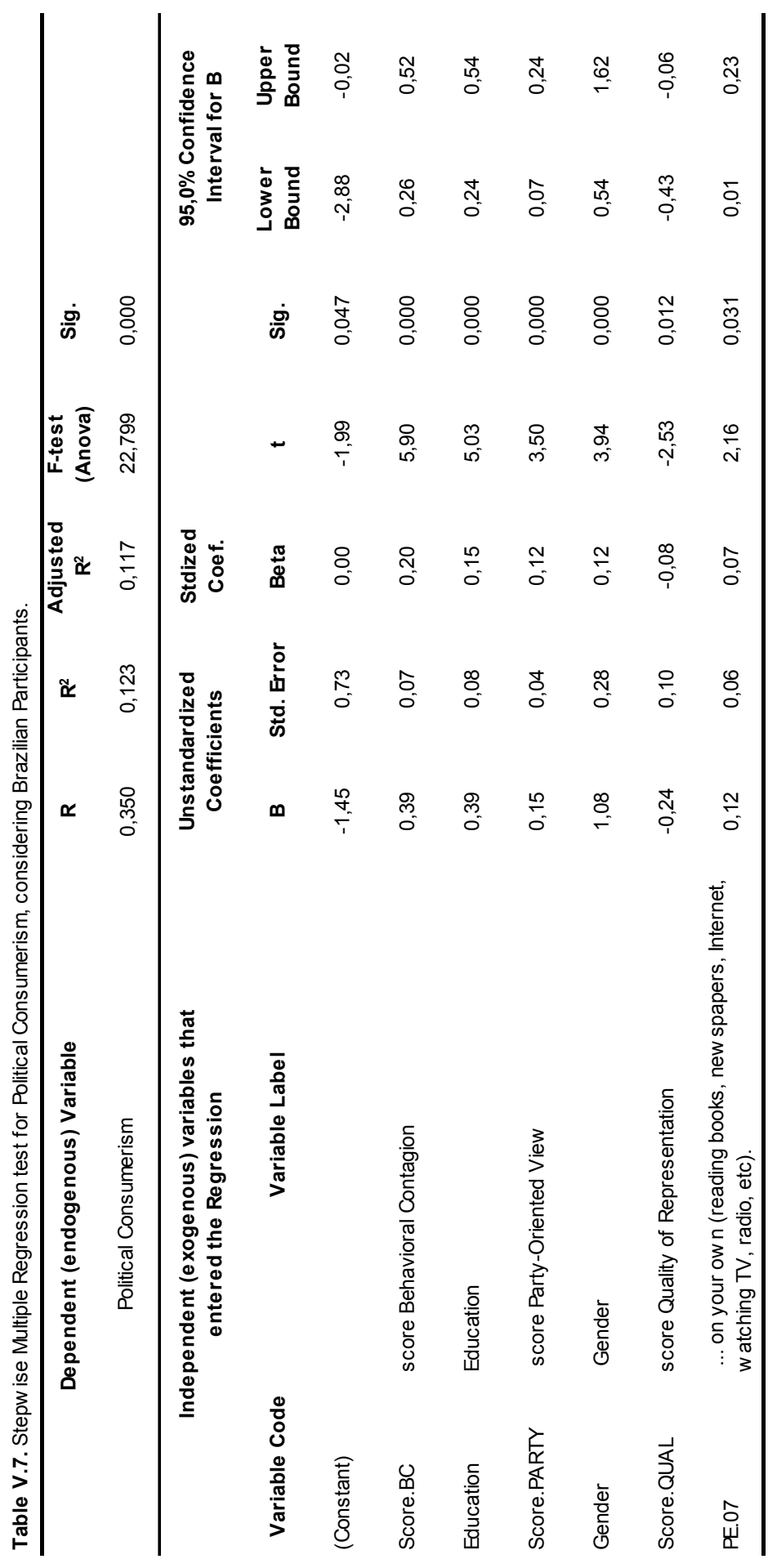




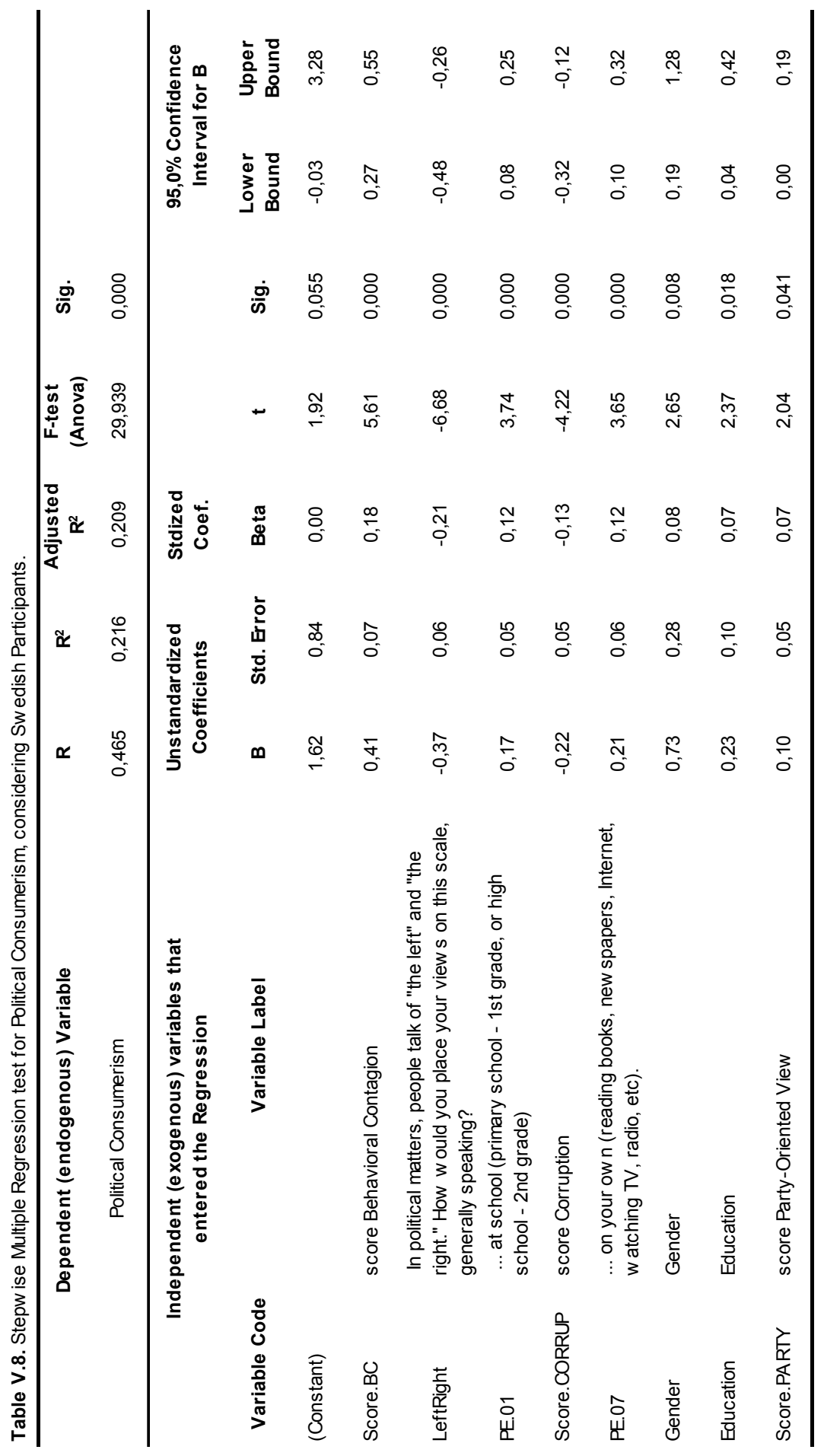




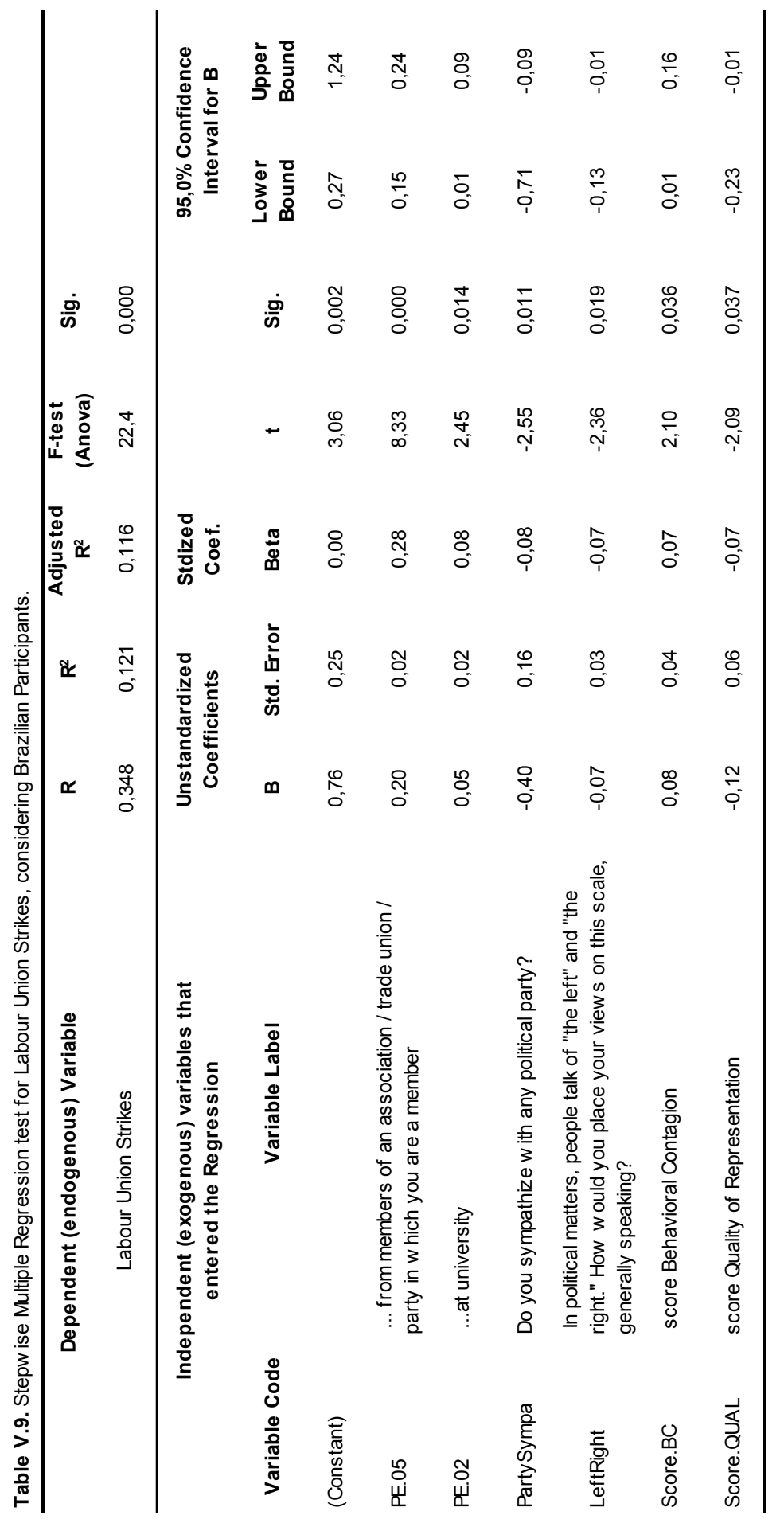




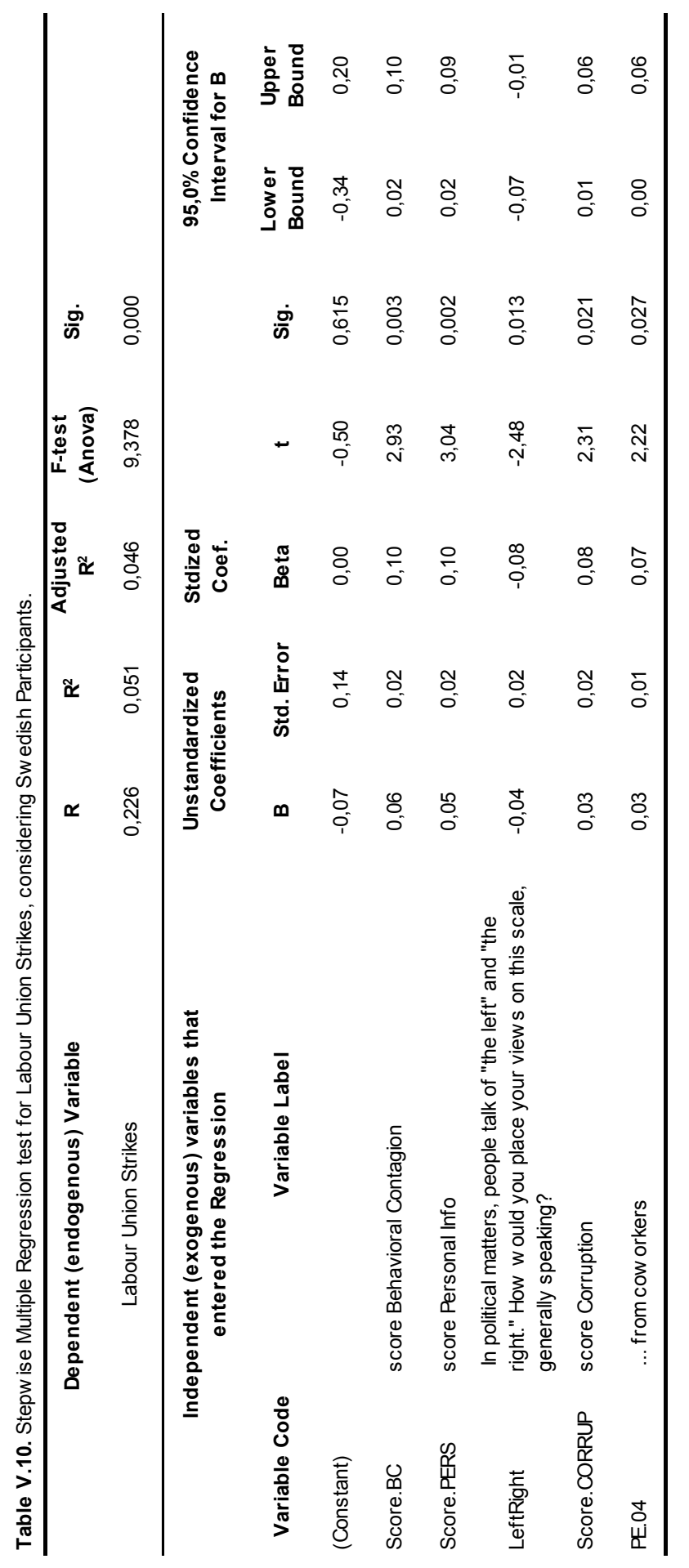




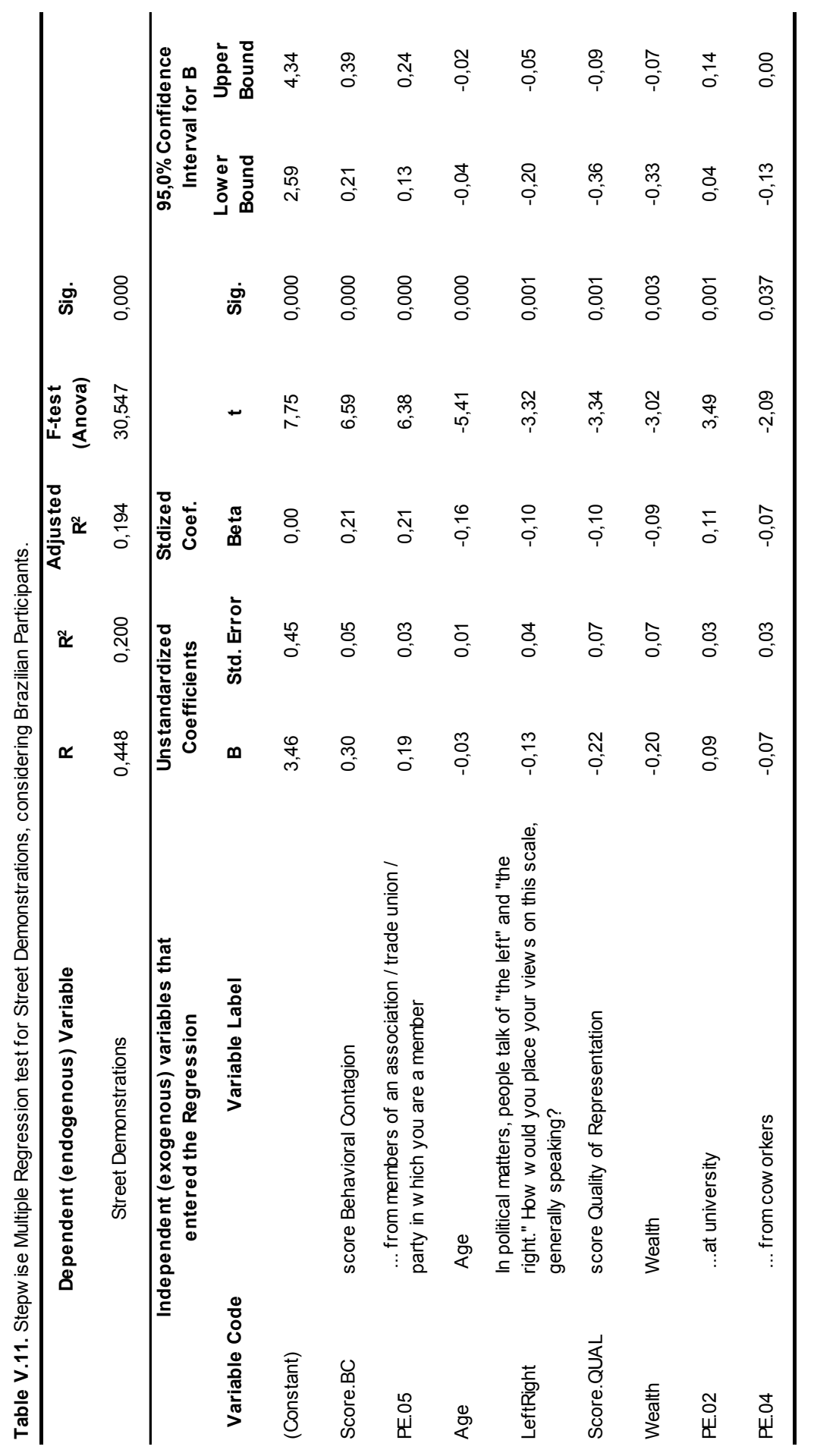




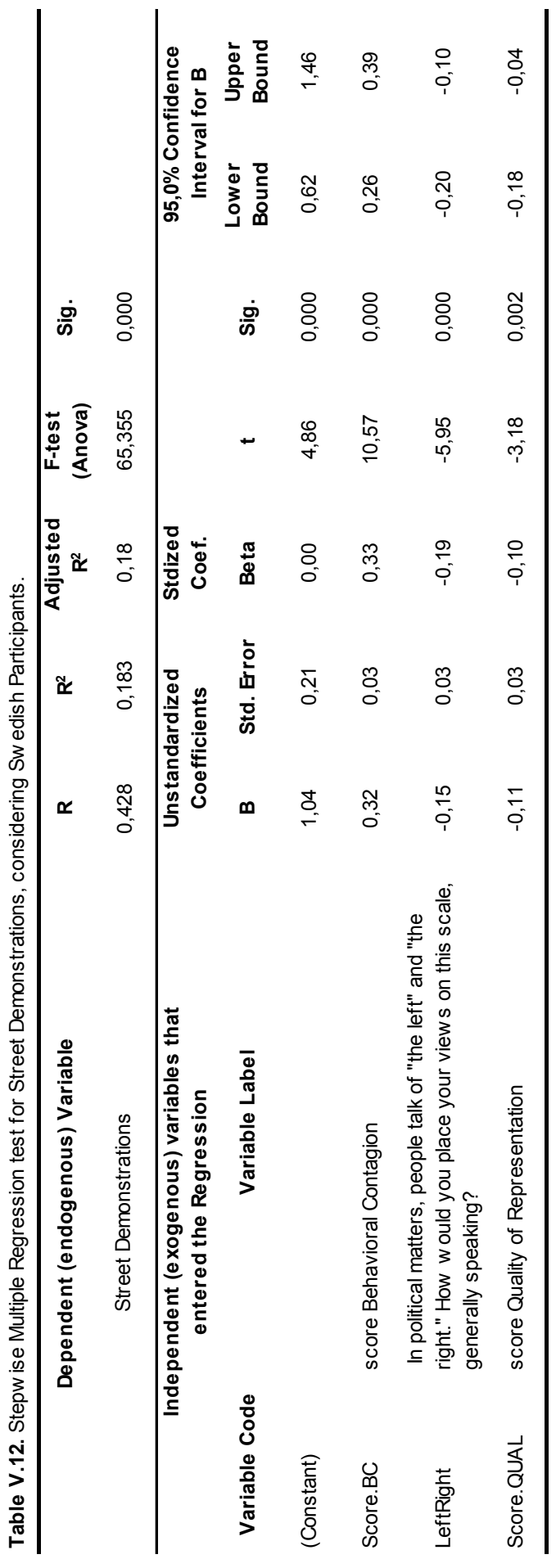




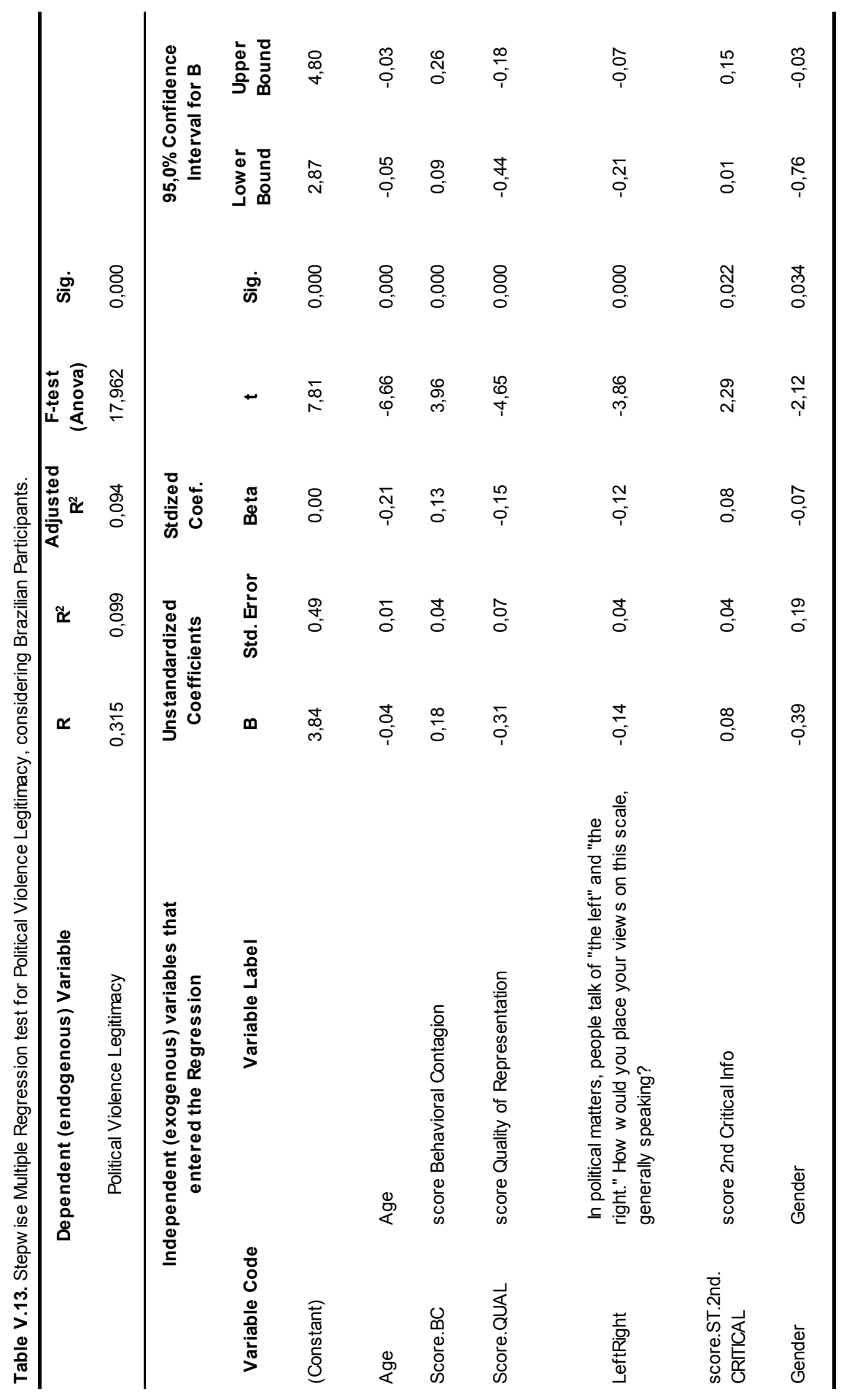




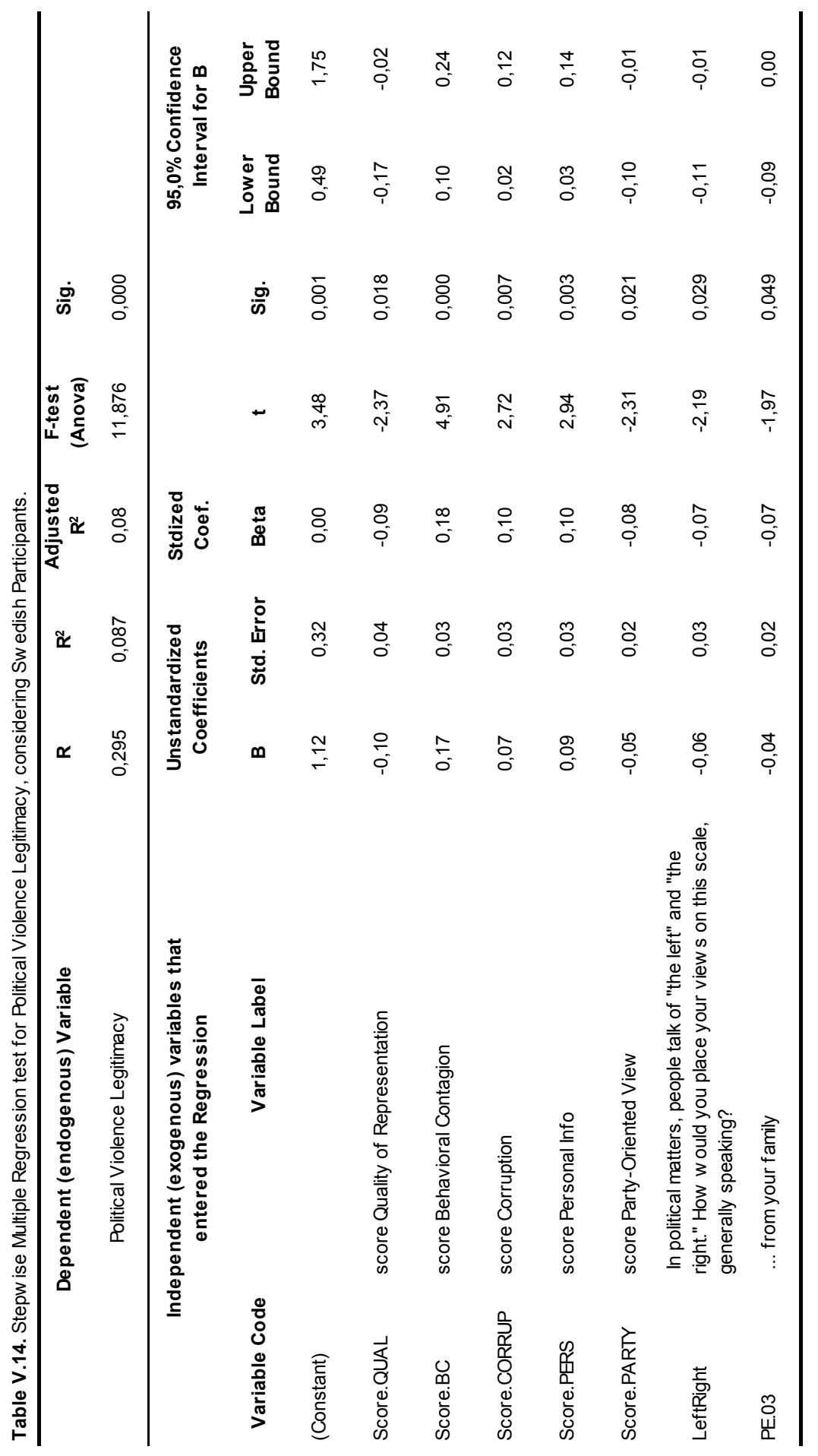

